\title{
Skeletal muscle dysfunction in COPD : from a metabolic and histochemical perspective
}

Citation for published version (APA):

Gosker, H. R. (2003). Skeletal muscle dysfunction in COPD : from a metabolic and histochemical perspective. [Doctoral Thesis, Maastricht University]. Universiteit Maastricht. https://doi.org/10.26481/dis.20030228hg

Document status and date:

Published: 01/01/2003

DOI:

10.26481/dis.20030228hg

Document Version:

Publisher's PDF, also known as Version of record

\section{Please check the document version of this publication:}

- A submitted manuscript is the version of the article upon submission and before peer-review. There can be important differences between the submitted version and the official published version of record.

People interested in the research are advised to contact the author for the final version of the publication, or visit the DOI to the publisher's website.

- The final author version and the galley proof are versions of the publication after peer review.

- The final published version features the final layout of the paper including the volume, issue and page numbers.

Link to publication

\footnotetext{
General rights rights.

- You may freely distribute the URL identifying the publication in the public portal. please follow below link for the End User Agreement:

www.umlib.nl/taverne-license

Take down policy

If you believe that this document breaches copyright please contact us at:

repository@maastrichtuniversity.nl

providing details and we will investigate your claim.
}

Copyright and moral rights for the publications made accessible in the public portal are retained by the authors and/or other copyright owners and it is a condition of accessing publications that users recognise and abide by the legal requirements associated with these

- Users may download and print one copy of any publication from the public portal for the purpose of private study or research.

- You may not further distribute the material or use it for any profit-making activity or commercial gain

If the publication is distributed under the terms of Article $25 \mathrm{fa}$ of the Dutch Copyright Act, indicated by the "Taverne" license above, 


\section{Skeletal muscle dysfunction in COPD from a metabolic and histochemical perspective}


Druk: Datawyse

ISBN: $90-9016581-9$

(C) Harry Reinier Gosker, Maastricht 2003

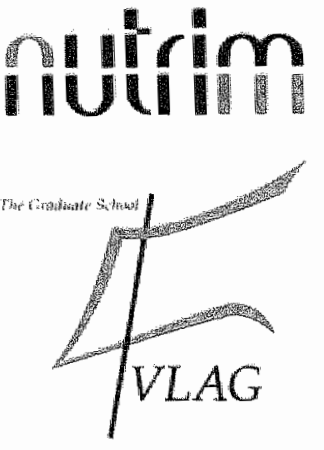

The study presented in this thesis was performed at the Nutrition and Toxicology Research Institute Maastricht (NUTRIM), which participates in the Graduate School VLAG (Food Technology, Agrobiotechnology, Nutrition, accredited by the Royal Netherlands Academy of Arts and Sciences (KNAW). 


\section{Skeletal muscle dysfunction in COPD from a metabolic and histochemical perspective}

\section{PROEFSCHRIFT}

ter verkrijging van de graad van doctor aan de Universiteit Maastricht, op gezag van de Rector Magnificus Prof. dr. A.C. Nieuwenhuijzen

Kruseman, volgens het besluit van het College van Decanen, in het openbaar te verdedigen op vrijdag 28 februari 2003 om 14:00 uur

door

Harry Reinier Gosker 


\section{Promotores:}

Prof. dr. E.F.M. Wouters

Prof dr. G.J. van der Vusse

\section{Co-promotor:}

Dr. ir. A.M.W.J. Schols

\section{Beoordelingscommissie:}

Prof. dr. M. van Dieijen-Visser (voonzitter)

Prof. dr. M. Borgers

Prof. dr. M. Daemen

Prof. dr. H. Kuipers

Prof. J. Roca (Hospital Clinic, Universitat de Barcelona, Spain)

The studies described in this thesis were supported by a research grant from the Netherlands Asthma Foundation. The publication of this thesis was financially supported by: Stichting Pulmonologie, Stichting Hornerheide, Glaxo Wellcome, Nutricia Nederland B.V., Boehringer Ingelheim, AstraZeneca, Klinipath, Zambon, Beun-De Ronde B.V. 


\section{Table of Contents}

.Chapter 1 General introduction

Chapter 2 Skeletal muscle dysfunction in chronic obstructive pulmonary disease and chronic heart failure: underlying mechanisms and therapy perspectives

Chapter 3 Striking similarities in systemic factors contributing to decreased exercise capacity in patients with severe chronic heart failure or chronic obstructive pulmonary disease

Chapter 4 Myopathologic features in skeletal muscle of patients with chronic obstructive pulmonary disease

Chapter 5 Skeletal muscle fiber type and metabolic shifts in chronic obstructive pulmonary disease

Chapter 6 Muscle fiber type IIX atrophy is involved in the loss of fat-free mass in chronic obstructive pulmonary disease

Chapter 7 Uncoupling protein 3 content is decreased in skeletal muscle of patients with chronic obstructive pulmonary disease

Chapter 8 Antioxidant capacity is increased in the vastus lateralis of patients with chronic obstructive pulmonary disease

Chapter 9 Summary \& general discussion

Samenvatting

Dankwoord

Publications 
.

a

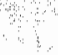

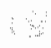


CHAPTER 1

General introduction 
Chronic obstructive pulmonary disease (COPD) is a disease characterized by the presence of airflow obstruction, which does not change markedly over several months and is, by definition, largely irreversible $(1,2)$. Worldwide, COPD is expected to become the third leading cause of death in 2020 . In the Netherlands, over $7 \%$ of the total population is diagnosed as having COPD (3). Aging of the population will only lead to an increase in the prevalence and with it will rise the related medical costs $(4,5)$. It is therefore easy to understand that COPD represents a major and growing problem for health care.

Currently, the most important measure of disease severity is airflow obstruction, measured as the forced expiratory volume in one second $\left(\mathrm{FEV}_{1}\right)$. On this basis disease severity stages are defined, ranging from mild (stage I) via moderate (stage II) to severe COPD (stage III) (1). A division between two COPD subtypes can be made, namely chronic bronchitis and emphysema. In short, chronic bronchitis is predominantly characterized by chronic or recurrent excessive mucus production in the bronchial tree, whereas emphysema is a condition of the lungs characterized by permanent, abnormal enlargement of airspaces and destruction of the alveolar walls. However, many patients show characteristics of both subtypes. In addition to airflow obstruction, particularly the structural changes of the lung parenchyma lead to a decreased diffusion capacity of the lung, indicating that gas exchange is impaired. In such cases, impaired oxygenation of the blood may occur. Currently, smoking is the causal factor in more than $90 \%$ of the patients in westernized countries. It is now apparent that local inflammatory processes also play a critical role in the pathogenesis of COPD (6).

There is increasing evidence of systemic (extrapulmonary) effects in patients with COPD (i.e. systemic inflammation, oxidative stress, muscle wasting), which have an important negative influence on the quality of life. The most prominent symptoms leading to disablement in COPD are exercise intolerance and dyspnea during physical exercise and in later stages also at rest. The last decade, it has become clear that skeletal muscle dysfunction plays an important role in dyspnea and exercise limitation. This provides a unique treatment opportunity: up till now, medical treatment aimed at the ameliorating lung function impaiment in COPD has proved to be rather disappointing, whereas focusing on the systemic impairments offers novel perspectives for therapy. The same may apply for other degenerative chronic disorders, since, at the systemic level, COPD is very comparable to chronic heart failure (CHF) and probably also to chronic renal failure and other chronic inflammatory diseases. However, in order to develop or optimize the effectiveness of these treatments, more understanding is required of the characteristics of and mechanisms underlying impaired skeletal muscle function in COPD. 


\section{Ams and outline of the thesis}

The overall aim of this study was to investigate the muscular pathology in COPD at the functional, histopathological and molecular level. Three specific aims were addressed in this thesis:

1. To evaluate the similarities in the systemic impaiments of COPD and CHF and the contribution of systemic relative to local impaiment to the decreased exercise capacity in these conditions.

2. To histochemically characterize the morphology and pathology of skeletal muscle in COPD, in relation to muscle wasting and muscle weakness.

3. To characterize two putative affecters of skeletal muscle weakness in COPD: muscular uncoupling protein 3 and antioxidant capacity.

Chapter 2 provides an extensive overview of the existing literature concerning skeletal muscle dysfunction in COPD and therefore serves as a detailed introduction to this thesis. Note that besides COPD, also chronic heart failure (CHF) is taken into account. Although COPD and CHF are two distinct disorders, there are striking similarities between the two at the systemic level. The review provides a more complete picture of muscle dysfunction and the underlying muscular abnormalities in these disorders.

The degree and nature of muscle dysfunction in COPD and CHF was studied as described in chapter 3. It was established if muscle function, fat-free mass and daily activity level are indeed comparably affected in CHF and COPD patients and to what extent these factors are determinants of exercise capacity.

In general, anybody suffering from severe peripheral muscle weakness will be referred to a pathologist or neurologist to assess the kind and extent of the muscle pathology. However, a complete pathological picture of the changes in limb muscle of patients with COPD is not yet at hand. Therefore, in chapter 4, biopsies from the vastus lateralis (a muscle of the upper leg) were histochemically evaluated and screened for traditional myopathological features.

Assessment of muscle fiber types is one of the aspects of histochemical valuation of muscle biopsies. As outlined in chapter 3, the proportion of the oxidative type I fibers as well as the capacity of enzymes involved in oxidative energy metabolism are reduced in the vastus lateralis of patients with COPD, but the mechanism behind this apparent shift in fiber type proportions is unclear. Therefore, in chapter 5 , the nature of the fiber type redistribution was studied. A combination of traditional histochemical and modern immunohistochemical techniques was used, which allowed for a more detailed classification of fiber types, including hybrid fibers. In addition, the metabolic profile of fiber types was determined in order to examine the association between changes in fiber types and oxidative capacity.

The loss of muscle mass, or muscle wasting, is a major problem in COPD and is directly related to muscle weakness. Here too, little data is available about the mechanism behind the loss of muscle mass. In chapter $\mathbf{6}$, the size of muscle fibers, as measured as their cross sectional area, was studied in relation to fat-free mass as a marker of muscle mass.

Not only the strength of muscles, but also their mechanical efficiency is reduced in COPD. This suggests that intrinsic muscular alterations, other than the loss of muscle mass, are probably involved. Recently, human uncoupling protein 3 (UCP3) has been identified and this protein 
is potentially an important determinant of energy metabolism. For this purpose, the UCP3 content in vastus lateralis biopsies was assessed and its relation to mechanical efficiency was studied, as deseribed in chapter 7.

Oxidative stress in the pulmonary compartment is central to the pathogenesis of COPD. Likewise, it is very well possible that oxidative stress is also involved in muscle wasting and weakness in this disorder. Oxidative stress occurs when the balance between the antioxidant capacily and the generation of free radicals shifts in favor of the latter. It is therefore important to evaluate the antioxidant capacity of the affected muscles. In chapter 8, key components of the antioxidant system were examined in muscle biopsies from patients with COPD.

Finally, chapter 9 comprises a general discussion of this thesis and provides suggestions for future investigations.

\section{REFERENCES}

1. ATS. Standards for the diagnosis and care of patients with chronic obstructive pulmonary disease. Am J Respir Crit Care Med 1995; 152:S77-121.

2. Siafakas NM, Vermeire $\mathrm{P}$, Pride NB, et al. Optimal assessment and management of chronic obstructive pulmonary disease (COPD). Eur Respir J 1995;8:1398-420.

3. van den Boom $G$, van Schayck $C P$, wan Mollen MP, et al. Active detection of chronic obstructive pulmonary disease and asthma in the general population. Results and economic consequences of the DIMCA program. Am J Respir Crit Care Med 1998;158:1730-8.

4. Rutten-van Molken MP, Postma MJ, Joore MA, Van Genugten ML, LeidI R, Jager JC. Current and future medical costs of asthma and chronic obstructive pulmonary disease in The Netherlands. Respir Med 1999;93:779-87.

5. Pawwels RA, Buist AS, Calverley PM, Jenkins CR, Hurd SS. Global strategy for the diagnosis, management, and prevention of chronic obstructive pulmonary disease. NHLBI/WHO Global Initiative for Chronic Obstructive Lung Disease (GOLD) Workshop summary. Am J Respir Crit Care Med 2001;163:1256-76.

6. Barnes PJ. Chronic obstructive pulmonary disease. N Engl J Med 2000;343:269-80. 


\title{
CHAPTER 2
}

\section{Skeletal muscle dysfunction in chronic obstructive pulmonary disease and chronic heart failure: underlying mechanisms and therapy perspectives}

\begin{abstract}
Low exercise tolerance has a large influence on health status in chronic obstructive pulmonary disease and chronic heart failure. In addition to primary organ dysfunction, impaired skeletal muscle performance is a strong predictor of this reduced exercise capacity. There are striking similarities between both disorders with respect to the muscular alterations underlying the impairment. However, different alterations occur in different muscle types. Histologic and metabolic data show that peripheral muscles undergo a shift from oxidative to glycolytic energy metabolism, whereas the opposite is observed in the diaphragm. These findings are in line with the notion that peripheral muscles and the diaphragm are mainly limited by endurance and strength capacity respectively. In both diseases muscular impairment is multifactorially determined; hypoxia, oxidative stress, disuse, medication, nutritional depletion and systemic inflammation may contribute to the observed muscle abnormalities and each factor has its own potential for innovative treatment approaches.
\end{abstract}

Harry R. Gosker', Emiel F.M. Wouters', Ger J. van der Vusse ${ }^{2}$, Annemie M.W.J. Schols'. Departments of 'Respiratory Medicine and 'Physiology, University of Maastricht, The Netherlands. American Joumal of Clinical Nutrition 2000; 71:1033-1047 


\section{INTRODUCTION}

According to the definitions of the World Health Organization chronic diseases are not only characterized by their primary impairments, but also by the resulting disabilities or even handicaps (1). Although the primary impairments in chronic obstructive pulmonary disease (COPD) and chronic heart failure (CHF) clearly differ, there is a striking resemblance in the systemic consequences of these diseases and their effects on exercise capacity and health status (figure 1). Impaired skeletal muscle function in COPD and CHF has long been ignored by focusing on the respective ventilatory and cardiac limitations on exercise performance. Research has shown that impaired skeletal muscle function also is an important predictor of exercise limitation in both diseases (2-6). Progression of the primary impairments in these disorders can be slowed down with medication $(7,8)$. Reversion can only be partially achieved through surgical interventions such as lung volume reduction surgery, lung transplantation ( 9 , 10), coronary bypass surgery and heart transplantation (11). However, there are limits on the age of most eligible patients and the availability of donor organs for these interventions. In addition, such interventions not always confer a survival benefit; since no improvement was found after lung transplantation for patients with end-stage emphysema (12). Also, irrespective of the reversibility of the organ impairment, exercise intolerance in both disorders remains after surgical interventions $(13,14)$, indicating that more detailed insight in the systemic consequences is required for effective treatment of these diseases.

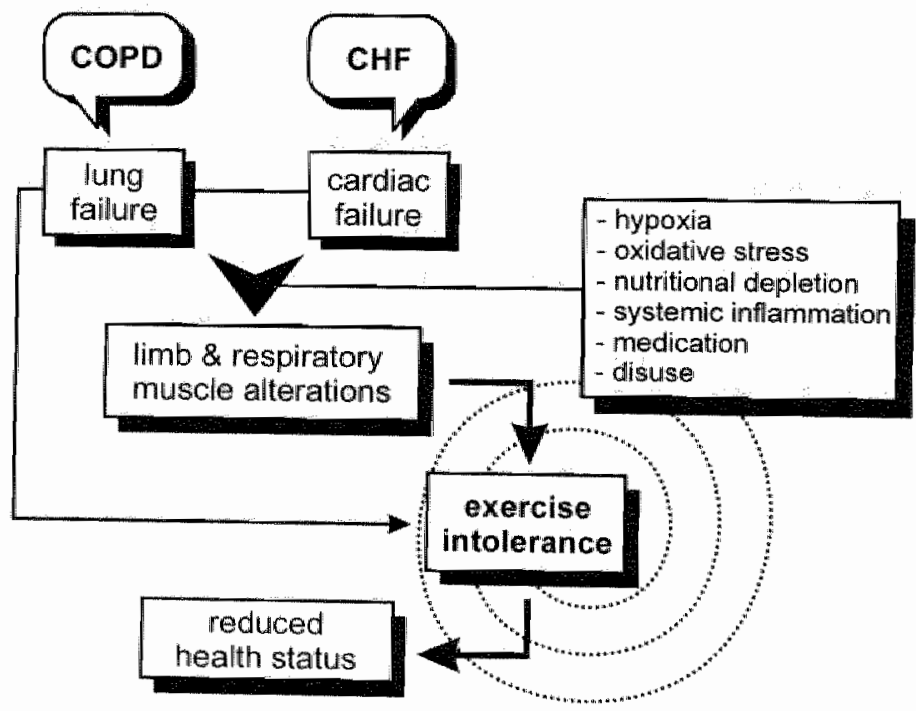

Figure 1, Contributors to exercise intolerance in $\mathrm{COPD}$ and $\mathrm{CHF}$.

Muscle function depends, among others, on perfusion, muscle mass, fiber composition and energy metabolism (15). It can be inferred that alterations in one or more of these determinants play a role in reduced muscle performance. Indeed, both in COPD and in CHF such changes have been lound and striking similarities between the two etiologically distinct disorders
appear to be present. 
In this review we will first present an overview of clinical studies that have investigated impaired muscle function with special emphasis on muscle morphology and energy metabolism in COPD and CHF. The advantage of discussing both diseases simultaneously is that the combined evidence complements each other and therefore provides more insight into the possible underlying causes of these muscle alterations. In the second part of the paper, potential causes will be discussed including hypoxia, oxidative stress, disuse, medication, nutritional depletion and systemic inflammation. The third part deals with therapeutic perspectives.

\section{MUSCLE ALTERATIONS IN COPD AND CHF}

\section{Muscle performance}

Muscle performance is largely characterized by strength and endurance. Strength is defined as the capacity of the muscle to develop maximal force and endurance as the capacity of the muscle to maintain a certain force over time, thus to resist fatigue. Loss of either one of these aspects results in muscle weakness and, hence, in impaired muscle performance. Numerous studies have now convincingly demonstrated that COPD and CHF are commonly associated with muscle weakness $(6,16-21)$. Probably the most extensive study on the influence of muscle weakness on exercise capacity in cardiorespiratory disorders was done by Hamilton and coworkers (4). They found significantly reduced strengths of both peripheral and respiratory muscles in patients suffering from respiratory failure, heart failure, or a combination of both as compared to healthy subjects. However, strength and endurance seem not to be affected in the same way in respiratory and peripheral muscles. This is illustrated by the poor correlation between the strengths of both muscle groups in both disorders $(18,20,21)$, compared to a much stronger correlation in healthy subjects (22). This implies that the strength component of muscle weakness is affected differently in peripheral and respiratory muscles. In healthy subjects, as well as in patients, exercise limiting symptoms are the sense of leg effort (exertional discomfort) and/or breathlessness (exertional dyspnea) $(23,24)$. Thus despite correlations between peripheral muscle strength and performance in COPD and CHF $(18,23$, 25), reduced endurance (ie, fatigue) seems to be the dominant limiting factor in peripheral muscles in these patients, since the sense of leg effort was one of the main reasons to stop exercise $(4,24,26-29)$. Recently it is shown that early lactic acidosis occurs in COPD during exercise $(30,31)$ and that this is largely the result of lactate release from the lower exercising limb (32). Muscle acidosis is a contributing factor to muscle fatigue (33).

Fatigue probably is nor the main limiting factor in respiratory muscle function. Morrison and colleagues found that COPD subjects have decreased respiratory muscle strength and endurance (34). Fatigue of the respiratory muscle may indeed occur during exercise, but it is not certain whether this is an independent determinant of exercise capacity $(27,35-38)$. In addition, it is unlikely that the respiratory muscles of exercising COPD patients contribute to the lactate response mentioned earlier (39). It also should be emphasized that the respiratory muscles must operate against the mechanical airway impedances in this specific disorder (40) for which the force component of respiratory muscle function is most likely of great importance. For CHF it was found that respiratory muscle strength and not respiratory muscle fatigability correlated with the degree of dyspnea (41). Thus, it seems that strength is the 
liniting aspect of muscle performance in the respiratory muscle, whereas endurance limitation dominates in peripheral muscles. However, more detailed studies are required to clarify the individual roles of strength and endurance limitation in peripheral and respiratory muscles in COPD and CHF.

\section{Muscle morphology}

In both CHF $(23,42-44)$ and COPD $(3,45-50)$ marked loss of muscle mass or decline in crosssectional area is observed. This muscle wasting plays an important role in the loss of exercise tolerance in these patients. However, morphological alterations may also be related to muscle function impaiment, although direct relationships with exercise performance have not (yet) been shown. Some histological information is available on abnormalities in skeletal muscle in CHF but hardly any on COPD. Gertz and coworkers (51) found no signs of increased fibrosis or other alterations in intercostal muscles of patients with respiratory failure, whereas endomysial fibrosis has been found in skeletal muscle of a limited number of CHF patients (52). Increased acid phosphatase activity, a lysosomal enzyme contributing to protein degradation, has been found in the quadriceps of some patients with CHF (25) or respiratory failure (50). Increased lipid deposits have been found in the quadriceps, biceps and deltoids of some patients with CHF $(25,52)$. Very contradicting results have been obtained with respect to capillary density in peripheral skeletal muscle in CHF. A normal capillary density has been found (25), which is in confirmation with two other studies in which both a reduced capillary/fiber ratio and atrophy resulted in an unchanged capillary density $(53,54)$. An unaltered capillary/fiber ratio has also been reported, however, capillary density increased due to fiber atrophy (55). In contrast, reduced capillary density in combination with a reduced capillary/fiber ratio has been in shown in CHF patients (56) and even in heart transplant recipients (57). Thus overali, there is a tendency toward a reduced capillary/fiber ratio, but depending on the degree of atrophy the capillary density may even be increased. This has recently been confirmed for COPD (46). In a few studies morphometry of mitochondria has been performed using electron microscopy, showing that mitochondrial volume densities in skeletal muscle are lower in CHF patients compared to control subjects $(56,58)$, which was still the case 10 months after heart transplantation (57). Histochemical alterations reflecting mitochondrial abnormalities have also been reported in biceps muscle biopsies of COPD patients (50). These results suggest that the oxidative capacity of peripheral skeletal muscles may be altered.

\section{Muscle fiber type distribution}

Probably the most remarkable muscle alteration in COPD and CHF is a relative shift in fiber composition which seems to occur in opposite directions in peripheral and respiratory muscles. Fiber typing is mainly performed histochemically, based on the differences in myosin ATPase activities, or immunocytochemically (59). Adult mammalian skeletal muscle contains four myosin heavy chain (MyHC) isoforms, namely types I, IJa, IIb and IIx (60). In most older studies fiber typing is limited to determining fiber types I, Ila and IIb. Furthermore, human fibers formerly identified as being IIb with myosin ATPase staining are probably IIx fibers (61). Therefore the notation $\mathrm{IIb} / \mathrm{x}$ will be used in the subsequent text. Fiber type I has a slowtwitch and develops a relatively small tension, but since it depends mainly on aerobic 
metabolism it is fatigue resistant. In contrast, fiber $\mathrm{ype} \mathrm{Ib} / \mathrm{x}$ has a fast-1witch and develops large tensions, but it is susceptible to fatigue, since its energy conversion is based on anaerobic. glycolytic metabolism. Fber type Ia has intermediate properties in that it also has a fast twitch, develops a moderate tension, is relatively resistant to fatigue and is apt to work under both aerobic and anaerobic conditions $(15,59,62)$. A decrease in the percentage of type I fibers and a corresponding increase in type $\mathbb{I}$ (mainly type $\mathrm{Ib} / \mathrm{x}$ ) fibers compared to normal subject has been reported for COPD $(46,63-66)$ and for CHF $(25,53-56,67)$ in limb nuscles. In addition, in one of these studies also an increase in intemediate fiber types (1+ H) was observed in $\mathrm{CHF}$ (55). These fibers may represent transformation intermediates in the I $\rightarrow$ IIb shift. In contrast to peripheral muscles, a shift from type Ilb/x to type I fibers has been reported in the diaphragnss of both COPD and CHF patients. In healthy subjects the diaphragm comprises about $50 \%$ type $1,25 \%$ type IIa and $25 \% \mathrm{Ib} / \mathrm{x}$ fibers $(68)$, whereas the diaphragm of CHF palients contains $60 \%$ type I, $35 \%$ type IIa and only $10 \%$ type IIb/x fibers (69). A IIb/x $\rightarrow$ I shift was also observed analyzing the distribution of $\mathrm{MyHC}$ isoforms in diaphragms of patients with CHF (70) $\mathrm{or}^{\circ}$ COPD (71). Furthermore, a larger fiber type I population in the diaphragm (conrected for fiber type I percentage of the quadriceps femoris) was found in both COPD and CHE $(26,72)$ compared to sedentary controls $(68,73)$. The proportion of type I fibers in both the internal (IIC) and the external (EIC) intercostals is about $62 \%$ in both COPD patients and controls (68, 74), but in other studies patients had lower proportions of type Ifibers $(46-48 \%)$ in these muscles $(73,75)$. Also, an increased expression of fast MyHC has been reported in the EIC of COPD patients (76). These results suggest that these accessory respiratory muscles do not show a II-I fiber shift as occurs in the diaphragm. No such data have been published for $\mathrm{CHF}^{\mathrm{F}}$.

Despite some variation in the results obtained till now, there is most likely a $I-I l b / x$ shift in peripheral muscles and a IIb/ $x \rightarrow I$ shift in the respiratory muscle. It is feasible that these shifts have functional consequences in the affected muscles, since the distinct fiber types have different contractile properties with respect to twitch and fatigue resistance. Therefore, in COPD and CHF, a $\mathrm{I} \rightarrow \mathrm{IIb} / \mathrm{x}$ shift accompanied by more glycolytic and less oxidative capacity in peripheral muscles implies loss of fatigue resistance. This change might contribute to the observed loss of exercise tolerance, since peripheral muscle fatigue is the main limiting factor in these patients. This is confirmed by a study in which a faster twitch response in combination with less resistance to fatigue was observed in leg muscles of CHF patients (77). Accordingly, a IIb/ $\rightarrow$ I shift towards more oxidative metabolism in the respiratory muscle implies a shift towards a more fatigue-resistant, but less strength adapted muscle. This too is in line with our notion that strength and not fatigue seems to be the main limiting factor for respiratory muscle function.

\section{Muscle metabolism}

Considerable amounts of data are available on skeletal muscle metabolism in CHF and COPD, partly because of the applicability of ${ }^{31} \mathrm{P}$-nuclear magnetic resonance ( $\mathrm{P}-\mathrm{NMR}$ ) which has enabled a direct and non-invasive assessment of tissue levels of high-energy phosphates and pH. High levels of adenosine triphosphate (ATP), creatine phosphate (CrP) and nicotinamide adenine dinucleotide in the reduced form (NADH) reflect a high energy state, whereas elevated levels of adenosine diphosphate (ADP), adenosine monophosphate 
(AMP), inorganic phosphate (Pi) and oxidized nicotinamide adenine dinucleotide (NAD) commonly reflect a low energy state. Lactate and glycogen levels are often measured, but it must be noted that low levels may reflect either increased clearance or reduced formation and visa versa for high levels. Although activities of enzymes involved in muscle energy metabolism do not reflect the physiological situation since only maximal activities are obtained under the optimal circumstances of in vitro measurements, they do provide an indication for adaptations in expressions of proteins involved in metabolic pathways.

Typical oxidative enzymes are citrate synthase (CS), succinate dehydrogenase (SDH) and $\beta$ hydroxyacyl-CoA dehydrogenase (HAD). Typical glycolytic enzymes are hexokinase (HK), phosphofructokinase (PFK) and lactate dehydrogenase ( $\mathrm{LDH})$, the latter catalyzing the last step of anaerobic glycolysis. Measurements of substrate and cofactor levels in peripheral skeletal muscle of COPD and CHF patients indicate impaired energy metabolism (table 1).

Table 1. Muscle metabolite levels

\begin{tabular}{|c|c|c|c|c|}
\hline Metabolite & Muscle & Disorder & Direction & References \\
\hline $\mathrm{CrP}^{\mathrm{P}}$ & $\begin{array}{l}\text { QF } \\
\mathrm{QF} \\
\mathrm{IIC} \& \mathrm{EIC} \\
\end{array}$ & $\begin{array}{l}\text { COPD } \\
\text { CHF } \\
\text { COPD }\end{array}$ & $\begin{array}{l}\nabla \\
\nabla\end{array}$ & $\begin{array}{l}\left(51,64,73,78^{*}\right) \\
\left(79,80^{*}\right) \\
(51,75) \\
\end{array}$ \\
\hline ATP & $\begin{array}{l}\text { QF } \\
\text { QF } \\
\text { IIC \& EIC }\end{array}$ & $\begin{array}{l}\text { COPD } \\
\text { CHF } \\
\text { COPD } \\
\end{array}$ & $\nabla$ & $\begin{array}{l}\left(51,64,73,78^{*}\right) \\
\left(79,80^{*}\right) \\
(51,75) \\
\end{array}$ \\
\hline IMP & TA & COPD & $\Delta$ & $(81)$ \\
\hline glycogen & $\begin{array}{l}\mathrm{QF} \\
\mathrm{QF} \\
\end{array}$ & $\begin{array}{l}\mathrm{CHF} \\
\mathrm{COPD} \\
\end{array}$ & $\nabla$ & $\begin{array}{l}(53,79,80) \\
\left(64,73^{*}\right) \\
\end{array}$ \\
\hline glucose & $\begin{array}{l}\text { IIC \& EIC } \\
\mathrm{QF}\end{array}$ & $\begin{array}{l}\text { COPD } \\
\text { CHF }\end{array}$ & $\Delta$ & $\begin{array}{l}(51) \\
(82) \\
\end{array}$ \\
\hline lactate & $\begin{array}{l}\mathrm{QF} \\
\mathrm{QF} \\
\mathrm{IIC} \& \mathrm{EIC} \\
\end{array}$ & $\begin{array}{l}\text { COPD } \\
\text { CHF } \\
\text { COPD } \\
\end{array}$ & $\stackrel{\Delta}{\Delta}$ & $\begin{array}{l}(51,78) \\
(82) \\
(51) \\
\end{array}$ \\
\hline pyruvate & QF & $\mathrm{CHF}$ & $\Delta$ & (53) \\
\hline
\end{tabular}

$\mathrm{ATP}=$ adenosine triphosphate, $\mathrm{CrP}=$ crealine phosphate, $\mathrm{IMP}=$ inosine monophosphate, $\mathrm{QF}=$ quadriceps femoris, $\mathrm{DIA}=$ diaphragm, $\mathrm{IIC}=$ internal intercostal, $\mathrm{EIC}=$ external intercostal, $\mathrm{TA}=$ tibialis anterior, ${ }^{*}=$ nearly reached significance.

Most striking are the observed reduced levels of the high-energy phosphates in rest. Pouw and colleagues (81) observed higher $\mathrm{Pi} / \mathrm{CrP}$ and $\mathrm{ADP} / \mathrm{ATP}$ ratios associated with slightly, but statistically significantly elevated inosine monophosphate (IMP) levels. The latter may be due to increased degradation of accumulating AMP by deamination, which probably reflects reduced aerobic capacity ( 83 ). The situation becomes even worse during exercise: greater increase in the $\mathrm{Pi} / \mathrm{CrP}$ ratio and a faster drop in $\mathrm{pH}$ were found in the calf muscle of COPD patients $(47,84,85)$ and of CHF patients $(55,86,87)$ performing exercise. Similar results have been obtained for the forearm muscle $(14,87-89)$. In addition, a slower recovery of $\mathrm{CrP}$ was 
observed after exercise $(14,47,55,85-89)$. These results suggest that rephosphorylation of high-energy phosphates is less efficient in these patients both during and after muscular exercise. In addition, glycogen contents in patients tend to be lower, whereas lactate levels are higher (table 1). It thus seems that anaerobic energy metabolism is enhanced and since this process yields far less ATP compared to complete oxidative degradation of glucose this could explain the reduced high-energy phosphate levels.

Table 2. Muscle enzyme activities

\begin{tabular}{lllcl}
\hline Enzyme & Muscle & Disorder & Direction & References \\
\hline CS & QF & COPD & $\mathbf{\nabla}$ & $(30,90)$ \\
& QF & CHF & $\mathbf{\nabla}$ & $(53,55,82,91)$ \\
& DIA & CHF & $\mathbf{\Delta}$ & $(70)$ \\
& IIC \& EIC & COPD & $\mathbf{\Delta}$ & $(92)$ \\
\hline HAD & QF & COPD & $\mathbf{\nabla}$ & $(30,90)$ \\
& QF & CHF & $\mathbf{v}$ & $(53,55,82,91)$ \\
& DIA & CHF & $\mathbf{\Delta}$ & $(70)$ \\
& IIC \& EIC & COPD & $\mathbf{\Delta}$ & $(92)$ \\
\hline SDH & QF & COPD & $\mathbf{\nabla}$ & $(90)$ \\
& QF & CHF & $\mathbf{\nabla}$ & $(53,91)$ \\
\hline COX & QF & COPD & $\mathbf{\Delta}$ & $(93)$ \\
\hline CCRT & QF & CHF & $\mathbf{\Delta}$ & $(80)$ \\
\hline HK & QF & CHF & $\mathbf{\nabla}$ & $(91)$ \\
& DIA & COPD & $\mathbf{\nabla}$ & $(94)$ \\
& IIC \& EIC & COPD & $\mathbf{\Delta}$ & $(92)$ \\
\hline PFK & QF & COPD & $\mathbf{\Delta}$ & $(90)$ \\
\hline LDH & QF & COPD & $\mathbf{\Delta}$ & $(90)$ \\
& QF & CHF & $\mathbf{\Delta}$ & $(82 *)$ \\
& DIA & CHF & $\mathbf{\nabla}$ & $(70)$ \\
& DIA & COPD & $\mathbf{\nabla}$ & $(92)$ \\
\hline
\end{tabular}

$\mathrm{CS}=$ citrate synthase, $\mathrm{HAD}=\beta$-hydroxyacyl-COA dehydrogenase, $\mathrm{SDH}=$ suceinate dehydrogenase, $\mathrm{COX}=$ cytochrome $c$ oxidase, $\mathrm{CCRT}=\mathrm{NADH}$ cytochrome $c$ reductase, $\mathrm{HK}=$ hexokinase, $\mathrm{PFK}=$ phosphofructokinase, $\mathrm{LDH}=$ lactate dehydrogenase, $\mathrm{QF}=$ quadriceps femoris, $\mathrm{DIA}=$ diaphragm, $\mathrm{IIC}=$ internal intercostal, $\mathrm{EIC}=$ external intercostal, ${ }^{*}=$ nearly reached significance.

Analysis of enzyme activities too suggest an overall increase in glycolytic and an overall decrease in oxidative activities in peripheral muscles of COPD and CHF patients (table 2). Since these enzyme activities depend largely on the fiber type (95), it is likely that this shift in activities is related to the shift in fiber distribution mentioned above. Whether enzyme activities adapt to the fiber type redistribution or the other way around remains unclear. In addition to these chronic alterations of enzyme activities, which are measured in vitro, there probably allso is an acute effect on the activities of these enzymes: As a consequence of impaired electron 
transpon, regeneration of $\mathrm{NAD}$ from $\mathrm{NADH}$ is reduced and $\mathrm{CS}$ and $\mathrm{HAD}$ are inhibited by a high $N A D H / N A D$ ratio (96). In addition, an increased $A M P$ level resulting from the ineficient ATP rephosphorylation stimulates glycolysis (96). However, it should be noted that this acute effect is invisible in the in who activity measurements. In two studies an additional inverse relationship of oxidative enzyme activities with arterial lactate levels was found during exercise, emphasizing the assumed shift from oxidative towards glycolytuc energy generation $(30,91)$. This loss of oxidative capacity probably accounts for the abovementioned lipid deposits (97), since it is feastble that fatty acid consumption is reduced, while supply of blood fatty acids continues. Recently, increased activities of two other oxidative enzymes, cytochrome c oxidase (COX) and NADH cytochrome $c$ reductase (CCRT), were found to be increased in patients (table 2). On first notice, this seems to be paradoxical in light of the observed reductions in the oxidative enzymes mentioned earlier. However, these enzymes are involved in either the citric acid cycle or fatty acid oxidation, whereas COX and CCRT are enzymes of the respiratory chain. COX interacts with oxygen and therefore is the main determinant of mitochondrial oxygen affinity (98). Since a correlation was found with hypoxemia (93) it is feasible that an increased number of COX enzymes is a mechanism to enhance the efficiency of residual oxygen extraction and utilization and with that respiratory chain function. In this study COX-I (a mitochondrial encoded subunit of COX) mRNA levels were not increased, but mitochondrial 12S rRNA levels did. Since this particular $r R N A$ is a component of mitochondrial ribosomes, which are involved in translation, it is feasible that mitochondrial protein synthesis is enhanced. The mechanism of hypoxia sensing and subsequent stimulation of mitochondrial gene expression remains, however, unclear (93).

Due to technical difficulties with 3 P-NMR and muscle biopsies of the diaphragm and accessory respiratory muscles, very little is known about energy metabolism in these muscles. However, the observed alterations in enzyme activities (table 2) are in confirmation with the morphological data, in that oxidative enzyme activities are reduced and glycolytic enzyme activities are increased. As in peripheral muscles, this shift probably results from the shift in fiber type distribution.

\section{POSSIBLE UNDERLYING FACTORS}

\section{Hypoxia}

In COPD and CHF oxygen delivery to peripheral and respiratory muscles may be insufficient, caused by either hypoxemia and/or reduced blood supply. In both cases muscle tissue may become hypoxic and this could lead to the adaptive changes in skeletal muscle as those described above. In this respect relevant information is now available from mountaineering expeditions (lasting at least 6 weeks above $5000 \mathrm{~m}$ ), since oxygen is limited at this altitude. Under these conditions reductions in mitochondrial volume densities, in oxidative enzyme activities and in cross sectional areas of muscle fibers were found in the quadriceps (99-101). It must be noted, however, that such expeditions are accompanied by strenuous physical activity, which also causes muscular adaptations other than those caused by hypoxia. In fact, the effect of training in combination with hypoxia may even cause a shift towards more 
oxidative metabolism (102). More information about the effect of hypoxiat on musele has been obtained from animal studies.

Several animal studies have shown that hypoxia can indeed lead to the muscular alterations as described for limb muscles of COPD and CHF patients. For example, reduced fiber diameters in combination with unaffected numbers of capillaries resulting in increased capillary densities, have been reported in rats exposed to hypoxia (103-105). It is suggested that due to this increased capillary density in combination with the loss of oxidative capacity the oxygen availability to remaining muscle mitochondria is enhanced (99). Furthermore, animal studies revealed that hypoxia depresses protein synthesis (106-109), including in muscle tissue (106, 107). Whether hypoxia itself can contribute to the shift in muscle fiber distribution as observed in COPD and CHF remains uncertain. There is evidence that chronic hypoxia inhibits the normal conversion of type Ila to type I fibers in growing rats, with the final outcome that these rats finally may have a predominating proportion of type Ila fibers compared to control rats (110-112). However, no differences were found when adult full-grown rats were exposed to chronic hypoxia $(110,111,113)$. It thus seems that hypoxia does not directly causes a type $\mathrm{I} \rightarrow \mathrm{II}$ fiber shift and it is more likely that the abnormal fiber type distribution results from alterations in muscular development. It is feasible that in COPD and CHF a similar mechanism underlies the abnormal fiber type distribution in the regeneration of damaged muscle or the adaption of muscles to consequences of the disease. In addition, there is evidence that hypoxia causes a shift towards glycolytic metabolism. In studies in which rats were exposed to intermittent hypoxia it was found that the citric acid cycle activity was reduced, whereas glycolytic metabolism was enhanced, resulting in an increased lactate-to-pyruvate ratio (114, 115). Malate dehydrogenase, a citric acid enzyme, has also been found to be reduced by hypoxia (1 16). Furthermore, hypoxia causes stimulation of glucose transport (117) and increased levels of membrane-associated glucose transporters (GLUT1 and GLUT4) in rat muscle (118). In muscle cell cultures this up-regulation of GLUT1 can be mediated either by hypoxia or by inhibition of the respiratory chain (119), suggesting that hypoxia affects glucose transport (and probably also metabolism) via impairment of oxidative phosphorylation.

However, in COPD and CHF this reduction in oxidative capacity does not occur in the diaphragm. It is feasible that hypoxia causes an endurance training effect in the diaphragm due to increased ventilation, which overrides its direct effect ultimately resulting in a shift towards more aerobic metabolism.

\section{Oxidative stress}

Oxidative stress may be another factor contributing via reactive oxygen species to muscle damage. In both COPD and CHF increased plasma levels of lipid peroxidation products have been found $(120,121)$. The main source of these free oxygen radicals are mitochondria, since $2-5 \%$ of the total oxygen consumed is not fully reduced in the electron transport chain and may leak away as superoxide radicals $(122,123)$. An alternative source of free radicals are immune cells activated during inflammation (124). Monocytes and macrophages produce cytokine tumor necrosis factor $\alpha$ (TNF $\alpha$ ) which may in turn induce oxidative stress in myocytes (125). Indeed, elevated TNF $\alpha$ blood levels have been found in both COPD (126-128) and CHF (129. 
133), in particular in those patients characterized by weight loss and/or muscle wasting. A third generator of free radicals is xanthine oxidase, that, in case of a low energy state, is involved in the degradation of AMP (123). The abovementioned elevated IMP levels in COPD (81) indeed suggest an enhanced AMP breakdown.

Susceptibility to these fire radicals largely depends on the antioxidant status of tissue (123). The main antioxidant scavengers and enzymes are, amongst others, reduced glutathione, vitamin $\mathrm{E}$ (in cell membranes), superoxide dismutase (SOD), glutathione peroxidase and catalase $(123,134,135)$. Repeated exposure to oxidative stress, for example in long-term training, stimulates the defense system against oxygen free radicals, in that levels of scavenger and activities of antioxidant enzymes are increased $(122,123,134-136)$. Oxygen flux to muscles and the resulting oxidative stress can increase tremendously during exercise $(123,137)$ and the disuse of muscles thus may lack this antioxidant stimulating trigger resulting in a reduced antioxidant status. Chronic hypoxia probably acts in the same way, since less oxygen is available to form reactive oxygen species. Limitations of oxygen supply are indeed found to be associated with reductions in SOD activity in mammalian tissues like brain, lungs and heart, although this change was not found in skeletal muscle tissue $(138,139)$. In addition, in myocytes (obtained from chronic hypoxic human myocardium) cultured at low oxygen tension, antioxidant enzyme activities were lower than in myocytes cultured at a higher oxygen tension, illustrating the direct modulatory effect of oxygen (140). In vivo and in vitro hypoxiareoxygenation studies revealed that oxygen oversupply following a period of oxygen shortage may give rise to free radical formation in myocytes (138, 141, 142). Accordingly, in COPD and CHF chronic hypoxia may result in a reduced antioxidant status and occasional bouts of exercise may cause a burst of free radicals exceeding the capacity of the defense system (122). It is also feasible that the reduced oxidative capacity in the patients itself leads to enhanced oxidative stress, since the sudden oversupply of oxygen during exercise is inefficiently metabolized.

Reactive oxygen species are well capable of damaging lipids and proteins $(122,123,134,143)$. Radicals that react with fatty acyl moieties in membrane phospholipids cause a chain reaction of peroxidations increasing the membrane permeability (1.43). Maintenance of membrane integrity is crucial for adequate functioning of the respiratory chain, since the driving force for oxidative ATP synthesis is the electrochemical proton gradient over the inner membrane of the mitochondrion, which is generated during the electron transfer from NADH to oxygen (96). Leakage of ions through a more permeable mitochondrial inner membrane may thus very well impair mitochondrial function by uncoupling oxidative phosphorylation. Indeed, rats with an inherited overproduction of free oxygen radicals showed a higher degree of lipid peroxidation and protein damage in combination with impaired respiratory chain function in liver mitochondria (144). Furthermore, a marked fall in ATP levels was observed in cultured endothelial cells exposed to reactive oxygen species (145). In addition, there is evidence that an intracellular calcium overload, probably caused by a damaged sarcoplasmic reticulum membrane in combination with impaired activity of calcium ATPases, accompanies oxidative stress in animal myocytes $(122,138,141,142,146-148)$, which may further uncouple respiration from ATP production through extensive depolarization of the inner membrane (149). 
Protein oxidation by oxygen free radicals leads to formation of earbonyl groups on amino acid residues, which may modify the structure and/or chemical properties of the proteins affected (150). These alterations may cause a decline in protein function or even complete protein unfolding. The latter gives rise to enhanced susceptibility to proteinases. These modified proteins may also be recognized as foreign substances and, hence, be attacked by the immune system. Whether radical induced protein damage plays a role in the abnormalities in muscles of COPD and CHF patients is unclear. It has been shown in animal studies that in vivo induced oxidative stress caused myofibrillar muscle protein modification and that these proteins were rapidly degraded by proteases (15:). Thus theoretically, muscle atrophy can be enhanced by radical induced protein damage. Indeed, it has been shown that a calcium overload is involved in muscle atrophy (152) and that vitamin $\mathrm{E}$ deficiency facilitates muscle wasting and necrosis (153), both probably mediated by oxidative damage to proteins. Also, in human skeletal muscle it has been shown that mitochondria and mitochondrial proteins were more susceptible to oxidative damage compared to other subcellular components (154), which suggests that protein damage may cause impaired oxidative metabolism.

As opposed to necrosis, which is the result of exogenous damage as described above, apoptosis of muscle cells is an active process of cell death, which recently also has been associated with oxidative stress (155). In this study the exposure of rat myoblasts to nitric oxide or hydrogen peroxide led to apoptotic cell death. Since these chemical stimuli are also released by immune cells, it cannot be excluded that apoptosis underlies muscle wasting during inflammation.

\section{Disuse}

Disuse (low level of physical exercise) of skeletal muscle is also a factor that most likely contributes to the observed muscle alterations in COPD and CHF. Hampered by their disease, these patients perform less physical activity which may have a detraining effect on their peripheral muscles. First, detraining causes muscle weakness, due to reduced motor neuron activity and muscle wasting $(59,156)$. Second, disuse may cause a relative reduction in the percentage of type If fibers and an increase in the percentage of type IIb/x fibers $(59,157)$. Third, detraining causes a decline in the activity of enzymes involved in oxidative energy conversion. This occurs both in type I and type II fibers (157, 158), suggesting that loss of oxidative capacity can occur even without any change in fiber composition. As mentioned earlier, muscular disuse has a negative effect on the antioxidant status and, hence, enhances the risk of oxidative damage. Reduced physical activity thus contributes to the loss of muscle mass and probably also to the I $\rightarrow$ II fiber shift, and the reduced oxidative capacity observed in limb muscles in COPD and CHF. As mentioned above, the diaphragm is probably not disused and a kind of endurance training effect may even occur. This may not only be true for COPD, but for $\mathrm{CHF}$ as well, since especially in severe CHF dyspnea and elevated ventilation occurs already at rest $(28,159)$.

\section{Medication}

Of the wide range of drugs used to treat COPD and CHF, only corticosteroids have been associated with skeletal muscle alterations. Especially in COPD, but less frequently in CHF, 
conticosteroids are used in low doses as maintenance medication or in higher doses during acute disease exacerbations $(160,161)$. Depending on the type of steroid, the dose and the duration of treatment the drug induced defects range from alterations in energy metabolism to muscle weakness with underlying muscle wasting and histological abnormalities $(160,161)$. From both clinical and animal studies it became clear that steroid induced muscle wasting is often associated with an overall negative nitrogen balarce, reduced protein synthesis in combination with increased protein catabolism in muscle tissues and increased plasma levels of amino acids (162). These findings suggest that corticosteroids probably stimulate the mobilization of amino acids from muscle proteins (161), supplying the liver with gluconeogenic precursors, which corresponds with a shift towards glycolytic metabolism. No such data are available for CHF, but a few reports reveal that COPD patients who chronically receive conticosteroids indeed may show more muscle weakness alone or with an accompanying loss of muscle mass compared to non-treated COPD patients $(17,163-165)$. However, since the latter group of patients receive corticosteroids to treat inflammation, it is difficult to distinguish between the effect of steroid administration and the effects of the exacerbations. Also, decreased levels of testosterone have been reported for male COPD patients receiving glucocorticoids (166). Assuming that corticosteroids are involved in muscular alterations, the question rises whether this effect is generalized or muscle type specific? Experimental studies indicate that especially the glycolytic fibers seem susceptible to steroid-induced muscle wasting $(161,162,167)$, suggesting that vulnerability depends on muscle fiber composition. The diaphragm, which especially in patients has a relative high proportion of type I fibers, therefore could be less affected by steroid usage and limb muscles consisting of more type II fibers would be more vulnerable. On the other hand, the diaphragm already has a lower type II fiber content and selective wasting of type II fibers could further reduce diaphragm strength, being the main limiting factor in diaphragm muscle performance. This suggests exactly the opposite, namely that the diaphragm is more vulnerable to corticosteroids than limb rmuscles. Furthermore, it is difficult to isolate the effect of corticosteroids on diaphragm function from the complex of other unfavorable influences on lung function in COPD (165). Therefore, Wang studied the effect of prednisone on the respiratory muscle function in normal subjects (thus without disturbing influences) and found no differences compared to the control group (168). This does not exclude the possibility that other steroids might not have an effect since a recent animal study showed different effects between fluorinated and non-fluorinated steroids at equipotent doses (169). Other animal studies are in confirmation with the lhypothesized shift towards glycolytic metabolism in peripheral muscle and a shift towards ox dative metabolism in the diaphragm: in corticosteroid treated rats it was found that diaphragm force generation and the proportion of type IIb was reduced in combination with a decreased activity of the glycogenolytic enzyme phosphorylase and increased activities of HAD and CS (170). Increased PFK and glycogen synthase activities have been reported for limb muscle of corticosteroid treated rats (169). Expressed per gram of muscle, limb twitch tension may even increase in steroid treated animals, also in confimation with an increase in fiber type II content $(169,171)$. The fact that corticosteroids selectively affect type If fibers but also are associated with a shift towards glycolytic metabolism in peripheral muscle seems contradictory and needs further investigation. 
It is noteworthy that in both CHF and COPD muscle performance is not filly recovered $(5$ to 38 months) after heart or lung transplantation and intrinsic skeletal muscle alterations remain $(57,172)$. Corticosteroids and also cyclosporin are often used as immunosuppressives after transplantations and it is therefore feasible that these drugs might be related to impaned muscle function $(13,57,172)$.

\section{Nutritional depletion and systemic inflammation}

Nutritional depletion commonly occurs in COPD $(173,174)$ and in CHF $(42,175)$. In both disorders mutritional depletion is an important determinant for exercise capacity $3,44,45$, 176). Body weight (usually corrected for height) is often used to determine the nutritional status of patients, but this method neglects the differences in body composition between individuals (3). Determination of body composition with respect to nutritional depletion is very important since different patterns of weight loss can be distinguished: predominant loss of fat mass, predominant loss of fat free mass or a combination of both. Predominant loss of fat mass involves an impaired balance between energy requirement and energy intake. Dietary intake can be decreased in COPD due to symptoms such as dyspnea, fatigue and early satiety (177). Besides recently systemic inflammation has been suggested to affect appetite and dietary intake, mediated by the appetite regulating homone leptin (178). However, patients with COPD may lose weight despite a normal or above normal dietary intake (179). In COPD and CHF resting energy expenditure (REE) is often elevated (180-183). In addition, elevated total daily energy expenditure (TDEE) independent of REE has been shown for COPD (184). Increased oxygen cost of breathing (OCB) probably attributes to the increased TDEE due to increased hyperinflation during exercise $(185,186)$, but since hyperinflation is not increased at rest it is unlikely that an elevated OCB accounts for the elevated REE (180). Suggested contributors to the elevated REE are the thermogenetic effect of broncholidating agents (180) and systemic inflammation (127). Furthermore, the observed loss of efficient aerobic energy metabolism might play a role in the increased REE and TDEE. In this situation of semistarvation loss of both fat mass and fat free mass occurs, but the loss of fat free mass is relatively preserved. Therefore, intrinsic muscle abnormalities besides muscle mass probably account for impaired muscle performance. Studies of muscle function and histology in anorexia nervosa patients provide strong data on the eflect of undernutrition in muscles. Muscle performance is markedly impaired in these patients (187-189) and is associated with weight loss, loss of muscle mass and fiber atrophy (particularly of type II fibers) (190, 191). Data from animal studies confirm these effects of undernutrition. First of all, loss of muscle mass associated with fiber atrophy was observed in limb muscles upon nutritional deprivation (171, 192). Furthermore activities of the oxidative enzymes SDH and HADH were found to be reduced (192, 193). The activity of the glycolytic enzyme PFK was also reduced (193), but this was not confirmed by Koerts and coworkers (169). In addition high ADP and low CrP levels were observed in food deprived animals (193, 194), suggesting that muscle energy metabolism indeed is impaired after deprivation. However, it remains unclear whether nutritional deprivation results in a general loss of activities of enzymes involved in energy netabolism or predominantly affects either oxidative or glycolytic energy metabolism. The contribution of nutritional depletion to a shift from oxidative to glycolytic metabolism in COPD and CHF patients needs further investigation. 
Predominant loss of fat free mass involves an impaired balance between protein anabolism and catabolism resulting in the loss of fat free mass. For empliysema a decreased muscle protein synthesis was found (49), but protein degradation probably was not increased $(195,196)$. Also, nitrogen intake was not lower in these patients, while nitrogen excretion was increased (196). It is therefore feasible that amino acids are required in other processes than muscular protein synthesis, such as gluconeogenesis. Since in both COPD and CHF weight loss and loss of fat free mass has often been associated with systemic inflammation $(126,127,133)$ it is also feasible that amino acids are required for an increased inflammatory protein synthesis in the liver. Disturbed plasma and muscle amino acid levels have been observed in COPD, suggesting that amino acids are indeed redirected from the muscle (197). Animal and in vitro studies confirm this notion (198): exposure of myocytes to TNF $\alpha$. resulted in a decrease in protein synthesis, which occurs even during anabolic stimulation with insulin-growth factor-1 (IGF-1). Furthermore, chronic administration of TNF $\alpha$ led to increased muscle protein catabolism and liver protein anabolism in rats. In addition, the above-mentioned involvement of TNF $\alpha$ in oxidative stress may contribute to muscle wasting (125). Protein depletion itself may impair skeletal muscle performance as reflected by reduced maximum voluntary handgrip strength, reduced respiratory muscle strength and increased fatigability of in vivo electrically stimulated adductor pollicis muscle (199).

\section{THERAPEUTIC PERSPECTIVES}

\section{Training}

It is obvious that exercise training improves muscular performance, since, depending on the training program, strength and/or endurance can be improved (59). Because disuse has been suggested to be an important factor responsible for the alterations in muscle metabolism in COPD and CHF, it is feasible that training of the affected muscles could reverse these abnormalities. Indeed, exercise training improves exercise capacity in both COPD $(200,201)$ and CHF $(6,43,202)$. Furthermore, increased cross sectional areas of oxidative fibers and elevated oxidative enzyme activities in the quadriceps muscle in combination with less arterial lactate accumulation during exercise has been found in $\operatorname{COPD}(46,203)$. Training induced increase of oxidative capacity and muscle mass of the quadriceps muscle has also been reported for $\mathrm{CHF}(58,87)$, In addition, the abovementioned exercise induced increase of the $\mathrm{Pi} / \mathrm{CrP}$ ratio and drop in $\mathrm{pH}$ is less upon training (202). Thus in peripheral muscles training induces a partial improvement of the oxidative capacity in combination with increased exercise performance. In general, prolonged endurance training leads to increased percentages of type I and Ila fibers accompanied with an increased oxidative capacity resulting in a higher fatigue resistance (59). Therefore, combined with fatigue being the main limiting factor in peripheral muscle performance, it is feasible that an endurance training protocol is most suitable for improving exereise capacity of limb muscles. This is also illustrated by the fact that in COPD patients quadriceps endurance shows a larger improvement upon training than strength $(200,201)$.

No data on improvement of oxidative capacity upon training are available for respiratory muscles. However, the differences between respiratory and peripheral muscles in COPD and 
CHF suggest that different training approaches are required in order to effectively improve their performances. Whereas respiratory muscle training in CHF remains an unexplored field, a variety of studies have been performed for COPD (204). Although respiratory muscle training may improve its performance, there is little evidence of real clinical benefit. Best results are probably obtained with so called resistance training (204), in which the inspiratory muscles are subjected to an increased pressure load. The fact that this is a kind of power training affeeting especially respiratory muscle strength suggests that training of the respiratory muscle should be more focused on strength than on endurance $(205,206)$.

Another possible positive effect of exercise training probably is the increase in antioxidant status. As discussed above, disuse (or 'disuse hypoxia') has a negative effect on the antioxidant status and may therefore promote oxidative damage during occasional exercise due to temporarily enhanced oxygen supply to the exercising muscles. However, regular physical exercise involves a regular increase in exposure of muscle tissue to oxygen and training thus probably reduces the risk of oxidative stress (135).

\section{Nutritional support, anabolic steroids and anti-inflammatory therapy}

The effects of nutritional support strategies on muscle mass and muscle function have been investigated in COPD, but it is a rather unexplored area in CHF. Several studies in depleted patients with COPD have shown that nutritional supplementation can improve both respiratory and peripheral muscle function $(174,207,208)$. It is unclear however to what extent this improvement in muscle function is related to the increase in muscle mass per se (209). Muscle performance may reach normal values upon nutritional support while muscle mass is still lower compared to control subjects as shown for example in anorexia nervosa patients (189), suggesting that repletion of intrinsic muscle abnormalities are important in the improvement of muscle function. An early and a late response to nutritional supplementation has been proposed (199): after the first few days of repletion muscle function improves $10 \%$ to $20 \%$ without any demonstrable gain in tissue protein. This early response probably results from improved electrolyte content (210) and levels of energy-rich compounds $(51,199)$. Only during prolonged treatment physiologic functions further improve accompanied by an increase in tissue protein and muscle mass (211).

However, a substantial subgroup of COPD patients does not respond to high-caloric nutritional therapy in terms of weight gain (212). This subgroup was characterized by an elevated systemic inflammatory response as evidenced by enhanced levels of acute phase proteins, and soluble TNF-receptors. As mentioned earlier, systemic inflammation is associated with protein catabolism and probably plays a role in the loss of muscle mass. This suggests that anti-inflammatory therapy might be beneficial in this particular subgroup. Many COPD patients receive inhaled or oral corticosteroids to treat local inflammation and acute infections. Systemic inflammation however is not reversed during this treatment (213). In addition, oral steroids may even have a negative side effect on skeletal muscle as mentioned above. A possibility to modulate systemic inflammation is through ingestion of polyunsaturated fatty acids (PUFAs). PUFAs are incorporated into the phospholipids of the cell membrane and play an important role in the activation of inflammatory processes. Indeed fish oil supplementation reduced 
inflammatory mediators and had an anticachectic effect in pancreatic cancer patients (214). No studies are yet available regarding PUFA supplementation in COPD or CHF.

Adrninistration of anabolic steroids may be an additional mode of intervention to counteract protein catabolism either by the androgen receptor mediated promotion of protein anabolism and/or by neutralizing the effects of glucocorticosteroids through binding competition for the receptor mediating catabolism (215): Anabolic steroids could thus be useful in patients characterized by muscle wasting, especially in those who are treated with corticosteroids. Anabolic steroid treatment in addition to nutritional support as integrated part of a pulmonary rehabilitation program revealed a significantly enhanced FFM despite a similar weight gain as nutritional support only. This increased FFM was reflected in an improved respiratory muscle function $(209,216)$. No difference in response was noted for patients on maintenance oral corticosteroid treatment (209). Currently the effects of this combined treatment approach on peripheral skeletal muscle function, exercise performance and health status is being studied. Besides effects on muscle performance, anabolic steroids resulted in an improvement in negative acute phase proteins such as albumin and prealbumin (215) in depleted COPD patients. This may indicate an anti-inflammatory effect.

Others have investigated the effects of adjuvant treatment with recombinant human growth hormone (rhGH). Administration of this hormone induces lipolysis, protein anabolism and muscle growth, either directly or through IGF-1. Two uncontrolled studies reported the effects of thGH in nutritionally depleted patients with COPD. Administration of rhGH during 8 days ( $0.03 \mathrm{mg} / \mathrm{kg} / \mathrm{day}$ subcutaneous for 4 days, plus $0.06 \mathrm{mg} / \mathrm{kg} /$ day for another 4 days) failed to increase respiratory and peripheral skeletal muscle strength in COPD (217). In contrast an increase in inspiratory muscle strength was reported after 3 weeks of treatment $(0.05 \mathrm{mg} / \mathrm{kg} /$ day subcutaneous) (218). Using a similar treatment regimen however but in a placebo controlled fashion the effects of administration of rhGH on body composition, resting metabolic rate and functional capacity in underweight COPD patients in a stable clinical state were studied (219). Although FFM increased significantly during the 3 weeks treatment period, no improvement was seen in muscle function and exercise capacity even decreased in the treatment group. Furthermore a significant increase in resting metabolic rate was observed.

In the previous sections of this paper we state that COPD and CHF patients may suffer from increased oxidative stress, either in muscle or lung tissue. Furthermore, vitamin E deficiency is associated with the pathogenesis of the wasting and weakness in thalassemia major (220). Therefore, another mode of nutritional intervention might be supplementation with antioxidants stuch as vitamins, glutathione and $\mathrm{N}$-acetylcysteine. Several studies indeed revealed a beneficial effect of antioxidant supplementation (221). For example, vitamin $\mathrm{E}$ protects human skeletal muscle from damage during surgical ischemia-reperfusion (222) and vitamin C supplementation reduces exercise induced oxidative stress (223). Similar results have been obtained with animal studies $(153,224,225)$. Although antioxidant supplementation does reduce physical exercise induced oxidative stress, it remains unclear whether exercise performance is enhanced $(134,221)$. Most of these data are obtained from athletes who already have a high exercise capacity, whereas vitamin supplementation may have more effect in COPD and CHF patients, who have a tremendously lower exercise capacity. In addition, there 
are some indications that vitamin supplementation may improve lung function $(226,227)$. Antioxidant administration in $\mathrm{CHF}$ and COPD therefore deserves further investigation:

\section{Oxygen therapy}

Long-term oxygen therapy (LTOT) improves survival and quality of life of COPD patients $(228,229)$, but no such data are avallable for CHF. It is clear that acute oxygen administration is beneficial for exercise capacity in COPD (230-232). However, very little is known about the ability of LTOT to reverse the alterations found in skeletal muscles of COPD patients. In fact, improved exercise capacity during oxygen administration, including LTOT, could very well be an acute effect without reversal of these abnormalities. First of all, by supplying oxygen, hypoxemia is (partly) reversed and with that dyspnea may be improved (230). The latter is an important determinant of exercise tolerance in COPD. Therefore, relief of breathlessness may account for a great deal of improvement in exercise capacity (231). Second, the acute supply of oxygen to muscle tissue probably improves oxidative energy metabolism only during the oxygen administration period itself, since the indices of oxidative energy metabolism $(\mathrm{CrP} / \mathrm{Pi}$, $\mathrm{pH}$ and $\mathrm{Cr} \mathrm{P}$ recovery) showed some improvement in the COPD group only during oxygen administration (85). After exercise while breathing room air, COPD patients receiving LTOT still had a reduced $\mathrm{CrP} / \mathrm{Pi}$ ratio and $\mathrm{pH}$ in combination with slow $\mathrm{CrP}$ recovery compared to control subjects. Also, supplementation of oxygen does not add to the improving effects of training (232). Only in one study improvement of the $\mathrm{CrP} / \mathrm{Cr}$ ratio while breatling roon air has been reported in resting muscle of COPD patients after 6-9 months of LTOT (233). However, since the blood $\mathrm{PO}_{2}$ also improved, this increase probably is caused by an increased oxygen supply and not due to any reversal of muscle abnormalities. In addition, the reduced glycogen levels failed to improve, which further suggests that muscle abnormalities are not reversed.

Little attention has been paid to lung damage due to oxidative stress with respect to oxygen administration. It is clear that free radicals play an important role in the development of COPD, since $90 \%$ of all patients are (ex-)smokers and cigarette smoke is a rich source of oxidants that cause all sorts of lung damage (234). The levels of oxygen administered to patients ane potentially toxic and may also result in lung injury caused by oxidative stress $(235,236)$. More research on this field needs to be done in order to establish whether oxygen administration is beneficial or may contribute to lung or even peripheral tissue damage. In the meantime, if oxygen supplementation is necessary, it is recommended that the lowest effective concentration of oxygen should be used (236).

\section{CONCLUSIONS}

This review underscores the fact that reduced skeletal muscle performance contributes markedly to exercise intolerance in COPD and CHF patients. Morphologic and metabolic abnormalities occur in the skeletal muscles of these patients which, in both disorders, probably are determined by the same set of contributing factors, including hypoxia, oxidative stress, disuse, medication, nutritional depletion and systemic inflammation. Both diseases also share striking differences between peripheral muscles and the diaphragm which, therefore, may 
require a different therapeutical approaches. Future investigations of the mechanisms and relative contributions of each of the factors leading to these intrinsic muscular alterations are required.

\section{REFERENCES}

1. Wood PH. Appreciating the conisequences of disease: the international classification of impairments, disabilities, and handicaps. WHO Chron 1980;34:376-80.

2. Cotes JE, Zejda J; King B. Lung function impairment as a guide to exercise limitation in workrelated lung disorders. Am Rev Respir Dis 1988;137:1089-93.

3. Schols AM, Mostert R, Soeters PB, Wouters EF. Body composition and exercise performance in patients with chronic obstructive pulmonary disease. Thiorax 1991;46:695-9.

4. Hamilton AL, Killian KJ, Summers E, Jones NL. Muscle strength, symptom intensity, and exercise capacity in patients with cardiorespiratory disorders. Am J Respir Crit Care Med 1995; 152:2021-31.

5. Steele IC, Moore A, Nugent AM, Riley MS, Campbell NPS, Nicholls DP. Non-invasive measurement of cardiac output and ventricular ejection fractions in chronic cardiac failure: Relationship to impaired exercise tolerance. Clin Sci 1997;93:195-203.

6. Sullivan MI, Hawthorne MH. Exercise intolerance in patients with chronic heart failure. Prog Cardiovasc Dis 1995;38:1-22.

7. Senior RM, Anthonisen NR. Chronic obstructive pulmonary disease (COPD). Am J Respir Crit Care Med 1998;157:S139-S47.

8. Miller MM. Current trends in the primary care management of chronic congestive heart failure. Nurse Pract 1994;19:64-70.

9. Siafakas NM, Vermeire P, Pride NB, et al. Optimal assessment and management of chronic obstructive pulmonary disease (COPD). Eur Respir I 1995;8:1398-420.

10. Grover FL, Fullerton DA, Zamora MR, et al. The past, present, and future of lung transplantation. Am J Surg 1997;173:523-33.

11. Beller GA. Selecting patients with ischemic cardiomyopathy for medical treatment, revascularization, or heart transplantation. J Nucl Cardiol 1997;4:S152-7.

12. Hosenpud JD, Bennett LE, Keck BM, Edwards EB, Novick RJ. Effect of diagnosis on survival benefit of lung transplantation for end-stage lung discase. Lancet 1998;351:24-7.

13. Williams TI, Snell GI. Early and long-term functional outcomes in unilateral, bilateral, and living-related transplant recipients. Clin Chest Med 1997;18:245-57.

14. Stratton JR, Kemp GJ, Daly RC, Yacoub M, Rajagopalan B. Effects of cardiac transplantation on bioenergetic abnormalities of skeletal muscle in congestive heart failure. Circulation 1994;89:1624-31.

15. Armstrong RB. Muscle fiber recruitment patterns and their metabolic conrelates. In: Horton HS, Terjung RL, eds, Exercise, nutrition, and energy metabolism. New York: Macmillan Publishing Company, 1988: 9-26.

16. Decramer M, Gosselink R, Troosters T, Verschueren M, Evers G. Muscle weakness is related to utilization of health care resources in COPD patients. Eur Respir J 1997;10:417-23.

17. Bemard $S$, LeBlane $P$, Whittom $F$, et al. Peripheral muscle weakness in patients with chronic obstructive pulmonary disease. Am J Respir Crit Care Med 1998;158:629-34.

18. Gosselink R, Troosters T, Decramer M. Peripheral muscle weakness contributes to exercise limitation in COPD. Am I Respir Crit Care Med 1996;153:976-80.

19. Zattara-Hartmann MC, Badier M, Guillot C, Tomei C, Jammes $\mathrm{Y}$. Maximal force and endurance to fatigue of respiratory and skeletal muscles in chronic hypoxemic patients: the 
effects of oxygen breathing. Muscle Nerve 1995;18:495-502.

20. Chua TP, Anker SD, Harrington D, Coats AI. Inspiratory muscle strength is a determinant of maximum oxygen consumption in chronic heart failure $\mathrm{Br}$ Heart I 1995:74:381-5.

21. McParland C, Resch EF, Krishnan B, Wang Y, Cujec B, Gallagher CG. Inspiratory muscle weakness in chronic heart failure: role of nutrition and electrolyte status and systemic myopathy. An J Respir Crit Care Med 1995;151:1101-7.

22. Lands LC, Heigenhauser GJ, Jones NL. Respiratory and peripheral muscle function in cystic fibrosis. Am Rev Respir Dis 1993;147:865-9.

23. Harrington D, Anker SD, Chua TP, et al. Skeletal muscle function and its relation to exercise tolerance in chronic heart failure. J Am Coll Cardiol 1997;30:1758-64.

24. Killian KJ, Leblane P, Martin DH, Summers E, Jones NL, Campbell EI. Exercise capacity and ventilatory, circulatory, and symptom limitation in patients with chronic airflow limitation. Am Rev Respir Dis 1992;146:935-40.

25. Lipkin DP, Jones DA, Round JM, Poole Wilson PA. Abnormalities of skeletal muscle in patients with chronic heart failure. Int J Cardiol 1988;18:187-95.

26. Karlsson J, Diamant B, Folkers K. Exercise-limiting factors in respiratory distress. Respiration $1992 ; 2: 18-23$

27. Belman M.J. Exercise in patients with chronic obstructive pulmonary disease. Thorax 1993;48:936-46.

28. Myers J, Salleh A, Buchanan N, et al. Ventilatory mechanisms of exercise intollerance in chronic heart failure. Am Heart J 1992;124:710-9.

29. Drexler $H$. Changes in the peripheral circulation in heart faillure. Curr Opin Cardiol 1995; 10:268-73.

30. Maltais F, Simard AA, Simard C, Jobin J, Desgagnes P, LeBlanc P. Oxidative capacity of the skeletal muscle and lactic acid kinetics during exercise in normal subjects and in patients with COPD. Am J Respir Crit Care Med 1996;153:288-93.

31. Engelen MPKJ, Schols AMWJ, Does JD, Wouters EFM. Exercise induced lactate increase in relation to physical activity level and peripheral muscle substrates in COP D. Am J Respir Crit Care Med 1999;159:A475.

32. Maltais F, Jobin J, Sullivan MJ, et al. Metabolic and hemodynamic responses of lower limb during exercise in patients with COPD. J Appl Physiol 1999;84:1573-80.

33. Mainwood GW, Renaud JM. The effect of acid-base balance on fatigue of skeletal muscle. Can I Physiol Pharmacol 1985;63:403-16.

34. Morrison NJ, Richardson J, Dunn L, Pardy RL. Respiratory muscle performance in nomal elderly subjects and patients with COPD. Chest 1989;95:90 4.

35. Decramer $M$, Aubier $M$. The respiratory muscles: cellular and molecular physiology. Eur Respir J $1997 ; 10: 1943-5$.

36. Similowski T, Yan S, Gauthier AP, Macklem PT, Bellemare F. Contractilo properties of the human diaphragm during chronic hyperintlation. N Engl J Med 1991;325:917-23.

37. Pardy $\mathrm{RL}$, Rivington RN, Despas PJ, Macklem PT. The effects of inspiratory muscle training on exercise performance in chronic airflow limitation. Am Rev Respir Dis 1981;123:426-33.

38. Fitting JW. Respiratory muscle fatigue limiting physical exercise? Eur Respir J 1991;4:103-8.

39. Engelen MP, Casaburi R, Rucker R, Carithers E. Contribution of the respiratory muscles to the lactic acidosis of heavy exercise in COPD. Chest 1995;108:1246-51.

40. O'Donnell DE, Webb KA. Exertional breathlessness in patients with chronic arflow limitation. The role of lung hyperinflation. Am Rev Respir Dis 1993:148:1351-7.

41. Mancini DM, Henson D, LaManca J, Levine S. Respiratory muscle function and dyspnea in patients with chronic congestive heart failure. Circulation 1992;86:909-18.

42. Wilson JR, Mancini DM. The mechanism of extertional fatigue in heart failure. Cardioscience 


\section{$1990 ; 1: 13-7$.}

43. Shephard RJ. Exercise for patients with congestive heart lailure. Sports Med 1997;23;75-92.

44. Myagi $K$, Asanoi $H$, Ishizaka $S$, et al. Importance of total leg muscle mass for exercise intolerance in chronic heart falure. Jpn Heart J 1994;35:15-26.

45. Engelen MP, Schols AM, Baken WC, Wesseling GJ, Wouters EF. Nutritional depletion in relation to respiratory and peripheral skeletal muscle function in out-patients with COPD. Eur Respir J 1994;7:1793-7.

46. Whittom $\mathrm{F}$, Jobin I, Simard PM, et al. Histochemical and morphological characteristics of the vastus laterals muscle in patients with chronic obstructive pulmonary disease. Med Sci Sports Exere $1998 ; 30: 1467-74$.

47. Wuyam B, Payen JF, Levy P, et al. Metabolism and aerobic capacity of skeletal muscle in chronic tespiratory failure related to chronic obstructive pulmonary disease. Eur Respir J $1992 ; 5: 157-62$.

48. Rochester DF. Body weight and respiratory muscle function in chronic obstructive pulmonary discase. Am Rey Respir Dis 1986;134:646-8.

49. Morrison WL, Gibson JN, Scrimgeour C, Rennie MJ. Muscle wasting in emphysema. Clin Sci $1988 ; 75: 415-20$.

50. Sato $Y$, Asoh T, Honda Y, Fujimatsu Y, Higuchi I, Oizumi K. Morphologic and histochemical evaluation of muscle in patients with chronic pulmonary emphysema manifesting generalized. emaciation. Eur Neurol 1997;37:1 16-21.

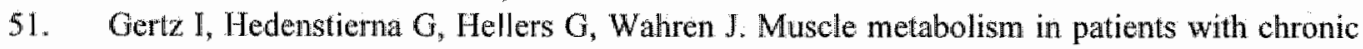
obstructive lung disease and acute respiratory failure. Clin Sci Mol Med 1977;52:395-403.

52. Dunnigan $A$, Staley NA, Smith SA, et al. Cardiac and skeletal muscle abnormalities in cardiomyopathy: comparison of patients with ventricular tachycardia or congestive heart failure. J Am Coll Cardiol 1987; 10:608-18.

53. Sullivan MJ, Green HI, Cobb FR. Skeletal muscle biochemistry and histology in ambulatory patients with long-term heart failure. Circulation 1990;81:518-27.

54. Schanfelberger $M$, Eriksson BO, Grimby $G_{3}$, Held P, Swedberg K. Skeletal muscle fiber composition and capillarization in patients with chronic heart failure: relation to exercise capacity and central hemodynamics. J Card Fail 1995;1:267-72.

55. Mancini DM, Coyle $\mathrm{E}$, Coggan $\mathrm{A}$, et al. Contribution of intrinsic skeletal muscle changes to ${ }^{31} \mathrm{P}$ NMR skeletal muscle metabolic abnormalities in patients with chronic heart failure. Circulation $1989 ; 80: 1338-46$.

56. Drexler H, Riede U, Munzel T, Konig H, Funke E, Just H. Alterations of skeletal muscle in chronic heart failure. Circulation 1992;85:1751-9.

57. Lampert E, Mettauer B, Hoppeler H, Charloux A, Charpentier A, Lonsdorfer J. Structure of skeletal muscle in heart transplant recipients. J Am Coll Cardiol 1996;28:980-4.

58. Hambrecht R, Fiehn E, Yu J, et al. Effects of endurance training on mitochondrial ultrastructure and fiber type distribution in skeletal muscle of patients with stable chronic heart failure. J Am Coll Cardiol 1997;29:1067-73.

59. McComas AJ. Skeletal muscle: form and function. Champaign: Human Kinetics, 1.996.

60. Schiaftino $\mathrm{S}$, Reggiani $\mathrm{C}$. Molecular diversity of myofibrillar proteins: gene regulation and functional significance. Physiol Rev 1996;76:371-423.

61. Pereira Sant Ana IA, Ennion S, Sargeant AJ, et al. Comparison of the molecular, antigenic and ATPase determinants of fast myosin heavy chains in rat and human: a single-fibre study. Pfugers Arch 1997:435:151-63.

62. Harridge SDR, Bottinelli R, Canepari $M$, et al. Whole-muscle and single-fibre contractile properties and myosin heavy chain isoforms in humans. Pflügers Arch 1996;432:913-20.

63. Satta A, Migliori GB, Spanevello A, et al. Fibre types in skeletal muscles of chronic obstructive 
pulmonary disease patients related to respiratory function and exercise tolerance. Eur Respir I $1997 ; 10: 2853-60$.

64. Jakobsson P, Jorfeldt $L$, Brundin A. Skeletal muscle metabolites and fibre types in patients with advanced chronic obstructive pulmonary disease (COPD), with and without chronic nespiratory failure. Eur Respir J 1990,3:192-6.

65. Maltais F, Sullivan MJ, LeBlanc P, et al. Altered expression of myosin heavy chain in the vastus lateralis muscle in patients with COPD. Eur Respir J 1999;13:850-4.

66. Hildebrand IL, Sylven C, Esbjörnsson M, Hellstroum K, Jansson E. Does chronic hypoxaemia induce transformations of fibre types? Acta Physiol Scand 1991:141:435-9.

67. Sullivan MJ, Duscha BD, Klitgaard H, Kraus WE, Cobb FR, Saltin B. Altered expression of myosin heavy chain in human skeletal muscle in chronic heart failure. Med Sci Sports Exerc $1997 ; 29: 860-6$.

68. Mizuno M. Human respiratory muscles: fibre morphology and capillary supply. Eur Respir 』 $1991 ; 4: 587-601$.

69. Lindsay DC, Lovegrove CA, Dunn MJ, et all. Histological abnormalities of muscle from limb, thorax and diaphragm in chronic heart failure. Eur Heart J 1996;1 7:1239-50.

70. Tikunov $B$, Levine $S$, Mancini $D$. Chronic congestive heart failure elicits adaptations of endurance exercise in diaphragmatic muscle. Circulation 1997;95:910-6.

71. Levine S, Kaiser L, Leferovich J, Tikunov B. Cellular adaptations in the diaphragn in chronic obstructive pulmonary disease. N Engl J Med 1997;337:1799-806.

72. Morton JM, McKenna MJ, Carey MF, et al. Skeletal muscle pathophysiology in subjects with severe COAD. In: The Thoracic Society of Australia \& New Zealand 1998 Annual Scientific Meeting; 1998; Adelaide; 1998. 012.

73. Hughes RL, Katz H, Sahgal V, Campbell IA, Hartz R, Shields TW. Fiber size and energy metabolites in five separate muscles from patients with chronic obstructive lung diseases. Respiration 1983;44:321-8.

74. Hards JM, Reid WD, Pardy RL, Pare PD. Respiratory muscle fiber morphometry, Correlation with pulmonary function and nutrition. Chest 1990;97:1037-44.

75. Campbell JA, Hughes $\mathbb{R L}$, Sahgal V, Frederiksen J, Shields TW. Alterations in intercostal muscle morphology and biochemistry in patients with obstructive lung disease. Am Rev Respir Dis 1980;122:679-86.

76. Gea JG. Myosin gene expression in the respiratory muscles. Eur Respir J 1997:10:2404-10.

77. Harridge SD, Magnusson G, Gordon A. Skeletal muscle contractile characteristics and fatigue resistance in patients with cluronic heart failure. Eur Heart J 1996;17:896-901.

78. Fiaccadori E, Del Canale S, Vitali P. Coffrini E, Ronda N, Guariglia A. Skeletal nuscle energetics, acid-base equilibrium and lactate metabolism in patients with severe hypercaphia and hypoxemia. Chest 1987;92:883-7.

79. Broqvist M, Arnquist $H$, Dahlström U, Larsson J, Nylander E, Perment J, Nutritional assessment and muscle energy metabolism in severe chronic congestive heart failure-effects of long-term dietary supplementation. Eur Heart J 1994;15:1641-50.

80. Opasich C, Aquilani R, Dossena M, et al. Biochemical analysis of muscle biopsy in ovemight fasting patients with severe chronic heart failure. Eur Heart I 1996;17:1686-93.

81. Pouw EM, Schols AMWJ, Vusse wan der GJ, Wouters EFM. Elevated inosine monophosphate levels in resting muscle of patients with stable COPD. Am J Respir Crit Care Med $1998 ; 157: 453-57$.

82. Schaufelberger M, Eriksson BO, Held $\mathrm{P}$, Swedberg K. Skeletal muscle metabolism during exercise in patients with chronic heart failure. Heart $1996,76: 29-34$.

83. Dudley GA, Terjung RL. Influence of aerobic metabolism on IMP accumulation in fast-twitch muscle. Am J Physiol 1985;248:C 37-42. 
84. Thompson CH, Davies RJ, Kemp GJ, Taylor DJ, Radda GK, Rajagopalan B. Skeletal muscle metabolism during exercise and recovery in patients with respiratory failure. Thorax $1993 ; 48: 486-90$.

85. Payen JF, Wuyam B, Levy P, et al. Muscular metabolism during oxygen supplementation in patients with chronic hypoxemia. Am Rev Respir Dis 1993;147:592-8.

86. Mancini DM, Walter G, Reichek $N$, et al. Contribution of skeletal muscle atrophy to exercise intolerance and altered muscle metabolism in heart failure. Circulation 1992;85:1364-73.

87. Kemp GJ, Thompson CH, Stratton JR, et all. Abnormalities in exercising skeletal muscle in congestive heart failure can be explained in terms of decreased mitochondrial ATP synthesis, reduced metabolic efficiency, and increased glycogenolysis. Heart 1996;76:35-41.

88. Kutsuzawa T, Shioya S, Kurita D, Haida M, Ohta Y, Yamabayashi H. "P-NMR study of skeletall muscle metabolism in patients with chronic respiratory impairment. Am Rev Respir Dis 1992;146:1019-24.

89. Tada $\mathrm{H}$, Kato $\mathrm{H}$, Misawa $\mathrm{T}$, et al. ${ }^{31} \mathrm{P}$-nuclear magnetic resonance evidence of abnormal skeletal muscle metabolism in patients with chronic lung disease and congestive heart failure. Eur Respir J 1992;5:163-9.

90. Jakobsson $P$, Jorfeldt $L$, Henriksson J. Metabolic enzyme activity in the quadriceps femons muscle in patients with severe chronic obstructive pulmonary disease. Am J Respir Crit Care Med 1995;151:374-7.

91. Sullivan MJ, Green HJ, Cobb FR. Altered skeletal muscle metabolic response to exercise in chronic heart failure. Relation to skeletal muscle aerobic enzyme activity. Circulation 1991;84:1597-607.

92. Sánchez J, Brunet $\mathrm{A}$, Medrano $\mathrm{G}$, Debesse $\mathrm{B}$, Derenne JP. Metabolic enzymatic activities in the intercostal and serratus muscles and in the latissimus dorsi of middle-aged normal men and patients with moderate obstructive pulmonary disease. Eur Respir J 1988;1:376-83.

93. Sauleda J, Garcia-Palmer F, Wiesner RJ, et al. Cytochrome oxidase activity and mitochondrial gene expression in skeletal muscle of patients with chronic obstructive pulmonary disease. Am J Respir Crit Care Med 1998;157:1413-7.

94. Sánchez J, Bastien C, Medrano G, Riquet M, Derenne JP. Metabolic enzymatic activities in the diaphragm of normal men and patients with moderate chronic obstructive pulmonary disease. Bull Eur Physiopathol Respir 1984;20:535-40.

95. Essén-Gustavsson B, Henriksson J. Enzyme levels in pools of microdissected human muscle fibres of identified type. Adaptive response to exercise. Acta Physiol Scand 1984;120:505-15.

96. Stryer L. Biochemistry. New York: W.H. Freeman and company, 1988.

97. Tein I. Metabolic myopathies. Semin Pediatr Neurol 1996;3:59-98.

98. Gnaiger E, Lassnig B, Kuznetsov A, Rieger G, Margreiter R. Mitochondrial oxygen affinity, respiratory flux control and excess capacity of cytochrome $c$ oxidase. $J$ Exp Biol 1998;201:1129-39.

99. Hoppeler H, Kleinert E, Schlegel C, et al. Morphological adaptations of human skeletal musele to chronic hypoxia. Int J Sports Med 1990;11:S3-9.

100. Hoppeler H, Desplanches D. Muscle structural modifications in hypoxia. Int J Sports Med 1992;13:S166-8.

101. Howald H, Pette D, Simoneau JA, Uber A, Hoppeler H, Cerretelli P. Effects of chronic hypoxia on muscle enzyme activities. Int J Sports Med 1990;11:S10-4.

102. Melissa L, MacDougall ID, Tarnopolsky MA, Cipriano N, Green HJ. Skeletal muscle adaptations to training under nomobaric hypoxic versus normoxic conditions. Med Sci Sports Exerc 1997;29:238-43.

103. Bigard AX, Brunet A, Guezennec CY, Monod H. Effects of chronic hypoxia and endurance training on muscle capillarity in rats. Pflügers Arch 1991;419:225-9. 


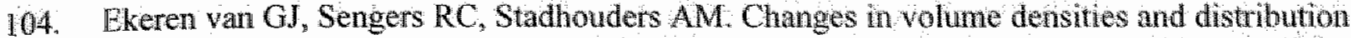
of mitochondria in rat skeletal muscle after chronic bypoxia. Int J Exp Pathol 1992;73:51-60.

105. Snyder GK, Farrelly C, Coelho IR. Adaptations in skeletal musele capillarity following changes in oxygen supply and changes in oxygen demands. Eur J Appl Physiol 1992;65:158-63.

106. Preedy VR, Smith DM, Sugden PH. The effects of 6 hours of hypoxia on protein synthesis in rat tissues in wivo and in vitro. Biochem $J 1985 ; 228: 179-85$.

107. Fuller SJ, Sugden PH. Acute inhibition of rat heart protein synthesis in vitro during betaadrenergic stimulation or hypoxia. Am J Physiol 1988;255:E537-47.

108. Milley JR. Protein synthesis during hypoxia in fetal lambs. Am J Physiol 1987;252:5:519-24.

109. Kwast $\mathrm{KE}$, Hand SC. Acute depression of mitochondrial protein synthesis during anoxia: contributions of oxygen sensing, matrix acidification, and redox state. $J$ Biol Chem $1996 ; 271: 7313-9$.

110. Ishihara $\mathrm{A}$, Itoh $\mathrm{K}$, Oishi $\mathrm{Y}$, Itoh $\mathrm{M}$, Hirofuji $\mathrm{C}$, Hayashi $\mathrm{H}$. Effects of hypobaric hypoxia on histochemical fibre-type composition and myosin heavy chain isoform component in the rat soleus muscle. Pflìgers Arch 1995;429:601-6.

111. Itoh $\mathrm{K}$, Itoh $\mathrm{M}$, Ishihara $\mathrm{A}$, Hirofuji $\mathrm{C}$, Hayashi $\mathrm{H}$. Influence of 12 weeks of hypobaric hypoxia on fibre type composition of the rat soleus muscle. Acta Physiol Scand 1995;154:417-8.

112. Taguchi $S$, Hata $\mathrm{Y}$, Itoh $\mathbb{K}$. Enzymatic responses and adaptations to swimming training and hypobaric hypoxia in postnatal rats. Jpn J Physiol 1985;35:1023-32.

113. Takahashi $H$, Kikuchi K, Nakayama H. Effect of chronic hypoxia on skeletal muscle fiber type in adult male rats. Ann Physiol Anthropol 1992;11:625-30.

114. Pastoris O, Dossena M, Foppa $P$, et al. Modifications by chronic intermittent hypoxia and drug treatment on skeletal muscle metabolism. Neurochem Res 1995;20:143-50.

115. Pastoris O, Grorini A, Vercesi L, Taglietti M, Dossena M. Modification of the skeletal muscle energy metabolism induced by intermittent normobaric hypoxia and treatment with biological pyrimidines. Farmaco Sci 1985;40:442-53.

116. Takahashi $\mathrm{H}$, Kikuchi $\mathrm{K}$, Nakayama $\mathrm{H}$. Effect of chronic hypoxia on oxidative enzyme activity in rat skeletal muscle. Ann Physiol Anthropol 1993;12:363-9.

117. Cartee GD, Douen AG, Ramlal T, Klip A, Holloszy JO. Stimulation of glucose transport in skeletal muscle by hypoxia. I Appl Physiol 1991;70:1593-600.

118. Xia Y, Warshaw JB, Haddad GG. Effect of chronic hypoxia on glucose transporters in heart and skeletal muscle of immature and adult rats. Am J Physiol 1997;273:R1734-41.

119. Bashan N, Burdett E, Guma A, et al. Mechanisns of adaptation of glucose transporters to changes in the oxidative chain of muscle and tat cells. Am J Physiol 1993;264:C430-40.

120. Rahman I, Morrison D, Donaldson K, MacNee W. Systemic oxidative stress in asthma, COPD, and smokers. Am J Respir Crit Care Med 1996;154:1055-60.

121. Keith M, Geranmayegan A, Sole MJ, et al. Increased oxidative stress in patients with congestive heart failure. J Am Coll Cardiol 1998;31:1352-6.

122. Giuliani A, Cestaro B. Exercise, free radical generation and vitamins. European Journal Of Cancer Prevention 1997;6:S55-67.

123. Ji LL. Exercise, oxidative stress, and antioxidants. Am J Sports Med 1996;24:\$20 4.

124. Reid MB. Reactive oxygen and nitric oxide in skeletal muscle. News Physiol Sci 1996;1 1:1149.

125. Buck $M$, Chojkier $M$. Muscle wasting and dedifferentiation induced by oxidative stress in a murine model of cachexia is prevented by imhibitors of nitric oxide synthesis and antioxidants. EMBO J 1996;15:1753-65.

126. de Godoy I, Donahoe M, Calhoun WJ, Mancino J, Rogers RM. Elewated TNF-alpha production by peripheral blood monocytes of weight-losing COPD patients. An J Respir Crit Care Med 1996;153:633-7. 
127. Schols AM, Buman WA, Staal van den Breket A "Dentener MA, Wouters EF. Evidence for a relation between metabolic derangements and increased levels of inflammatory mediators in a subgroup of patients with chronic obstructive pulmonary disease. Thorax 1996;51:819-24.

128. Di Francia M, Barbier D, Mege JL, Orehek J. Tumor necrosis factor-alpha levels and weight loss in chronic obstructive pulmonary disease. Am J Respit Crit Care Med 1994;150:1453-5.

129. Ferrari R, Bachetti T, Confortini R, et al. Tumor necrosis factor soluble receptors in patients with various degrees of congestive heart failure. Circulation 1995;92:1479-86.

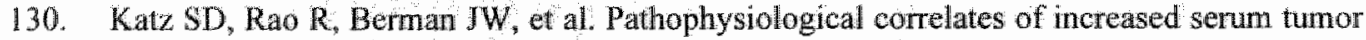
necrosis factor in patients with congestive hear failure. Relation to nitric oxide-dependent vasodilation in the forearm circulation. Circulation 1994;90:12-6.

131. Levine B, Kalman J, Mayer L, Fillit HM, Packer M. Elevated cireulating levels of tumor necrosis factor in severe chronic heart failure. N Engl J Med 1990;323:236-41.

132. McMutray I, Abdullah I, Dargie HJ, Shapiro D. Increased concentrations of tumour necrosis factor in "cachectic" patients with severe chronic heart failure. Br Heart J 1991;66:356-8.

133. Anker SD, Clark $A L$, Kemp M, et al. Tumor necrosis factor and steroid metabolism in chronic heart fetilure: possible relation to muscle wasting. J Am Coll Cardiol 1997;30:997-1001.

134. Clarkson PM. Antioxidants and physical performance. Crit Rev Food Sci Nitr 1995;35:131-41.

135. Sen CK, Hanninen O. Physiological antioxidants. In: Sen KC, Packer L, Hänninen O, eds. Exercise and oxygen toxicity. Amsterdam: Elsevier Science B.V., 1994: 89-126.

136. Ohishi $\mathrm{S}$, Kizaki T, Nagasawa J, et al. Effects of endurance training on superoxide dismutase activity, content and mrna expression in rat muscle. Clinical And Experimental Pharmacology And Physiology 1997:24:326-32.

137. Jackson MJ. Exercise and oxygen radical production by muscle. In: Sen KC, Packer L, Hảnminen O, eds. Exercise and oxygen toxicity. Amsterdam: Elsevier Science B.V., 1994: 4957.

138. Ferrari $R$, Ceconi $C$, Curello $S$, Alfieri $O$, Visioli $O$. Myocardial damage during ischaemia and reperfusion. Eur Heart J 1993; 14:25-30.

139. Liu J, Simon LM, Phillips JR, Robin ED. Superoxide dismutase (SOD) activity in hypoxic mammalian systems. J App/ Physiol 1977;42:107-10.

140. Li RK, Mickle DA, Weisel RD, et al. Effect of oxygen tension on the anti-oxidant enzyme activities of tetralogy of Fallot ventricular myocytes. J Mol Cell Cardiol 1989;21:567-75.

141. Gardner TJ. Oxygen radicals and myocardial stunning. J Card Surg 1994;9:422-4.

142. Smith DR, Stone D, Darley-Usmar VM. Stimulation of mitochondrial oxygen consumption in isolated cardionyocytes after hypoxia-reoxygenation. Free Radic Res 1996;24:159-66.

143. Haramaki $N$. Packer L. Oxidative stress indices in exercise. In: Sen KC, Packer L, Hänninen O, eds. Exercise and oxygen toxicity. Amsterdam: Elsevier Science B.V., 1994: 77-87.

144. Salganik RI, Shabalina IG, Solovyova NA, Kolosova NG, Solovyov VN, Kolpakov AR. Impaiment of respiratory functions in mitochondria of rats with an inherited hyperproduction of free radicals. Biochem Biophys Res Commun 1994;205:180-5.

145. Spragg RG, Hinshaw DB, Hyslop PA, Schraufstätter IU, Cochrane CG. Alterations in adenosine triphosplate and energy charge in cultured endothelial and P388D1 cells after oxidant injury. J Clin Invest 1985:76:1471-6.

146. Astier C, Rock E, Lab C, Gueux E, Mazur A, Rayssiguier Y. Functional alterations in sarcoplasmic reticulum membranes of magnesium-deficient rat skeletal muscle as consequences of free radical-mediated process. Free Radic Biol Med 1996;20:667-74.

147. Wang SY, Clague JR, Langer GA. Increase in calcium leak channel activity by metabolic inhibition or hydrogen peroxide in rat ventricular myocytes and its inhibition by polycation. $J$ Mol Cell Cardiol 1995;27:211-22.

148. Xu KY, Zweier JL, Becker LC. Hydroxyl radical inhibits sarcoplasmic reticulum Ca 
function by direct attack on the ATP binding site. Cire Res 1997,$80 ; 76-81$.

149. Minezaki KK, Suleiman MS, Chapman RA. Changes in mitochondrial function induced in isolated guinea-pig ventricular myocytes by calcium overload. I Physiol Lond 1994:476:459:71.

150. Dean RT, Fu SL, Stocker R, Davies MJ. Biochemistry and pathology of radical-mediated protein oxidation. Brochemical Jounal 1997;324:1-18.

151. Nagasawa T, Hatayama T, Watanabe $Y$, Tanaka M, Niisato $Y$, Kitts DD. Free radical nediated effects on skeletal muscle protein in rats treated with fe nitrilotriacetate. Biochem Biophys Res Commun 1997;231:37-41.

152. Soares IM, Duarte JA, Carvalho I, Appell HJ. The possible role of intracellular Ca ${ }^{2+}$ accumtlation for the development of immobilization atrophy. Int I Sponts Med 1993;14:437-9.

153. Thomas PK, Cooper JM, King RH, et al. Myopathy in vitamin E deficient rats: muscle fibre necrosis associated with disturbances of mitochondrial function. J Anat 1993;183:451-61.

154. Haycock JW, Jones P, Harris JB, Mantle D. Differential susceptibility of human skeletal muscle proteins to free radical induced oxidative damage: a histochemical, immunocytochamical and electron microscopical study in vitro. Acta Neuropathol Ber 1 1996;92:331-40.

155. Stangel $\mathrm{M}$, Zett UK, Mix E, et al. $\mathrm{H}_{2} \mathrm{O}_{2}$ and nitric oxide-mediated oxidative stress induce apoptosis in rat skeletal muscle myoblasts. J Neuropathol Exp Neurol 1996;55:36-43.

156. Berg HE, Tesch PA. Changes in muscle function in response to 10 days of lower limb unloading in humans. Acta Physiol Scand 1996;157:63-70.

157. Terjung RL, Dudley GA, Meyer RA. Metabolic and circulatory limitations to muscular performance at the organ level. J Exp Biol 1985;115:307-18.

158. Henriksson J, Reitman JS. Time course of changes in human skeletal muscle succinate dehydrogenase and cytochrome oxidase activities and maximal oxygen uptake with physical activity and inactivity. Acta Physiol Scand 1977;99:91-7.

159. Messner-Pellene $\mathrm{P}$, Brasileiro $\mathrm{C}$, Ahmaidi $\mathrm{S}$, et al Exercise intolerance in patients with chronic heart failure: role of pulmonary diffusing limitation. Eur Heart J 1995;16:201-9.

160. Balkom van RH, Heijden van der HF, Herwaarden van CL, Dekhuijzen PN. Corticosteroidinduced myopathy of the respiratory muscles. Neth J Med 1994:45:11.4-22.

161. LaPier TK. Glucocorticoid-induced muscle atrophy. The role of exercise in treatment and prevention. J Cardiopulm Rehabil 1997;17:76-84.

162. Mayer M, Rosen F. Interaction of glucocorticoids and androgens with skeletal muscle. Metabolism 1977;26:937-62.

163. Decramer M, Lacquet LM, Fagard $R$, Rogiers P. Corticosteroids contribute to muscle weakneas in chronic airflow obstruction. Am I Respir Crit Care Med 1994:150:11-6.

164. Decramer M, de Bock V, Dom R. Functional and histologic picture of steroid-induced myopathy in chronic obstructive pulmonary disease. Am J Respir Crit Care Med $1996 ; 153: 1958-64$.

165. Dekhuijzen PN, van Balkom RH. Steroid-induced change in the respiratory muscles: its relevance in patients with obstructive airways disease. Respir Med 1994;88:335-41.

166. Kamischke A, Kemper DE, Castel MA, al. Testosterone levels in men with chronic obstructive pulmonary disease with or without glucocorticoid therapy. Eur Respir J 1998:11:415.

167. Dekhuijzen PN, Decramer M. Steroid-induced myopathy and its significance to respiratory disease: a known disease rediscovered. Eur Respir J 1992:5:997-1003.

168. Wang YM, Zintel T, Vasquez A, Gallagher CG. Corticosteroid therapy and respiratory muscle function in humans. Am Rew Respir Dis 1991;144:108-12.

169. Koerts-de Lang E, Hesselink MKC, Drost MR, van der Vusse GI, Wouters EFM, Schols AMWJ. Enzyme activity of rat tibialis anterior muscle differs between treatment with triamcinolone and prednisolone and nutritional deprivation. Eur J Appl Physiol 1999;79:274-9. 
170. Balkom van RH, Dekbuijzen PN, Folgering HT, Veerkamp JH, Fransen JA, van Herwaarden CL. Effeets of long-lerm low-dose methylprednisolone on rat diaphragm function and structure. Muscle Nerve 1997;20:983-90.

171. Gardiner PF, Montanaro G, Simpson DR, Edgerton VR. Effects of glucocorticoid treatment and food restriction on rat hindlimb muscles. Am J Plrysiol 1980;238:E124-30.

172. Evans $A B$, Al Himyary AJ, Hrovat MI, et al. Abnormal skeletal muscle oxidative capacity after lung transplantation by ${ }^{31}$ P-MRS. Am I Respir Crit Care Med 1997;155:615-21.

173. Gray-Donald K, Gibbons L, Shapiro SH, Martin JG. Effect of nutritional status on exercise performance in patients with chronic obstructive pulmonary disease. Am Rev Respir Dis $1989 ; 140 ; 1544-8$.

174. Efthimiou $\mathrm{J}$, Fleming $\mathrm{J}$, Gomes $\mathrm{C}$, Spiro $\mathrm{SG}$. The effect of supplementary oral nutrition in poorly nourished patients with chronic obstructive pulmonary disease. Am Rev Respir Dis 1988;137:1075-82.

175. Carr JG, Stevenson LW, Walden IA, Heber D. Prevalence and hemodynamic correlates of malnutrition in severe congestive heart failure secondary to ischemic or idiopathic dilated cardiomyopathy. Am J Cardiol 1989;63:709-13.

176. Schols AM, Soeters PB, Dingemans AM, Mostert R, Frantzen PJ, Wouters EF. Prevalence and characteristics of nutritional depletion in patients with stable COPD eligible for pulmonary rehabilitation. Am Rev Respir Dis 1993;147:1151-6.

177. Vermeeren MAP, Schols A, Wouters EFM. Effects of an Acute Exacerbation On Nutritional and Metabolic Profile of Patients With Copd. European Respiratory Journal 1997;10:2264-9.

178. Schols AMWJ, Creutzberg EC, Buurman WA, Campfield LA, Saris WHM, Wouters EFM. Plasma leptin is related to proinflammatory status and dietary intake in patients with chronic obstructive pulmonary disease. Am J Respir Crit Care Med 1999;160:1220-6.

179. Hunter AM, Carey MA, Larsh HW. The nutritional status of patients with chronic obstruetive pulmonary disease. Am Rev Respir Dis 1981;124:376-81.

180. Creutzberg EC, Schols AMWJ, Bothmer-Quaedvlieg FCM, Wouters EFM. Prevalence of an elevated resting energy expenditure in patients with chronic obstructive pulmonary disease in relation to body composition and lung function. Eur J Clin Nutr 1998;52:396-401.

181. Schols AMWJ, Fredrix EW, Soeters PB, Westerterp KR, Wouters EF. Resting energy expenditure in patients with chronic obstructive pulmonary disease. Am $J$ Clin Nutr 1991;54:983-7.

182. Riley M, Elborn JS, McKane WR, Bell N, Stanford CF, Nicholls DP. Resting energy expenditure in chronic cardiac failure. Clin Sci Colch 1991;80:633-9.

183. Obisesan TO, Toth MJ, Donaldson $\mathrm{K}$, et al. Energy expenditure and symptom severity in men with heart failure. Am J Cardiol 1996;77:1250-2.

184. Baarends EM, Schols AM, Pannemans DL, Westerterp KR, Wouters EF. Total free living energy expenditure in patients with severe chronic obstructive pulmonary disease. Am I Respir Crit Care Med 1997;155:549-54.

185. Donahoe $\mathrm{M}$, Rogers RM, Wilson DO, Pennock BE. Oxygen consumption of the respiratory muscles in normal and in malnourished patients with chronic obstructive pulmonary disease. Am Rev Respir Dis 1989:140:385-91.

186. Sridhar MK, Carter R, Lean ME, Banham SW. Resting energy expenditure and mutritional state of patients with increased oxygen cost of breathing due to emphysema, scoliosis and thoracoplasty. Thorax 1994:49:781-5.

187. McLoughlin DM, Spargo E, Wassif WS, et al. Structural and functional changes in skeletal muscle in anorexia nervosa. Acta Neuropathol Berl 1998;95:632-40.

188. Russell DM, Prendergast PJ, Darby PL, Garfinkel PE, Whitwell J, Jeejeebhoy KN. A comparison between muscle function and body composition in anorexia nervosa: the effect of 
refeeding. Am J Clin Nutr $1983 ; 38: 229-37$.

189. Rigaud D, Moukaddem M, Cohen B, Malon D, Reveillard V, Mignon M. Refeeding improves muscle performance without normalization of nusele mass and oxygen consumption in anorexia nervosa patients. Am J Clin Nutr 1997:65:1845-51.

190. Lindboe $C F$, Askevold $F$, Slettebo $M$. Changes in skeletal muscles of young women with anorexia nervosa. An enzyme histochemical study. Acta Neuropathol Berl 1982,56:299-302.

191. Fssen B, Fohlin L, Thoren C, Saltin B. Skeletal muscle fibre types and sizes in anorexia nervosa patients: Clin Physiol 1981; 1:395-403.

192. Sieck GC, Lewis MI, Blanco CE. Effects of undernutrition on diaphragm fiber size, SDH activity, and fatigue resistance. J Appl Physiol 1989;66:2196-205.

193. Russell DM, Atwood HL, Whittaker JS, et al. The effect of fasting and hypocaloric diets on the functional and metabolic characteristics of rat gastrocnemius muscle. Clin Soi 1984;67:185-94.

194. Mijan de la Torre A, Madapalimattam A, Cross A, Armstrong RL, Jeejeebhoy KN. Effect of fasting, hypocaloric feeding, and refeeding on the energetics of stimulated rat muscle as assessed by nuclear magnetic resonance spectroscopy. J Clin Invest 1993:92:114-21.

195. Aguilaniu B, Goldstein Shapses S, Pajon A, et al. Muscle protein degradation in severely malnourished patients with chronic obstructive pulmonary disease subject to short-term total parenteral nutrition. J Parenter Enteral Nutr 1992;16:248-54.

196. Goldstein SA, Thomashow BM, Kvetan V, Askanazi J Kinney JM, Elwyn DH. Nitrogen and energy relationships in malnourished patients with emphysema. Am Rev Respir Dis $1988 ; 138: 636-44$.

197. Pouw EM, Schols AM, Deutz NE, Wouters EF. Plasma and muscle amino acid levels in relation to resting energy expenditure and inflammation in stable chronic obstructive pulmonary disease. Am J Respir Crit Care Med 1998;158:797-801.

198. Argilés JM, López-Soriano J. Catabolic proinflammatory cytokines. Curr Opinion Clin Nutr Metab Care 1998; 1:241-4.

199. Hill GL. Body composition research: implications for the practice of clinical nutrition. J Parenter Enteral Nutr 1992;16:197-218.

200. Serres I, Varray A, Vallet G, Micallef IP, Préfaut C. Improved skeletal muscle performance after individualized exercise training in patients with chronic obstructive pulmonary disease. J Cardiopulm Rehabil 1997;17:232-8.

201. ODonnell DE, McGuire M, Samis L, Webb KA. General exercise training improves ventilatory and peripheral muscle strength and endurance in chronic airflow limitation. Am d Respir Crit Care Med 1998;157:1489-97.

202. Adamopoulos S, Coats AJ. Peripheral abnormalities in chronic heart failure. Postgrad Med J $1991 ; 67: \mathrm{S} 74-80$.

203. Maltais $F$, LeBlanc $P$, Simard $C$ et al. Skeletal muscle adaptation to endurance training in patients with chronic obstructive pulmonary disease. Am J Respir Crit Care Med 1996;154:4427.

204. Smith $\mathrm{K}$, Cook D, Guyatt GH, Madhavan J, Oxman AD. Respiratory muscle training in chronic aiffow limitation: a meta-analysis. Am Rev Respir Dis 1992;145:533-9.

205. Rochester DF. The diaphragm in COPD. Better than expected but not good enough. N Engl J Med 1991;325:961-2.

206. Belman MJ, Botnick WC, Nathan SD, Chon KH. Ventilatory load characteristics during ventilatory muscle training. Am J Respir Crit Care Med 1994;149:925-9.

207. Rogers RM, Donahoe M, Costantino J. Physiologic effects of oral supplemental feeding in malnourished patients with chronic obstructive pulnonary disease. A randomized control study. Am Rev Respir Dis $1992 ; 146: 1511-7$.

208. Whittaker JS, Ryan CF, Buckley PA, Road JD. The effects of refeeding on peripheral and 
respiratory muscle function in mathourished chronic obstructive pulmonary disease patients. An Rev Respir Dis 1990,142:283-8.

209. Schols AM, Soeters PB, Mosten R, Plwymers RJ, Wouters EF. Physiologic effects of nutritional support and anabolic steroids in patients with chronic obstructive pulmonary disease. A placebo-controlled randomized trial. Am J Respir Crit Care Med 1995;152:1268-74.

210. Fiacadori $\mathrm{E}$, Coffrin $\mathrm{E}, \mathrm{Ronda} \mathrm{N}_{\mathrm{g}}$ et all $\mathrm{A}$ preliminary report on the effects of malinutrition on gkeletal muscle composition in chronic obstructive pulmonary disease. In. Ferranti RD, Rampulla $\mathrm{C}$, Fracchia $\mathrm{C}$, Ambrosino $\mathrm{N}$, eds. Nutrition and ventilatory function. Verona: Bi \& Gi Publishers, 1992:77-85.

211. Creutzberg EC, Scho] AMWI, Weling-Scheepers CAPM, Wouters EFM. Functional effects of nutritional supplementation therapy incorporated in a pulmonary rehabilitation programme in depleted patients with COPD. Am J Respir Crit Care Med 1998;157:A258.

212. Creutzberg EC, Schols AMWJ, Weling-Scheepers CAPM, Buurman WA, Wouters EFM. Characterization of nonrespons to high calonic oral mutritional therapy in depleted patients with chronic obstructive pulmonary disease. Am J Respir Crit Care Med 1999;160:in press.

213. Keatings VM, Jatakanon A, Worsdell YM, Barnes PJ. Effects of inhaled and oral glucoconticoids on inflammatory indices in asthma and COPD. Am J Respir Crit Care Med $1997: 155: 542-8$.

214. Wigmore SJ, Ross JA, Falconer JS, et al. The effect of polyunsaturated fatty acids on the progress of cachexia in patients with pancreatic cancer. Nutrition 1996;12:\$27-30.

215. Creutzberg LC, Schols AMWJ. Anabolic steroids. Curr Opin Clin Nutr Metab Care 1999;2:24353.

216. Ferreira IM, Verreschi IT, Nery LE, et all. The influence of 6 months of oral anabolic steroids on body mass and respiratory muscles in undernourished COPD patients. Chest 1998; 14:1928.

217. Suchner U, Rothkopf MM, Stanislaus G, Elwyn DH, Kvetan V, Askanazi I. Growth hormone and pulmonary disease. Metabolic effects in patients receiving parenteral mutrition. Arch Intern Med 1990;150:1225-30.

218. Pape GS, Friedman $M$, Underwood LE, Clemmons DR. The effeet of growth hormone on weight gain and pulmonary function in patients with chronic obstructive lung disease. Chest 1991;99:1495-500.

219. Burdet L, de Muralt B, Schutz Y, Pichard $C_{n}$ Fitting JW. Administration of growth hormone to underweight patients with chronic obstructive pulmonary disease. Am J Respir Crit Care Med $1997 ; 156: 1800-6$.

220. Shapira Y, Glick B, Finsterbush A, Goldfarb A, Rosenmann E. Myopathological findings in thatassemia major. Eur Neurol 1990;30:324-7.

221. Goldfarb AH, Sen CK. Antioxidant supplemention and the control of oxygen toxicity during exercise. In: Sen KC, Packer L, Hänninen O, eds. Exercise and oxygen toxicity. Amsterdam: Elsevier Science B.V., 1994: 163-89.

222. Novelli GP. Adembri $\mathrm{C}$, Gandini $\mathrm{E}$, et al. Vitamin $\mathrm{E}$ protects human skeletal muscle from damage during surgical ischemia-neperfusion. Am J Surg 1997;173:206-9.

223. Alessio HM, Goldfarb AH, Cao GH. Exercise induced oxidative stress before and after vitamin c supplementation. Int J Spott Nutr 1997;7:1-9.

224. Ser CK, Atalay M, Agren J, Laaksonen DE, Roy S, Hanninen O. Fish oil and vitamin $\mathrm{E}$ supplementation in oxidative stress at rest and after physical exercise. J Appl Physiol $1997 ; 83: 189-95$

225. Appell HI, Duarte JAR, Soares JMC. Supplementation of vitamin e may attenuate skeletal muscle immobilization atrophy. Int I Sports Med 1997;18:157-60.

226. Paiva SA, Godoy I, Vanmucchi H, Favaro RM, Geraldo RR, Campana AO. Assessment of 
vitamin A status in chronic obstructive pulmonary disease patients and healthy smokers. Am J Clin Nutr 1996;64:928-34.

227. Dow $\mathrm{L}$, Tracey $\mathrm{M}$, Villar $\mathrm{A}$, et al. Does dietary intake of vitamins $\mathrm{C}$ and $\mathrm{E}$ influence lung function in older people? Am I Respir Crit Care Med 1996;154:1401-4.

228. Nocturnal-Oxygen-Therapy-Trial-Group. Continuous or nocturnal oxygen therapy in hypoxemic chronic obstructive lung disease: a clinical trial. Ann Intern Med 1980;93:391-8.

229. Medical-Research-Council-Working-Party. Long term domiciliary oxygen therapy in chronic hypoxic cor pulmonale complicating chronic bronchitis and emphysema. Lancet 1981;1:681-6.

230. O'Donnell DE, Bain DJ, Webb KA. Factors contributing to relief of exertional breathlessness during hyperoxia in chronic airflow limitation. Am J Respir Crit Care Med 1997;155:530-5.

231. Woodcock AA, Geddes DM, Gross ER. Oxygen relieves breathlessness in "pink puffers". Lancet 1981;1:907-9.

232. Rooyackers IM, Dekhuijzen PN, Van Herwaarden CL, Folgering HT. Training with supplemental oxygen in patients with COPD and hypoxaemia at peak exercise. Eur Respir J 1997; 10:1278-84.

233. Jakobsson $\mathrm{P}$, Jorfeldt $\mathrm{L}$. Long-term oxygen therapy may improve skeletal muscle metabolism in advanced chronic obstructive pulmonary disease patients with chronic hypoxaemia. Respir Med 1995;89:471-6.

234. Repine JE, Bast A, Lankhorst I. Oxidative stress in chronic obstructive pulmonary disease. Oxidative Stress Study Group. Am J Respir Crit Care Med 1997;156:341-57.

235. Jackson RM. Pulmonary oxygen toxicity. Chest 1985;88:900-5.

236. Jenkinson SG. Oxygen toxicity. New Horiz 1993;1:504-11. 


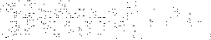




\title{
CHAPTER 3
}

\section{Striking similarities in systemic factors contributing to decreased exercise capacity in patients with severe chronic heart failure or chronic obstructive pulmonary disease}

\begin{abstract}
Chronic heart failure (CHF) and chronic obstructive pulmonary disease (COPD) are both characterized by muscular impairment. To assess whether the severity and functional consequences of muscular impairment are disease specific, skeletal muscle function, body composition and daily activity level relative to exercise capacity were compared between these two disorders. $25 \mathrm{CHF}$ and $25 \mathrm{COPD}$ patients, and 36 healthy gender- and age-matched controls underwent measurement of fat-free mass (FFM, by bioelectrical impedance analysis) as an index of muscle mass. Quadriceps and biceps functions were tested by isokinetic methods, and daily activity level was assessed by the Physical Activity Scale for Elderly (PASE) questionnaire. Peak oxygen consumption ( $\mathrm{VO}_{2}$ peak) was measured by incremental cycle ergometry. PASE was similar in CHF and COPD patients, each group scoring lower than controls. FFM was also lower in patients than controls and correlated closely with quadriceps and biceps strength in all 3 subgroups, $R$ values ranging from 0.63 to 0.78 , with identical slopes. FFM also correlated significantly with $\mathrm{VO}_{2}$ peak ( $\mathrm{p}<0.05$ ), but slopes were less steep in patients than controls. The type and severity of muscle dysfunction were similar in each group of patients. There were no significant correlations between indices of cardiopulmonary function and muscle function or exercise performance in either CHF or COPD. In both controls and patients, FFM was the most significant determinant of the VO $\mathrm{O}_{2}$ peak. It was concluded that muscle dysfunction is not limited to the lower limbs, but generalized and comparable between CHF and COPD patients with similar exercise capacity. FFM is a strong predictor of peripheral muscle strength, to a lesser extent of peak oxygen consumption and not at all of peripheral muscle endurance.
\end{abstract}

Harry R. Gosker', Nicole H.M.K. Lencer ${ }^{2}$, Frits M.E. Franssen', Ger J. van der Vusse ${ }^{3}$, Emiel F.M. Wouters", Annemie M.W.J. Schols'. Departments of 'Respiratory Medicine, ${ }^{2}$ Cardiology, and 'Physiology, University of Maastricht, The Netherlands. Chest; In press 


\section{INTRODUCTION}

Exercise intolerance is an important symptom in chronic heart fallure (CHF) and chronic obstuctive pumonary disease (COPD) that exerts a large impact on the quality of life of patients suffering from these disorders(1). Generally, research and therapy primarily focus on cardiac dys function in CHF, reflected by a reduced left ventricular ejection fraction (LVEF), and on lung dysfunction in COPD, reflected by a reduced forced expiratory volume in one second $\left(\mathrm{FEV}_{1}\right)$. However, these indices of primary organ failure are poor predictors of exercise capacity in moderate to severe disease $(2,3)$, in particular in patients with significant exercise intolerance.

Muscle wasting and weakness, two potential determinants of reduced exercise capacity, have been demonstrated in both COPD and CHF. Anker et al showed reduced muscle strength in cachectic (defined as $>7 \%$ involuntary weight loss) compared to non-cachectic CHF patients(4). We recently demonstrated that fat-free mass (FFM), an indirect measure of muscle mass, is a strong predictor of muscle strength in COPD(5). Since FFM is the metabolically active and oxygen consuming tissue mass, comprised mainly of muscle tissue, it is also likely to be a determinant of exercise capacity. A positive relationship between muscle function and exercise capacity, as previously shown in both $\mathrm{COPD}(6)$ and $\mathrm{CHF}(7)$, might therefore indirectly reflect a relationship with FFM. Muscle function is largely characterized by strength and endurance. Strength is defined as the capacity of the muscle to develop maximal force, while endurance is the capacity of the muscle to maintain a certain force to resist fatigue. Loss of either one of these components results in muscle weakness and impaired muscle performance. The relative contribution of strength and endurance to exercise capacity in COPD and CHF remains unknown. Furthermore, it is unclear whether muscle weakness is generalized or predominantly affects the lower extremities(6-8). CHF and COPD patients have reduced daily activity levels and it is therefore likely that deconditioning itself adversely affects their exercise capacity, by definition. The relative contributions of muscle function, FFM and daily activity level to exercise capacity have not been studied in CHF or in COPD. Furthermore no study has yet made a direct comparison between the two patient groups.

Therefore, the first objective of the present study was to establish if muscle function, FFM and daily activity level are similarly reduced in CHF and COPD patients and to what extent these factors are determinants of exercise capacity. The second objective of this study was to examine whether impaired peripheral muscle strength and endurance affects upper and lower limbs in CHF and COPD patients. For these purposes, we carefully assessed cardiac and pulmonary function, body composition, peripheral muscle function and daily activity level in patients with COPD, CHF and in healthy age-matched controls. 


\section{MATERIALS \& METHODS}

\section{Study population}

Groups of 25 COPD patients with moderate to severe airflow obstruction, 25 moderate to severe CHF patients and 36 healthy age-matched volunteers were studied. All pulmonary patients had COPD according to American Thoracic Society guidelines(9) and chronic airflow Iimitation, defined as measured $\mathrm{FEV}$, less than $70 \%$ of reference $\mathrm{FEV}$. Furthermore, $\mathrm{COPD}$ patients had irreversible obstructive airway disease (less than $10 \%$ improvenent of $F E V_{\text {, }}$ predicted baseline after $\beta_{2}$-agonist inhalation). COPD patients were in clinically stable condition and not suffering from a respiratory tract infection or an exacerbation of their disease at least 4 weeks prior to the study. Other exclusion criteria for the COPD group were concomitant confounding diseases like malignancies, gastrointestinal disorders, severe endocrine disorders, CHF or recent surgery. The cardiac patients had CHF based on clinical symptoms according to the Framingham(10) criteria, left ventricular ejection fiaction $<45 \%$, and were clinically stable. All CHF patients were controlled at the out-patient clinic of the university Hospital of Maastricht. The origins of heart failure were idiopathic $(\mathrm{N}=7)$, ischemic $(\mathrm{N}=8)$, valvular disease $(\mathrm{N}=1)$, multiple origins $(\mathrm{N}=6)$ and miscellaneous $(\mathrm{N}=3)$. They were all on extensive medication regiments - ACE-inhibitors $(N=24)$, diuretics $(N=24)$, $\beta$-blockers $(\mathrm{N}=16)$ and nitrates $(\mathrm{N}=16)$. Warfarin, was used by 20 patients. Exclusion criteria for the CHF group were non-cardiac disease with life-expectancy $<1$ year, episodes of heart fallure within the previous two months, unstable angina pectoris, scheduled for percutaneous transluminal coronary angioplasty or coronary artery bypass grafting, operable valwular disease, kidney failure (creatinine $>250 \mu \mathrm{mol} / \mathrm{l}$ ), restrictive cardiomyopathy, hypertrophic cardiomyopathy, primary pulmonary hypertension, diabetes mellitus, COPD, psychiatric disorder, or correctable cause of heart failure. The healthy age-matched control subjects were vollunteers recruited through advertisement in a local newspaper. They underwent a physical examination by a physician to ensure that they were free from significant pulmonary or cardiac disease. Written informed consent was obtained from all subjects and the study was approved by the medical ethical committee of the University Hospital Maastricht (Maastricht, The Netherlands).

\section{Assessment of body composition}

FFM was measured by bioelectrical impedance (Xitron 4000b, Xitron technologies, San Diego, California, USA). Resistance was measured in supine position at the right side as described by Lukaski(11). A patient specific regression equation was used to calculate FF in COPD(12). This equation was also used to calculate the FFM of CHF patients (validated against the deuterium dilution method; submitted for publication). Body mass index (BMI) was calculated by dividing whole body weight by the squared body height $\left(\mathrm{kg} / \mathrm{m}^{2}\right)$ in order to correct for differences in body size(13). For the same reason the fat-fiee mass index (FFMI) was calculated by diwiding the FFM by the squared body height $\left(\mathrm{kg} / \mathrm{m}^{2}\right)(13)$.

\section{Cardiopulmonary function}

All patients and control subjects underwent spirometry to determine the $\mathrm{F} E \mathrm{~V}_{1}$, with the highest value from at least three technically acceptable assessments being used. Diffusion capacity for carbon monoxide (DL $L_{c o}$ ) was measured using the single-breath method (Masterlab, Jaeger, Wurzburg, Germany). All values obtained were related to a reference vallue and expressed as 
percentage of the predicted value (14). In COPD as well as in CHF patients, the $F E V_{1}$ and the $\mathrm{DL}_{\mathrm{co}}$ were significantly lower than in controls, but as expected, the $F E V_{1}$ and the $\mathrm{DL}_{\mathrm{C}}$ were markedly lower in COPD than in CHF (table 1). In all CHF patients LVEF was measured, by M-mode echocardiogram to assess cardiac function. In COPD and control subjects 12-leads electrocardiograms (ECG's) were evaluated, since echocardiography was not available for logistical reasons Five COPD patients showed abnormalities on the ECG: one with prolonged PR interval, one with incomplete left bundle branch block and one with repolarisation disturbances infero-laterally. The two others showed left ventricular hypertrophy, together with conduction disturbances or left bundle branch block and abnormal ST-segments. Six COPD patients had normal ECG's. The other 14 COPD patients had signs of right ventricular conduction delay, as there were axis shifts to vertical or right, $s$ in lead I, q in lead III, (incomplete)-right bundle branch block. Only one patient had QRS widening of $120 \mathrm{msec}$. All COPD patients had sinus thythm. In the control group from 20 patients ECG's were available. Eleven subjects had normal ECG's, nine subjects showed right ventricular conduction delay as was defined above, one of them together with probable anterior wall myocardial infarction and two of them with inferior wall abnormalities. All subjects in the control group had sinus rhythm.

\section{Muscle function}

Isokinetic muscle functions (which are described and defined elsewhere(15)) of the dominant knee extensor (quadriceps) and elbow flexor muscles (biceps) were measured using a Biodex dynamometer (Biodex Corporation, Shirley, USA) or a Cybex II+ dynamometer (Ronkonkoma, NY, USA). There were no differences between results obtained using either machine (unpublished results). To assess leg muscle function, subjects were seated upright on the chair of the dynamometer and provided with back support. At the level of the chest, pelvis and thigh; subjects were restrained with straps. The hip joint was at an angle between $90^{\circ}$ and $100^{\circ}$ of flexion during testing. The lever arm was attached to the distal part of the tibia and its axis of rotation was visually aligned with the anatomical axis of flexion of the knee joint. Subjects were instructed to keep their hands on their thighs during testing. To assess arm muscle function, subjects sat upright on a chair with the shoulder of the dominant arm placed in $90^{\circ}$ abduction. The upper arm was supported and fixed with a belt in the horizontal plane on an adjustable stand. The ventral side of the forearm was placed in the frontal plane and the handgrip of the lever arm was held by the subjects. The lateral epicondyle of the humerus was used as the axis of elbow rotation and was visually aligned with the axis of rotation of the dynamometer. Subjects were instructed to keep their contralateral hand on their thigh. The isokinetic testing protocols of the dominant upper and lower extremities consisted of fifteen sequential voluntary maximal contractions at an angular velocity of $90^{\circ} / \mathrm{s}$. Maximal isokinetic strength was defined as the highest peak torque (in newton-meters $(\mathrm{Nm})$ ) in this series of fifteen. Fatigue was defined as the proportional decline in peak torque during 14 successive isokinetic flexions: the peak torques of the successive contractions were expressed as a percentage of the highest peak torque. The first contraction was excluded from analysis, because this value is unreliable due to the fact that the starting manoeuver is often submaximal. A linear curve was fitted through the calculated points. The slope of this curve was used to calculate the relative change in peak torque as a measure of muscle fatigue. Series in which the slope was ascending or in which the curve had an $R^{2}<0.209$ were excluded. The $R^{2}$ value is 
based on the critical value of the Pearson's correlation coefficient at a one-tailed $p$-value of 0.10 and 13 degrees of freedom. For comparison of upper and lower limb muscle functions. relative muscle strength and fatigue values were expressed as the percentage of mean control values and were calculated separately for male and female subjects.

\section{Questionnaire}

The daily activity level was assessed through the PASE questionnaire (Physical Activity Scale for Elderly, Dutch version)(18). Questions deal with physical activities during the most recent 7 days such as leisure, sports, housework and gardening.

\section{Exercise capacity}

All subjects performed an incremental exercise test on an electrically braked cycle ergometer (Corival 400®, Lode, Groningen, The Netherlands or Ergo-metrics 900, Ergoline, Frankfurt, Germany) under supervision of a chest physician or a cardiologist. Before the start of the test, while seated on the cycle ergometer, ventilation characteristics at rest were analysed over a period of two minutes. During the entire exercise test, expired gases were analyzed using breath by breath analysis through a breathing mask (Oxycon Beta@, Jaeger, Würzburg, Germany). Heart rate, systolic/diastolic blood pressure and percutaneous oxygen saturation were monitored. After one minute of unloaded cycling, power was increased by $10 \mathrm{~W}$ every minute for patients. For the control subjects, the load was increased with 15-25 W every minute, so that the length of the exercise test was comparable for all groups. None of the subjects knew the exercise load and all were encouraged to cycle at $60 \mathrm{revs} / \mathrm{min}$ until exhaustion. Peak oxygen consumption ( $\mathrm{VO}_{2}$ peak) was measured at the moment of cessation of the exercise. Peak heart rate (HR) reserve was calculated as $100 \%$-(100 $\times$ peak $H R) /(220$-age $)(16)$ and peak ventilatory (VE) reserve was calculated as $100 \%-(100 \times$ peak VE)/(FEV $\times 37.5)(16,17)$.

\section{Statistical analysis}

Data were analyzed with the unpaired Student's $t$ test (corrected for unequal variances, if appropriate), 1-way ANOVA (with unpaired Student's $t$ test as post hoc test), or the Pearson correlation test, as appropriate(19). For the comparison of relative strength and upper and lower limb muscle function the Student's $t$ test for paired data was used. Slopes and intercepts of regression lines were statistically compared using a small sample t-test, as described by Kleinbaum et al.(20) A two-tailed probability value of less than 0.05 was considered. statistically significant. Data are shown as mean $\pm \mathrm{SD}$; error bars in the figures represent the SEM.

\section{RESULTS}

Twenty-five COPD patients ( 16 males and 9 females), twenty-five CHF patients (17 males and 8 females) and thirty-six healthy controls ( 24 males and 12 females) participated in this study (table 1). There were no differences in gender or age between the groups. Only COPD patients had a lower BMI than controls. However, FFMI was reduced in COPD as well as in CHF patients compared to healthy subjects. PASE score was significantly lower in both patient groups than in controls, but there was no difference between COPD and CHF. 
percentage of the predicted value(14). In COPD as well as in CHF patients, the FEV, and the $\mathrm{DL}$ co were significantly lower than in controls, but as expected, the $\mathrm{FEV}$, and the $\mathrm{DL}_{\mathrm{O}}$ were markedly lower in COPD than in CHF (table 1). In all CHF patients LVEF was measured, by $\mathrm{M}$-mode echocardiogram to assess cardiac function. In COPD and control subjects 12-leads electrocardiogranis (ECG's) were evaluated, since echocardiography was not available for logistical reasons Five COPD patients showed abnormalities on the ECG: one with prolonged PR interval, one with incomplete left bundle branch block and one with repolarisation disturbances infero-laterally. The two others showed left ventricular hypertrophy, together with conduction disturbances or left bundle branch block and abnormal ST-segments. Six COPD patients had normal ECG's. The other 14 COPD patients had signs of right ventricular conduction delay, as there were axis shifts to vertical or right, s in lead I, $q$ in lead III, (incomplete)-right bundle branch block. Only one patient had QRS widening of $120 \mathrm{msec}$. All COPD patients had sinus thythm: In the control group from 20 patients ECG's were available. Eleven subjects had normal ECG's, nine subjects showed right ventricular conduction delay as was defined above, one of them together with probable anterior wall nyocardial infarction and two of them with inferior wall abnormalities. All subjects in the control group had sinus rhythm.

\section{Muscle function}

Isokinetic muscle functions (which are described and defined elsewhere(15)) of the dominant knee extensor (quadriceps) and elbow flexor muscles (biceps) were measured using a Biodex dynamometer (Biodex Corporation, Shirley, USA) or a Cybex II + dynamometer (Ronkonkoma, NY, USA). There were no differences between results obtained using either machine (unpublished results). To assess leg muscle function, subjects were seated upright on the chair of the dynamometer and provided with back support. At the level of the chest, pelvis and thigh, subjects were restrained with straps. The hip joint was at an angle between $90^{\circ}$ and $100^{\circ}$ of flexion during testing. The lever arm was attached to the distal part of the tibia and its axis of rotation was visually aligned with the anatomical axis of flexion of the knee joint. Subjects were instructed to keep their hands on their thighs during testing. To assess arm muscle function, subjects sat upright on a chair with the shoulder of the dominant arm placed in $90^{\circ}$ abduction. The upper arm was supported and fixed with a belt in the horizontal plane on an adjustable stand. The ventral side of the forearm was placed in the frontal plane and the handgrip of the lever arm was held by the subjects. The lateral epicondyle of the humerus was used as the axis of elbow rotation and was visually aligned with the axis of rotation of the dynamometer. Subjects were instructed to keep their contralateral hand on their thigh. The isokinetic testing protocols of the dominant upper and lower extremities consisted of lifteen sequential voluntary maximal contractions at an angular velocity of $90 \%$ s. Maximal isokinetic strength was defined as the highest peak torque (in newton-meters $(\mathrm{Nm})$ ) in this series of fifteen. Fatigue was defined as the proportional decline in peak torque during 14 successive isokinetic flexions: the peak torques of the successive contractions were expressed as a percentage of the highest peak torque. The first contraction was excluded from analysis, because this value is unrelliable due to the fact that the starting manoeuver is often submaximal. A linear curve was fitted through the calculated points. The slope of this curve was used to calculate the relative change in peak torque as a measure of muscle fatigue. Series in which the slope was ascending or in which the curve had an $R^{2}<0.209$ were excluded. The $R^{2}$ value is 
based on the critical value of the Pearson's correlation coefficient at a one-tailed p-value of 0.10 and 13 degrees of freedom. For comparison of upper and lower limb muscle functions, relative muscle strength and fatigue values were expressed as the percentage of mean control values and were calculated separately for male and female subjects.

\section{Questionnaire}

The daily activity level was assessed through the PASE questionnaire (Physical Activity Scale for Elderly, Dutch version)(18). Questions deal with physical activities during the most recent 7 days such as leisure, sports, housework and gardening.

\section{Exercise capacity}

All subjects performed an incremental exercise test on an electrically braked cycle ergometer (Corival 400巴), Lode, Groningen, The Netherlands or Ergo-metrics 900, Ergoline, Frankfurt, Germany) under supervision of a chest physician or a cardiologist. Before the start of the test, while seated on the cycle ergometer, ventilation characteristics at rest were analysed over a period of two minutes. During the entire exercise test, expired gases were analyzed using breath by breath analysis through a breathing mask (Oxycon BetaßB), Jaeger, Würzburg, Germany). Heart rate, systolic/diastolic blood pressure and percutaneous oxygen saturation were monitored. After one minute of unloaded cycling, power was increased by $10 \mathrm{~W}$ every minute for patients. For the control subjects, the load was increased with $15-25 \mathrm{~W}$ every minute, so that the length of the exercise test was comparable for all groups. None of the subjects knew the exercise load and al] were encouraged to cycle at $60 \mathrm{revs} / \mathrm{min}$ until exhaustion. Peak oxygen consumption $\left(\mathrm{VO}_{2}\right.$ peak) was measured at the moment of cessation of the exercise. Peak heart rate (HR) reserve was calculated as $100 \%-(100 \times$ peak HR)/(220-age $)(16)$ and peak ventilatory (VE) reserve was calculated as $100 \%-(100 \times$ peak $V E) /\left(F E V_{1} \times 37.5\right)(16,17)$.

\section{Statistical analysis}

Data were analyzed with the unpaired Student's $t$ test (corrected for unequall variances, if appropriate), 1-way ANOVA (with unpaired Student's $t$ test as post hoc test), or the Pearson correlation test, as appropriate (19). For the comparison of relative strength and upper and lower limb muscle function the Student's $t$ test for paired data was used. Slopes and intercepts of regression lines were statistically compared using a small sample t-test, as described by Kleinbaum et al.(20) A two-tailed probability value of less than 0.05 was considered statistically significant. Data are shown as mean $\pm \mathrm{SD}$; error bars in the figures represent the SEM.

\section{RESULTS}

Twenty-five COPD patients ( 16 males and 9 females), twenty-five CHF patients ( 17 males and 8 females) and thirty-six healthy controls ( 24 males and 12 females) participated in this study (table 1). There were no differences in gender or age between the groups. Only COPD patients had a lower BMI than controls. However, FFMI was reduced in COPD as well as in CHF patients compared to healthy subjects. PASE score was significantly lower in both patient groups than in controls, but there was no difference between COPD and CHF. 
Table 1. Subject characteristics

\begin{tabular}{|c|c|c|c|}
\hline & Controls & COPD & $\mathrm{CHF}$ \\
\hline $\mathrm{N}(\mathrm{M} / \mathrm{F})$ & $36(24 / 12)$ & $25(16 / 9)$ & $25(17 / 8)$ \\
\hline $\mathrm{Age}(\mathrm{yr})$ & $61 \pm 5.9$ & $62 \pm 9.8$ & $63 \pm 8.0$ \\
\hline Length (cm) & $172 \pm 9$ & $168 \pm 7$ & $168 \pm 9$ \\
\hline Werght $(\mathrm{kg})$ & $78.4 \pm 11.6$ & $67.8=15.1 * *$ & $71.9 \pm 11.9$ \\
\hline $\mathrm{BMT}\left(\mathrm{kg} / \mathrm{m}^{2}\right)$ & $26.4 \pm 2.5$ & $23.9 \pm 4.1 * *$ & $25.3 \pm 3.7$ \\
\hline FFM (kg) & $58.7 \pm 10.8$ & $49.5 \pm 8.2 * * *$ & $50.1 \pm 9.2 * *$ \\
\hline FFM $\left(\mathrm{kg} / \mathrm{m}^{2}\right)$ & $19.7 \pm 2.1$ & $17.5 \pm 2.0 *$ & $17.6 \pm 2.1 *$ \\
\hline $\mathrm{FEV}_{\|}(\%$ pred $)$ & $111 \pm 17$ & $32 \pm 11 * * *$ & $90 \pm 22 * * * 4$ \\
\hline $\mathrm{DL}_{\mathrm{QCo}}(\%$ pred $)$ & $112 \pm 17$ & 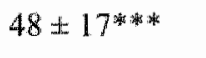 & $73 \pm 17 * * *$ \\
\hline $\mathrm{DL}_{\mathrm{co}} / \mathrm{V}_{\text {aly }}(\% \mathrm{pred})$ & $110 \pm 17$ & $57 \pm 20^{* * * *}$ & $81 \pm 18 * * * *$ * \\
\hline $\operatorname{LVEP}(\%)$ & - & - & $29 \pm 7.2$ \\
\hline PASE & $140 \pm 64$ & $89 \pm 39 * *$ & $83 \pm 56 *$ \\
\hline
\end{tabular}

Values are mean \pm SD; Significance of difference compared to controls: ${ }^{* *} \mathrm{p}<0,01 ; * * * \mathrm{p} \leq 0.001$. Significance of difference between COPD and CHF: $\mathrm{p} \leq 0.001$; BMI: body mass inclex; FFM: fat-free mass; FFMI: fat-free mass index; $F E V_{1}$ : forced expiratory volume in one second; $\mathrm{DL}_{\mathrm{C}}$ : diffusion capacity for carbon monoxide: $\mathrm{DL}_{\mathrm{CO}} / \mathrm{N}_{\text {aly }}$ : diffusion capacity for carbon monoxide corrected for alveolar vollume; LVEF: Left Ventricular Ejection Fraction; PASE: Physical Activity Scale for Elderly.

Peak exercise data are shown in table 2 . In patients, exercise capacity, assessed by bicycle ergometry $\left(\mathrm{VO}_{2}\right.$ peak), was about $50 \%$ that of controls. The difference between the $\mathrm{CHF}$ and COPD patient groups was small and statistically insignificant. There was also no difference in $\mathrm{VO}_{2}$ peak between COPD patients with and without abnormalities on the ECG (not shown). Ventilation reserve and respiratory quotient were significantly lower in CHF and COPD compared to controls, but only in COPD patients was the maximum ventilation reached and was the peak respiratory quotient below 1 . Only the control subjects reached their predicted maximal peak heart rates.

Quadriceps strength (fig 1A) was lower in COPD (85 Nm, p $\leq 0.001)$ and CHF (84 Nm, $\mathrm{p} \leq 0.001$ ) than in controls $(118 \mathrm{Nm})$. Biceps strength (fig $1 \mathrm{~A}$ ) was also lower in COPD (27 $\mathrm{Nm}, \mathrm{p} \leq 0.001)$ and $\mathrm{CHF}(26 \mathrm{Nm}, \mathrm{p} \leq 0.001)$ compared to controls $(38 \mathrm{Nm})$. Compared to controls, there was no significant difference between relative quadriceps and biceps strength in COPD (78\% vs. $77 \%$ ) nor in CHF patients $(72 \% v s .74 \%)$. Quadriceps fatigue (fig 1B), measured as the proportional decline in peak torque during 14 successive isokinetic extensions, was higher in COPD $(28 \%, \mathrm{p}=0.001)$ and $\mathrm{CHF}(30 \%, \mathrm{p}=0.002)$ compared to healthy subjects $(21 \%)$. Biceps tatigue (fig IB ), measured as the proportional decline in peak torque during 14 successive isokinetic flexions, was also markedly higher in COPD and CHF than in controls $(42 \%$ ws. $32 \%, \mathrm{p}<0.007)$. There were no statistically significant differences between COPD and CHF patients. Relative fatigue (as the percentage of mean control values) was also not significantly different between quadriceps and biceps in COPD $(133 \% \pm 32 \% v .134 \% \pm 34 \%)$ nor in $\mathrm{CHF}(1.59 \% \pm 44 \%$ vs. $130 \% \pm 42 \%)$. 
Table 2. Peak exercise test data

\begin{tabular}{|c|c|c|c|}
\hline 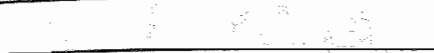 & Controls & COPD & $\mathrm{CH}^{2}$ \\
\hline $\mathrm{VO}_{2}$ peak $(\mathrm{ml} / \mathrm{min})$ & $2129+659$ & $840 \pm 261 *$ & $1092 \pm 271 * *$ \\
\hline $\mathrm{VO}_{2}$ peak/weight $(\mathrm{ml} / \mathrm{kg} / \mathrm{mm})$ & $27.1 \pm 6.5$ & $12.8+3.8 * *$ & $15.3 \pm 3.3 *$ \\
\hline $\mathrm{VCO}_{2}$ peak $(\mathrm{ml} / \mathrm{min})$ & $2636 \pm 788$ & $840 \pm 269 *$ & $1234 \pm 328 *$ \\
\hline VCO peak/weight $(\mathrm{m} / \mathrm{kg} / \mathrm{min})$ & $33.8 \pm 8$ & $13.0 \pm 4 * *$ & $17.3 \pm 4^{*}$ \\
\hline RQpeak & $1.21 \pm 0.08$ & $0.96 \pm 0.10 * * *$ & $1.11 \pm 0.08^{*}$ \\
\hline VEpeak (\% pred) & $88 \pm 26$ & $36 \pm 13 * *$ & $48 \pm 13^{* * 2 *}$ \\
\hline VEreserve $(\%)$ & $26 \pm 16$ & $-9 \pm 29 \cdots$ & 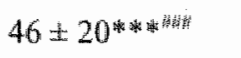 \\
\hline HRpeak (b/min) & $156 \pm 13$ & $121 \pm 17 *$ & $113 \pm 24 * *$ \\
\hline HRreserve $(\%)$ & $0 \pm 7$ & 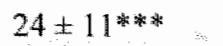 & $18 \pm 14^{2}$ \\
\hline
\end{tabular}

Values are mean $\pm \mathrm{SD}$; Significance of difference compared to controls: *** $p \leq 0.00 \mathrm{I}$. Significance of difference between COPD and CHF: $\mathrm{p}<0.05 ;{ }^{4 h t} \mathrm{p} \leq 0.001 ; \mathrm{VO}_{2}$ : oxygen consumption; $\mathrm{VCO}$ : carbondioxide production; RQ: respiratory quotient; VE: ventilation; $H R$ : heart rate.
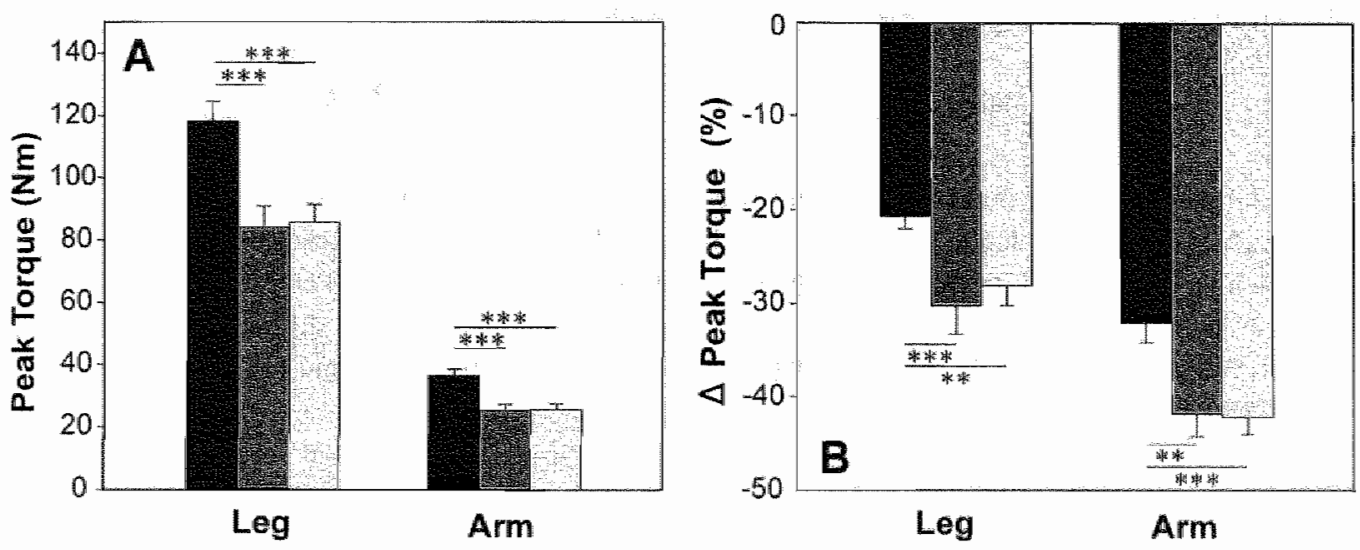

Figure I. Muscle strength (expressed as the maximal torcue) and fatigue (expressed as the proportional decline in peak torque), $\mathbf{V}=$ Controls; $=\mathrm{CHF}$; $=$ COPD. A) Leg and arm muscle strength. B) Leg and arm muscle fatigue. ** $\mathrm{p} \leq 0.01, * * 0,0.001$ 。

In each group (COPD, CHF and controls) quadriceps and biceps maximal torques correlated strongly with the FFM, as shown in figure $2 \mathrm{~A}$ and $\mathrm{B}$, respectively. There were no differences between the slopes of the individual subgroup regression lines in upper or lower limbs. Within each group, quadriceps and biceps strength correlated significantly with each other (data not shown). There was no relationship between quadriceps or biceps fatigue and FFM (figures $2 \mathrm{C}$ and D, respectively). In addition, there was no relation between the PASE and peripheral muscle maximal torque or fatigue (data not shown). 
FFM instead of body weight therefore appears important in nutritional assessment, especially in $\mathrm{CHF}$ where, in contrast to COPD, this is not a common procedure. Our results are in agreement with previous studies showing that these indices of the primary organ failure (the LVEF and $\mathrm{FEV}$ ) are poor predictors of exercise capacity in moderate to severely diseased patients $(2,3,21,22)$. Instead, we found that both in healthy subjects and in the two patient groups, the quadriceps strength and the FM correlated with the $\mathrm{VO}_{2}$ peak. In all groups, both controls and patients, the same strong relation between FFM and quadriceps or biceps strength was found, whereas the FFM did not correlate with muscle fatigue. It is obvious that peripheral muscle strength depends largely on the FFM, thereby explaining why quadriceps strength correlates with the $\mathrm{VO}_{2}$ peak. We thus demonstrate that the FFM is an important determinant of exercise capacity. However, this relation was weaker in the patient groups than in controls, suggesting that other factors are involved in the impaired exercise capacity and increased muscle fratigue in COPD and CHF patients.

Besides muscle wasting, intrinsic muscular abnormalities might be involved in skeletal muscle dysfunction and exercise intolerance. We recently reviewed intrinsic muscular abnormalities, such as altered fibre type distribution and metabolic profile, in COPD and CHF(23). Although no studies have yet performed a direct comparison, striking similarities were also found here, pointing towards a decreased oxidative capacity. Physical inactivity is frequently assumed to have a negative or "detraining" effect on exercise capacity, although this influence has never been studied in CHF and COPD. In the present study, daily physical activity level expressed as the PASE, was approximately $39 \%$ lower in patients than in controls, but not different between COPD and CHF. The PASE score is an expression of exercise capacity in healthy controls, but it remains unclear from our data whether it is also true for patients. Since the observed relationship in CHF patients between PASE and $\mathrm{VO}_{2}$ peak in this study is based on one outlier, the possible connection between daily activity level and the $\mathrm{VO}_{2}$ peak needs further investigation. Nevertheless, whether PASE is or is not a predictor of exercise capacity in patients, it appears less important than FFM in these severely diabled patients. We therefore conclude that a reduced daily activity level may negatively affect exercise capacity in COPD and CHF, but its role should not be over-interpreted.

Although muscle weakness in COPD and CHF has been reported before $(1,8,21)$, it remains unclear from the literature whether muscle weakness is generalized and of similar severity in these disorders. Only few studies compared strength of different muscle groups and some of them suggested that upper limb muscle strength is relatively preserved(6-8). It is difficult to compare these studies because of differences in methods and target muscles measured. For the lower limb, the quadriceps muscle is commonly tested, but for the upper limb, a wide diversity of muscle groups have been tested such as the flexor digitorum (handgrip force), adductor pollicis, biceps, deltoid or shoulder abductors. To avoid this problem in the present study, quadriceps and biceps strength and fatigue were therefore measured with the same isokinetic protocol. Neither COPD nor CHF demonstrated preserved upper limb muscle strength relative to lower limb muscle strength. We therefore conclude that skeletal muscle weakness is generalized in both disorders. 
In this study, pulmonary function was impaired in CHF, though obviously not to the same degree as in COPD. This is shown by the somewhat lower FEV reduced $\mathrm{DL}_{\mathrm{CO}}$. Even if corrected for the alveolar volume the $\mathrm{DL}_{\mathrm{Co}}$ was still decreased, which was also observed by Puri et al.(24), whose data suggested intrinsic abnormalities of the alveolar-capillary membrane. In turn, cardiac function may to some degree be impaired in COPD. Recently, left ventricular dysfunction was found in $32 \%$ of COPD patients in deteriorating condition(25), and in about $20 \%$ of clinically stable patients(26). Since it is known that left ventricular dysfunction is very unlikely in subjects with a normal ECG (27) we evaluated the ECG's of COPD patients and healthy controls. A substantial part of the COPD patients had some degree of right ventricular conduction delay, which is a common phenomenon in progressive $\mathrm{COPD}(28)$ and can also be a normal electrophysiological variant $(29,30)$. Since the literature is controversial with respect to the interdependency of left and right ventricular dysfunction(28,31), some degree of left ventricular dysfunction can not be excluded in this study. Five COPD patients had abnormal ECG's, but none of them had signs of heart failure on physical examination nor used cardiac medication. The 20 control subjects showed no abnormalities on the ECG's except right ventricular conduction delay, which is often seen in the normal population. The three subjects with anterior and inferior wall abnormalities also had no signs of left ventricullar dysfunction on physical examination. Furthermore, the peak ventilatory and heart rate reserve values clearly demonstrated that COPD patients were primarily limited by their reduced ventilatory capacity and not by cardiac function, showing that a potential cardiac impairment is subordinate to the pulmonary impairment in this group. Our data also show that CHF patients were not ventilatory limited during the exhausting cycling exercise (their maximum peak heart rates were not reached either, but this is due to the fact that most patients received $\beta$-blockers). These results do however emphasize the need to adjust for both cardiac and pulmonary organ dysfunction in these patient groups when evaluating the impact of systemic impairment.

In summary, we conclude that skeletal muscle wasting and weakness are generalized in COPD and CHF patients with similar exercise intolerance. The FFM and daily activity level are strong predictors of exercise capacity in healthy control subjects. The FFM is also a significant determinant of exercise capacity in COPD and CHF, in addition to other yet unidentified systemic factors. This study strengthens the importance of rehabilitation in both disorders, and mutual exchange of studies and experience in treatment modalities including nutrition, exercise and anabolic medication.

\section{ACKNOWLEDGEMENTS}

We would like to thank Petra Heuts, Femke Ellens and Dr. Matthijs Hesselink for their assistance with the isokinetic muscle testing. 


\section{REFERENCES}

1. Hamilton $A_{L}$; Killan $K J$, Summers $E$, Jones $N L$. Muscle strength, symptom intensity, and exercise capacity in patients with cardiorespiratory disorders. Am J Respir Crit Care Med $1995 ; 152: 2021-31$.

2. Steele 1C, Moore A, Nugent AM, Rilley MS, Campbell NPS, Nicholls DP Non-invasive measurement of cardiac output and ventricular ejection fractions in chronic cardiac failure: Relationship to impaired exercise tolerance. Clin Sci 1997:93:195-203.

3. Cotes $\triangle E$, Zejda I, King B. Lung function impaiment as a guide to exercise limitation in workrelated lung disorders. Am Rev Respir Dis 1988;137:1089-93.

4. Anker SD, Swan IW, Volterrani $\mathrm{M}$, et al. The influence of muscle mass, strength, fatigability and blood flow on exercise capacity in cachectic and non-cachectic patients with chronic heart failure. Lur Heart J 1997:18:259-69.

5. Engelen MP, Schols AM, Does JD, Wouters EF. Skeletal muscle weakness is associated with wasting of extremity fat-free mass but not with airflow obstruction in patients with chronic obstructive pulmonary disease. Am J Clin Nutr 2000;71:733-8.

6. Gosselink R, Troosters T, Decramer M. Peripheral muscle weakness contributes to exercise limitation in COPD. Am J Respir Crit Care Med 1996;153:976-80.

7. Buller NP, Jones D, Poole-Wilson PA. Direct measurement of skeletal muscle fatigue in patients with chronic heart failure. Br Heart J 1991;65:20-4.

8. Bernard S, LeBlanc P, Whittom F, et al. Peripheral muscle weakness in patients with chronic obstructive pullmonary disease. Am J Respir Crit Care Med 1998;158:629-634.

9. ATS. Standards for the diagnosis and care of patients with chronic obstructive pulmonary disease (COPD) and asthma. Am Rev Respir Dis 1987;136:225-44.

10. McKee PA, Castelli WP, McNamara PM, Kannel WB. The natural history of congestive heart failure: the Framingham study. N Engl J Med 1971;285:1441-6.

11. Lukaski HC, Johnson PE, Bolonchuk WW, Lykken GI. Assessment of fat-free mass using bioelectrical impedance measurements of the human body. Am J Clin Nutr 1985;41:810-7.

12. Schols AM, Wouters EF, Soeters PB, Westerterp KR. Body composition by bioelectricalimpedance analysis compared with deuterium dilution and skinfold anthropometry in patients with chronic obstructive pulmonary disease. Am J Clin Nutr 1991;53:421-4.

13. Vanltallie TB, Yang MU, Heymsfield SB, Funk RC, Boileau RA. Heightmormalized indices of the body's fat-fiee mass and fat mass: potentially useful indicators of nutritional status. Am $J$ Clin Nutr 1990;52:953-959.

14. Quanjer P, Tammeling G.J, Cotes JE, Pedersen OF, Peslin R, Yernault JC. Standardized lung function testing. Eur Respir J 1993;6:5-40.

15. Dvir Z. Isokinetios. Muscle testing, interpretation and clinical applications. 1st ed. Edinburgh: Churchill Livingstone, 1995.

16. Wasserman K, Hansen JE, Sue DY, Whipp BJ, Casaburi R. Principles of exercise testing and interpretation. 2nd ed. Philadelphia: Lea \& Febiger, 1994.

17. Carter $\mathrm{R}$, Peavler M, Zinkgraf S, Williams J, Fields S. Predicting maximal exercise ventilation in patients with chronic obstructive pulmonary disease. Chest 1987;92:253-9.

18. Washburn RA, Smith KW, Jette AM, Janney CA. The Physical Activity Scale for the Elderly (PASE): development and evaluation. J Clin Epidemiol 1993;46:153-62.

19. Altman DG, Gore SM, Gardner MJ, Pocock SJ. Statistical guidelines for contributors to medical 
journals. Br Med J Clin Res Ed 1983;286:1489-93.

20. Kleinbaum D, Kupper L, Muller K. Applied Regression Anaiysis and Other Multivariable Methods. 2nd ed. Boston: PWS-KENT Publishing Company, 1988.

21. Minotti JR, Christoph I, Oka R, Weiner MW, Wells L, Massie BM. Impaired skeletal muscle function in patients with congestive heart failure. Relationship to systemic exercise performance. J Clin Invest 1991;88:2077-82.

22. Harrington D, Anker SD, Chua TP, et al. Skeletal muscle function and its relation to exercise tolerance in chronic heart failure. J Am Coll Cardiol 1997;30:1758-64.

23. Gosker HR, Wouters EF, van der Vusse GJ, Schols AM. Skeletal muscle dysfunction in chronic obstructive pulmonary disease and chronic heart failure: underlying mechanisms and therapy perspectives. Am J Clin Nutr 2000;71:1033-47.

24. Puri S, Baker BL, Dutka DP, Oakley CM, Hughes JM, Cleland JG. Reduced alveolar-capillary membrane diffusing capacity in chronic heart failure. Its pathophysiological relevance and relationship to exercise performance. Circulation 1995;91:2769-74.

25. Render ML, Weinstein AS, Blaustein AS. Left ventricular dysfunction in deteriorating patients with chronic obstructive pulmonary disease. Chest 1995;107:162-8.

26. Chabot F, Schrijen F, Poincelot F, Polu JM. Interpretation of high wedge pressure on exercise in patients with chronic obstructive pulmonary disease. Cardiology 2001;95:139-45.

27. Khan MA, Sinha S, Hayton S, Fynn S, Henderson RA, Bennett DH. A normal electrocardiogram precludes the need for left ventriculography in the assessment of coronary artery disease. Heart 1998;79:262-7.

28. Matthay RA, Berger HJ, Davies RA, et al. Right and left ventricular exercise performance in chronic obstructive pulmonary disease: radionuclide assessment. Ann Intern Med 1980;93:2349.

29. Medvegy M, Antaloczy Z. Clinical significance of incomplete right bundle branch block. Orv Hetil 1993;134:1525-8.

30. Mauric AT, Samani NJ, de Bono DP. When should we diagnose incomplete right bundle branch block? Eur Heart J 1993; 14:602-6.

31. Schena M, Clini E, Errera D, Quadri A. Echo-Doppler evaluation of left ventricular impairment in chronic cor pulmonale. Chest 1996;109:1446-51. 

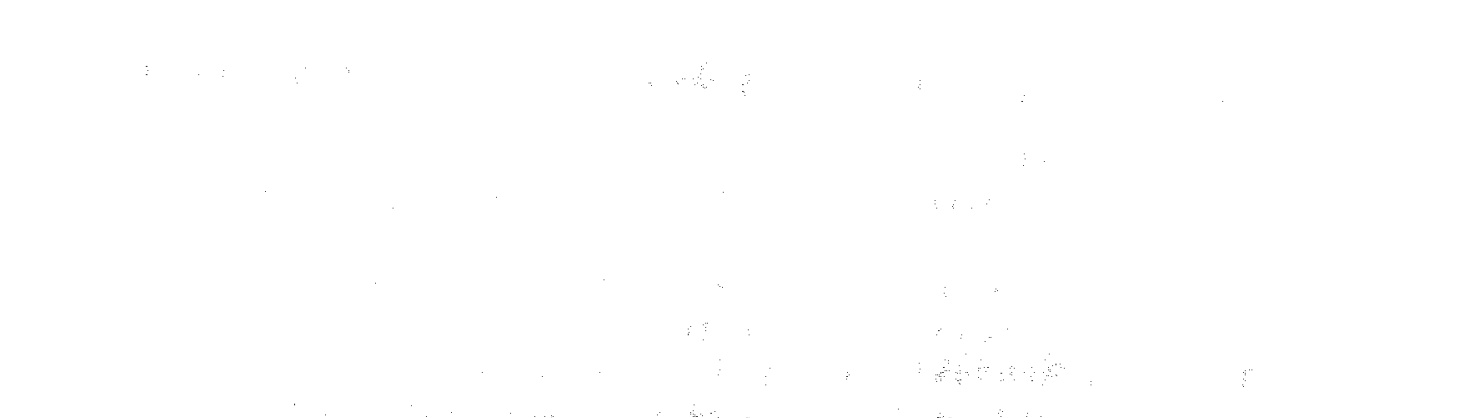


\title{
CHAPTER 4
}

\section{Myopathologic features in skeletal muscle of patients with chronic obstructive pulmonary disease}

\begin{abstract}
Despite the fact that muscle weakness is a major problem in COPD, detailed information on myopathologic changes in these patients, if any, at the microscopical level is scarce. Vastus lateralis biopsies of 15 COPD weight stable patients (BMI $23.9 \pm 1.0 \mathrm{~kg} / \mathrm{m}^{2}$; FFMI $17.2 \pm 1.7 \mathrm{~kg} / \mathrm{m}^{2}$ ) and 16 healthy age-matched controls (BMI $26.3 \pm 0.8 \mathrm{~kg} / \mathrm{m}^{2}$; FFMI $19.6 \pm 2.2 \mathrm{~kg} / \mathrm{m}^{2}$ ) were evaluated. Histochemistry was used to evaluate myopathologic features. Immunohistochemistry was used for the detection of macrophages and leukocytes, and of active caspase 3 and TdT dUTP nick-end labelling (TUNEL) as markers of apoptosis. Fatty cell replacement and fibrosis were observed in both groups, the latter being slightly, but significantly, more pronounced in COPD $\left(\chi^{2}=7.06 ; p=0.008\right)$. No differences between COPD and controls were found with respect to central nuclei, necrosis, regeneration, or fiber splitting. Signs of mitochondrial abnormalities were absent and normal numbers of inflammatory cells were found. Active caspase 3 positive myocytes were not observed and no difference was found in the number of TUNEL-positive myonuclei between controls and COPD patients ( $1.1 \%$ vs. $1.0 \%$, respectively). The cross sectional area of type IIX muscle fibers was smaller in COPD than in controls (2566 vs. $4248 \mu \mathrm{m}^{2} ; \mathrm{p}=0.003$ ). In addition to selective type IIX atrophy in patients with decreased fat-free mass, a slightly more pronounced mild neurogenic atrophy was observed in COPD relative to age-matched controls. In this group of clinically and weight stable COPD patients, apoptosis does not appear to be involved in muscle pathollogy.
\end{abstract}

Harry R. Gosker", Bèla Kubat ${ }^{2}$, Gert Schaart, Ger J. van der Vusse, Emiel F.M. Wouters, Annemie M.W.J. Schols". Departments of 'Respiratory Medicine, ${ }^{2}$ Pathology, " "Physiology, University of Maastricht, The Netherlands. Submitfed 


\section{NTRODUCTION}

Peripheral muscle weakness is a major problem in chronic obstructive pulmonary disease (COPD) $(1,2)$, contributing to exercise intolerance(3) and, hence, to a decreased health status(4). The loss of muscle mass has been well described in these patients $(1,2)$, but surprisingly, little data are reported regarding the morphology of limb muscles in COPD. First of all, muscle weakness has long been ignored, because studies focussed primarily on the ventilatory limitations of exercise capacity. Secondly, those studies that did describe intrinsic muscular abnormalities in COPD tended to focus primarily on muscle fiber type distributions and fiber sizes or dealt with molecular and biochemical alterations(5). Thus, a complete pathological picture of the changes in limb muscle of patients with COPD is not yet at hand, whereas the microscopic examination of muscle biopsies is a first crucial step to enlarge our understanding of the underlying pathology in peripheral muscles of COPD patients.

It is beyond the scope of this paper to describe all the different kinds of myopathies (for a review see Pearson et al.(6)), but the parameters that are being used to screen the muscle may prove very helpful in the examination of myopathologic features in the diseased muscle of COPD patients. In general, anybody suffering from severe peripheral muscle weakness will be referred to a pathologist or neurologist to assess the kind and extent of the muscle pathology. The first step in the assessment of a peripheral muscle biopsy is to determine whether the changes, if any, are neurogenic, myopathic or inflammatory(7): neurogenic changes are characterized by fiber atrophy of both fiber types and the angular form of the atrophied fibers. Fiber type grouping occurs when reinnervation takes place. In the mitochondrial enzyme staining moth-eaten fibers may occur. Fibrosis and replacement of myocytes by fat cells occurs in longstanding and substantial atrophy. In the second group, i.e. myopathies, the atrophied fibers are rounded, nuclei tend to migrate from their normal subsarcolemmal position into the center of the fiber (centralization of the nuclei), often a predominance of type I fibers is found and the atrophy occurs in one fiber type, commonly type I fibers. There is no fiber type grouping. Fibrosis and fatty cell replacement of muscle tissue occurs especially in dystrophies (these could be defined as a severe and well defined subgroup of myopathies). The third group are the inflammatory muscle diseases, i.e. myositis, characterized by inflammatory cell infiltration and more or less pronounced necrosis, myolysis and regeneration of muscle fibers. Depending on the extent of muscle destruction, fibrosis may occur in the late stages.

The aim of the current study was to provide a detailed picture of skeletal muscle pathology in COPD, in order to gain more insight in the process of muscle wasting in these patients. For this purpose, muscle biopsies firom the vastus lateralis of patients with COPD and healthy control subjects were examined. Microscopical evaluations were performed by means of standard histochemical techniques. Myopathologic features were evaluated by an expert pathologist. In addition, inflammatory cells and apoptosis were evaluated immunohistochemically. 


\section{METHODS}

A group of 15 patients with moderate to severe airflow obstruction and 16 healthy age-natched volunteers was studied. All patients had COPD according to ATS guidelines(8) and chronic airflow limitation, defined as the measured forced expiratory volume in one second (FEVi $)$ less than $70 \%$ of reference $\mathrm{FEV}_{1}$. Furthermore, patients had irreversible obstructive airway disease (less than $10 \%$ improvement of FEV, predicted baseline after $\beta_{2}$-agonist intalation). They were in clinically stable condition and not suffering from a respiratory tract infection or an exacerbation of their disease at least 4 weeks prior to the study. Seven COPD patients were on a maintenance dose $(5-10 \mathrm{mg} /$ day) of prednisolone. Exclusion criteria were malignancy, cardiac failure, distal arteriopathy, recent surgery, severe endocrine, hepatic oi renal disorders, and use of anticoagulant medication. The healthy age-matched control subjects were volunteers recruited through advertisement in a local newspaper. They underwent a physical examination by a physician to ensure that they were free from significant pulmonary or cardiac disease. Written informed consent was obtained from all subjects and the study was approved by the medical ethical committee of the University Hospital Maastricht (Maastricht, The Netherlands).

\section{Pulmonary function tests}

All patients and control subjects underwent spirometry to determine, amongst others, the forced expiratory volume in one second $\left(\mathrm{FEV}_{1}\right)$, with the highest value from at least three technically acceptable assessments being used. Residual volume (RV) and intrathoracic gas volume (ITGV) were assessed by whole-body plethysmography and diffusion capacity for carbon monoxide $\left(\mathrm{DL}_{\mathrm{co}}\right)$ was measured by using the single-breath method (Masterlab, Jaeger, Wurzburg, Germany). All values obtained were expressed as percentage of the predicted value(9). Arterial oxygen tension ( $\mathrm{PaO}_{2}$ ) was determined ( $\mathrm{ABL}$ 330; Radiometer, Copenhagen, Denmark) in a blood sample from the radial artery while breathing room air.

\section{Assessment of body composition}

Body height was determined to the nearest $0.5 \mathrm{~cm}$ and body weight was assessed to the nearest $0.1 \mathrm{~kg}$ while subjects wore light clothing and no shoes. Fat-free mass (FFM) was determined by scanning subjects on a DPX bone densitometer (Lunar Radiation Corporation, Madison, WI, USA) as described previously(10). Weight parameters were adjusted for body surface, resulting in the body mass index (BMI) and FFM index (FFMI)(11).

\section{Assessment of muscle function}

Isometric handgrip strength was assessed in all subjects by using a Harpenden handgrip dynamometer (Yamar; Preston, Jackson, MI, USA). Linear isokinetic muscle function of the lower limbs was assessed by a multijoint dynamometer device (Aristokin; LODE, Groningen, Netherlands) at $20 \mathrm{~cm} / \mathrm{s}$ and at $60 \mathrm{~cm} / \mathrm{s}$ as described previously $(2)$. At a speed of $20 \mathrm{~cm} / \mathrm{s}$, the maximal power generated by the legs mainly determined the outcome of performance. At a speed of $60 \mathrm{~cm} / \mathrm{s}$ performance is also influenced by muscle coordination. Before testing, each subject was familiarized in a standardized way with the equipment and the requested movement. 


\section{Collection and processing muscle tissue}

Postabsorptive muscle biopsies of the vastus lateralis were obtained by the needle biopsy technique(12). The examination of muscle morphology was performed on serial cryostat crosssections, thick $10 \mu \mathrm{m}$. General muscle architecture and fiber morphology were shown by routine haematoxylin-eosin (H\&E) staining or van Gieson staining (for additional collagen staining). Muscle fiber typing and distribution (fiber types I, IA and IIX) were evaluated by myofibrillar ATPase (mATPase) staining and immunohistochemistry as described previously (13). Fiber cross sectional area (CSA) and roundness (values between 0 and 1 , with 1 being perfectly round) were measured with an interactive image analysis system (Leica $Q W$ in Image Analysis System; Leica Microsystems BV, Rijswijk, Netherlands)(14). Cytochrome $c$ oxidase (COX), succinate dehydrogenase (SDH) and glycogen phosphorylase (GlyP) staining was performed as described previously(13). The altered muscle fiber type distribution, metabolic profile and reduced fiber type IIX CSA shown th table 1 have been reported earlier( $(13,14)$. DNA fragmentation in muscle fiber nuclei was detected by TdT dUTP nick end labelling (TUNEL) after pretreatment with proteinase $\mathrm{K}$ for $5 \mathrm{~min}$, followed by diaminobenzidine staining with a peroxidase conjugated antibody (TdT-FragEL ${ }^{\mathrm{TM}}$ DNA Fragmentation Detection Kit, Oncogene Research Products, Boston, MA, USA): 300 to 500 myocyte nuclei were counted using a grid and the percentage of positive nuclei was determined. A common problem of the TUNEL reaction is the weak background staining of nuclei. Therefore as TUNEL-positive control, muscle sections were treated with $1 \mathrm{mg} / \mathrm{ml}$ DNAse I, to obtain DNA fragmentation. The staining intensity in these nuclei served as positive controls. Active caspase 3 was evaluated by immunostaining with the polyclonal anti-caspase 3 antibody CMI (IDUN Pharmaceuticals, La Jolla, CA, USA). Mouse monoclonal antibodies were used for identification of leukocytes (anti-leukocyte common antigen CD45, M0701; Dako Ltd., High Wycombe, UK) and macrophages (anti-CD68, M0814; Dako). Primary antibody binding was detected with the StreptABComplex/HRP method (K0377; Dako) and staining with diaminobenzidine. Cryosections of a human malignant sarcoma and human tonsil were used as a positive control for active caspase 3, and leukocytes/macrophages, respectively. The following features were evaluated semi-quantitatively: inflammatory infiltrates; fibrosis, fatty cell rejlacement, fiber splitting, vacuoles, necrosis, regeneration, liyaline and ring fibers, and central nuclei $(\mathrm{H \& E})$; mitochondrial rearrangements like subsarcolemmal accumulation, targets, moth-eaten fibers and cores (COX and SDH); fiber type distribution and grouping, atrophied/hypertrophied fibers (mATPase). This screening was performed in a blinded manner by an expert pathologist who assigned scores 0 to 5 indicating the severity of each feature, 0 for the absence of the feature, 5 for severe abnormalities.

\section{Statistical analysis}

Data were analyzed with the unpaired Student's $t$ test (corrected for unequal variances if required), Pearson Chi-Square test, or the Pearson correlation test(15). Analysis of covariance with sex as covariate was used to compare leg power between COPD and controls. Data are represented as the means $\pm S D$. A two-tailed probability value of less than 0.05 was considered statistically significant. 
Table 1. Subject characteristics, lung function and nusclle biopsy data

\begin{tabular}{|c|c|c|c|c|}
\hline \multirow[b]{2}{*}{ General characteristies } & \multicolumn{2}{|c|}{ Controls } & \multicolumn{2}{|c|}{ COPD } \\
\hline & \multirow{2}{*}{\multicolumn{2}{|c|}{$16(2 / 14)$}} & & \\
\hline $\mathrm{N}($ Female/Male) & & & \multicolumn{2}{|c|}{$15(3 / 12)$} \\
\hline Age (years) & 64 & \pm 3 & 67 & \pm 9 \\
\hline $\mathrm{BMI}\left(\mathrm{kg} / \mathrm{m}^{2}\right)$ & 26.3 & \pm 3.3 & 23.9 & \pm 4.0 \\
\hline FFM (kg) & 58.2 & \pm 9.0 & 48.8 & $\pm 6.9+$ \\
\hline FFMI $\left(\mathrm{kg} / \mathrm{m}^{2}\right)$ & 19.6 & \pm 2.2 & 17.2 & $\pm 1.7+$ \\
\hline FEV $(\%$ predicted $)$ & 109 & \pm 17.2 & 42 & $\pm 13.9 \%$ \\
\hline $\mathrm{PaO}_{2}(\mathrm{kPa})$ & 11.8 & \pm 1.6 & 9.9 & \pm 1.24 \\
\hline $\mathrm{DL}_{c o}(\%$ predicted $)$ & 123 & \pm 23 & 63 & \pm 24 \\
\hline RV (\% predicted) & 114 & \pm 15 & 167 & $\pm 32 \pm$ \\
\hline ITGV (\% predicted) & 108 & \pm 17 & 144 & \pm 22 \\
\hline \multicolumn{5}{|l|}{ Muscle function } \\
\hline Leg power at $20 \mathrm{~cm} / \mathrm{s}(\mathrm{W})$ & 265 & \pm 62 & 203 & $\pm 88 *$ \\
\hline Leg power at $60 \mathrm{~cm} / \mathrm{s}(\mathrm{W})$ & 561 & \pm 154 & 363 & $\pm 145+$ \\
\hline Handgrip strength (kg) & 43 & \pm 8 & 31 & $\pm 8 \pm$ \\
\hline \multicolumn{5}{|l|}{ Muscle biopsy } \\
\hline Proportion of type I fibers (\%) & 43.4 & $\pm \mathbb{1 2 . 6}$ & 19.4 & \pm 14.0 \\
\hline Proportion of type IIA fibers $(\%)$ & 29.4 & \pm 12.1 & 34.8 & \pm 11.9 \\
\hline Proportion of type IIX fibers $(\%)$ & 27.2 & \pm 12.3 & 45.7 & $\pm 18.9 *$ \\
\hline CSA of type IIX fibers $\left(\mu \mathrm{m}^{2}\right)$ & 4248 & \pm 1300 & 2566 & $\pm 1137 \uparrow$ \\
\hline Proportion of CSG- fibers (\%) & 0.2 & \pm 0.3 & 5.4 & $\pm 4.9+$ \\
\hline
\end{tabular}

Values are mean $\pm \mathrm{SD}$; Significance of difference compared to controls: ${ }^{*} \mathrm{p}<0.05 ; \uparrow \mathrm{p}<0.01 ; \ddagger \mathrm{p} \leq 0.001$. BMI: body mass index; FFM: fat-free mass; FFMI: fat-free mass index; $\mathrm{DL}$ co diffision capacity for carbon monoxide; $\mathrm{FEV}_{1}$ : forced expiratory volume in one second; $\mathrm{RV}$ : residual volume; ITGV: intrathoracic gas volume; CSA: cross sectional area; CSG-: no stainable activties of cytochrome $c$ oxidase, succinate dehydrogenase and glycogen phosphorylase.

\section{RESULTS}

Subject characteristics are shown in table 1. There were no differences in gender or age between the groups. FFMI was significantly lower in COPD than in controls, despite a similar BMI. Isokinetic leg power was significantly lower in COPD than in controls, at both speeds. Handgrip strength was also lower in the patients. The proportions of type I fibers and fibers with high oxidative capacity were markedly lower in patients, whereas the fiber type IIX proportion was higher compared to healthy subjects. The proportion of fibers deficient for COX, SDH and GlyP activity was higher and fiber type IIX CSA was significantly smaller in COPD patients. 
Table 2. Severity score frequencies of myopthologic features

\begin{tabular}{lcccccc}
\hline Pathologic feature & \multicolumn{5}{c}{ Number of patients: Control $(\mathrm{N}=16)$} & COPD (N=15) \\
& severity score 0 & severity score $\mathbb{1}$ & severity score 2 \\
& Control & COPD & Control & COPD & Control & COPD \\
\hline Atrophied fibers & 8 & 1 & 8 & 5 & 0 & 9 \\
Hypertrophied fibers & 15 & 10 & 1 & 5 & 0 & 0 \\
Fiber type grouping & 4 & 5 & 11 & 9 & 1 & 1 \\
Fiber spliting & 13 & 13 & 3 & 2 & 0 & 0 \\
Fibrosis perimysial & 12 & 10 & 4 & 2 & 0 & 3 \\
Fibrosis endomysial & 8 & 1 & 8 & 14 & 0 & 0 \\
Fat cells & 12 & 8 & 3 & 6 & 1 & 1 \\
Inflammatory cells & 16 & 12 & 0 & 3 & 0 & 0 \\
Central nuclei & 15 & 13 & 1 & 2 & 0 & 0 \\
Necrotizing fibers & 16 & 12 & 0 & 3 & 0 & 0 \\
Regenerating fibers & 13 & 8 & 3 & 7 & 0 & 0 \\
Cores & 16 & 15 & 0 & 0 & 0 & 0 \\
Moth-eaten fibers & 16 & 12 & 0 & 3 & 0 & 0 \\
Targets & 16 & 15 & 0 & 0 & 0 & 0 \\
Hyaline fibers & 16 & 15 & 0 & 0 & 0 & 0 \\
Ring fibers & 16 & 14 & 0 & 1 & 0 & 0 \\
\hline
\end{tabular}

Frequencies for severity scores $3-5$ are not shown, since none of the subjects had scores $>2$ for any of the features. Significance of difference compared to controls (based on Pearson Chi-Square) $\uparrow p<0.01 ; \neq p \leq 0.001$. Atrophy and hypertrophy: abnormal fiber size and/or shape; fiber type grouping: replacement of the normal mosaic pattern by groups of histochemically uniform fiber types; inflammatory cells: macrophages and leukocytes; cores: zones devoid of oxidative enzyme activity staining; targets: unreactive core surrounded by a darker staining rim; moth-eaten: patchy staining due to the disruption of the intermyofibrillar; hyline fibers: rounded, heavily H\&E stained fibers (due to hypercontraction of myofibrils); ring fibers: dense subsarcolemmal staining.

Frequencies of the severity scores in controls versus patients are shown in table 2 . No scores $>2$ for severity (on a scale of 0-5) were obtained for any of the semi-quantitatively screened myopathologic features either in COPD patients or in healthy. Normal amounts of macrophages and leukocytes were found, randomly scattered between fibers in control subjects as well as in patients. There were no clear signs of excessive necrosis and/or regeneration in either group. In neither group there were signs of mitochondrial or cytoskeletal rearrangements, such as moth-eaten fibers, cores, target fibers, hyaline fibers or ring fibers (apart from the higher proportion of fibers deficient for COX and SDH in COPD). In both patients and controls a mild replacement of muscle by fat cells and fibrotic material was observed (figure $1 \mathrm{~A}$ and $\mathrm{B}$ ), the latter being slightly more pronounced in $\mathrm{COPD}\left(\chi^{2}=7.06 ; \mathrm{p}=0.008\right)$. Atrophy of muscle fibers was clearly more pronounced in $\operatorname{COPD}\left(\chi^{2}=15.12 ; \mathrm{p}=0.001\right)$. In both groups, the atrophied fibers were randomly scattered and mainly had angulated shapes (figure $1 \mathrm{C}$ ), although rounded fibers were also observed. We assessed the roundness of type IIX fibers, which was less in COPD compared to controls $(0.70 \pm 0.07$ vs. $0.78 \pm 0.06 ; \mathrm{p}=0.007)$. 


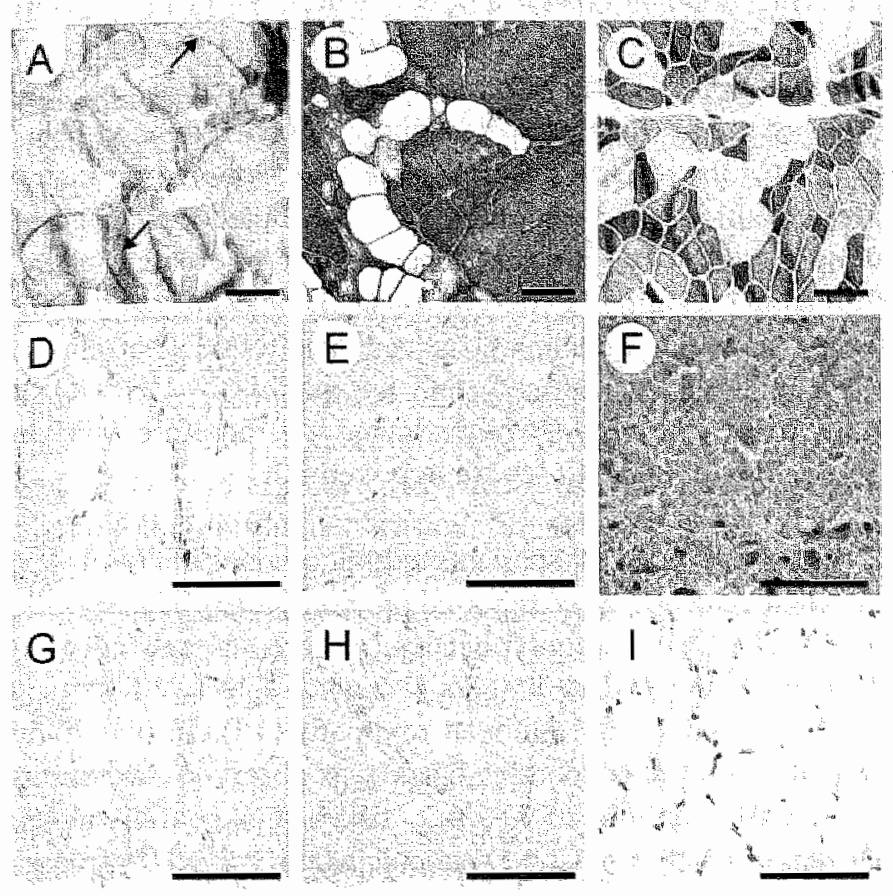

Figure 1. A) Van Gieson stain showing increased anounts of permysial and endonysial fibrosis (collagen stains red/dark, indicated by the arrows). B) Hatenatoxylin eosin stain showing replacenent by fat cells, which appear as "holes", because of the lack of staining. C) mATPase stain (preincubations at $\mathrm{pH} \quad 10.4$ and 4.6 ) showing small and angulated dark fibers, which are atrophied type IIX fibers. Note the large variation in fiber sizes. D) Caspase 3 stain of a healthy control. E) Caspase 3 stain of a COPD patient. F) Positive control for caspase 3 (human malignant sarcoma, dark staining of cytoplasm). G) TUNEL stain of a healthy control. H) TUNEL stain of a COPD patient. I) Positive control for TUNEL (a DNAse I streated section, positive nuclei stain brown/dark). Internal scale bars $=100 \mu \mathrm{m}$.

DNA fragmentation was assessed with TUNEL staining (figure 1D-F). The proportion of positive nuclei was not different between controls and COPD patients $(1.1 \pm 1.6 \%$ ws. $1.0 \pm$ $0.8 \%$ ). The proportion of TUNEL-positive nuclei did not correlate with fiber CSA or with FFM in patients or controls. The presence of active caspase 3 as a marker of apoptosis was also examined, but positive fibers were absent in both groups (figure $1 \mathrm{G}-\mathrm{l}$ ).

Seven of the 15 COPD patients were on a maintenance dose of prednisolone during the study. There were however no differences for any of the myopathologic features examined in the current study between the patients who received corticosteroids and non-receivers. Also, the proportion of TUNEL-positive nuclei was not different between receivers and non-reccivers $(1.1 \pm 0.8 \%$ vs. $0.9 \pm 0.9 \%$, respectively $)$.

\section{DISCUSSION}

In this study we assessed "classical" myopathologic features in the vastus lateralis of healthy controls and patients with COPD. The patients had reduced muscle mass and sulfered from muscle weakness. Both patients and controls exhibit an appearance of a mild neurogenic atrophy, based on the finding of the following features: there were angulated fibers in all fiber 
types, there was some fiber type grouping (which occurs upon reinnervation), and fibrosis and fatty cell replacement was observed. The abundant presence of comnective tissue and fat cells is common for the severely atrophying muscle(6). Some degree of fibrosis and fatty cell replacement is not uncommon for the skeletal muscle of the elderly, which is probably assoelated with the age related atrophy of type II fibers(16). The observation of rounded fibers secondary to angulated fibers, suggests that the observed muscle atrophy is slowly progressing and longstanding. Therefore, the abnormalities found can probably be attributed to the general pathology in the elderly, for example caused by physical inactivity or microangiopathy. Microangiopathy in peripheral neuropathy (examined in nerve biopsies) has been reported for COPD and the involvenent of hypoxia was suggested(17). Ozge et al also found a correlation between the degree of neuropathy (functionally assessed) and hypoxemia in COPD(18). However, patients in the current study were not extremely hypoxic and it is therefore worth to examine these myopathologic features in patients with severe hypoxemia.

However, on top of the mild neurogenic atrophy, COPD patients exhibit marked fiber type IIX atrophy compared to healthy age-matched controls, as we reported previously(14). This specific form of atrophy can not be attributed to physical inactivity, because a more generalized, nonfiber type specific atrophy would be expected $(6,7)$. Decramer et al showed selective fiber type II atrophy in COPD patients with diagnosed steroid-induced myopathy(19). In that study affected fibers were also angulated and increased connective tissue was observed. In contrast to their data, we did not find increased numbers of necrotic fibers and central nuclei. Furthermore, we did not find any differences between COPD patients who received (low doses of) prednisolone and those who did not.

The etiology of fiber type IIX atrophy is still incompletely understood, but its involvement in the loss of muscle mass and, hence, its effect on muscle strength in COPD is obvious(14). Although the COPD patients in the current study were not cachectic, they were characterized by a reduced FFMI relative to the control group. Atrophy may not be the only factor that is associated with the loss of muscle mass. Necrosis and apoptosis (i.e. "programmed" cell death) are two other processes that may lead to the reduction of muscle mass through the disappearance of muscle cells. The present data suggest that necrosis is not involved, which is underscored by the fact that we did not observe any widespread infiltrates of immune cells that nomally accompany necrosis(20). We found that only about $1 \%$ of all myocyte nuclei was TUNEL-positive, for controls as well as for patients. However, using the TUNEL for the detection of apoptosis should be interpreted wit caution, because nonspecific DNA fragmentation may also be detected(21). Therefore, we also immunostained for active caspase 3, an established marker for apoptosis $(21)$ : in neither controls nor patients we found cytoplasmatic immunostaining for active caspase 3 . Our data thus suggest that apoptosis of muscle fibers does not occur, certainly not to a higher degree in patients compared to controls. However, despite of our reservations regarding the TUNEL data, we did find few positive nuclei in patients as well as in healthy subjects. Since myocytes are multi-nucleated, apoptotic nuclei could very well be important to adjust the number of myonuclei in fibers during atrophying conditions(22). A relation between fiber CSA and the number of TUNEL-positive 
myonuclei has indeed been shown in chronic heart failure(23). However, we did not find this relation in COPD, which may be related to the low frequency of TUNEL-positivity or because the patients in our study were in a weight stable condition and may be less underweight. Alternatively, since apoptosis is a very dynamic process and the progress of muscle wasting is relatively slow, very small differences may be expected between patients and controls. It is therefore possible that the current methodology is not sufficient to detect those potential differences.

Muscle wasting has convincingly been associated with systemic inflammation in COPD(2426). Also, it is feasible that circulating inflammatory cells infiltrate into the muscle in a way similar to bronchial inflammatory cell infiltration. Presence of inflammatory cells in the wasting muscle can therefore be expected. However, we did not find abnormal numbers of macrophages and leukocytes in the muscle tissue of COPD patients. This indicates that intramuscular inflammatory cells are most likely not the source of inflammatory mediators that affect the muscle. Alternatively, circulating cytokines and chemokines or mediators produced by local endothelial cells or even the myocytes themselves, may be involved in the association between inflammation and skeletal muscle wasting. However, this assumption requires further investigation, which was beyond the scope of the present study.

In summary, this is the first time that peripheral muscle weakness in COPD has been approached from a myopathologic perspective using a broad set of standard histochemical techniques. Apart from the marked fiber type IIX atrophy in COPD, the results show only little differences between patients with COPD and healthy age-matched control subjects. Both groups show a mild, probably age-related, neurogenic atrophy that is slightly more pronounced in COPD. Furthermore, there were no sign that necrosis and apoptosis are involved in muscle pathology. Future studies are required to determine potential differences in muscle pathology in the sub-groups of severe hypoxic patients and cachectic COPD patients (characterized by weight loss and disproportionate wasting of FFM) and to further describe the mechanisms underlying skeletal muscle fiber atrophy.

\section{ACKNOWLEDGMENTS}

The authors thank Dr. Matthijs Hesselink for general assistance and Ewald Dumont for performing the active caspase 3 staining. 


\section{REFRENCES}

1. Bemard $\$$, LeBlanc $\mathbf{P}_{\text {; }}$ Whittom $\mathrm{F}$, al Peripheral muscle weakness in patients with chronic obstructive pulmonary disease. Am J Respir Crit Care Med 1998;158:629-634.

2. Engelen MP. Schols AM, Does JD, Wouters EF. Skeletal muscle weakness is associated with wasting of extremity fatfree mass but not with airflow obstruction in patients with chronic obstructive pulmonary disease. Am J Clin Nutr 2000;71:733-8.

3. Schols AM, Mostert R, Soeters PB, Wouters EF. Body composition and exercise performance in patients with chronic obstructive pulmonary disease. Thorax $1991 ; 46: 695-9$.

4. Wood PH. Appreciating the consequences of disease: the international classification of impairments, disabilities, and handicaps. WHO Chron 1980;34:376-80.

5. Gosker HR, Wouters EF, van der Vusse GJ, Schols AM. Skeletal muscle dysfunction in chronic obstructive pulmonary disease and chronic heart failure: underlying mechanisms and therapy perspectives. Am J Clin Nutr 2000:71:1033-47.

6. Pearson AM, Young RB. Diseases and disorders of muscle. Adv Food Nutr Res 1993;37:339423.

7. Dubowitz V. Muscle biopsy. A practical approach. 2nd ed. London: Baillière Tindall, 1985.

8. ATS. Standards for the diagnosis and care of patients with chronic obstructive pulmonary disease (COPD) and asthma. Am Rev Respir Dis 1987;136:225-44.

9. Quanjer P, Tammeling GJ, Cotes JE, Pedersen OF, Pestin R, Yernault JC. Standardized Jung function testing, Eur Respir J 1993;6:5 40.

10. Engelen MPKJ, Schols AMWJ, Heidendal GAK, Wouters EFM. Dual-energy X-ray absorptiometry in the clinical evaluation of body composition and bone mineral density in patients with chronic obstructive pulmonary disease. Am J Clin Nutr 1998;68:1298 1303.

11. VanItallie TB, Yang MU, Heymsfield SB, Funk RC, Boileau R.A. Height-normalized indices of the body's fat-free mass and fat mass: potentially useful indicators of mutritional status. Am I Clin Nutr 1990;52:953-959.

12. Bergstrom L. Muscle electrolytes in man. Determination by neutron activation analysis on needle biopsy specimens. A study on normal subjects, kidney patients, and patients with chronic diarrhea. Scand J Clin Lab Invest 1962;68:1-110.

13. Gosker HR, van Mameren $H$, van Dijk PJ, et al. Skeletal muscle fiber type shifting and metabolic profile in patients with COPD. Eur Respir J 2002;19:617-626.

14. Gosker HR, Engelen MPKJ, van Mameren $H$, et al. Muscle fiber type IIX atrophy is involved ith the loss of fat-free mass in chronic obstructive pulmonary disease. Am J Clin Nutr $2002 ; 76: 113-119$.

15. Altman DG, Gore SM, Gardner MJ, Pocock SJ. Statistical guidelines for contributors to medical journals. Br Med J Clin Res Ed 1983;286:1489-93.

16. O'Rourke KS. Myopathies in the elderly. Rheum Dis Clin North Am 2000;26:647-72.

17. Stoebner P, Mezin P, Vila A, Grosse $R$, Kopp N, Paramelle B. Microangiopathy of endoneurial vessels in hypoxemic chronic obstructive pumonary disease (COPD). A quantitative ultrastructural study. Acta Neuropathol (Berl) 1989;78:388-95.

18. Ozge A, Atis S, Sevim S. Subclinical peripheral neuropathy associated with chronic obstructive pulmonary disease. Electromyogr Clin Neurophysiol 2001;41:185-91.

19. Decramer $M$, de Bock $V$, Dom $\mathbb{R}$. Functional and histologic picture of steroid-induced myopathy in chronic obstructive pulmonary disease. Am J Respir Crit Care Med $1996 ; 153: 1958-64$. 
20. McConkey DJ. Biochemical determinants of apoptosis and necrosis. Toxicol Let 1998;99:15768.

21. de Boer RA, van Veldhuisen DJ, van der Wijk J, et al. Additional use of immunostaning for active caspase 3 and cleaved actin and PARP fragments to detect apoptosis in patients with chronic heart failure. J Card Fail 2000;6:330-7.

22. Allen DL, Roy RR, Edgerton VR. Myonuclear domains in muscle adaptation and disense. Muscle Nerve 1999;22:1350-60.

23. Vescovo G, Volterrani M, Zennaro R, et al. Apoptosis in the skeletal muscle of patients with heart failure: investigation of clinical and biochemical changes. Heart 2000;84:431-7.

24. Eid AA, lonescu AA, Nixon LS, et al. Inflammatory response and body composition in chronic obstructive pulmonary disease. Am J Respir Crit Care Med 2001;164:1414-8.

25. Di Francia M, Barbier D, Mege JL, Orehek J. Tumor necrosis factor-alpha levels and weight loss in chronic obstructive pulmonary disease. Am J Respir Crit Care Med 1994;150:1453-5.

26. Schols AM, Buurman WA, Staal van den Brekel AJ, Dentener MA, Wouters EF. Evidence for a relation between metabolic derangements and increased levels of inflammatory mediators in a subgroup of patients with chronic obstructive pulmonary disease. Thorax 1996;51:819-24. 
H:

$\therefore \quad \therefore \quad \cdots$

$\ldots$

$\therefore$ 


\title{
CHAPTER 5
}

\section{Skeletal muscle fiber type and metabolic shifts in chronic obstructive pulmonary disease}

\begin{abstract}
The aim of this study was to examine the nature of fiber type redistribution in relation to fiber metabolic profile in the vastus lateralis in COPD and COPD subtypes. Fifteen COPD patients ( 8 with emphysema stratified by high-resolution computed tomography) and 15 healthy control subjects were studied. A combination of myosin ATPase staining and immunohistochemistry was used to identify pure as well as hybrid fiber types. For oxidative capacity fibers were stained for cytochrome $c$ oxidase and succinate dehydrogenase activities, and glycogen phosphorylase for glycolytic capacity. Fiber type I proportion was markedly lower ( $16 \% \mathrm{vs} .42 \%)$, especially in emphysema, and the proportion of hybrid fibers was higher $(29 \%$ vs. 16\%) in COPD patients compared to controls. The proportion of fibers staining positive for oxidative enzymes was lower in patients, which correlated with fiber type I proportion. Within IIA fibers oxidative capacity was lower in COPD. We conclude that fiber type transitions are involved in the fiber type redistribution in COPD. Low oxidative capacity is closely related to the fiber type I proportion, but an additional reduction of oxidative enzyme activity is present within IIA fibers of patients. Fiber type abnormalities may be aggravated in emphysema.
\end{abstract}

Harry R. Gosker', Henk van Mameren², Paul J. van Dijk ${ }^{2}$, Mariëlle P.K.J. Engelen', Ger J. van der Vusse', Emiel F.M. Wouters', Annemie M.W.J. Schols'. Departments of 'Respiratory Medicine, 'Anatomy \& Embryology, 'Physiology, University of Maastricht, The Netherlands. European Respiratory Joumal 2002; 19: 617-626 


\section{INTRODUCTION}

One of the hallmarks in COPD patients is the progressively reduced exercise capacity. Besides lung failure, skeletal muscle dysfunction also contributes to exercise intolerance in COPD( 1 , 2). Both biochemical and morphological changes in peripheral skeletal muscles of COPD patients have been described (3), but it is unclear how these alterations develop. Abnormal fiber type proportions have been found in the quadriceps femoris in COPD (4-6), but in these studies fibers were only classified as either type I, IIA or IIX on the basis of myofibrillar ATPase (mATPase) staining. In the current study we combined mATPase and immunohistochemical identification of fibers which makes it possible to detect hybrid fibers fibers expressing multiple myosin heavy chain ( $\mathrm{MyHC}$ ) isoforms - providing useful information on the mechanism underlying fiber type redistribution in COPD. Furthermore, data with respect to metabolic enzyme activities in the quadriceps femoris in COPD are not consistent. Glycolytic enzyme activity may or may not be increased $(7,8)$. Oxidative enzyme activities are reduced $(7,8)$, however, Sauleda $e t$ al found that the activity of cytochrome $c$ oxidase ( $\mathrm{COX}$ ), an enzyme involved in the oxidative energy metabolism, was increased in COPD (9). We therefore studied the enzyme profile within the identified fiber type categories. COX is a mitochondrial enzyme that is involved in the oxidative phosphorylation. Succinate dehydrogenase (SDH) is also a mitochondrial enzyme and exerts its catalytic action in the citric acid cycle. Glycogen phosphorylase (GlyP) is involved in the glycogenolysis and mobilizes glucose-1-phosphate from glycogen storage for glycolysis. Hence, COX and SDH were used as markers for oxidative energy metabolism and GlyP was used as marker for glycolytic energy metabolism in the present work. With this approach it is also possible to establish to what extend changes in fiber type proportions and enzyme activities are coupled.

Using gel electrophoresis techniques a lower type I and a higher type II myosin heavy chain (MyHC) isoform content was found in the quadriceps femoris of COPD patients compared to healthy subjects $(10,1 \mathrm{j})$. In these studies the MyHC type I content was positively related to the $\mathrm{DL}_{\mathrm{Co}}$ and the FEV . On the one hand, the relation with the $\mathrm{DL}_{\mathrm{Co}}$ suggests that the loss of type I fibers is more pronounced in patients with emphysema and on the other hand, the relation with the FEV, suggests that the loss is more pronounced in patients with severe COPD. In the current research we provide more insight in muscular changes in patients with and without emphysema stratified by high-resolution computed tomography (HRCT).

The aims of this study are to 1) establish whether fiber type redistribution in COPD occurs through gradual shifts in intracellular MyHC isoform content, which would result in a greater proportion of hybrid fiber types in patients; 2) provide more insight in the behavior of metabolic enzyme activities (oxidative and glycolytic) and their relation with the fiber type distribution; 3) establish if abnormal fiber type distribution is aggravated in emphysema patients compared to non-emphysema patients. 


\section{MATERIALS AND METHODS}

\section{Study population}

A group of 15 patients with moderate to severe airflow obstruction and 15 healthy age matched volunteers was studied (table 2). All patients had COPD according to ATS guidelines (12) and clironic airflow limitation, defined as measured forced expiratory volume in one second (FEV) less than $70 \%$ of reference $\mathrm{FEV}_{1}$. Furthermore, patients had irreversible obstructive airway disease (less than $10 \%$ improvement of $\mathrm{FEV}_{1}$ predicted baseline after $\mathrm{B}_{2}$-agonist inhalation). They were in clinically stable condition and not suffering from a respiratory tract infection or an exacerbation of their disease at least 4 weeks prior to the study. Medication usage and doses were retrieved form available hospital files and data form the referring physician. Patients received standard optimized inhalation treatment. Due to the potiential adverse effects of oral glucocorticoids on skeletal muscle, we specifically investigated the influence of this medication on our findings. Doses were expressed as hydrocortisone equivalents day"' At the time of the biopsy 7 of the 15 COPD patients were on a maintenance dose of prednisolone (ranging from 5 to $10 \mathrm{mg} /$ day). Exclusion criteria were malignancy, cardiac failure, distal arteriopathy, recent surgery, alpha 1-antiprotease deficiency, severe endocrine, hepatic or renal disorder and use of anticoagulant medication. Written informed consent was obtained from all subjects and the study was approved by the medical ethical committee of the University Hospital Maastricht (Maastricht, The Netherlands).

\section{Pulmonary function tests}

All patients and control subjects underwent spirometry to determine, amongst others, the forced expiratory volume in one second $\left.(\mathrm{FEV})_{1}\right)$, with the highest value from at least three technically acceptable assessments being used. Residual volume (RV) and intrathoracic gas volume (ITGV) was assessed by whole-body plethysmography and diffusion capacity for carbon monoxide $\left(\mathrm{DL}_{\mathrm{CO}}\right)$ was measured by using the single-breath method (Masterlab, Jaeger, Wurzburg, Germany). All values obtained were related to a reference value and expressed as percentage of the predicted value (13).

\section{Assessment of emphysema}

Evaluation of the presence of parenchymal destruction, the hallmark of emphysema (14), was performed by HRCT as described previously (15). The severity and extent of emphysema in each scan were visually scored by two independent observers according to the direct observational method developed by Sakai (16). HRCT scores ranged from 0 (no emphysema) to 120 (severe emphysema). Patients were stratified by HRCT score into two groups: HRCT score $<30(\mathrm{EMPH}-)$ and HRCT score $\geq 30(\mathrm{EMPH}+)$.

\section{Tissue collection and processing}

Arterial oxygen tension $\left(\mathrm{PaO}_{2}\right)$ was determined ( $\mathrm{ABL} 330$; Radiometer, Copenhagen, Denmark) in a blood sample obtained by puncture of the radial artery while breathing room air. Postabsorptive muscle biopsies of the lateral part of the quadriceps femoris were obtained under local anaesthesia by the needle biopsy technique (17). Biopsies were placed in a drop of

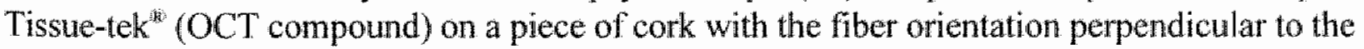
plane of the cork. The specimen was frozen in melting isopentane pre-cooled in liquid nitrogen 
and stored at $-35^{\circ} \mathrm{C}$. Serial cryostat cross-sections $(10 \mu \mathrm{m})$ were made on a cryostat microtome at $-20^{\circ} \mathrm{C}$ and mounted on slides which were stored at $-35^{\circ} \mathrm{C}$ until analysis. Per biopsy sample, nine consecutive slides (each carrying two or three cross-sections) were used for fiber type characterization and enzyme activity staining. At least 100 (but up to 200) fibers co-existing on all 9 slides were numbered and analyzed as described earlier (18). Fibers were included if they were part of a cluster of at least 30 fibers and excluded if disturbing artefacts were present. All staining intensities were analyzed by the same person.

Table 1. Fiber type classification.

\begin{tabular}{|c|c|c|c|c|c|c|}
\hline pH 4.4 & $\begin{array}{c}\text { mATPase } \\
\text { pH } 10.4\end{array}$ & double & MyHC I & $\begin{array}{c}\text { MyHC } \\
\text { MyHC } \\
\text { IA }\end{array}$ & MyHC ILAX & $\begin{array}{l}\text { CMM fiber } \\
\text { type }\end{array}$ \\
\hline+ & - & - & + & $+/-$ & +1 & I \\
\hline$H+4$ & $+1 / t+$ & - & + & + & + & \multirow{2}{*}{ I/IIA } \\
\hline$+1++$ & +1 & - & + & + & + & \\
\hline 2 & +1 & - & $+/-$ & + & + & IIA \\
\hline$-1+$ & $+t$ & $+1++$ & - & + & + & IIA/IIX \\
\hline+ & ++ & $+1++$ & - & - & + & IIX \\
\hline++ & ++ & $+/ 4+$ & H & + & + & Misc \\
\hline$+/+t$ & $+w / 4+$ & - & + & - & + & Misc \\
\hline
\end{tabular}

Fibers were classified first on the basis of $\mathrm{mATPase}$ staining intensities $(-,+$ or ++$)$ and further classified by immunioreactivity $(-$ or +$)$. Based on these intensities the following CMM fiber type categories were made: type $\mathrm{I}, \mathrm{I} / \mathrm{II}, \mathrm{IIA}, \mathrm{IIA} / \mathrm{IIX}$, IIX and Misc (miscellaneous).

\section{Fiber type characterization}

The mATPase acidic pre-incubation was performed at $\mathrm{pH} 4.4$ (19) and the $\mathrm{mAT}$ Pase alkali preincubation was performed at $\mathrm{pH} 10.4(20)$. The double pre-incubation method was performed at $\mathrm{pH} 10.4$ and $\mathrm{pH} 4.6$ (21) with the only difference being that the fixation of sections was performed prior to the alkaline pre-incubation. After pre-incubation sections were stained and mounted (22). Panels a-c in figure 1 show examples of mATPase staining. Immunohistochemistry was performed with a panel of $\mathrm{mAbs}$, respectively anti-type I MyHC (mAb 219-1D1), anti-type IIA MyHC (mAb 333-7HI) and anti-types IIA + IIX MyHC (mAb 332-3D4) (23). Panels d-f in figure I show examples of MyllC staining. Fibers were assigned to categories first on the basis of three mATPase staining intensities $(-,+$ or ++$)$ and further classified by immunoreactivity $(-$ or +$)($ table 1$)$. The following combination of $\mathrm{MATPase}$ and MyHC (CMM) fiber type categories were made: type I, I/IIA, IIA, IIA/IIX, IIX and Misc (miscellaneous). 


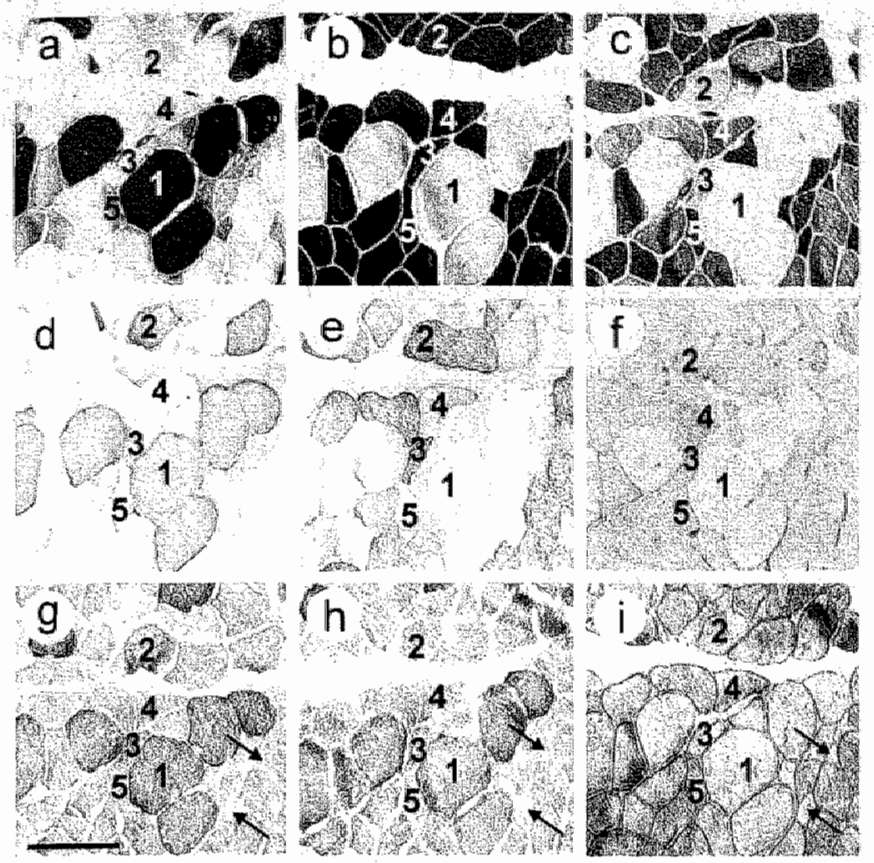

Figure 1. Example of listochemical andy sis in 9 consecutive cross-sections. Panels ato show mArPase staining with acido, alkaline and double pre-incubation respectively (positive fibers stain dark). Panels d-f show immunohistochemistry with anti-type I, anti-type IIA and anti-types IIA+IIX respectively (positive fibers stain dark). Fibers numbered $1-5$ are assigned to the $\mathrm{I},\|/ 1 \mathrm{~A},\| \mathrm{A}, \| \mathrm{IA} / \mathrm{LX}$ and $1 \mathrm{LX}$ CMM fiber type respectively (staining intensities are given in table 1). Panel g shows cytochrome $c$ oxidase activity staining (positive fibers are brown/dark). Panel th shows succinate dehydrogenase activity (positive fibers are blue/dark). Panel i shows glyoogen phosphorylase activity (positive fibers are purple/dark and negative fibers yellow/light). Internal scale bar $=150 \mu \mathrm{m}$.

\section{Enzyme activity staining}

Cytochrome $c$ oxidase (COX) and succinate dehydrogenase (SDH) were stained as markers for oxidative energy metabolism and glycogen phosphorylase (GlyP) was stained as marker for glycolytic energy metabolism. COX staining was performed by incubating sections for one hour in a $50 \mathrm{mM}$ Tris/ $\mathrm{HCl}$ buffer ( $\mathrm{pH} 7.6$ ) containing $0.22 \mathrm{M}$ sucrose, $14 \mathrm{mM} \mathrm{3,3-}$ diaminobenzidine tetrahydrochloride, $80 \mu \mathrm{M}$ cytochrome $c$ and $1300 \mathrm{U}$ catalase. Sites of COX activity are colored brown (24). SDH staining was performed by incubating sections for one hour at $37^{\circ} \mathrm{C}$ in a $0.2 \mathrm{M}$ sodium phosphate buffer containing $0.1 \mathrm{M}$ succinic acid and $1.2 \mathrm{mM}$ nitre blue tetrazolium. Sites of SDH activity are coloured blue (25). GlyP staining was performed by incubating sections for 5 minutes in a $43 \mathrm{mM}$ sodium acetate buffer (pH 5.6 ) containing $7 \mathrm{mM}$ glucose-1-phosphate, $1 \mathrm{mM} \mathrm{AMP}, 0.01 \%$ glycogen and $15 \%$ ethanol (25), after which the newly formed polysaccharide was coloured blue with Lugol's iodine. COX and SDH cross-sections were dehydrated in an ethanol range and mounted in Entallan*. GlyP sections were mounted in aqueous glycerin/gelatine that has been coloured with Lugol's iodine. Within each section, three staining intensities were decided reflecting fiber enzyme activity: positive $(+)$, negative $(-)$ or intermediate $( \pm)$; for example, a fiber positive for COX, intermediate for SDH and negative for GlyP would be $\mathrm{COX}+, \mathrm{SDH} \pm$ and GlyP-. Panels $\mathrm{g}-\mathrm{i}$ in figure 1 show examples of enzyme activity staining.

\section{Statistical analysis}

Values are reported as mean \pm standard deviation (SD) and error bars in figures reflect standard error of the mean. Intergroup data were compared using an unpaired Student's t-test (corrected for unequal variances if appropriate) or one-way ANOVA (with unpaired Student's t-test as 
post hoc test). Potential relationships between variables of interest were evaluated using the Pearson correlation test or a partial corretation to correct for age. Data were analyzed according to the guidelines of Altrian et al. (26), using SPSS (Statistical Package for the Social Sciences, version 8.0 for Windows, SPSS Inc., Chicago, IL, U.S.A.). A two-tailed probability value of less than 0.05 was considered statistically significant.

Table 2. Subject characteristics and lung function data

\begin{tabular}{|c|c|c|c|c|}
\hline & Controls & COPD & EMPH- & EMPH+ \\
\hline N (Female/Male) & $15(2 / 13)$ & $15(3 / 12)$ & $7(3 / 4)$ & $8(0 / 8)$ \\
\hline Age $(y r)$ & $64 \pm 3$ & $67 \pm 9$ & $64 \pm 12$ & $69 \pm 4$ \\
\hline BMI $\left(\mathrm{kg} / \mathrm{m}^{2}\right)$ & $26.7 \pm 3.0$ & $23.9 \pm 4.0^{\circ}$ & $25.3 \pm 2.8$ & $22.6 \pm 4.4$ \\
\hline $\mathrm{FEV}_{1}(\%$ pred $)$ & $108 \pm 18$ & $42 \pm 14^{0 * 0 *}$ & $57 \pm 15$ & $32 \pm 7^{34}$ \\
\hline $\mathrm{PaO}_{3}(\mathrm{kPa})$ & $11.8 \pm 1.7$ & $9.9 \pm 1.2^{\circ}$ & \pm 1.2 & $9.2 \pm 0.8$ \\
\hline $\mathrm{DL}_{\text {co }}(\%$ pred $)$ & $121 \pm 23$ & $63 \pm 24^{n * * x}$ & $84 \pm 14$ & $43 \pm 8^{\text {Hthith }}$ \\
\hline RV (\% pred) & $114 \pm 15$ & $167 \pm 32^{\circ 08}$ & \pm 22 & $178 \pm 39$ \\
\hline ITGV (\% pred) & $107 \pm 18$ & $\pm 22^{* 4 *}$ & \pm 15 & $156 \pm 22^{4}$ \\
\hline
\end{tabular}

Values are mean \pm SD; Significance of difference compared to controls: * $p<0.05 ; * * * 00.01 ; * * * p<0.001$;

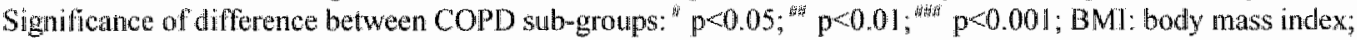
$\mathrm{DL}_{t, 2}$ diffusion capacity for carbon monoxide; $\mathrm{FEV}_{4}$ : forced expiratory volume in one second; $\mathrm{RV}$ : residual volume; ITGV:intrathoracic gas volume.

\section{RESULTS}

Fifteen COPD patients ( 12 males and 3 females) and fifteen healthy controls ( 13 males and 2 females) participated in this study (table 2). There were no differences in gender or age between the groups. The $\mathrm{BMI}, \mathrm{PaO}_{2}, \mathrm{FEV}$ and the $\mathrm{DL} \mathrm{Co}_{\mathrm{O}}$ were significantly lower, whereas the RV and the ITGV were higher in patients than in controls. Eight patients (with HRCT scores 230 ) were assigned to the emplyysema (EMPH - ) and 7 patients (with HRCT scores $<30$ ) to the non-emphysema (EMPH-) subgroup. The $\mathrm{PaO}_{2}, \mathrm{FEV}_{1}$ and the $\mathrm{DL}(\mathrm{co}$ were lower and the RV and the ITGV were higher for the EMPH+ than for the EMPH- COPD subtype.

A typical example of histochemical results is shown in figure 1. First we interpreted our data as if they were based only on mATPase staining (figure 2A). The proportion of mATPase type I fibers was lower $(19 \%, v s .43 \%, \mathrm{p}<0.001)$ and the proportion of mATPase type IIX fibers was higher $(46 \%$ vs. $27 \%, \mathrm{p}=0.004)$ in the COPD group compared to controls. There was no difference in the percentage of $\mathrm{MATPase}$ type IIA fibers. By combining the three mATPase pre-incubation protocols with immunohistochemistry five fiber type categories were made (table 1): CMM type I, IIA, IIX, I/IIA and IIA/IIX fibers, the latter two representing hybrid fibers. 


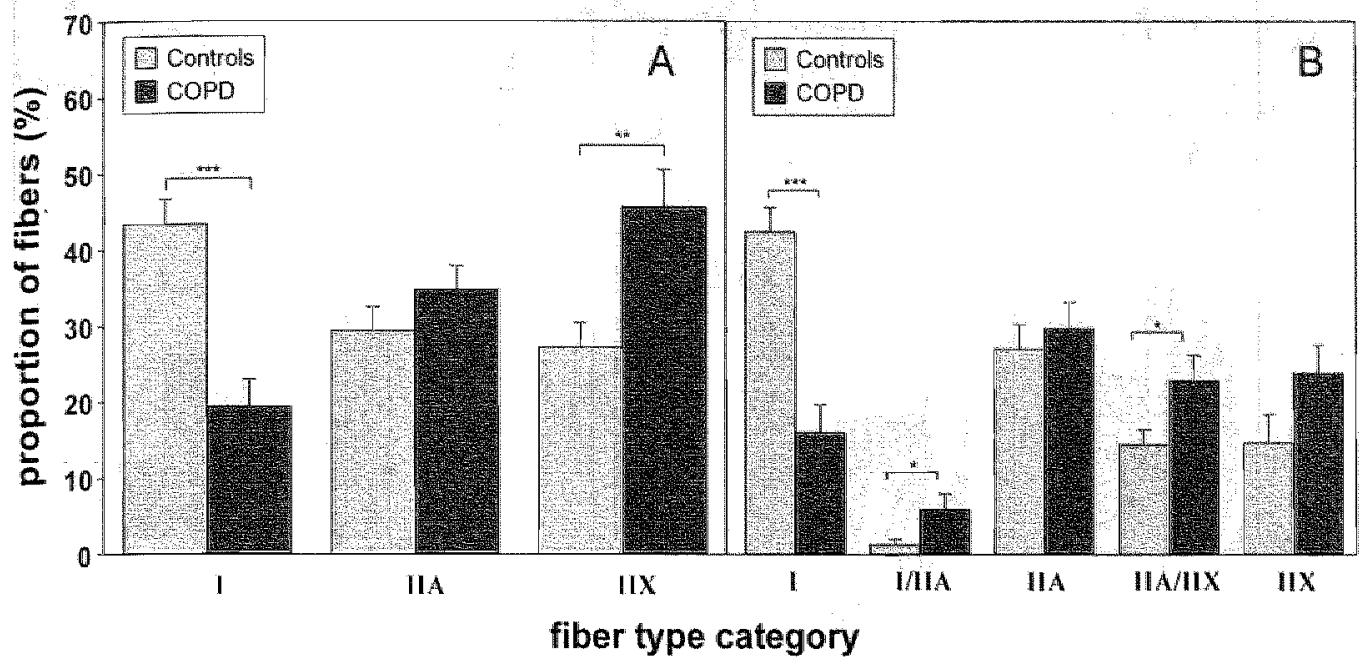

Figure 2. mATPase (A) and CMM (B) fiber type distribution in the vastus lateralis. Significance of difference between the groups: * $p<0.05, * 0<0.01, * * 0<0.001$.

Fiber type distribution was subsequently re-established with this more accurate method (figure $2 B)$. Again, the proportion of type I fibers was lower ( $16.1 \%$ vs. $42.4 \%, p<0.001)$ and the percentage of IIX fibers tended to be higher $(23.8 \% v s .14 .7 \%, \mathrm{p}=0.088)$ in COPD than in controls. In addition, the proportion of hybrid fibers V/TIA $(5.9 \%$ vs. $1.3 \%, \mathrm{p}=0.044)$, IIA/IIX (22.9\% vs. 14.4\%, $\mathrm{p}=0.041)$, and total (I/IA +IIA/IIX) $(28.8 \%$ vs. $15.7 \%, \mathrm{p}=0.008)$ was higher in COPD compared the healthy subjects. Fibers that did not fit in one of the above mentioned categories were assigned to the miscellaneous group. Although the percentage of these fibers was also higher in COPD than in controls $(1.6 \%$ vs. $0.2 \%, \mathrm{p}=0.017)$, their overall contribution to fiber type composition is neglectable. There was no difference in the percentage of type IIA fibers between both groups.

Figure 3 shows the results of enzyme activity staining of COX + , SDH + and GlyP + . Overall,

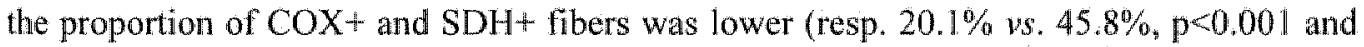
$14.2 \%$ vs. $36.3 \%, \mathrm{p}<0.001$, whereas the proportion of $\mathrm{COX}$ - and $\mathrm{SDH}$. fibers was higher (resp. $35.3 \%$ vs. $23.8 \%, \mathrm{p}=0.003$ and $47.9 \%$ vs. $25.0 \%, \mathrm{p}<0.001$, not shown) in COPD than in the control group. The percentage of COX \pm (intermediate) fibers was also higher in COPD than in controls $(44.6 \%$ vs. $30.3 \%, \mathrm{p}=0.002$, not shown). There were no differences in the proportion of GlyP+, GlyP-, GlyP \pm and SDH \pm fibers between patients and controls. The proportion of Gly $\mathrm{P}+$ fibers in patients not treated with glucocorticosteroids $(45.8 \%)$ was higher than in controls $(34.2 \%, \mathrm{p}=0.045)$ and also higher than in patients who did receive glucocorticosteroids $(29.2 \%, \mathrm{p}=0.017)$. 


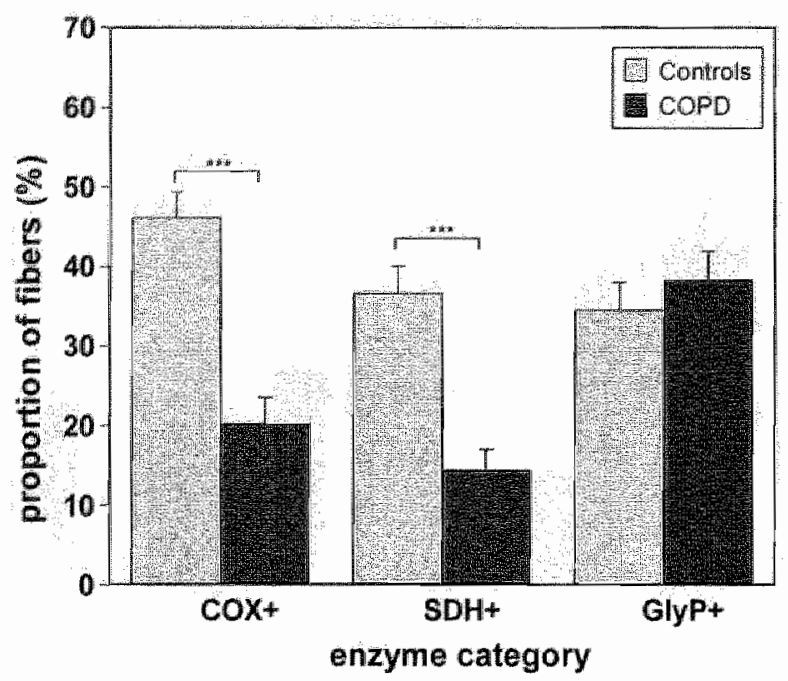

Figure 3. Enzyme activiry staining in the vastus lateralis. Significatice of difference between the groups: $p^{\circ}<0.01$; $p<0.001$.

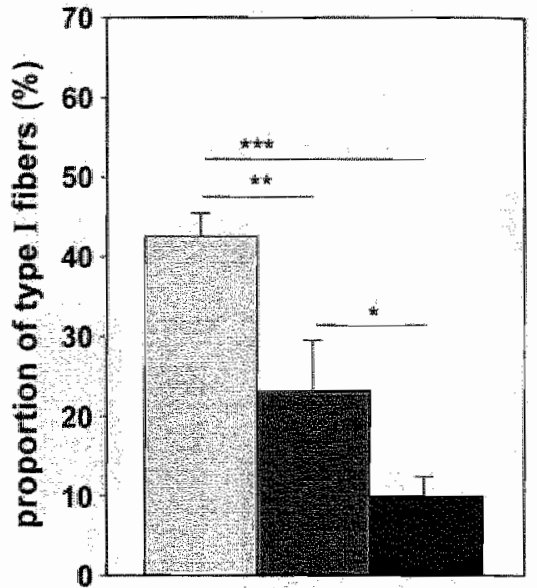

Controls EMPH- EMPH+

Figure 4. CMM fiber type I proportion in COPD subgroups. Significance of difference between the groups: * $\mathrm{p}<0.05, * * \mathrm{p}<0.01$.

Tabel 3. Proportions of COX+ and SDH+ fibers within CMM fiber type categories.

\begin{tabular}{lcccc}
\hline & \multicolumn{2}{c}{ COX + fibers $(\%)$} & \multicolumn{2}{c}{ SDH+ fibers $(\%)$} \\
\hline fiber type & Controls & COPD & Controls & COPD \\
I & 87.8 & 82.7 & 81.4 & 76.8 \\
I/IA & 73.3 & $33.3^{*}$ & 56.0 & $19.9^{*}$ \\
IIA & 34.1 & $7.8^{* *}$ & 10.2 & $1.6^{*}$ \\
IIA/IIX & 2.5 & 2.4 & 0.7 & 1 \\
IIX & 0 & 0.4 & 0 & 0.1 \\
\hline
\end{tabular}

Proportions of COX+ and SDH fibers within CMM fiber type categories. Significance of difference compared to controls: * $p<0.05$; ${ }^{*}$ 吸 $p<0.01$.

Since enzyme activity staining and fiber type characterization were performed on serial crosssections, enzyme activity could be evaluated within fiber type categories. In the CMM fiber type categories I/IIA and IIA COPD patients had a lower proportion of fibers positive for the oxidative enzymes, as shown for COX+ and SDH+ (table 3). In CMM fiber type I/IIA the proportion of COX土 fibers was higher for patients (not shown).

Within COPD there was a more pronounced decrease in the percentage of CMM type I fibers in EMPH+ than in EMPH- $(10.0 \%$ w. $23.1 \%, \mathrm{p}=0.045)$ compared to controls (figure 4$)$. In each group even one patient was found who had no CMM type I fibers at all. No differences between the two subtypes were observed with respect to enzyme activity staining.

Strong relationships were found for COPD between the proportion of CMM type I and the proportions of $\mathrm{COX}+(\mathrm{r}=0.77, \mathrm{p}=0.001)$ and $\mathrm{SDH}+(\mathrm{r}=0.84, \mathrm{p}<0.001)$ fibers (figure 5$)$. We also 
observed a positive relationship between age and the percentage of type I fiters in the healthy controls $(r=0.61 ; \mathrm{p}=0.015)$. This relation was also present in the EMPH- COPD subtype, although this did not reach statistical significance $(r=0.73 ; p=0.061)$. This relation was absent in $\mathrm{EMPH}+(\mathrm{r}=0.49 ; \mathrm{p}=0.290)$. No correlations were found between fiber type proportions and lung function data. The proportion of $\mathrm{COX}+$ fibers positively correlated with the $\mathrm{PaO}_{3}(\mathrm{r}=0.60$, $\mathrm{p}=0.019)$.

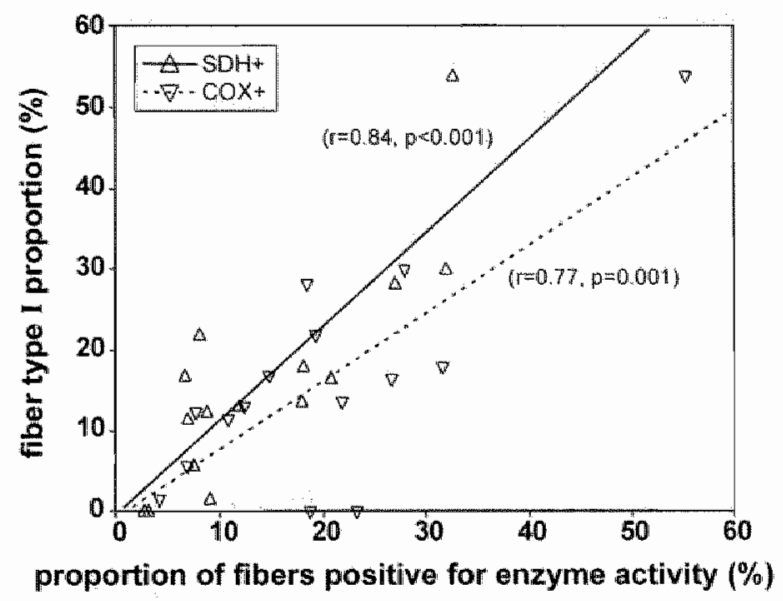

Figure 5. Relation between CMM fiber type 1 proportion and oxidative capacity in COPD patients.

\section{DISCUSSION}

This study strongly suggests that the I to IIX fiber type redistribution in the vastus lateralis of COPD patients occurs through gradual shifts in intracellular MyHC isoform content. Accordingly, the proportions of fibers with high activities of enzymes involved in oxidative energy metabolism are reduced in patients. These proportions are closely related to the type $\mathrm{I}$ fibers proportion, but even within IIA fibers oxidative capacity is reduced in COPD. There were no differences in glycolytic capacity between patients and controls. Furthermore, for the first time we show that the low fiber type I proportion is aggravated in patients with emphysema compared to COPD patients without emphysema.

In the present study we identified individual fibers on the basis of a combination of three different mATPase staining techniques and immunohistochemistry. By doing this we were able to distinguish very accurately type I, IIA and IIX fibers, but also I/IIA and IIA/IIX hybrid fibers. Hybrid fibers contain multiple $\mathrm{MyHC}$ isoforms, which can co-exist in any ratio. In the present study, fibers were identified as being hybrid only if this was indicated by mATPase staining and immunohistochemistry. The higher percentage of hybrid fibers in COPD strongly suggests that gradual transformation of one fiber type into another takes place: I $-\|/\| I A \rightarrow I I A$ $-\mathrm{IIA} / \mathrm{IIX} \rightarrow \mathrm{IIX}$. 
Unlike the MATPase type IIX fiber type proportion, the difference in CMM fiber type IIX proportion between COPD patients and controls did not reach statistical significance. This can be explained by the fact that part of the mATPase IIX fibers are now assigned to the hybrid IIA/IIX fiber type category. Compared to healthy subjects, a reduced proportion of $\mathrm{mA}$ TPase type I fibers and an increased percentage of MATPase type II (IIA and/or IXX) have also been reported previously in COPD (4-6). However, large variations in fiber type distribution exist between these studies. Differences in disease severity and study populations may explain in part these differences, but the large diversity in applied histochemical techniques is most likely also a contributing factor. In addition, hybrid fibers were formerly not detected often and therefore missclassified. For example, hybrid V/IIA fibers stain intermediate for mATPase activity after pre-incubation at $\mathrm{pH} 4.4$ and will be identified as IIX fibers.

In our study, the proportions of COX+ and SDH+ fibers are reduced in the COPD group compared to controls, while the percentages of $\mathrm{COX}$ - and SDH- fibers are increased. Although we are aware of the fact that enzyme activity staining is a semi-quantitative method, it provides useful information with respect to localization. Accordingly, in muscle biopsy specimens reduced activities of the mitochondrial enzymes citrate synthase, SDH and $\beta$-hydroxyacyl-CoA dehydrogenase have been reported in $\operatorname{COPD}(7,8)$. The present data are not consistent with the outcome of the study performed by Sauleda et al. (9). They found an increased COX activity and a negative correlation between $\mathrm{COX}$ activity and the $\mathrm{PaO}_{2}$ for $\mathrm{COPD}$ patients. Since $\mathrm{COX}$ is involved in oxidative phosphorylation and it is the final enzyme of the respiratory chain interacting with oxygen, we previously suggested that its increased activity may therefore enhance the efficiency of residual oxygen extraction as an adaptation to hypoxia (3). In contrast, we observed a decrease in the percentage of $\mathrm{COX}+$ fibers and a positive correlation between the proportion of $\mathrm{COX}+$ fibers and the $\mathrm{PaO}_{2}$. Various explanations can be offered for the discrepancy between our data and those published earlier (9). First, a point of consideration is the fact that the mean $\mathrm{PaO}_{2}$ in our patient group was not as low as the $\mathrm{PaO}_{2}$ found by Sauleda et al. ( $9.9 \mathrm{kPa}$ vs $8.3 \mathrm{kPa}$ respectively). If hypoxia could upregulate COX activity this would imply that the COX activity in our patient group is lower than the COX activity in Sauleda's COPD group, which would explain part of the discrepancy. Second, one could also argue that despite the reduced proportion of COX + fibers, overall COX activity is elevated due to the observed increased proportion of $\mathrm{COX} \pm$ tibers in patients. However, overall staining intensity for $\mathrm{COX}$ was certainly not higher in COPD sections compared to controls. In addition, there was no relationship between the proportion of COX 1 fibers and the $\mathrm{PaO}_{2}$. More research is necessary to clarify the behavior of COX in skeletal muscle of COPD. One study deseribed increased glycolytic enzyme activity - phosphofructokinase (PFK) - in the vastus lateralis of COPD patients (8). In addition, increased PFK activity has been reported for lung transplantant recipients compared to controls, although GlyP activity was found to be unchanged (27). We did not find an increased percentage of Gly + + fibers either. An explanation for the unchanged Gly $\mathrm{P}+$ fiber proportion in the present study is that 7 from the 15 COPD patients received low doses of oral glucocorticosteroids. The proportion of GlyP+ fibers in patients not receiving corticosteroids was higher than in controls, suggesting that corticosteroids adversely affect GlyP activity. However, patients frequently suffering from exacerbations are more likely to receive corticosteroids and therefore systemic inflammation may be involved as well. The effect of glucocorticosteroids on glycolytic metabolism needs to be further ellucidated. 
In the COPD patients in this study the proportions of fibers that stained positive for COX and SDH declined in the same order of magnitude as the percentage of type Ifibers. In fact, the majority of the COX+ and SDH+ fibers were classified as type I fibers, which is underscored by the strong correlations between their proportions. Thus overall, the relative loss of type I fibers and the loss of oxidative enzyme activity are indeed linked. It has never been established before that the decline in both percentages of fiber type $I$ and the activity of enzymes involved in oxidative energy metabolism in COPD are linked. Since enzyme activity staining and fiber type classification in this study were performed on serial cross-sections it was not only possible to examine the relation between the fiber type redistribution and enzyme activity, but also enzyme activities within the fiber type categories. The proportions of COX+ and SDH+ fibers within each of the individual CMM fiber types I/IIA and ILA are significantly lower for COPD compared to controls (table 3 ). In addition, the proportion of $\mathrm{COX} \pm$ fibers was higher in $\mathrm{CMM}$ type IIA fibers of patients. It is therefore feasible that $\mathrm{COX}+$ fibers transformed into $\mathrm{COX} \pm$ fibers. It is possible that this extra loss of oxidative capacity is specific for type lliA fibers. Another possibility is that the loss of oxidative enzyme activity occurs in an early stage of fiber type transition. It is feasible that as a result of the disease (ie hypoxia) oxidative energy metabolism is disturbed and that the activities of the enzymes involved are reduced. Type I and also IIA fibers strongly depend on aerobic metabolism, whereas in type IIX fibers energy conversion is based mainly on anaerobic, glycolytic metabolism. It is therefore tempting to state that in type I fibers the co-expression of the MyHC IIA isoform and that in type IIA fibers the co-expression of the MyHC IIX isoform is an adaptation to impaired oxidative energy metabolism. Alternatively, it is possible that either the reduced oxidative capacity is secondary to the changes in $\mathrm{MyHC}$ isoform contents or that one or more common factors affect both oxidative capacity and $\mathrm{MyHC}$ isoform contents simultaneously.

The present results indicate that the low fiber type I proportion in COPD is more pronounced in emphysema patients (stratified by HRCT) compared to non-emphysema patients. Like others we found a positive relation between fiber type I proportion and age in healthy subjects (28-30). Due to the relative loss of type I fibers this relation is disturbed in COPD patients, being totally absent in the emphysema group. The proportion of $\mathrm{COX}$ thibers was also lower in EMPH+, but not statistically significant. A positive correlation between the $\mathrm{PaO}_{2}$ and the percentage of type I fibers has been reported previously $(5,6)$. In addition, a positive relation between the MyHC I content and the $\mathrm{DL}_{\mathrm{CO}}$ and the FEV, has been shown $(10,11)$. However, in the present study we did not observe these relations between fiber type proportions and lung function data, suggesting that fiber type I proportion is not related to disease severity per sé. COPD patients with a $\mathrm{DL}_{C \infty}$ below $55 \%$ of predicted are likely to desaturate during exercise (31). Since the $\mathrm{DL}_{c o}$ is lower in the emphysema patients it can be speculated that chronic and especially intermittent hypoxia is directly or indirectly involved in causing the lower fiber type I proportion compared to non-emphysema patients. This issue requires further investigation.

At this point, it is incompletely understood which factors are causing the muscular abnormalities in COPD. Hypoxia has already been discussed above. Oxidative stress, on the other hand, may also play a role in the loss mitochondrial enzyme activity and relative loss of type I fibers, since it has been demonstrated that mitochondrial proteins are highly susceptible to oxidative damage (32). The possible role of malnutrition is demonstrated by animal studies 
in which nutritionall deprivation caused depressed muscular mitochondrial capacity (33-35). Physical inactivity or disuse of limb muscles are potential contributors to the observed fiber type shift (36). However, we previously observed no difference between the daily physical activity levels of EMPH+ and EMPH- patients (37), while we now find differences in fiber type 1 proportions between these subgroups. In addition, none of our patients was bedridden and it is therefore unlikely that disuse alone caused the very low fiber type I proportions that we observed.

In summary, this study demonstrates the involvement of increased proportions of hybrid I/LIA and IIA/IIX fiber types in the fiber type shift from I to IIX in the vastus lateralis of COPD patients compared to controls. The abnormal fiber type I proportion is aggravated in emphysema patients. In addition, the percentages of fibers with high oxidative enzyme activities are also reduced in COPD patients, being closely linked to the reduced fiber type I proportion. Morever, despite comparable IIA fiber type proportions between patients and controls, oxidative capacity is reduced in this fiber type in patients. Further research should be carried out to identify the factors involved and the mechanisms underlying the muscular alterations in order to evaluate available and to develop new treatment approaches.

\section{ACKNOWLEDGMENTS}

The authors kindly thank Prof. A.F.M. Moorman for providing the antibodies against MyHC isoforms I, IIA and IIA+ IIX. 


\section{REFERENCES}

1. Schols AM, Mostert R, Soeters PB, Wouters EF. Body composition and exercise performance in patients with chronic obstructive pulmonary disease. Thorax $1991,46,695-9$.

2. Cotes $\mathrm{JE}$, Zejda $\mathrm{J}$, King $\mathrm{B}$. Lung function impaiment as a guide to exercise limitation in workrelated lung disorders. Am Rev Respir Dis 1988;137:1089-93.

3. Gosker HR, Wouters EF, van der Vusse GJ, Schols AM. Skelletal muscle dysfunction in chronic obstructive pulmonary disease and chronic heart failure: undellying mechanisms and therapy perspectives. Am J Clin Nutr 2000;71:1033-47.

4. Whittom F, Jobin $\int$, Simard PM, et al. Histochemical and morphological characteristics of the vastus lateralis muscle in patients with chronic obstructive pulmonary disease. Med Sci Sports Exerc 1998;30:1467-1474.

5. Jakobsson $\mathrm{P}$, Jorfeldt L, Brundin A. Skeletal muscle metabolites and fibre types in patients with advanced chronic obstructive pulmonary disease (COPD), with and without chronic respiratory failure. Eur Respir J 1990;3:192-6.

6. Hildebrand IL, Sylvẻn C, Esbjörnsson M, Hellström K, Jansson E. Does chronic hypoxaemia induce transformations of fibre types? Acta Physiol Scand 1991;141:435-9.

7. Maltais F, Simard AA, Simard C, Jobin J, Desgagnes P, LeBlanc P. Oxidative capacity of the skeletal muscle and lactic acid kinetics during exercise in normal subjects and in patients with COPD. Am J Respir Crit Care Med 1996;153:288-93.

8. Jakobsson P, Jorfeldt L, Henriksson J, Metabolic enzyme activity in the quadriceps femoris muscle in patients with severe chronic obstructive pulmonary disease. Am II Respir Crit Care Med 1995;151:374-7.

9. Sauleda J, Garcia-Palmer F, Wiesner RI, et al. Cytochrome oxidase activity and mitochondrial gene expression in skeletal muscle of patients with chronic obstructive pulmonary disease. Am 『Respir Crit Care Med 1998;157:1413-1417.

10. Satta A, Migliori GB, Spanevello A, et al. Fibre types in skeletal muscles of chronic obstructive pulmonary disease patients related to respiratory function and exercise tolerance. Eur Respir J $\rrbracket 997 ; 10: 2853-2860$.

11. Maltais F, Sullivan MJ, LeBlanc $P$, et al. Altered expression of myosin heavy chain in the vastus lateralis muscle in patients with COPD. Eur Respir J 1999;13:850-4.

12. ATS. Standards for the diagnosis and care of patients with chronic obstructive pulmonary disease (COPD) and asthma. Am Rev Respir Dis 1987;136:225 44.

13. Quanjer P, Tammeling GJ, Cotes JE, Pedersen OF, Peslin R, Yornault JC. Standardized lung function testing. Eur Respir J 1993;6:5-40.

14. ATS: Chronic bronchitis, asthma, and pulmonary emphysema by the conmittee on diagnostic standards for nontubercolosis respiratory disease. Am Rev Respir Dis 1962;85:762-812.

15. Lamers RJ, Thelissen GR, Kessels AG, Wouters EF, van Engelshoven JM. Chronic obstructive pulmonary disease: evaluation with spirometrically controlled CT lung densitometry. Radiology 1994:193:109-13.

16. Sakai F, Gamu G, Im JG, Ray CS. Pulmonary function abnormalities in patients with CTdetermined emplyysema. I Comput Assist Tomogr 1987;11:963-968.

17. Bergstrom L. Muscle electrolytes in man. Determination by neutron activation analysis on needle biopsy specimens. A study on normal subjects, kidney patients, and patients with chronic diarrhea. Scand IClin Lab Invest 1962;68:1-1 110.

18. Dammeijer PF, van Mameren $H$, van Dijk P, et al. Stapedius muscle fibre composition in the rat. Hear Res 2000; 141:169-79.

19. Ogilvie RW, Feeback DL. A metachromatic dye-ATPase method for the simultaneous identification of skeletal muscle fiber types I, IIA, IIB and IIC. Stain Technol 1990;65:231-41. 
20. Guth L, Samalla FI. Procedure for the histochemical demonstration of actomyosin ATPase. Exp Neurol $1970 ; 28: 365-7$.

21. Sant Ana Pereira IA. Ennion S, Sargeant AJ, et al. Comparison of the molecular, antigenic and ATPase determinamts of fast myosin heavy chains in rat and hunan: a single-fibre study. Pflugers Arch 1997;435:151-63.

22. Brooke MH, Kaiser KK. Muscle fiber types: how many and what kind? Arch Neurol $1970,23,369-79$.

23. Sant'Ana Pereira JA, Wessels A, Nijtmans L, Mooman AF, Sargeant AJ. New method for the accurate characterization of single human skeletal muscle fibres demonstrates a relation between mATPase and MyHC expression in pure and hybrid fibre types. J Muscle Res Cell Motil $1995 ; 16: 21-34$.

24. Pearse AG. Histochemistry: Theoretical and applied. 3 ed. Edinburgh: Churchill Livingstone, 1972.

25. Sheehan DC, Hrapchak BB. Theory and practice of histotechnology. 2 ed. Columbus: Battelle Memorial Institute, 1987.

26. Altman DG, Gore SM, Gardner MJ, Pocock SJ. Statistical guidelines for contributors to medical journals. Br Med J Clin Res Ed 1983;286:1489-93.

27. Wang XN, Williams TJ, McKerna MJ, et al. Skeletal muscle oxidative capacity, fiber type, and metabolites after lung transplantation. Am I Respir Crit Care Med 1999;160:57-63.

28. Larsson $\mathrm{L}$, Grimby $\mathrm{G}$, Karlsson J. Muscle strength and speed of movement in relation to age and muscle morphology. J Appl Physiol 1979;46:451-6.

29. Klitgaard H, Mantoni M, Schiaffino S, et al. Function, morphology and protein expression of ageing skeletal muscle: a cross-sectional study of elderly men with different training backgrounds. Acta Physiol Scand 1990;140:41-54.

30. Poggi P, Marchetti C, Scelsi R. Automatio morphometric analysis of skeletal muscle fibers in the aging man. Anat Rec 1987;217:30-4.

31. Owens GR, Rogers RM, Pennock BE, Levin D. The diffusing capacity as a predictor of arterial oxygen desaturation during exercise in patients with chronic obstructive pulmonary disease. $\mathrm{N}$ Engl J Med 1984;310:1218-21.

32. Haycock JW, Jones $\mathbb{P}$, Hartis JB, Mantle D. Differential susceptibility of human skeletal muscle proteins to free radical induced oxidative damage: a histochemical, immunocytochemical and electron microscopical study in vitro. Acta Neuropathol (Berl) 1996;92:331-40.

33. Sieck GC, Lewis MI, Blanco CE. Effects of undermutrition on diaphragm fiber size, SDH activity, and fatigue resistance. J Appl Physiol 1989;66:2196-205.

34. Russell DM, Atwood HL, Whittaker JS, et al. The effect of fasting and hypocaloric diets on the functional and netabolic characteristics of rat gastrocnemius muselle. Clin Sci 1984;67:185-94.

35. Madapallimattam A, Law $L$, Jeejeebhoy $K$. Effect of hypocaloric feeding on mitochondrial respiratory chain activity (abstract). Clinical Nutrition 2000;19:23.

36. Burnham R, Martin T, Stein R, Bell G, MacLean I, Steadward R. Skeletal muscle fibre type transformation following spinal cord injury, Spinal Cord 1997;35:86-91.

37. Engelen MPK.I, Schols AMW J, Does ID, H.R. G, Deutz NEP, Wouters EFM. Exercise induced lactate increase in relation to muscle substrates in patients with COPD. Am J Respir Crit Care Med 2000:162:1697-1704. 


\title{
CHAPTER 6
}

\section{Muscle fiber type IIX atrophy is involved in the loss of fat-free mass in chronic obstructive pulmonary disease}

\begin{abstract}
Although the loss of peripheral muscle mass has convincingly been demonstrated in COPD, the underlying pathogenesis remains unclear. The aim of the present study was to determine relations between skeletal muscle fiber types, fiber cross sectional area (CSA), enzyme activities and fat-free mass (FFM) in COPD patients and controls. In 15 COPD patients and 15 healthy age-matched controls FFM was assessed by dualenergy $\mathrm{X}$-ray absorptiometry and bioelectrical impedance analysis. In biopsies from the vastus lateralis fiber types, CSA, and activities of cytochrome $c$ oxidase (COX), succinate dehydrogenase (SDH) and glycogen phosphorylase (GlyP) were examined (immuno)histochemically. FFM (49 kg vs. $59 \mathrm{~kg}, \mathrm{p}=0.003$ ) and mean fiber CSA (3839 $\mu \mathrm{m}^{2}$ vs. $4647 \mu \mathrm{m}^{2}, \mathrm{p}=0.037$ ) were lower in COPD than in controls. A strong correlation was observed between the FFM measured by bioelectrical impedance analysis and mean fiber CSA $(r=0.87, p<0.001)$ in COPD. Within fiber type categories only the mean CSA of IIA/IIX and IIX fiber types were lower in patients than in controls (3358 $\mu \mathrm{m}^{2}$ vs. $4427 \mu \mathrm{m}^{2}, \mathrm{p}=0.022$ and $2566 \mu \mathrm{m}^{2}$ vs. $4248 \mu \mathrm{m}^{2}, \mathrm{p}=0.003$ respectively). In COPD, $20 \%$ of the type IIX fibers lacked stainable activities of COX, SDH and GlyP and this proportion negatively correlated with the IIX CSA $(r=-0.65, p=0.012)$. In conclusion, muscle fiber atrophy occurs in the vastus lateralis of COPD patients and contributes to the loss of muscle mass in COPD. Atroply is specific to IIA/ILX and IIX fiber types and is associated with a disturbed metabolic capacity.
\end{abstract}

Harry R. Gosker', Mariëlle P.K.J. Engelen', Henk van Mameren², Paul J, van Dijk', Ger J. van der Vusse ${ }^{3}$, Emiel F.M. Wouters", Annemie M.W.J. Schols'. Departments of 'Respiratory Medicine, ${ }^{2}$ Anatomy \& Embryology, ${ }^{3}$ Physiology, University of Maastricht, The Netherlands. American Journal of Clinical Nutrition 2002; 76: 113-119 


\section{INTRODUCTION}

Skeletal muscle weakness is frequently observed in patients with chronic obstructive pulmonary disease (COPD) (1) and plays a pivotal role in exercise intolerance (2). Recently, we demonstrated that skeletal muscle weakness is associated with wasting of extremity fat-free mass (FFM), but not with airflow obstruction (3). It is therefore cruciall to examine the muscular abnormalities that are potentially involved in musele wasting.

Whole sketetal muscle crosis-sectional area (CSA) is $\approx 25 \%$ lower in COPD than in controls, which has been assessed by computed tomography (1). Muscle fiber atrophy can directly lead to a decrease in whole muscle CSA (assuming that the total amount of fibers is constant). However, information on muscle fiber dimensions in COPD is relatively scarce. A lower mean fiber CSA was found in 20 COPD patients than in 9 healthy control subjects (4). A similar result was found for 8 COPD patients with severe muscle weakness developed under treatment with corticosteroids (5). As an alternative to fiber CSA the fiber cross-sectional diameter has been assessed. With the use of this method, fiber atrophy was shown in emphysema patients with severe emaciation (6). In none of the mentioned studies relations between muscle mass or body composition and fiber CSA were reported, although muscle fiber atrophy may very well play a crucial role in the loss of FFM in COPD. Potential factors that may lead to muscle liber artophy are, amongst others, mallnutrition, physical inactivity and oral corticosteroids. Since these factors differently affect muscle cells with respect to type I and type II fibers (7-9), analyzing the CSA of individual fiber types may provide insight in the relative contribution of these factors. Furthermore, studying the metabolic profile of the muscle fibers will help to clarify the intracellular and subsequent functional consequences of atrophy.

The present study was designed to address the following questions: 1 ) is there a relation between FFM and fiber CSA, 2) do fiber type specific differences in fiber CSA exist between COPD patients and healthy controls, and 3) is energy metabolism capacity disturbed in the affected fibers. For this purpose, 15 COPD patients and 15 healthy control subjects were evaluated by means of body composition assessment and a needle biopsy of the vastus lateralis. Fiber lypes were identified (immuno) histochemically and their mean CSA was measured. In addition, fibers were stained for cytochrome $c$ oxidase (COX) and succinate dehydrogenase (SDH) activity as markers of oxidative energy metabolism and glycogen phosplorylase (GlyP) activity as a marker of glycolytic energy metabolism.

\section{MATERIALS AND METHODS}

\section{Study population}

A group of 15 patients with moderate to severe airflow obstruction and 15 healthy age-matched volunteers was studied. All patients had COPD according to ATS guidelines (10) and chronic airflow limitation, defined as measured forced expiratory volume in one second $\left(F E V_{\|}\right)$less than $70 \%$ of reference $\mathrm{FEV}$. Furthermore, patients had irreversible obstructive airway disease (less than $10 \%$ improvement in $\mathrm{FEV}_{1}$ predicted baseline after $\beta_{2}$-agonist inhalation). They were in clinically stable condition and not suffering from a respiratory tract infection or an exacerbation of their disease at least 4 weeks prior to the study. Oral corticosteroid usage and 
doses were retrieved from available hospital files and data from the referring physician. Doses were expressed as hydrocortisone equivalents per day. At the time of the biopsy 7 of the 15 COPD patients were on a maintenance dose of prednisolone (ranging from 5 to $10 \mathrm{mg} / \mathrm{day}$ ). Of the remaining 8 patients, 4 patients had received corticosteroids at sone time prior to the biopsy and 4 had never used corticosteroids. Exclusion criteria were malignancy, cardiac failure, distal arteriopathy, recent surgery, severe endocrine, hepatic or renal disorders and use of anticoagulant medication. Written informed consent was obtained from all subjects and the study was approved by the medical ethical committee of the University Hospital Maastricht (Maastricht, The Netherlands).

\section{Pulmonary function tests}

All patients and control subjects underwent spirometry to determine, amongst others, the forced expiratory volume in one second $\left(\mathrm{FEV}_{1}\right)$, with the highest value from at least three technically acceptable assessments being used. Residual volume (RV) and intrathoracic gas volume (ITGV) were assessed by whole-body plethysmography and diffusion capacity for carbon monoxide ( $\mathrm{DL}_{\mathrm{CO}}$ ) was measured with the single-breath method (Masterlab, Jaeger, Wurzburg, Germany). All values obtained were related to a reference value and expressed as a percentage of the predicted value (11).

\section{Assessment of body composition}

Body height was determined to the nearest $0.5 \mathrm{~cm}$ with subjects standing barefoot and body weight was assessed to the nearest $0.1 \mathrm{~kg}$ while subjects wore light clothing and no shoes. Whole-body FFM, which consists of lean mass and bone mineral mass, was determined by scanning each subject on a DPX bone densitometer (FFM $\mathrm{PIXA}_{\mathrm{XA}}$ ) (Lunar Radiation Corporation, Madison, WI) as done previously (12). FFM of patients was also determined using single-frequency $(50 \mathrm{kHz}$ ) bioelectrical impedance analysis (BIA) (Xitron Technologies Inc., San Diego, CA) while subjects were in a supine position. $\mathrm{FFM}_{\mathrm{BA}}$ was calculated using the disease-specific equation of Schols and coworkers (13). Weight parameters were divided by squared body height $\left(\mathrm{kg} / \mathrm{m}^{2}\right)$, resulting in the body mass index (BMI) and FFM index (FFMI), to adjust for body surface (14).

\section{Collection and processing blood and muscle tissue}

Arterial oxygen tension $\left(\mathrm{PaO}_{2}\right)$ was determined $(\mathrm{ABL}$ 330; Radiometer, Copenhagen, Denmark) in a blood sample obtained by puncture of the radial artery while breathing room air. Postabsorptive muscle biopsies of the lateral part of the quadriceps femoris were obtained under local anesthesia by the needle biopsy technique (15). Biopsies were placed in a drop of Tissue-tek ${ }^{\text {. }}$ (OCT compound) on a piece of cork with the fiber orientation perpendicular to the plane of the cork. The specimen was frozen in melting isopentane precooled in liquid nitrogen and stored at $-80^{\circ} \mathrm{C}$. Serial cryostat cross-sections $(10 \mu \mathrm{m})$ were made on a cryostat microtome at $-20^{\circ} \mathrm{C}$ and mounted on slides which were stored at $-35^{\circ} \mathrm{C}$ until analysis. For each biopsy sample, nine consecutive slides (each carrying two or three cross-sections) were used for fiber type characterization and enzyme activity staining. At least 100 (but up to 200) fibers coexisting on all 9 slides were numbered and analyzed as described earlier (16). Only fibers without artefacts were included which were part of a cluster of at least 30 fibers. 


\section{Fiber type, metabolic enzyme characterization and morphometry}

The mATPase acidic and alkaline pre-incubations were performed at $\mathrm{pH} 4.4(17)$ and $\mathrm{pH} 10.4$ (18), tespectively. Double pre-incubation was performed at $\mathrm{pH} 10.4$ and $\mathrm{pH} 4.6$ (19) with fixation of sections prior to the alkaline pre-incubation. After pre-incubation sections were stained and mounted (20). Panels a-c in figure 1 of chapter 5 show examples of mATPase staining. Immunohistochemistry was performed with a panel of mAbs, respectively anti-type I myosin heavy chain (MyHC) (mAb 219-1D1), anti-type IIA MyHC (mAb 333-7H1) and antitypes IIA + IX MyHC (mAb 332-3D4) (21). Panels d-f in figure I of chapter 5 represent examples of MyHC staining. Table I of chapter 5 shows how fibers were assigned to fiber type categories. For $\mathrm{COX}$ activity staining sections were incubated for one hour in a $50 \mathrm{mmol} / \mathrm{L}$

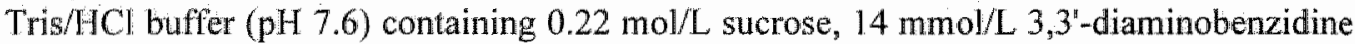
tetrahydrochloride, $80 \mu \mathrm{M}$ cytochrome $c$ and $1300 \mathrm{U}$ catalase (22). SDH activity staining was performed by incubating sections for one hour at $37^{\circ} \mathrm{C}$ in a $0.2 \mathrm{~mol} / \mathrm{L}$ sodium phosphate buffer containing $0.1 \mathrm{~mol} / \mathrm{L}$ succinic acid and $1.2 \mathrm{mmol} / \mathrm{L}$ nitro blue tetrazolium (23). GlyP staining was performed by incubating sections for 5 minutes in a $43 \mathrm{mmol} / \mathrm{L}$ sodium acetate buffer $(\mathrm{pH}$ 5.6) containing $7 \mathrm{mmol} / \mathrm{L}$ glucose- 1 -phosphate, $1 \mathrm{mmol} / \mathrm{L}$ AMP, $0.01 \%(\mathrm{w} / \mathrm{v})$ glycogen and $15 \%(\mathrm{v} / \mathrm{v})$ ethanol after which the newly formed polysaccharide was colored with Lugol's iodine (23). COX and SDH cross-sections were dehydrated in ethanol and mounted in

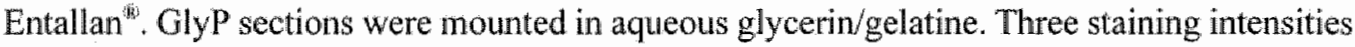
were decided reflecting fiber enzyme activity: positive $(+)$, negative $(-)$ or intermediate $( \pm)$. The panels $g-i$ in figure 1 of chapter 5 show examples of enzyme activity staining. Fibers lacking any stainable enzyme activity are refered to as $\mathrm{CSG}$ negative $(\mathrm{COX}, \mathrm{SDH}$, and GlyP negative) fibers. Fiber CSA was measured with an interactive image analysis system (Leica QWin Image Analysis System). The proportion of mini-fibers (MF's) is referred to as the percentage of fibers having a smaller CSA than the mean CSA of the control group minus twice the SD. To avoid the influence of comparing the CSA of different fiber types, the proportion of minifibers was first calculated within each fiber type category and was then recalculated as an overall percentage.

\section{Statistical analysis}

Data were analyzed with the unpaired Student's $t$ test (corrected for unequal variances if appropriate), 1-way ANOVA (with unpaired Student's $t$ test as post hoc test), or the Pearson correllation test, as appropriate (24). A two-tailed probability value of less than 0.05 was considered statistically significant.

\section{RESULTS}

As shown in table 1, there were no differences in sex or age between patients with COPD and control subjects. In patients $\mathrm{PaO}_{2}, \mathrm{FEV}_{1}$ and the $\mathrm{DL}_{\mathrm{CO}}$ were significantly lower, whereas the $\mathrm{RV}$ and the ITGV were higher than in controls. Both the FFMI $\mathrm{DPAA}_{\mathrm{A}}$ and $\mathrm{BMI}$ were significantly lower in COPD patients than in healthy controls. 
Table 1. Subject characteristics and lung function data

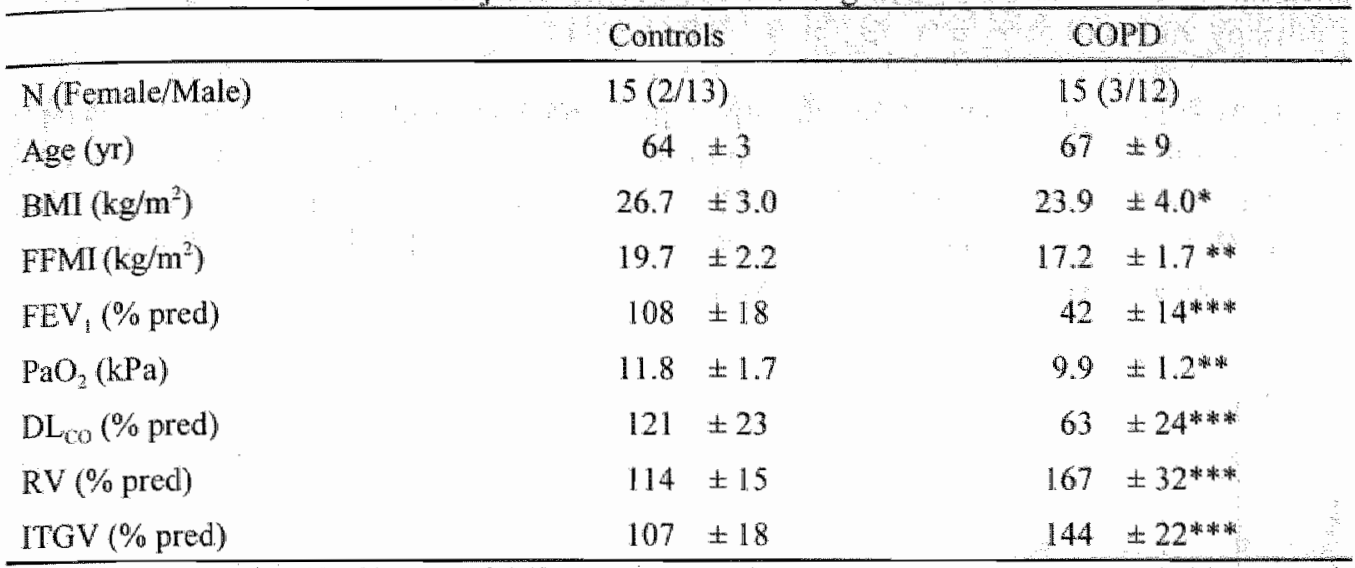

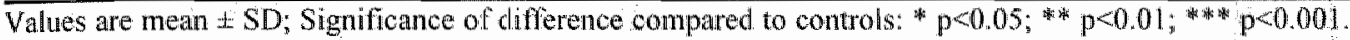
BMI: body mass index; FFMI: fat-free mass index; $D_{C L}$ : diffusion capacity for carbon monoxide; $F E V_{1}$; forced expiratory volume in one second; RV: residual volume; ITGV: intrathoracic gas volume.

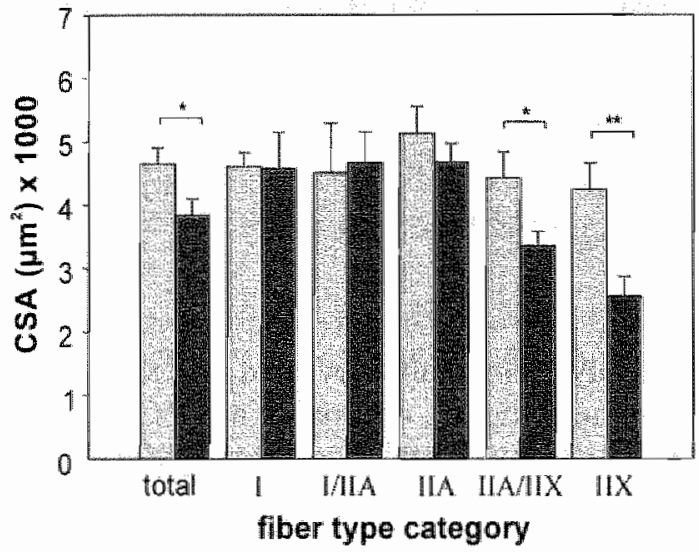

Figure 1. Overall and type-specific muscle fiber CSA. $=$ Controls; $=$ COPD. Mean values $\pm \mathbb{S E}$ are shown. Significance of difference between the groups: * p<0.05, ** p $<0.0 \%$

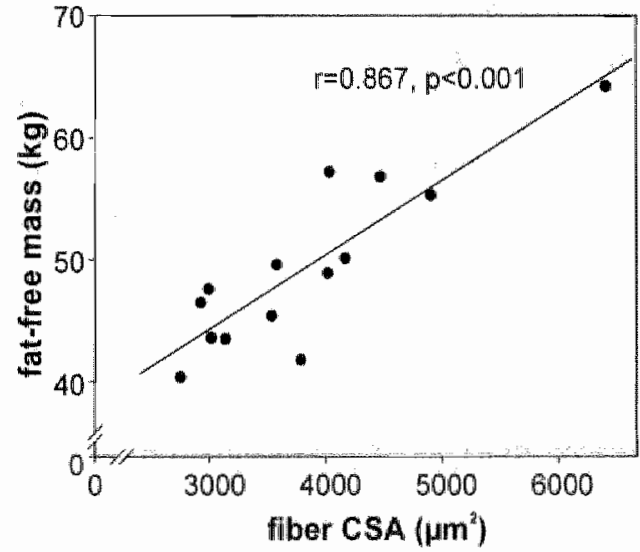

Figure 2. Relation between fiber CSA and fatfree mass in COPD.

A typical example of histochemical results is shown in figure 1 of chapter 5 . The mean fiber CSA of 12 controls and 14 patients are shown in figure I (for technical reasons the sections of 4 subjects were not suitable for morphometric analysis). In patients the overall mean fiber CSA was smaller than in the healthy control subjects $\left(3839 \mu \mathrm{m}^{2} v s .4647 \mu \mathrm{m}^{2}, \mathrm{p}=0.037\right)$. Within fiber type categories, mean CSA was smaller in the IIA/IIX $\left(3358 \mu \mathrm{m}^{2}\right.$ vs. $4428 \mu \mathrm{m}^{2}$, $\mathrm{p}=0.022)$ and IIX $\left(2566 \mu \mathrm{m}^{2}\right.$ vs. $\left.4248 \mu \mathrm{m}^{2}, \mathrm{p}=0.003\right)$ fiber type categories of patients compared to controls, while there were no differences in the CSA of type I, I/IIA and IIA fibers. In addition, there was a higher occurrence of mini-fibers (MF's) in patients than in healthy 
subjects $(19.1 \%$ vs. $7.7 \%, \mathrm{p}=0.005)$. Predominant type IIA/IX and IIX fiber atrophy is clearly shown by the small dark fibers in figure $1 \mathrm{c}$ of chapter 5 .

The BMI of patients correlated significantly with the total mean fiber CSA ( $r=0.54, p=0.047)$. This relation was not found for the healthy controls. In addition, total mean fiber CSA correlated even stronger with both the FFM the $\mathrm{FFMI}_{\mathrm{BIA}}(\mathrm{r}=0.72, \mathrm{p}=0.003)$ in COPD patients. In controls, the $\mathrm{FFM}_{\mathrm{D}) \mathrm{EXA}}$ also correlated with the total mean fiber CSA $(r=0.58, p=0.048)$.

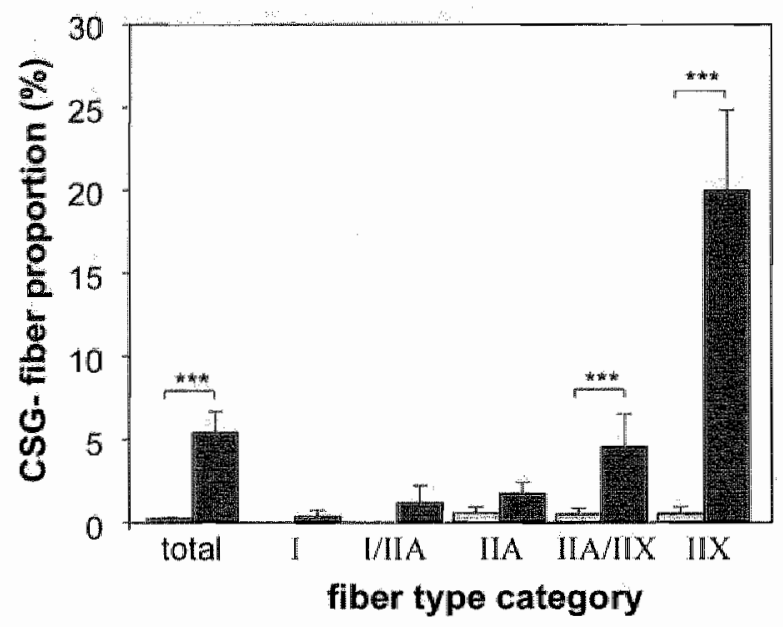

Figure 3. Overall and fiber typespecific proportions of COX, SDH, and GlyP negative (CSG-) fibers. Mean values \pm 1 SE are shown. 1 = Controls; $=$ COPD. Significance of difference between the groups: *** $\mathrm{p}=0.001$.

See panels $g-i$ in figure 1 of chapter 5 for examples of some $\operatorname{CSO}$ - fibers, indicated by arrows.

Staining for enzyme activities of COX, SDH and GlyP remarkably revealed the existence of fibers that stained negative for each of these enzyme activities, referred to as CSG negative (COX, SDH, and GlyP negative) fibers (figure 3): In healthy controls hardly any CSG negative fibers were found, in contrast to COPD patients $(0.2 \% v s .5 .4 \%, \mathrm{p}=0.001)$. CSG negative fibers were frequently observed in the IIX fiber type category: for patients a large proportion of the type IIX fibers were CSG negative (20.0\% vs. $0.6 \%, \mathrm{p}=0.001)$ compared to controls, which to a lesser extent - was also the case for type IIA/IIX fibers ( $4.6 \%$ vs. $0.5 \%, p=0.001)$. The fibers indicated by arrows in figure $1 \mathrm{~g}-\mathrm{i}$ of chapter 5 are examples of CSG negative fibers.

In COPD, the proportion of CSG negative fibers was negatively correlated with the total mean fiber CSA $(r=0.60, p=0.024)$ and with the mean CSA of IIX fibers (figure 4A). A high correlation (figure 4B) was also found between the percentage of MF's and CSG negative fibers in the patient group. Note that the CSG negative fibers in figure 1 of chapter 5 are indeed very small and identified as type IIX fibers. These correlations were not found in the control group.

There were no differences for overall fiber CSA $\left(3703 \mu \mathrm{m}^{2} v \mathrm{~s} .3976 \mu \mathrm{m}^{2}, \mathrm{p}=0.620\right)$ or type IIX liber CSA $\left(2339 \mu \mathrm{m}^{2}\right.$ ws. $\left.2792 \mu \mathrm{m}^{2}, \mathrm{p}=0.620\right)$ between patients receiving $(\mathrm{N}=7)$ and those not receiving $(\mathrm{N}=7)$ corticosteroids at the time of the study. Accordingly, there was no difference 
between patients with $(\mathrm{N}=10)$ and those without a corticosteroid history $(\mathrm{N}=4)$ in overall tiber CSA $\left(3615 \mu \mathrm{m}^{2}\right.$ vs. $\left.3929 \mu \mathrm{m}^{2}, \mathrm{p}=0.607\right)$ or type IIX fiber CSA $\left(2306 \mu \mathrm{m}^{2}\right.$ ws. $2670 \mu \mathrm{m}^{2}$, $\mathrm{p}=0.620$ ). Within the subgroup of patients receiving corticosteroids there was no correlation between fiber CSA (overall or fiber type specific) and the corticosteroid dose: There were no differences in fiber type composition, or proportions of MFs or CSG negative fibers between COPD patients with and without a corticosteroid history, nor could any correlations between corticosteroid dose and these variables be found.

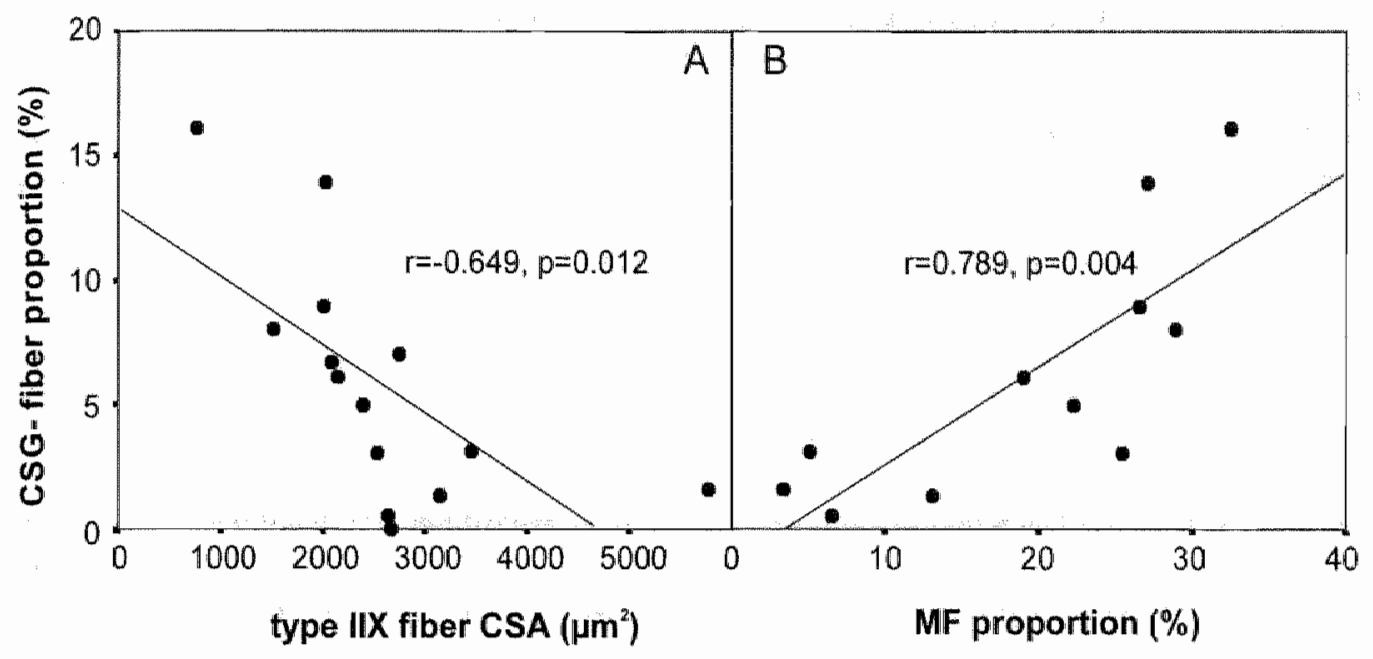

Figure 4. Relation between the propontion of COX, SDH, and GlyP negative (CSG-) fibers and (A) the type IIX fiber CSA or (B) the proportion of mini-fibers (MFs).

\section{DISCUSSION}

In this study we clearly show that fiber atrophy significantly contributes to the loss of total body weight and muscle mass in COPD, which is most obvious from the strong correlation between the mean fiber CSA and the FFM. We also show that fiber atrophy is mainly confined to type IIA/IIX and IIX fibers. Furthermore, a large proportion of the affected fibers lacks stainable activity of the oxidative enzymes $\mathrm{COX}$ and SDH and the glycolytic enzyme GlyP.

Our finding that atrophy occurs predominantly in type IIA/IIX and IIX fibers is in contrast with data from Whittom et al,, who found the largest CSA reduction in type I fibers (4). However, they reported a normal fiber type I CSA in COPD patients, but a relative high fiber type I CSA (nearly $7000 \mu \mathrm{m}^{2}$ ) in their healthy age-matched controls compared with normal 65 year old subjects (25-27). Therefore, the observed decrease in fiber type I CSA was probably biased by the aphysiologically high CSA in the muscles of the control subjects. The CSA of type I fibers in both healthy subjects and COPD patients in our study was $4600 \mu \mathrm{m}^{2}$ which is in the normal range (25). Predominant type II fiber atrophy was also found in emphysema patients with 
severe emaciation compared to control patients or healthy subjects, but this was established by measuring fiber diameter instead of the CSA (6). A disadvantage of this approach is that it is based on the assumption that the fiber cross-sections are perfectly round, which is certainly not the case for atrophied fibers which are often angulated. Moreover, none of these previous studies reported a relation between FFM and musele fiber CSA.

Hampered by their disease COPD patients perform less physical activity and therefore disuse may be one of the factors leading to atrophy. On limb unloading or immobilization overal muscle mass declines and this decline is initially associated with fiber type I but later with other fiber types as well $(8,28,29)$. The influence of unloading on muscle morphology in humans was studied in subjects undergoing a 6-week unilateral lower limb suspension which resulted in type I and IIA fiber type atrophy (30). In addition, significant type I fiber atrophy and a tendency for type II fiber atrophy was observed in subjects after 6 weeks of bed rest (31). These collective findings indicate that disuse cannot - at least not alone - explain the predominant fiber type IIX atrophy found in COPD patients in this study, since disuse causes either predominant fiber type I or generalized muscle fiber atrophy.

In both animals and man it has been shown that in a state of energy-deficiency muscle fiber atrophy occurs (7). Predominant fiber type II atrophy has been found in anorexia nervosa (3234). Animal food deprivation studies also show muscle fiber atrophy that is more pronounced in type II fibers (35-38). The relative preservation of type I fiber size would be advantageous because there is evidence that the energy expenditure per unit tension developed is lowest in slow-twitch fibers (7). Nutritional depletion is very common in COPD (39-41) and hence, being in a negative energy balance could thus very well contribute to the selective atrophy of type II fibers in patients suffering from this disease. For other chronic diseases similar results were found with respect to muscle fiber sizes. Compared to the present study, a similar mean muscle fiber CSA has been reported for patients with chronic heart failure (CHF) (42). In addition, predominant liber type II atrophy was also found in CHF $(43,44)$, AIDS (45) and chronic renal failure (46-48). As in COPD, malnutrition is a frequent problem in CHF $(49,50)$, AIDS (51) and chronic renal failure (52) and it is therefore very likely that the selective type II fiber atrophy is caused by a common mechanism.

In the present report, patients with a corticosteroid history and patients receiving corticosteroids at the time of the muscle biopsy did not show any differences (not even a tendency) between mean muscle fiber CSA (overall nor fiber type specific) or between the proportion of CSG negative fibers compared to each other nor to patients with no corticosteroid history. Accordingly, in the subgroup of patients receiving corticosteroids there was no relation between dosage and muscle fiber CSA. Patients did not receive high doses of oral corticosteroids. We previously found no differences in enzyme activities in the tibialis anterior between COPD patients who received a low dose of oral corticosteroids and those who did not (53). In addition, thigh muscle CSA was not different between patients who did and those who did not receive systemic corticosteroids (1). In the past, oral corticosteroids have indeed been associated with skeletal muscle fiber atrophy and as in malnutrition type II fibers are more susceptible than type I fibers $(9,54)$. However, animal studies demonstrate that type IIX fiber atrophy is induced by fluorinated corticosteroids (like dexamethasone and triamcinolone) and 
not by non-fluorinated corticosteroids (55-57). Prednisolone is a non-fluorinated corticosteroid and therefore is unlikely to have caused the marked type IXX fiber atrophy in the present study. Selective fiber type IX atrophy was demonstrated in the vastus lateralis in 8 COPD patients with the diagnosis of steroid-induced myopathy (5), but there probably is a sellection bias in this study since patients were selected by the diagnosis of steroid-induced myopathy (5). Therefore, our data combined with the literature suggest that oral corticosteroid treatment in which prednisolone is given at a maintenance dose is not an important factor contributing to muscle fiber atrophy in COPD.

We can only speculate on the molecular mechanisms involved in muscle fiber atrophy in COPD. The fact that many of the atrophied IIX fibers in the present study lacked stainable enzyme activity for COX, SDH or GlyP suggests that at a certain stage of fiber atrophy the muscle cell loses its potential to metabolize substrates required for ATP synthesis. This will inevitably lead to dysfunction of the affected muscle fiber, additional to the loss of functional muscle mass. As in CHF, muscle fiber atrophy may be associated with apoptosis (42) and it has been suggested that apoptosis is involved in muscle remodeling (58). The loss of muscle mass may also be caused by a reduction in the total number of fibers. We can not exclude the involvement of such fiber loss, moreover, atrophy may even be a process that precedes and eventually leads to the loss of fibers. The fact that minifibers lose activity of enzymes involved in energy metabolism and are probably "dying" favors this theory.

In summary, we previously demonstrated that the FFM is a strong predictor of skeletal muscle weakness in COPD (3). In the present study we show that loss of FFM is associated with muscle fiber atrophy. It can therefore be concluded that muscle fiber atrophy, especially of type IIX fibers, is involved in the loss of muscle mass in COPD and most likely results in muscle weakness. An abnormal metabolic profile is associated with fiber atrophy, but additional research is necessary to further clarify the molecular pathogenesis of muscle wasting in COPD. 


\section{REFERENCES}

1. Bernard 5 , LeBlanc $\mathbb{P}$, Whittom $\mathbb{P}$, et al. Peripheral muscle weakness in patients with chronic obstructive pulmonary disease. Am J Respir Crit Care Med 1998; 158:629-634.

2. Gosselink R, Troosters $T$, Decraner $M$ Peripheral muscle weakness contributes to exercise limitation in COPD. Am I Respir Cric Care Med 1996;153:976-80.

3. Engelen MP, Sehols AM, Does JD, Wouters EF. Skeletal muscle weakness is associated with wasting of extremity fat-free mass but not with airflow obstruction in patients with chronic obstructive pulmonary disease. Am J Clin Nutr 2000;71:733-8.

4. Whittom $F$, Jobin J, Simard PM, et al. Histochemical and morphological characteristics of the vastus lateralis muscle in patients with chronic obstructive pulmonary disease. Med Sci Sports Exerc 1998;30:1467\%1474.

5. Decramer M, de Bock V, Dom R. Functional and histologic picture of steroid-induced myopathy in chronic obstructive pulmonary disease. Am $\mathrm{J}$ Respir Crit Care Med 1996; 153:1958 -64.

6. Sato $\mathrm{Y}$, Asoh T, Honda $\mathrm{Y}$, Fujimatsu $\mathrm{Y}$, Higuchi I, Oizumi K. Morphologic and histochemical evaluation of muscle in patients with chronic pulmonary emphysema manifesting generalized emaciation. Eur Neurol 1997:37:116-21.

7. Henriksson $\mathbb{N}$. The possible role of skeletal. muscle in the adaptation to periods of energy deficiency. Eur J Clin Nutr 1990;44:55-64.

8. Appell HJ. Muscular atrophy following immobilisation. A review. Sports Med 1990;10:42-58.

9. Mayer $M$, Rosen $F$. Interaction of glucocorticoids and androgens with skeletal muscle. Metabolism 1977;26:937-62.

10. ATS. Standards for the diagnosis and care of patients with chronic obstructive pulmonary disease (COPD) and asthma. Am Rev Respir Dis 1987;136:225-44.

11. Quanjer P, Tammeling G.J, Cotes JE, Pedersen OF, Peslin R, Yernault JC. Standardized lung function testing. Eur Respin J 1993;6:5-40.

12. Engelen MPKJ, Schols AMWJ, Heidendal GAK, Wouters EFM. Dual-energy X-ray absorptiometry in the clinical evaluation of body composition and bone mineral density in patients with chronic obstructive pulmonary disease. An J Clin Nutr 1998;68:1298-1303.

13. Schols AM, Wouters EF, Soeters PB, Westerterp KR. Body composition by bioelectricalimpedance analysis compared with deuterium dilution and skinfold anthropometry in patients with chronic obstructive pulmonary disease. Am J Clin Nutr 1991;53:421-4.

14. Vanliallie TB, Yang MU, Heymsfield SB, Funk RC, Boileau RA. Height-normalized indices of the body's fat-free mass and fat mass: potentially useful indicators of nutritional status. Am J Clin Nutr 1990;52:953-959.

15. Bergstrom L. Muscle electrolytes in man. Determination by neutron activation analysis on needle biopsy specimens. A study on nomal subjects, kidney patients, and patients with chronic diarthea. Scand J Clin Lab hnest 1962;68:1-110.

16. Dammejjer PF, van Mameren $\mathrm{H}_{\text {, van }}$ Dijk $\mathrm{P}$, et al. Stapedius muscle fibre composition in the rat. Hear Res 2000; 141:169-79.

17. Ogivie RW, Feback DL. A metachromatic dye-ATPase method for the simultaneous identification of skeletal muscle fiber types I, IIA, IIB and IIC. Stain Technol 1990;65:231-41.

18. Guth L, Samaha FJ. Procedure for the histochemical demonstration of actomyosin ATPase. Exp Neurol $1970 ; 28: 365-7$.

19. Sant"Ana Pereira JA, Ennion S, Sargeant AJ, et al. Comparison of the molecular, antigenic and ATPase determinants of fast myosin heavy chains in rat and human: a single-fibre study. Pfligers Arch 1997;435:151-63.

20. Brooke MH, Kaiser KK. Muscle fiber types: how many and what kind? Arch Neurol 
$1970 ; 23: 369-79$.

21. Sant'Ana Pereira JA, Wessels A, Nijmans L, Mooman AF, Sargeant AI. Nex method for the accurate characterization of single human skeletall nuscle fibres demonstrates a relation between $\mathrm{mATP}$ ase and MyHC expression in pure and hybrid tibre types. J Muscle Res Cell Motil 1995;16:21-34.

22. Pearse AG. Histochemistry: Theoretical and applied. 3 ed Edinburgh: Churchil Livingstone, 1972.

23. Sheehan DC, Hrapchak BB. Theory and practice of histotechnology 2 ed. Columbus: Battelle Memorial Institute, 1987.

24. Altman DG, Gore SM, Gardner MJ, Pocock SI. Statistical guidelines for contributors to medical journals. Br Med J Clin Res Ed 1983;286:1489-93.

25. Simoneau JA, Bouchard C. Human wariation in skeletal muscle fiber-type proportion and enzyme activities. Am J Physiol 1989;257:E567-72.

26. Klitgaard $H$, Mantoni $M$, Schiaffino $S$, et al. Function, morphology and protein expression of ageing skeletal muscle: a cross-sectional study of elderly men with different training backgrounds. Acta Physiol Scand 1990;140:41-54.

27. Coggan $A R$, Spina RJ, King $D S$, et al. Histochemical and enzymatic comparison of the gastrocnemius muscle of young and elderly men and women. J Gerontol 1992;47:B71-6.

28. Booth FW, Gollnick PD. Effects of disuse on the structure and function of skeletal muscle. Med Sci Sports Exerc 1983;15:415-20.

29. Wallis $\mathrm{MG}_{*}$ Appleby GJ, Youd JM, Clark MG, Penschow JD. Reduced glycogen phosphorylase activity in denervated hindlimb muscles of rat is rellated to muscle atrophy and fibre type. Life Sci 1999;64:221-8.

30. Hather BM, Adams GR, Tesch PA, Dudley GA. Skeletal muscle responses to lower limb suspension in humans. J Appl Physiol 1992;72:1493-8.

31. Berg HE, Larsson L, Tesch PA. Lower limb skeletal muscle function after 6 wk of bed rest. J Appl Physiol 1997;82:182-8.

32. Lindboe CF, Askevold F, Slettebo M. Changes in skeletal muscles of young women with anorexia nervosa. An enzyme histochemical study. Acta Neuropathol Berl 1982;56:299-302.

33. Slettebo M, Lindboe CF, Askevold F. The neuromuscular system in patients with anorexia nervosa: electrophysiological and histologic studies. Clin Neuropathol 1984;3:217-24.

34. McLoughlin DM, Spargo E, Wassif WS, et al. Structural and functional changes in skeletal muscle in anorexia nervosa. Acta Neuropathol Berl 1998;95:632-40.

35. Sieck GC, Lewis MI., Blanco CE Effects of undernutrition on diaphragm fiber size, SDH activity, and fatigue resistance. J Appl Physiol 1989;66:2196-205.

36. Gardiner PF, Montanaro G, Simpson DR, Edgetton VR. Effects of glucocorticoid treatment and food restriction on rat hindlimb muscles. Am J Physiol 1980;238:E124-30.

37. Dekhuijzen PNR, Gayan Ramirez G, Bisschop A, Bock de V, Dom R, Decramer $M$. Corticosteroid treatment and nutritional deprivation cause a different pattern of atrophy in rat diaphragm. J Appl Physiol 1995;78:629-637.

38. Lewis MI, Sieck GC, Fournier M, Belman MJ. Effect of nutritional deprivation on diaphragm contractility and muscle fiber size. J Appl Physiol 1986;60:596-603.

39. Gray-Donald K, Gibbons L, Shapiro SH, Martin JG. Effect of nutritional status on exercise performance in patients with chronic obstructive pulmonary disease. Am Rev Respir Dis $1989 ; 140: 1544-8$.

40. Efthimiou J, Fleming $J$, Gromes $C$, Spiro SG. The effect of supplementary oral nutrition in poorly nourished patients with chronic obstructive pulmonary disease. Am Rev Respir Dis $1988 ; 137: 1075-82$.

41. Schols AM. Nutrition in chronic obstructive pulmonary disease. Curr Opin Pulm Med 
$2000,6: 110-5$

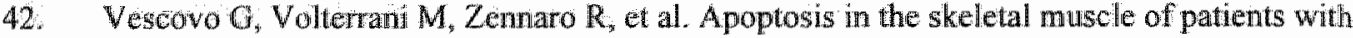
heart fallure: inwestigation of clinical and biochemical changes. Heart 2000;84:431-7.

43. Sullivan MJ, Green HJ, Cobb FR. Skeletal musele biochemistry and histology in ambulatory patients with long-term heart fallure. Circulation 1990;81:518-27.

44. Mancin DM, Coyle $\mathrm{E}$, Coggan $\mathrm{A}$, et al Contribution of intrinsic skeletal muscle changes to ${ }^{3} \mathrm{P}$ NMR skeletal muscle metabolic abnormalities in patients with chronic heart failure. Criculation $1989,80: 1338-46$.

45. Miro O, Pedrol $\mathrm{E}$, Cebrian $M$, et al. Skeletal muscle studies in patients with HIV-related wasting syndrome. J Neurol Sci 1997;150:153-9.

46. Diesel W, Emms M, Knight BK, et al. Morphologic features of the myopathy associated with chronic renal failure. Am J Kidney Dis 1993;22:677-84.

47. Fahal IH, Bell GM, Bone JM, Edwards RH. Physiological abnormalities of skeletal muscle in dialysis patients. Nephrol Dial Transplant 1997;12:119-27.

48. Kouidi $\mathrm{E}$, Albani $\mathrm{M}$, Natsis $\mathrm{K}$, et al. The effects of exercise training on muscle atrophy in haemodialysis patients. Nephrol Dial Transplant 1998;13:685-99.

49. Wilson JR, Mancini DM. The mechanism of extertional fatigue in heart failure. Cardioscience 1990;1:13-7.

50. Carr JG, Stevenson LW, Walden JA, Heber D. Prevalence and hemodynamic correlates of malnutrition in severe congestive heart failure secondary to ischemic or idiopathic dilated cardionyopathy. Am J Cardiol 1989;63:709-13.

51. Hecker LM, Kotler DP. Malnutrition in patients with AIDS. Nutr Rev 1990;48:393-401.

52. Mitch WE, Maroni BJ. Factors causing malnutrition in patients with chronic uremia. Am J Kidney Dis 1999;33:176-9.

53. Pouw EM, Koerts-de Lang E, Gosker HR, et al. Muscle metabolic status in patients with severe COPD with and without long-term prednisolone. Eur Respir J 2000;16:247-52.

54. LaPier TK. Glucocorticoid-induced muscle atrophy. The role of exercise in treatment and prevention. I Cardiopulm Rehabil 1997;17:76-84.

55. Balkom van RH, Dekhuijzen PN, Folgering HT, Veerkamp JH, Fransen JA, van Herwaarden CL. Lffects of long-term low-dose methylprednisolone on rat diaphragm function and structure. Muscle Nerve 1997;20:983-90.

56. Koerts-de Lang E Schols AM, Rooyackers OE, Gayan-Ramirez G, Decramer M, Wouters EF. Different effects of corticosteroicl-induced muscle wasting compared with undernutrition on rat diaphragm energy metabolism. Eur I App I Physiol 2000;82:493-8.

57. Lewis MI, Monn SA, Sieck GC. Effect of corticosteroids on diaphragm fatigue, SDH activity, and muscle fiber size. I Appl Physiol 1992;72:293-301.

58. Allen DL, Roy RR, Edgerton VR. Myonuclear domains in muscle adaptation and disease. Muscle Nerve 1999;22:1350-60. 


\title{
CHAPTER 7
}

\section{Uncoupling protein 3 content is decreased in skeletal muscle of patients with chronic obstructive pulmonary disease}

\begin{abstract}
Mechanical efficiency is reduced in patients with chronic obstructive pulmonary disease (COPD). Furthermore, altered fiber type distribution and metabolic profile has been observed in peripheral skeletal muscle of COPD. Since skeletal muscular uncoupling protein 3 (UCP3) has been implicated in the regulation of energy metabolism we assessed UCP3 in peripheral skeletal muscle of COPD patients and healthy controls. 16 COPD patients and 11 healthy age-matched control subjects were studied. Mechanical efficiency was measured by means of cycle ergometry. Biopsies were taken from the vastus lateralis and UCP3 and cytochrome $c$ (as a marker for mitochondrial content) were assessed by Western blotting. Muscle fiber types and metabolic profile were examined histochemically. UCP3 levels were markedly decreased in COPD compared to controls $(48 \pm 8$ vs $95 \pm 13 \mathrm{AU}, \mathrm{p}<0.01)$. In patients, there was a positive correlation between UCP 3 content and the FEV 1 (\%predicted; $r=0.66 ; p=0.008)$. UCP3 content was not related to mechanical efficiency or other muscular data such as fiber types, markers of oxidative/glycolytic energy metabolism, or cytochrome $c$. We conclude that UCP3 content is decreased in peripheral skeletal muscle of patients with COPD and is related to disease severity, but not to mechanical efficiency. The low UCP3 content is independent of the loss of oxidative capacity observed in these patients.
\end{abstract}

Harry R. Gosker', Patrick Schrauwen², Matthijs M.K.C. Hesselink', Gert Schaart ${ }^{3}$, Ger J. van der Vusse', Emiel F.M. Wouters', Annemie M.W.J. Schols'. Departments of 'Respiratory Medicine, ${ }^{2}$ Human Biology, ${ }^{3}$ Movement Sciences, and ${ }^{4}$ Physiology, University of Maastricht, The Netherlands. Submitted 


\section{INTRODUCTION}

Total daily energy expenditure (EE) is often elevated in chronic obstructive pulmonary disease (COPD) patients (1), suggesting that these patients are characterized by hypermetabolism. Total daily $\mathrm{EE}$ consists of the resting $\mathrm{EE}$, diet induced thermogenesis and energy spent during daily activities. Whereas diet induced thermogenesis is normal in COPD and can therefore be ignored (2), elevated resting EE has been observed in some COPD patients $(3,4)$. However, it has been shown that total daily $\mathrm{EE}$ is elevated independent of the resting $\mathrm{EE}$ (5), suggesting that the elevated total EE in COPD is related to the daily activities. Because of their physical disabilities, it must be assumed that COPD patients perform less physical activities compared to healthy subjects. Therefore, the levated total daily $\mathrm{EE}$ is most likely explained by an elevated energy cost for physical activity. Indeed, mechanical efficiency, measured by means of submaximal exercise testing, is decreased in these patients (6).

The reason for the decreased mechanical efficiency in COPD patients is not known. Sala et al showed that for any specific workload, oxygen uptake of the leg is higher compared to healthy control subjects (7), suggesting that intrinsic muscular abnormalities are involved. Intrinsic abnormalities have indeed been found in peripheral skeletal muscles in COPD, of which, from a metabolic point of view, the most obvious are a reduction of the fiber type I proportion and a decreased oxidative capacity (8). These findings suggest a potential relationship between mechanical inefficiency and muscular abnormalities in COPD. Recently, human homologues of the brown adipose tissue uncoupling protein 1 have been identified and these proteins are potentially important determinants of human energy metabolism $(9,10)$. Uncoupling protein 3 (UCP3) is predominantly expressed in skeletal muscle and uncouples oxidative phosphorylation from ATP production (11). The first evidence for a relation between UCP3 and energy metabolism came from genetic studies showing that the locus of the UCP3 gene is in the vicinity of markers strongly linked to resting $\mathbb{E} E$ (12). Measurements of UCP3 mRNA expression and protein content in relation to EE further supported a role of UCP3 in energy metabolism. In Pima Indians, Schrauwen et al found a positive correlation between the mRNA expression of UCP3 and the sleeping metabolic rate (13). Decreased levels of UCP3 in humans accompany weight reduction and endurance training (14-16), conditions that result in a reduced resting metabolic rate and/or improved energy efficiency. Also, mice overexpressing UCP3 eat more but weigh less compared to wildtype controls, pointing towards increased EE (17). Finally, a clear inverse relation was observed between mechanical efficiency and UCP3 expression in healthy subjects (14). Although there is also evidence that the primary function of UCP3 is not the regulation of energy expenditure $(11,18,19)$, the above mentioned studies clearly indicate that UCP3 is related to human energy expenditure, perhaps as a secondary effect of its unknown function. Therefore, it is feasible that the increased EE and decreased mechanical efficiency in COPD could be attributed to elevated UCP3 levels. Elevated UCP3 levels in COPD would also be consistent with the finding that human UCP3 is highly expressed in type IIX (or IIB) libers (20), since it has been shown that COPD patients have an increased proportion of type II fibers (8).

Therefore, the aim of the present study was to investigate the UCP3 content in peripheral skeletal muscles of COPD patients relative to healthy age-matched controls. Furthermore, we 
investigated the relation between UCP3 contents, muscle fiber type distribution, muscle metabolic profile and mechanical efficiency of cycle ergometry:

\section{METHODS}

A group of 15 patients with moderate to severe airflow obstruction and 11 healthy age-matched volunteers was studied. All patients had COPD according to ATS guidelines (21) and chronic airflow limitation, defined as measured forced expiratory volume in one second (FEV, less than $70 \%$ of reference $\mathrm{FEV}_{1}$. In addition, all patients had a $\mathrm{FEV} /$ forced vital capacity (FVC) below $70 \%$. Furthermore, patients had irreversible obstructive airway disease (less than $10 \%$ improvement of $\mathrm{FEV}_{1}$ predicted baseline after $\beta_{2}$-agonist inhalation). Five of the 15 patients had severe COPD or disease severity stage III according to the ATS guidelines (21). They were in clinically stable condition and not suffering from a respiratory tract infection of an exacerbation of their disease at least 4 weeks prion to the study. Exclusion criteria were malignancy, cardiac failure, distal arteriopathy, recent surgery, severe endocrine, hepatic or renal disorders and use of anticoagulant medication. The healthy age-matched control subjects were volunteers recruited through advertisement in a local newspaper. Written informed consent was obtained from all subjects and the study was approved by the medical ethical committee of the University Hospital Maastricht (Maastricht, The Netherlands).

\section{Pulmonary function tests}

All patients and control subjects underwent spirometry to determine, anongst others, FEV, and FVC, with the highest value from at least three technically acceptable assessments being used. Residual volume (RV) and intrathoracic gas volume (ITGV) were assessed by whole-body plethysmography and diffusion capacity for carbon monoxide $\left(\mathbb{D L} L_{c o}\right)$ was measured by using the single-breath method (Masterlab, Jaeger, Wurzburg, Germany). All values obtained were related to a reference value and expressed as percentage of the predicted value (22). Arterial oxygen tension $\left(\mathrm{PaO}_{2}\right.$ ) was determined (ABL 330; Radiometer, Copenhagen, Denmark) in a blood sample obtained by puncture of the radial artery while breathing room air.

\section{Assessment of body composition}

Body height was determined to the nearest $0.5 \mathrm{~cm}$ with subjects standing barefoot and body weight was assessed to the nearest $0.1 \mathrm{~kg}$ while subjects wore light clothing and no shoes. Whole-body fat-free mass (FFM), which consists of lean mass and bone mineral mass, was determined by scanning each subject on a DPX bone densitometer (Lunar Radiation Corporation, Madison, WI) as described previously (23). Weight parameters were divided by squared body height $\left(\mathrm{kg} / \mathrm{m}^{2}\right)$, resulting in the body mass index (BMI) and FFM index (FFMI), to adjust for body surface (24).

\section{Resting energy expenditure}

Energy expenditure at rest (REE) was measured by indirect calorimetry using a ventilated hood system (Oxycon BetaQB), Jaeger, Wurzburg, Germany). Reproducibility and validity of this method in COPD patients was shown by Schols et al (25). The system was calibrated daily at the start of the experiment. The accuracy of the system was regularly assessed using a methanol 
combustion test. Measurements were performed in the early morning after an overnight fast, while the subject was comfortably lying on a bed in supine position. Energy expenditure was calculated from oxygen consumption and carbon dioxide production using the abbreviated Weir formula (26). Measured REE was expressed as a percentage of predicted REE, which was calculated using the linear regression equation of REE on FFM, as described by Creutzberg et all (4).

\section{Mechanical efficiency during cycle ergometry}

Recently, a close correlation between the mechanical efficiency during submaximal exercise testing and the ratio of the peak oxygen consumption ( $\mathrm{VO}_{2}$ peak) to the peak work rate (WRpeak) during maximal exercise testing was found in COPD (27). Therefore, we used the $\mathrm{VO}_{2}$ peak/WRpeak as a measure of gross efficiency in the current study. All subjects performed

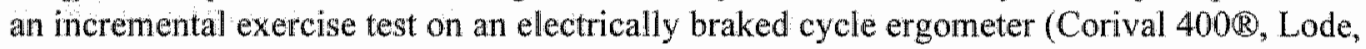
Groningen, The Netherlands) under supervision of a chest physician. Before the start of the test, while seated on the cycle ergometer, ventilation characteristics at rest were analyzed during two minutes. During the entire exercise test, expired gases were investigated using breath by breath analysis through a breathing mask (Oxycon Betaß), Jaeger, Würzburg, Germany). After one minute of unloaded cycling, power was increased by $10 \mathrm{~W}$ every minute for patients. For the control subjects, the load was increased with 15-25 W every minute, so that the length of the exercise test was comparable for patients and controls. None of the subjects knew the exercise load and all were encouraged to cycle at $60 \mathrm{revs} / \mathrm{min}$ until exhaustion. At the moment of cessation of the exercise, the $\mathrm{VO}_{2}$ peak and the WRpeak were measured. A high $\mathrm{VO}_{2}$ peak to WRpeak ratio corresponds to a low gross efficiency.

\section{Collection and processing of muscle tissue}

Postabsorptive muscle biopsies of the lateral part of the quadriceps femoris were obtained under local anesthesia by the needle biopsy technique (28). Part of the tissue was used to obtain serial cryostat cross-sections $(10 \mu \mathrm{m})$ for histochemistry. Evaluation of fiber type distribution was performed using a combination of myofibrillar ATPase (mATPase) staining and immonohistochemistry as deseribed previously (29). In short, the mATPase acidic and alkaline pre-incubations were performed at $\mathrm{pH} 4.4$ and $\mathrm{pH} 10.4$, respectively. Double pre-incubation was performed at $\mathrm{pH} 10.4$ and $\mathrm{pH}$ 4.6. After pre-incubation sections were stained and mounted. Immunohistochemistry was performed with a panel of $\mathrm{mAbs}$, respectively anti-type I myosin heavy chain (MyHC) (mAb 219-IDI), anti-type IIA MyHC (mAb 333-7H1) and anti-types IIA * IIX MyHC (mAb 332-3D4). Fiber cross sectional area (CSA) was measured with an interactive image analysis system (Leica QWin Image Analysis System, Leica Microsystems BV, Rijswijk, The Netherlands) as reported before (30). The relative contribution of type II fibers to total fiber CSA (\%CSA of type II fibers) was calculated. Metabolic profile of muscle fibers was evaluated by staining for cytochrome $c$ oxidase $(\mathrm{COX})$ and succinate dehydrogenase (SDH) activity as markers for oxidative energy metabolism and glycogen phosphorylase (GlyP) activity for glycolytic energy metabolism, as described previously (29). In short, for COX activity staining sections were incubated for one hour in a $50 \mathrm{mM}$ Tris/ $\mathrm{HCl}$ buffer $(\mathrm{pH} 7.6)$

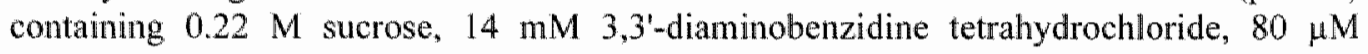
cytochrome $c$ and $1300 \mathrm{U}$ catalase. SDH activity staining was performed by incubating sections for one hour at $37^{\circ} \mathrm{C}$ in a $0.2 \mathrm{M}$ sodium phosphate buffer containing $0.1 \mathrm{M}$ succinic acid and 
$1.2 \mathrm{mM}$ nitro blue tetrazolium. GlyP staining was performed by ineubating sections for 5 minutes in a $43 \mathrm{mM}$ sodium acetate buffer ( $\mathrm{pH} 5.6$ ) containing $7 \mathrm{mM}$ glucose-1-phosphate, 1 $\mathrm{mM} \mathrm{AMP}, 0.01 \%$ glycogen and $15 \%$ ethanol after which the newly formed polysaccharide was coloured with Lugol's lodine. Three staining intensities were decided reflecting fiber enzyme activity: positive $(+)$, negative $(-)$ or intermediate $( \pm)$. We previously reported the altered fiber type distribution, fiber CSAs and metabolic profile as presented in the current study $(29,30)$, in chapters 5 and 6 . The remaining parts of the muscle biopsies were homogenized in ice-cold Tris-EDTA buffer at $\mathrm{pH} 7.4$, and then the homogenates were sonicated for $4 \times 15 \mathrm{~s}$. Subsequently, two volumes of each skeletal muscle homogenate and one volume of SDS-sample buffer were boiled for $4 \mathrm{~min}$. Next, $13 \%$ polyacrylamide gels containing $0.1 \%$ SDS were loaded with equal amounts of protein from each sample, and electrophoresis was performed using a Mini-Protean 3 Electrophoresis Cell (Bio-Rad Laboratories, Hercules, CA, USA). After gel electrophoresis, this gel was scanned, and the optical density of the $43-\mathrm{kDa}$ band, previously immuno-identified to represent actin, was assessed. Then, a second gel was prepared and loaded with the sample volume (which had been recalculated based on the optical density of the actin band), after which Western blotting was performed using a Mini Trans-Blot Electrophoretic Transfer Cell (Bio-Rad Laboratories) as described previously (20). We used a rabbit polyclonal UCP3 antibody (code 1331; kindly provided by L.l Slieker, Eli Lilly) prepared against a 20-amino acid (aa) peptide (human sequence aa 147-166), which recognizes both the long and the short form of UCP3 and was previously shown to not recognize UCP2. The antibody was affinity-purified on a Sulfolink column (Pierce, Omnilabo International, Breda, The Netherlands) containing the peptide coupled through a $\mathrm{COOH}$-terminal cysteine. Cross-reaction of the antibody with other proteins was checked by examining the entire 5- to $94-\mathrm{kDa}$ range for additional bands. For a more detailed description of the selectivity and specificity checks see previous reports $(15,20,31)$. Cytochrome $c$ level, as a marker of mitochondrial content, was measured comparably, using a mouse monoclonal cytochrome $c$ antibody (BD PharMingen, Woerden, The Netherlands). Both UCP3 and cytochrome $c$ were expressed as arbitrary units (AU).

\section{Statistical analysis}

Data were analyzed with the unpaired Student's $t$ test (corrected for unequal variances if appropriate), 1-way ANOVA (with unpaired Student's $t$ test as post hoc test), or the Pearson correlation test, as appropriate (32). Data are represented as the means \pm SEM. A two-tailed probability value of less than 0.05 was considered statistically significant.

\section{RESULTS}

Characteristics of patients and control subjects are summarized in table 1. There were no differences in gender or age between the groups. FFMI was significantly lower in COPD while BMI was not significantly different from controls. Plasma glucose levels were within normal range in COPD. The proportions of type I fibers and fibers with high oxidative capacity were markedly lower in patients, whereas the fiber type IIX proportion was higher compared to healthy subjects. The relative contribution of the CSA of type II fibers tended to be larger in COPD, but this was not statistically significant $(p=0.085)$. 
Table 1. Subject characteristics

\begin{tabular}{|c|c|c|}
\hline$\because$ & Controls & COPD \\
\hline $\mathrm{N}(\mathrm{F} / \mathrm{M})$ & $11(1 / 10)$ & $\mathbb{1 5}(3 / 12)$ \\
\hline Age (yr) & $64 \pm 1$ & $67 \pm 2$ \\
\hline BMI $\left(\mathrm{kg} / \mathrm{m}^{2}\right)$ & $26.1 \pm 1$ & $23.9 \pm 1$ \\
\hline FFMI $\left(\mathrm{kg} / \mathrm{m}^{2}\right)$ & $19.5 \pm 0.6$ & $17.2 \pm 0.5 * *$ \\
\hline $\mathrm{FEV}_{1}(\%$ pred $)$ & $105 \pm 5$ & $42 \pm 4^{* * \cdots}$ \\
\hline FVC $(\%$ pred $)$ & $115 \pm 4.0$ & $83 \pm 3.8^{* * * *}$ \\
\hline $\mathrm{PaO}_{2}(\mathrm{kPa})$ & $11.4 \pm 0.5$ & $9.9 \pm 0.3^{*}$ \\
\hline $\mathrm{DL}_{\mathrm{Co}}(\%$ pred $)$ & $118 \pm 7$ & $63 \pm 7^{* * *}$ \\
\hline RV (\% pred) & $114 \pm 5$ & $167 \pm 8^{* * *}$ \\
\hline ITGV $(\%$ pred $)$ & $107 \pm 5$ & $144 \pm 6 * * *$ \\
\hline plasma glucose (mmol/L) & $6.0 \pm 0.8$ & $5.6 \pm 0.9$ \\
\hline REE (kcal/24h/kg FFM) & - & $27.3 \pm 1.2$ \\
\hline \multicolumn{3}{|l|}{ Muscle biopsy data: } \\
\hline cytochrome $c(\mathrm{AU})$ & $141 \pm 20$ & $60 \pm 8$ \\
\hline proportion of type I fibers $(\%)$ & $40 \pm 4$ & $19 \pm 4^{* * *}$ \\
\hline proportion of type IIA fibers $(\%)$ & $30 \pm 4$ & $35 \pm 3$ \\
\hline proportion of type IIX fibers $(\%)$ & $30 \pm 4$ & $46 \pm 5^{*}$ \\
\hline type II $\% \operatorname{CSA}(\%)$ & $62 \pm 5$ & $74 \pm 4$ \\
\hline proportion of $\mathrm{COX}+$ fibers $(\%)$ & $47 \pm 4$ & $20 \pm 3^{* * * *}$ \\
\hline proportion of SDH+ fibers (\%) & $38 \pm 4$ & $14 \pm 3^{* * *}$ \\
\hline proportion of GlyP+ fibers $(\%)$ & $38 \pm 5$ & $38 \pm 4$ \\
\hline
\end{tabular}

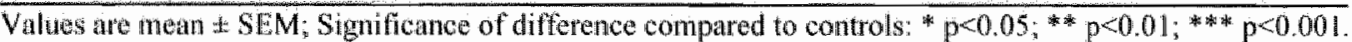
BMI: body mass index; FFMl: fat-free mass index; DL co: diffusion capacity for carbon monoxide; FEV; forced expiratory volume in one second; FVC: forced vital capacity; RV: residual volume; ITGV: intrathoracic gas volune; REE: resting energy expenditure; type II \%CSA: relarive contribution of type II fibers to total fiber CSA; COX+, SDHt and GlyPt: fibers staining positive for cytochrome $c$ oxidase, succinate dehydrogenase and glycogen phosphorylase, respectively.

Figure 1 shows a representative Western blot of 4 controls and 4 COPD patients. On average, UCP3 content was 50\% lower in COPD patients compared with control subjects (95 \pm 13 vs. $47 \pm 8 \mathrm{AU} ; p=0.004)$, as shown in figure 2 . There was a significant positive correlation between the FEV, and the peripheral skeletal muscle UCP 3 content in COPD patients $(r=0.66$, $\mathrm{p}<0.01$ ), as shown in figure 3 . There was no correlation between resting energy expenditure and UCP3 content in COPD. 


\section{UCP3 Western blot}

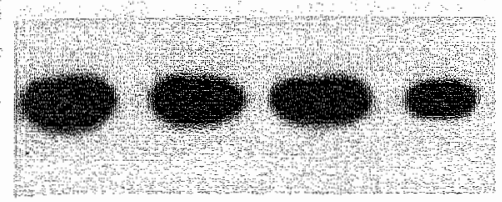

Controls

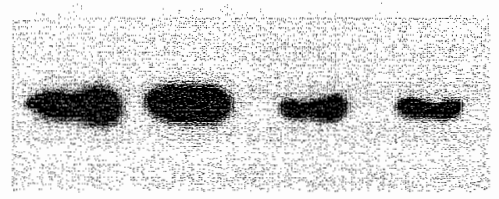

COPD

Figure 1. Representative sample of UCP3 using Western blot. Equal amounts of protein (normalized on the actin band) were loaded in every lane. Blotting and antibody incubation were performed simultaneously for control and COPD samples, and all samples were exposed to the same film. UCP 3 was identified as the $33 \mathrm{kDa}$ band.

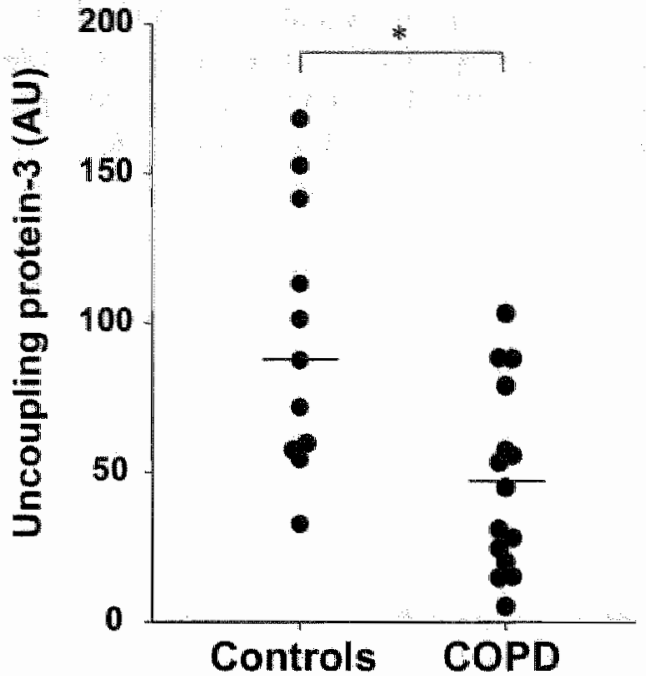

Figure 2. Peripheral skeletal muscle UCP3 content in COPD patients (Now 15 ) and healthy controls $(\mathrm{N}=11)$. Horizontal bars indicate the median values. Significance of difference between the groups: $* 0.01$.

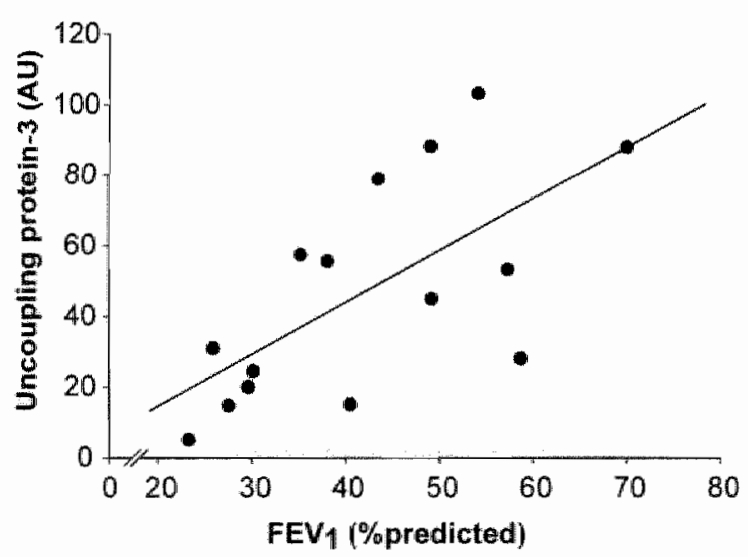

Figure 3. Correlation between the FEV, and peripheral skeletal muscle UCP3 content in COPD patients $(r=0.66, p<0.01)$

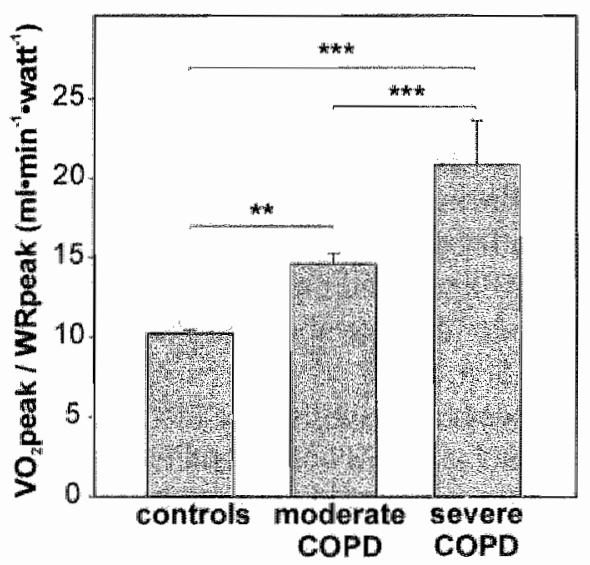

Figure 4. Mechanical efficiency of leg exercise in patients with moderate or severe COPD and healthy controls. Significance of difference compared to controls: * p $<0.01$; *** p 0.001 . Error bars indicate the SEM. 
Five of the 15 patients had severe COPD or disease severity stage III according to the ATS guidelines. These patients had a markedly lower UCP3 content compared to the patients with moderate COPD $(19 \pm 4.4 \mathrm{vs} .61 \pm 8.9 \mathrm{AU} ; \mathrm{p}=0.001)$. The $\mathrm{VO}_{2}$ peak/WRpeak was significantly higher in COPD than in controls $\left(16.7 \pm 1.2 \mathrm{ws} .10 .2 \pm 0.3 \mathrm{ml} \cdot \mathrm{min}^{-1} \cdot \mathrm{watt}^{-1} ; \mathrm{p}<0.001\right)$. In addition, $\mathrm{VO}_{2}$ peak/WRpeak was significantly higher in the patients with severe COPD than in the patients with moderate COPD (figure 4). In COPD, an inverse correlation was found between the $\mathrm{VO}_{2}$ peak/WRpeak and UCP 3 content $(\mathrm{r}=-0.568 ; \mathrm{p}=0.027)$, but after adjustment for the disease severity, as measured by the $F E V_{1}$, this correlation was not statistically significant anymore $(r=-0.402 ; \mathrm{p}=0.154)$. There was no relation between $\mathrm{VO}_{2}$ peak/WRpeak and fiber types or indices of metabolic profile.

To assess whether the reduced UCP 3 content could be explained by the reduced oxidative capacity, cytochrome $c$ content was measured in the same samples. There was no significant correlation ( $r=0.43 ; p=0.13$ ) between UCP3 content and cytochrome $c$ content in COPD. In addition, in the patients group, there were no correlations between UCP3 and the proportions of fibers with high staining activities for cytochrome $c$ oxidase, succinate dehydrogenase or glycogen phosphorylase. Furthermore, there was no relation between UCP3 and fiber type distribution in COPD, nor did the UCP3 content correlate with the relative contribution of type II fibers to the total fiber CSA (or \%CSA of type II fibers). Peripheral skeletal muscle UCP3 content did also not correlate with fat-free mass (a measure of muscle mass). DL co $_{\text {did not }}$ correlate with UCP3 content in patients. There was a correlation between UCP3 and the $\mathrm{PaO}_{2}$, but not anymore after adjustment for the $\mathrm{FEV}_{1}$.

\section{DISCUSSION}

The main finding of the present study is the significantly lower UCP3 content in peripheral skeletal muscle of COPD patients, being lowest in the patients with the highest severity of COPD. This is the opposite of what we had expected with respect to mechanical inefficiency and the increased muscle fiber type II proportion in COPD. The low UCP 3 levels could not be quantitatively attributed to the reduction in muscle mass or other muscular abnormalities, since UCP3 levels did not correlate with the fat-free mass index, nor with fiber type distribution or muscle fiber metabolic profile.

Our data clearly indicate that decreased leg efficiency in COPD is not the result of elevated muscular UCP3 contents. First of all, we found reduced instead of elevated levels of UCP3. In addition, we did not find the expected inverse correlation between leg efficiency and UCP3. This result is in contrast to findings observed in healthy subjects, in which low levels of muscular UCP3 contents were associated with increased mechanical efficiency (14), although UCP3 was not evaluated in subjects with such a low mechanical efficiency as in the current COPD group. It can be speculated that the reduced UCP3 levels in COPD represent a compensatory adaptation to the decreased mechanical efficiency and/or elevated $\mathrm{EE}$ in these patients. However, there is also growing evidence that the primary function of UCP3 is not the regulation of energy metabolism, although UCP3 might (as a secondary effect of its primary function) influence energy metabolism in certain circumstances. For example, fasting, a 
condition associated with energy conservation, results in upregulation of UCP3 (18). Also, UCP3 knockout mice have normal EE and body weight, even though their mitochondria showed improved coupling (33). Thus, what the primary function of UCP3 is, is at present unknown. UCP3 has been suggested to be involved in the regulation of fuel metabolism. In this context, it is interesting to note the accumulating evidence that substrate metabolism is also impaired in COPD patients. Although we did not find abnormal plasma glucose levels in COPD in the current study, we previously reported presence of hyperinsulinaemia in moderate to severe COPD (34). Impaired glucose tolerance and impaired B-adrenoceptor-mediated lipolysis have been shown for COPD $(35,36)$. Furthermore, reduced activities of enzymes involved in oxidative substrate metabolism have been found in the vastus lateralis of COPD patients (8). With respect to these abnormalities it is feasible that the reduced UCP3 contents in COPD may be associated with impaired substrate metabolism $(37,38)$. Mice overexpressing UCP3 show improved glucose metabolism (reduced fasting plasma glueose and insulin levels and improved glucose tolerance after an oral glucose load), which suggests a role for UCP3 in carbohydrate metabolism and type 2 diabetes (17). Indeed, Schrauwen et al recently reported markedly reduced levels of UCP3 in patients with type 2 diabetes compared to control subjects (39). If and how UCP3 is involved in substrate metabolism in COPD needs to be further exploited. A novel hypothesis is that UCP3 plays in important role in the export of fatty acid anions from the mitochondrial matrix in order to prevent their accumulation $(40,41)$. However, the reported reduced activity of $\beta$-hydroxyacyl $\mathrm{COA}$ dehydrogenase in peripheral muscle in COPD by Maltais et al in 1996 is the only indication of a disturbed muscular fatty acid metabolism so far (42). Another putative function of UCP3 is the regulation of reactive oxygen species production (43). Several observations point towards an imbalance between the production of oxygen species and the antioxidant status in muscles of COPD patients (44-46). Whether reduced UCP3 is involved in or associated with the defence against reactive oxygen species in COPD needs further examination.

The finding of lower UCP3 levels in COPD is also remarkable considering that human UCP3 is predominantly expressed in type II fibers (20). Despite an increase of the fiber type II proportion in COPD patients in the current study, there was a decrease of the UCP3 levels. The observed increase in the fiber type II proportion is however accompanied by selective atrophy of type II fibers in COPD, as reported recently (30). The relative contribution of type II fibers to the total fiber CSA is not larger in the patient group and this may partly explain why peripheral muscular UCP3 content is not increased in COPD. Alternatively, since oxidative capacity is also reduced in these patients and UCP 3 is a mitochondrial protein, a reduction of UCP3 could be explained by a reduction of the mitochondrial content. However, we did not find a correlation between UCP3 and cytochrome $c$ as a marker of mitochondrial content. There were also no relations between UCP3 and the proportions of fibers staining positive for the mitochondrial enzymes COX or SDH. It can therefore be concluded from the present data that the low UCP3 content in COPD is probably not just an epiphenomon of altered muscle fiber composition and related oxidative capacity. Further studies are needed to examine whether the reduction of UCP3 in COPD is fiber type specific. 
In conclusion, to the best of our knowledge, it is the first time that UCP3 content in the peripheral skeletal muscle of patients with COPD has been studied. In contrast to what we expected, UCP3 levels in patients were substantially lower compared to healthy control subjects. In addition, it can be concluded that UCP3 is not responsible for the decreased mechanical efficiency and therefore probably also is not involved in elevated energy expenditure in these patients. The clinical significance of the reduced UCP3 in COPD and its relation to disease severity requires further investigations.

\section{ACKNOWLEDGMENTS}

We thank Lawrence J. Slieker from Eli Lilly for providing us with the UCP3 antibody and Prof. A.F.M. Moorman for providing the antibodies against MyHC isoforms I, IIA and IIA + IIX. Dr. Schrauwen was supported by a grant from the Netherlands Organization for Scientific Research (NWO).

\section{REFERENCES}

1. Baarends EM, Schols AM, Pannemans DL, Westerterp KR, Wouters EF. Total free living energy expenditure in patients with severe chronic obstructive pulmonary disease. Am J Respir Crit Care Med 1997;155:549-54.

2. Hugli $O$, Frascarolo $P$, Schutz Y, Jequier E, Leuenberger P, Fitting JW. Diet-induced thermogenesis in chronic obstructive pulmonary disease. Am Rev Respir Dis 1993;148:147983.

3. Schols AMWJ, Fredrix EW, Soeters PB, Westerterp KR, Wouters EF. Resting energy expenditure in patients with chronic obstructive pulmonary disease. Am J Clin Nutr 1991:54:983-7.

4. Creutzberg EC, Schols AMWJ, Bothmer-Quaedvlieg FCM, Wouters EFM. Prevalence of an elevated resting energy expenditure in patients with chronic obstructive pulmonary disease in relation to body composition and lung function. Eur J Clin Nutr 1998;52:396-401.

5. Baarends EM, Schols AM, Westerterp KR, Wouters EF. Total daily energy expenditure relative to resting energy expenditure in clinically stable patients with COPD. Thorax 1997;52:780-5.

6. Baarends EM, Schols AM, Akkermans MA, Wouters EF. Decreased mechanical efficiency in clinically stable patients with COPD. Thorax 1997;52:981-6.

7. Sala E, Roca J, Marrades RM, et al. Effects of endurance training on skeletal muscle bioenergetics in chronic obstructive pulmonary disease. Am J Respir Crit Care Med $1999 ; 159: 1726-34$.

8. Gosker HR, Wouters EF, van der Vusse GJ, Schols AM. Skeletal muscle dysfunction in chronic obstructive pulmonary disease and chronic heart failure: underlying mechanisms and therapy perspectives. Am J Clin Nutr 2000;71:1033-47.

9. Ricquier D, Bouillaud F. The uncoupling protein homologues: UCP1, UCP2, UCP3, StUCP and AtUCP. Biochem J 2000;345 Pt 2:161-79.

10. Schrauwen $\mathrm{P}$, Walder $\mathrm{K}$, Ravussin E. Human uncoupling proteins and obesity. Obes Res 1999;7:97-105.

11. Boss O, Samec S, Paoloni-Giacobino A, et al. Uncoupling protein-3: a new member of the mitochondrial carrier family with tissue-specific expression. FEBS Lett 1997;408:39-42.

12. Bouchard C, Perusse L, Chagnon YC, Warden C, Ricquier D. Linkage between markers in the 
vicinity of the uncoupling protein 2 gene and resting metabolic rate in humans. Hum Mol Genet $1997 ; 6: 1887-9$.

13. Schrauwen P, Xia J, Bogardus C, Pratley RE, Ravussin E. Skeletall muscle uncoupling protein 3 expression is a determinant of energy expenditure in Pima Indians. Diabetes 1999;48:146-9.

14. Schrauwen P, Troost FJ, Xia J, Ravussin E, Saris WH. Skeletal muscle UCP2 and UCP3 expression in trained and untrained male subjects. Int J Obes Relat Metab Disord 1999;23:96672.

15. Schrauwen $P$, Schaart G, Saris WH, et al. The effect of weight reduction on skeletal muscle UCP2 and UCP3 mRNA expression and UCP3 protein content in Type II diabetic subjects. Diabetologia 2000;43:1408-16.

16. Vidal-Puig A, Rosenbaum M, Considine RC, Leibel RL, Dohm GL, Lowell BB. Effects of obesity and stable weight reduction on UCP2 and UCP3 gene expression in humans. Obes Res $1999 ; 7: 133-40$.

17. Clapham JC, Arch JR, Chapman $\mathrm{H}$, et al. Mice overexpressing human uncoupling protein-3 in skeletal muscle are hyperphagic and lean. Nature 2000;406:415-8.

18. Millet $\mathrm{L}$, Vidal $\mathrm{H}$, Andreelli $\mathrm{F}$, et al. Increased uncoupling protein- 2 and -3 mRNA expression during fasting in obese and lean humans. J Clin Invest 1997;100:2665-70.

19. Gong DW, Monemdjou S, Gavrilova O, et al. Lack of obesity and normal response to fasting and thyroid hormone in mice lacking uncoupling protein-3. J Biol Chem 2000;275:1625I-7.

20. Hesselink MK, Keizer HA, Borghouts LB, et al. Protein expression of UCP3 differs between human type 1, type 2a, and type 2b tibers. Faseb J 2001;15:1071-3.

21. ATS. Standards for the diagnosis and care of patients with chronic obstructive pulmonary disease. Am J Respir Crit Care Med 1995;152:S77-121.

22. Quanjer P, Tammeling GJ, Cotes JE, Pedersen OF, Peslin R, Yernault JC. Standardized lung function testing. Eur Respir J 1993;6:5-40.

23. Engelen MPKJ, Schols AMWJ, Heidendal GAK, Wouters EFM. Dual-energy X-ray absorptiometry in the clinical evaluation of body composition and bone mineral density in patients with chronic obstructive pulmonary disease. Am J Clin Nutr 1998;68:1298-1303.

24. Vanitallie TB, Yang MU, Heymsfield SB, Funk RC, Boileau RA. Height-normalized indices of the body's fat-free mass and fat mass: potentially useful indicators of nutritional status. Am J Clin Nutr 1990;52:953-959.

25. Schols AM, Schoffelen PF, Ceulemans $H$, Wouters EF, Saris WH. Measurement of resting energy expenditure in patients with chronic obstructive pulmonary disease in a clinical setting. JPEN J Parenter Enteral Nutr 1992;16:364-8.

26. Weir JB. New methods for calculating metabolic rate with special reference to protein metabolism. 1949. Nutrition 1990;6:213-21.

27. Franssen FME, Wouters EFM, Baarends EM, Akkermans MA, Schols AMWJ. Arm mechanical efficiency and arm exercise capacity are relatively preserved in COPD. Med Sci Sports Exerc 2002.

28. Bergstrom L. Muscle electrolytes in man. Determination by neutron activation analysis on needle biopsy specimens. A study on normal subjects, kidney patients, and patients with chronic diarrhea. Scand J Clin Lab Invest 1962;68:1-110.

29. Gosker HR, van Mameren H, van Dijk PJ, et al. Skeletal muscle fiber type shifting and metabolic profille in patients with COPD. Eur Respir J 2002;19:617-626.

30. Gosker HR, Engelen MPKJ, van Mameren H, et al. Muscle fiber type IIX atrophy is involved in the loss of fat-free mass in chronic obstructive pulmonary disease. Am $\|$ Clin Nutr 2002;76:113-119.

31. Hesselink MKC, Greenhaff PL, Constantin-Teodosiu D, et al. A diet-induced increase in uncoupling protein 3 content does not affect mitochondrial coupling in human skeletal muscle. 
JCl 2003 in press.

32. Altman DG, Gore \$M, Gardner MJ, Pocock SJ. Statistical guidelines for contributors to medical joumals. Br Med J Clin Res Ed 1983;286:1489-93.

33. Vidal-puig $A_{3}$, Grujic $D$, Zhang $C Y$, et al Energy metabolism in uncoupling protein 3 gene knockout mice. I Biol Chem 2000;275:16258-66.

34. Engelen MP, Wouters EF, Deutz NE, Menheere PP, Schols AM. Factors contributing to alterations in skeletal muscle and plasma amino acid profiles in patients with chronic obstructive pulmonary disease. Am II Clin Nutr 2000;72:1480-7.

35. Hjalmarsen A, Aasebo $U$, Brikeland $K$, Sager $G$, Jorde $R$. Impaired glucose tolerance in patients with chronic hypoxic pulmonary disease. Diabetes Metab 1996;22:37-42.

36. Schiffelers $\mathrm{SL}_{\mathrm{s}} \mathrm{Blaak} \mathrm{EE}$, Baarends $\mathrm{EM}$, et al beta-Adrenoceptor-mediated themogenesis and lipolysis in patients with chronic obstructive pulmonary disease. Am $\mathbb{J}$ Physiol Endocrinol Metab 2001;280:E357-64.

37. Samee S, Seydoux J, Dulloo AG. Role of UCP homologues in skeletal muscles and brown adipose tissue: mediators of thermogenesis or regulators of lipids as fuel substrate? Faseb J $1998 ; 12: 715-24$.

38. Garcia-Martinez C, Sibille B, Solanes G, et al. Overexpression of UCP3 in cultured human muscle lowers mitochondrial membrane potential, raises $A T P / A D P$ ratio, and favors fatty acid vs. glicose oxidation. Faseb J 2001;15:2033-5.

39. Schrauwen P, Hesselink MK, Blaak EE, et al. Uncoupling protein 3 content is decreased in skeletal muscle of patients with type 2 diabetes. Diabetes $2001 ; 50: 2870-3$.

40. Himms-Hagen J, Harper ME. Physiological role of UCP3 may be export of fatty acids from mitochondria when fatty acid oxidation predominates: an hypothesis. Exp Biol Med (Maywood) $2001: 226: 78-84$

41. Schrauwen P, Saris WH, Hesselink MK. An alternative function for human uncoupling protein 3: protection of mitochondria against accumulation of nonesterified fatty acids inside the mitochondrial matrix. Faseb J 2001;15:2497-502.

42. Maltais F, Simard AA, Simard C, Jobin J, Desgagnes P, LeBlanc P. Oxidative capacity of the skeletal muscle and lactic acid kinetics during exercise in normal subjects and in patients with COPD. Am J Respir Crit Care Med 1996;153 «288-93.

43. Pecqueur C, Couplan E, Bouillaud F, Ricquier D. Genetic and physiological analysis of the role of uncoupling proteins in human energy homeostasis. J Mol Med 2001;79:48-56.

44. Pouw EM, Schols AMWJ "Vusse van der GJ, Wouters EFM. Elevated inosine monophosphate levels in resting muscle of patients with stable COPD. Am J Respir Crit Care Med $1998 ; 157: 453-57$.

45. Rahman 1, Morrison D, Donaldson K, MacNee W. Systemic oxidative stress in asthma, COPD, and smokers. An J Respir Crit Care Med 1996;154:1055-60.

46. Enge len MP, Schols AM, Does JD, Deutz NE, Wouters EF. Altered gllutamate metabolism is associated with reduced muscle glutathione levels in patients with emphysema. Am J Respir Crit Care Med 2000;161:98-103. 


\title{
CHAPTER 8
}

\section{Antioxidant capacity is increased in the vastus lateralis of patients with chronic obstructive pulmonary disease}

\begin{abstract}
Despite the growing field of interest in the role of pulmonary oxidative stress in chronic obstructive pulmonary disease (COPD), barely any data are available with respect to the antioxidant status in the peripheral skeletal muscles of these patients. The main objective of this study was to assess in detail the antioxidant status in skeletal muscle of patients with COPD. Biopsies from the vastus lateralis of 21 patients with COPD and 12 healthy age-matched controls were analyzed. Total antioxidant capacity was measured by means of the Trolox equivalent antioxidant capacity (TEAC). In addition, vitamin $\mathrm{E}$, glutathione, and uric acid levels were determined and the enzyme activities of superoxide dismutase, glutathione reductase, glutathione peroxidase, and glutathione-S-transferase were measured. Malondialdehyde was measured as an index of lipid peroxidation. The TEAC and the uric acid levels were markedly higher in COPD patients than in healthy controls $(25 \%, p=0.006$ and $24 \%, p=0.029$, respectively). Glutathione-S-transferase activity was also increased ( $35 \% ; \mathrm{p}=0.044)$ in patients compared to healthy subjects. The vitamin $E$ level was lower in patients than in controls $(p<0.05)$. The malondialdehyde level was not different between the two groups. It can be concluded that the muscle total antioxidant capacity is increased in patients with COPD. Together with the reduced vitamin E levels, the increased glutathione-S-transferase activity and normall levels of lipid peroxidation products, these findings suggest that the antioxidant system may be exposed to and subsequently triggered by elevated levels of reactive oxygen species.
\end{abstract}

Harry. R. Gosker', Aalt Bast', Guido R.M.M. Haenen', Mare A.J.G Fischer ${ }^{2}$, Ger J. van der Vusse, Emiel F.M Wouters' and Annemie M.W.J. Schols'. Departments of 'Respiratory Medicine, 'Pharmacology \& Toxicology, and ${ }^{3}$ Physiology, University of Maastricht, The Netherlands. Submitted' 


\section{INTRODUCTION}

Evidence is accumulating that oxidative stress plays an important role in chronic obstructive pulmonary disease (COPD). Considerable attention has especially been paild to oxidative stress in the pulmonary comparment during the last decade (1). Free radical fomation is associated with local inflammation and cigarette smoking and may result in the inactivation of antiproteases, airspace epithelial damage, mucus hypersecretion, increased influx of neutrophils into lung tissue, and the expression of pro-inflammatory mediators $(1,2)$. In addition to the pulmonary impairment, skeletal muscle wasting and muscle dysfunction are hallmarks of COPD $(3,4)$. Likewise, oxidative stress may also be involved in the systemic consequences of COPD. Oxidative stress occurs when the balance between oxidants, for instance reactive oxygen species (ROS), and antioxidants shifts in favor of the ROS. A few studies indicate that the antioxidant status is impaired at the systemic level: increased levels of lipid peroxidation products have been demonstrated in serum of patients with stable COPD (5). In patients with acute exacerbations, but not in clinical stable condition, plasma antioxidant capacily was reduced (5). After exercise, serum levels of lipid peroxidation products and oxidized glutathione were increased in patients compared to controls (6-8). The latter findings indicate that exercise-induced oxidative stress occurred and it is therefore most likely that the source of oxidative stress is the exercising muscle. A direct indication of oxidative stress in skeletal muscle comes from a study performed by Allaire et $a l$, who found increased accumulation of lipofuscin, a marker of oxidative damage, in vastus lateralis biopsies from COPD patients (9). Many diseases are associated with oxidative stress and the use of antioxidant supplements became very popular the last decades. However, the adverse side effects and toxicity of these supplements are not always recognized (10). Moreover, a detailed study is required to establish if and at what level the muscular antioxidant defense system is impaired in COPD in order to create a platform from which targetted intervention strategies can be developped.

Therefore, the aim of the present study was to assess in detail the antioxidant status in skeletal muscle of patients with COPD compared to healthy controls in rest. For this purpose the total antioxidant capacity was measured. In addition, the activities of several key antioxidant enzymes were measured, including superoxide dismutase (SOD), glutathione peroxidase (GPX), glutathione reductase (GR), and glutathione-S-transferase (GST). Also, the contents of total glutathione, uric acid, and vitamin E were measured. Finally, malondialdehyde (MDA) was detemined as an index of lipid peroxidation.

\section{METHODS}

A group of 21 patients with moderate to severe airflow obstruction and 12 healthy age-matched volunteers was studied. All patients had COPD according to ATS guidelines (11) and chronic airflow limitation, defined as measured forced expiratory volume in one second $(\mathbb{F E V})$ less than $70 \%$ of reference FEV.. Furthemore, patients had irreversible obstructive airway disease (less than $10 \%$ improvement of FEV 1 predicted baseline after $\beta_{2}$-agonist inhalation). They were in clinically stable condition and not suffering from a respiratory tract infection or an exacerbation of their disease at least 4 weeks prior to the study. Exclusion criteria were 
malignancy, cardiac failure, distal arteriopathy, recent surgery, severe endocrine, hepatic or renal disorders and use of anticoagulant medication. The healthy age-matched control subjects were volunteers recruited through advertisement in a local newspaper. Written informed consent was obtained from all subjects and the study was approved by the nedical ethical committee of the University Hospital Maastricht (Maastricht, The Netherlands).

\section{Pulmonary function tests}

All patients and control subjects underwent spirometry to determine FEV . Forced vital capacity (FVC) was assessed by whole-body plethysmography and diffusion capacity for carbon monoxide ( $\mathrm{DL}_{\mathrm{CO}}$ ) was measured by using the single-breath method (Masterlab, Jaeger, Wurzburg, Germany). All values obtained were related to a reference value and expressed as percentage of the predicted value (12). Arterial oxygen tension $\left(\mathrm{PaO}_{2}\right)$ was determined (ABL 330; Radiometer, Copenhagen, Denmark) while breathing room air.

\section{Assessment of body composition}

Body height and weight were assessed. Whole-body fat-free mass (FFM) was determined by bioelectrical impedance (Xitron 4000b, Xitron teclnologies, San Diego, California, USA) as described previously (13). Weight parameters were adjusted for body surface, resulting in the body mass index (BMI) and FFM index (FFMI) (14).

\section{Muscle strength}

Isokinetic muscle strength of the dominant knee extensor (quadriceps) was measured using a Biodex dynamometer (Biodex Corporation, Shirley, NY, USA) (15). The highest torque value (expressed as $\mathrm{Nm}$ ) of three sequential voluntary maximal contractions at an angular velocity of $60 \%$ was used.

\section{Exercise capacity}

Exercise capacity was assessed by means of cycle ergometry. Subjects performed an incremental $(10 \mathrm{~W} / \mathrm{min}$ for patients and $15-25 \mathrm{~W} / \mathrm{min}$ for controls) cycle ergometry test as described previously (16). Expired gases were investigated using breath by breath analysis through a breathing mask (Oxycon Beta $\mathrm{O}_{3}$, Jaeger, Wurzburg, Gemany). Peak VO $\mathrm{V}_{2}$ and peak load were measured at the moment of cessation of the exercise.

\section{Collection and processing of muscle tissue}

Postabsorptive muscle biopsies of the lateral part of the quadriceps femoris were obtained under local anesthesia by the needle biopsy technique (17) and the specimens were immediately frozen in liquid nitrogen. The frozen biopsies were weighed and subsequently grinded with a mortar cooled in liquid nitrogen. The frozen powder was resuspended in buffer $(100 \mathrm{mM}$ sodium phosphate, $\mathrm{pH} \mathrm{7.4)} \mathrm{to} \mathrm{a} \mathrm{final} \mathrm{concentration} \mathrm{of} 250 \mathrm{mg}$ tissue/ $\mathrm{ml}$ and directly re-frozen in liquid nitrogen and stored at $-80^{\circ} \mathrm{C}$ until use. For the determination of vitamin $\mathrm{E}$, an aliquot of the total muscle biopsy homogenate was used. For analysis of the other parameters the homogenate was centrifuged $\left(5 \mathrm{~min}\right.$. at $14,000 \mathrm{xg}$ and $\left.4{ }^{\circ} \mathrm{C}\right)$ and the muscle biopsy supernatant was used. Total protein content in the homogenates was assayed according to Smith et $a$. (18) using BSA as standard. 


\section{Masurements of antioxidants and lipid peroxidation}

GST activity was detemined by the GST catalyzed reaction of chlorodinitrobenzene (Sigma Chemical Co, St. Lours, USA) with reduced glutathone (GSH), resulting in a yellow colored product, glutathione-dinitrobenzene, of which the increase in absorbance was measured ( 2 min. at $340 \mathrm{~nm}$ ) (19). After correction for the non-enzymatic reaction, the activity of GST in the sample was calculated using the molar absorptivity coefficient of glutathione-dinitrobenzene. the GR activity was determined by measuring the decrease in absorbance ( 2 min. at 340 nm) by the consumption of NADPH (Sigma) in the enzymatic reduction of oxidized glutathione (GSSC) to GSH by GR (20). The activity was calculated using the molar absorptivity coefficient of $\mathrm{NADPH}$. The selenium dependent $\mathrm{GPX}$ activity, with $\mathrm{H}_{2} \mathrm{O}_{2}$ as substrate, was also determined by measuring the decrease in absorbance ( 3 min. at $340 \mathrm{~nm}$ ) due to the consumption of NADPH (21). GPX activity was calculated using the molar absorptivity coefficient of NADPH. Total glutathione level was determined by measuring the increase in absorbance ( 2 min. at $405 \mathrm{~mm}$ ), caused by the GSH driven reduction of 5 ' 5 dithiobis 2-nitrobenzoic acid (ICN Biomedicals Inc., Costa Mesa, USA), using the recycling method described by Vandeputte ef al. (22). The activity of the SOD was measured using the xanthine - xanthine oxidase system (Sigma) for the generation of superoxide anions and nitro blue tetrazolium (NBT) (Sigma): NBT is reduced by superoxide anions to the blue formazan which can be measured at $560 \mathrm{~nm}$. SOD scavenges superoxide anions resulting in less reduction of NBT. The increase in absorbance was measured ( 2 min. at $560 \mathrm{~nm}$ ) (25). After adding an internal standard, vitamin $\mathbb{E}$ nicotinate (Sigma), vitamin $\mathrm{E}$ was extracted by hexane extraction. Vitamin E concentration was determined with the HPLC method as previously described by van Haaften et al. (23), using an Agilent HPLC system (Agilent, Palo Alto, CA, USA) and a Nucleosil C 18 column ( $125 \times 4 \mathrm{~mm}$, particle size $5 \mu \mathrm{m}$, Agilent). Uric acid was determined in ultra filtrates with the HPLC method described by Lux et al. (24) using a Hypersil BDS C18 end-capped column ( $125 \times 4 \mathrm{~mm}$, particle size $5 \mu \mathrm{m}$, Agilent). The total antioxidant capacity was measured by means of the Trolox equivalent antioxidant capacity (TEAC) assay, as described by van den Berg et al. (25): MBS samples were deproteinated with trichloro-acetic acid. The absorbance (at $734 \mathrm{~nm}$ ) of the radical solution was $0.7 \pm 0.02$. Then the decrease in absorbance, caused by antioxidant capacity in the sample, was measured and related to that of trolox standards. The determination of MDA was based on the formation of a colored adduct of MDA with 2-thiobarbituric acid, which was measured according to the HPLC method described by Lepage et al. (26), using a Nucleosi. C 18 column (150 x $3.2 \mathrm{~mm}$, particle size 5 $4 \mathrm{~m}$, Supelco Inc, Bellefonte, PA, USA).

\section{Statistical analysis}

Data were analyzed with the unpaired Student's $/$ test (corrected for unequal variances if appropriate) or the Pearson correlation test, as appropriate (27). Data are represented as the means \pm SD. A two-tailed probability value of less than 0.05 was considered statistically significant. 


\section{RESULTS}

Subject characteristics are presented in table 1. Lung function was clearly impaired in pattents with COPD. Patients had a lower body mass index, a reduced peripheral muscle strength, and a decreased exercise capacity compared to control subjects.

The results of muscle biopsy analysis are shown in table 2. Total antioxidant capacity, as measured by the TEAC, was significantly increased in COPD, being $25 \%$ higher than in healthy controls. Muscle tissue uric acid levels were also significantly higher $(24 \%)$ in patients compared to control subjects. The antioxidant capacities of the TEAC and uric acid can be directly compared on a one-to-one basis. From this it can be calculated that the difference in uric acid level $(0.25 \mathrm{nmol} / \mathrm{mg}$ protein) accounts only for $2 \%$ of the difference in TEAC (12 $\mathrm{nmol} / \mathrm{mg}$ protein). Glutathione levels were normal in patients. The activities of all four antioxidant enzymes tended to be somewhat higher in COPD, but only GST activity was statistically significant higher (35\%). The level of vitamin $\mathbb{E}$, a lipid soluble scavenger, was reduced in patients, being $66 \%$ of control values. $\mathrm{MDA}$, the marker of lipid peroxidation, was not different between patients and controls.

Table 1. Subject characteristics

\begin{tabular}{|c|c|c|}
\hline & Controls & COPD \\
\hline $\mathrm{N}$ (Female/Male) & $12(4 / 8)$ & $21(3 / 18)$ \\
\hline Age (yr) & $65 \pm 7$ & $65 \pm 8$ \\
\hline $\mathrm{FEV}_{1}(\%$ pred $)$ & $113 \pm 25$ & $\pm 23^{\text {*線妆 }}$ \\
\hline $\mathrm{DL}_{\mathrm{co}}(\%$ pred $)$ & $114 \pm 16$ & $64 \pm 23^{* * *}$ \\
\hline FVC (\% pred) & $118 \pm 18$ & $86 \pm 19^{* * * 3}$ \\
\hline $\mathrm{PaO}_{2}(\mathrm{kPa})$ & $10.5 \pm 1.4$ & $9.7 \pm 1.1$ \\
\hline $\mathrm{SaO}_{2}(\%)$ & $95 \pm 2.0$ & $94 \pm 1.9$ \\
\hline \multicolumn{3}{|l|}{ Systemic characteristics: } \\
\hline BMI $\left(\mathrm{kg} / \mathrm{m}^{2}\right)$ & $27.3 \pm 2$ & $24.1 \pm 4^{* * *}$ \\
\hline $\mathrm{FFMT}\left(\mathrm{kg} / \mathrm{m}^{2}\right)$ & $19.8 \pm 1.8$ & $17.3 \pm 2.9^{* * *}$ \\
\hline exercise capacity as peak $\mathrm{VO}_{2}(\mathrm{ml} / \mathrm{min})$ & $2175+889$ & $894 \pm 343^{* * * *}$ \\
\hline exercise capacity as peak load (W) & $193 \pm 78$ & $68 \pm 29$ *** \\
\hline leg muscle strength as peak torque (Nm) & $154 \pm 43$ & $\pm 47^{* * *}$ \\
\hline smoking history (pack years) & $15 \pm 5$ & $51 \pm 7^{* * * x^{*}}$ \\
\hline
\end{tabular}

Values are mean $\pm \mathrm{SD}$; Significance of difference compared to controls: *** $\mathrm{p}<0.01 ; * * * \mathrm{p} \leq 0.001$. BMII: body

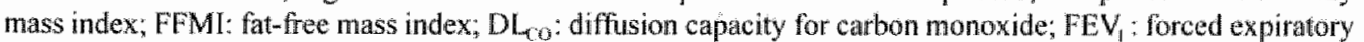
volume in one second; $\mathrm{FVC}$ : forced vital capacity; peak $\mathrm{VO}_{2}$ : peak oxygen consumption. 
Table 2. Muscle biopsy data

\begin{tabular}{lcc}
\hline & Controls & COPD \\
\hline SOD (U/mg protein) & $6.9 \pm 5.0$ & $9.5 \pm 4.0$ \\
GR (mU/mg protein) & $12.8 \pm 2.5$ & $13.3 \pm 3.6$ \\
GST (U/mg protein) & $0.17 \pm 0.07$ & $0.23 \pm 0.08^{*}$ \\
GPX (nmol NADPH/min/mg protein) & $20.7 \pm 6.7$ & $23.1 \pm 6.4$ \\
glutathione (nmol/mg protein) & $18.5 \pm 4.9$ & $19.6 \pm 5.2$ \\
TEAC (nmol Trolox Eq/mg protein) & $46 \pm 8.8$ & $58 \pm 12.7^{*} *$ \\
Uric acid (nmol/mg protein) & $1.04 \pm 0.21$ & $1.29 \pm 0.31^{*}$ \\
Vitamin E ( $\mu$ g/mg tissue) & $21.6 \pm 0.5$ & $17.3 \pm 0.5^{*}$ \\
MDA (nmol/mg protein) & $0.69 \pm 0.17$ & $0.77 \pm 0.37$ \\
\hline
\end{tabular}

Values are mean $\mathrm{SD}$; Significance of difference compared to controls: $* 00,05 ; * * \mathrm{p}<0.01$. GPX: glutathione peroxidase; GR: glutathione reductase; GST: glutathione S-transferase; SOD: stuperoxide dismutase; TEAC: Trolox equivalent antioxidant capacity; MDA: matondialdehyde.

Muscle antioxidant status was not related to disease severity as measured by the $F E V_{1}$. In addition, the increased antioxidant capacity can not be explained by differences smoking history. There were also no relations between antioxidant status and muscle strength or exercise capacity.

\section{DISCUSSION}

The most striking results of this study are that the overall antioxidant capacity of peripheral skeletal muscle in rest was higher in patients with COPD compared to healthy age-matched control subjects, whereas the vitamin $E$ level was reduced. These are very important findings, because they indicate that the muscular antioxidant status is chronically altered in COPD patients characterized by peripheral muscle weakness and wasting. Probably the most important way by which the antioxidant defense system can be triggered is exposure to ROS (28-30). It: is therefore likely that the observed increased antioxidant capacity is a compensatory adaptation to elevated ROS formation in skeletal muscle of patients with COPD.

Oxidative stress occurs when the balance between oxidants, i.e. ROS, and antioxidants shifts in favor of the ROS. The reactive superoxide anions may subsequently give rise to hydrogen peroxide, hydroxyl radicals, and other redox-reactive molecules. An inadequate defense system may be overwhelmed by the ROS, leading to damage of proteins, lipids, and DNA, which in turn may result in extensive cell and tissue damage. SOD catalyzes the dismutation of superoxide anions to hydrogen peroxide, which in turn is converted to harmless water and oxygen by the glutathione system. This system includes the enzymes GPX, GST, and GR. GPX and GST activities require reduced glutathione (GSH) as a co-factor, GPX activity results in oxidized glutathione (GSSG) and the accumulating GSSG can subsequently be recycled to 
GSH via the enzyme GR (31). Uric acid has been suggested as ROS seavenger, aluough its action in muscle has not been studied systematically (31). ROS can also raget with lipids, forming lipid radicals and lipid peroxyl radicals. The lipid peroxyl radicals can be seavenged

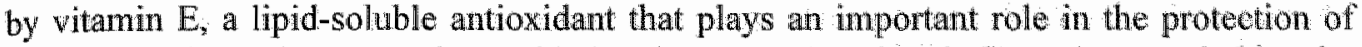
plospholipid membranes against oxidative damage (31). Vitamin E can be recycled by, for example GSH. Lipid peroxidation products can be detoxilied by GST. But if the scavenging capacity is insufficient, lipid peroxidation products may accumulate, as reflected by increased MDA levels. Figure 1 shows a schematic representation of ROS formation and the antioxidant system in skeletal muscle.

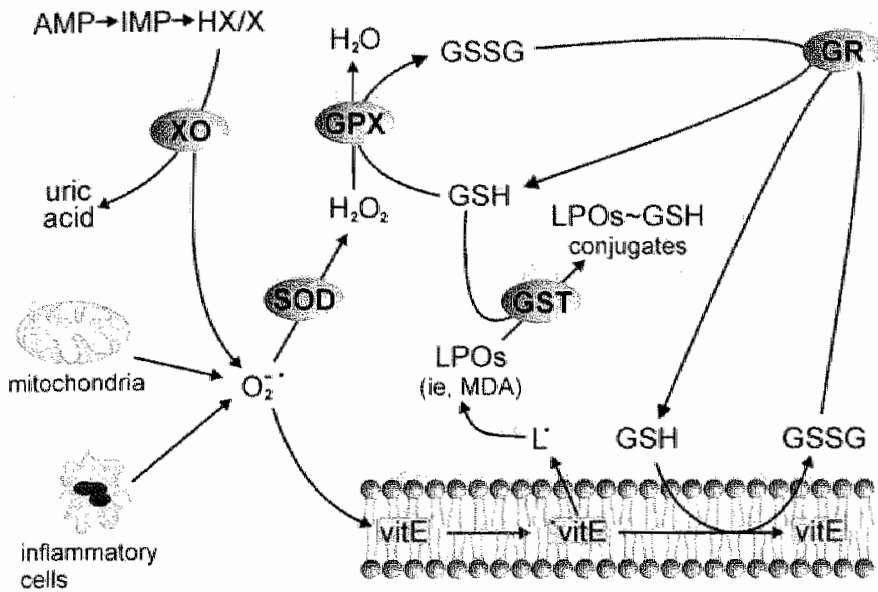

Figure 1. A schematio representation of antioxidants and ROS formation. AMP: adenosine monophosphate; IMP: inosine monophosphate; $\mathrm{XO}$ : xanthine oxidase; $\mathrm{HX}$ : hypoxanthine; $\mathrm{X}$ : xanthine; $\mathrm{SOD}_{\text {: }}$ superoxide dismutase; GPX: glutathione peroxidase; GSH: reduced glutathione; GSSG: oxidized glutathione; GR: glutathione reductase; GST; glutathione Stransferase; $L$ : lipid radical; LPOs: lipid peroxidation products; MDA: malondialdehyde; vite: vitamin $\mathbb{E}$.

In the present study, the total antioxidant capacity, as measured by the TEAC, was markedly higher in COPD than in controls and, as mentioned earlier, oxidative stress may very well be the trigger. The only direct indication for muscular oxidative stress in COPD has recently been provided by Allaire et al, who reported accumulation of intramuscular lipofiscin (9). The fact that vitamin $E$ levels were decreased in patients also supports this notion, because this may reflect its utilization during oxidative stress. Interestingly, reduced vitamin $\mathbb{E}$ was reported for COPD recently in blood as well (8). However, in the current study no significantly increased lipid peroxidation products (MDA) were found in the muscle biopsies from COPD patients. There are two possible explanations for this. The first option is that, in rest, there is no muscular oxidative stress; thus there is a balance between the increased antioxidant capacity and the, supposedly elevated free radical formation. In this respect, it is also possible that the observed increase in GST activity provides extra potential to detoxify lipid peroxidation products, thereby preventing a rise in MDA. Skeletal muscle fibers generate ROS at a relative low rate continuously, because $\sim 3 \%$ of total oxygen consumed leaks away from the mitochondrial electron transport in the form of superoxide anions. ROS formation is dramatically increased during exercise (31). It is therefore still possible that exercise induced oxidative stress is responsible for reduced vitamin E levels and the stimulated TEAC. Unlike lipofuscin, MDA does not accumulate in the muscle cells over time, but diffuses away from the muscle and can be metabolized. Therefore, a second option is that, in rest, oxidative stress 
and subsequent lipid peroxidation do oecur, but at such a low rate that MDA may not be a sensible marker.

Although the present study was not designed to determine the mechanism and sources of muscular oxidative stress in COPD, some possibilities will be briefly discussed below. First of all, mitochondria in the muscle cells are a major source of ROS, especially during exercise: Normally, the antioxidant status in the oxidative type I fibers is higher compared to the less oxidative type II fibers $(31,32)$. However, despite the currently observed increased tota] antioxidant capacity, a I $\rightarrow$ II fiber type shift and a reduction of oxidative capacity have consistently been observed in the vastus lateralis of patients with COPD (33-36). This would suggest that ROS formation in the remaining type I fibers may be higher than normal, which is supported by the recent study in which increased lipofuscin accumulation was indeed greater in type I fibers than in type II fibers (9). Because COPD patients are certainly not more physically active than healthy subjects, this suggests that relatively more free radicals are produced in exercising muscles of these patients. Baarends et al. recently reported that leg muscle mechanical efficiency is less in COPD compared to controls (37). This, and the reduced capacity of oxidative energy metabolism mentioned earlier may lead to the incomplete oxygen reduction and subsequent ROS formation. A second source of ROS is inflammation. Systemic inflammation is indeed common in COPD and has been associated with muscle wasting in these patients (38-40). There is also evidence that immune cells that are activated during inflammation are a source of ROS in the skeletal muscles $(41,42)$. In addition, there are indications that the muscle cells themselves can be triggered by circulating inflammatory mediators to produce ROS (43-46). A third alternative source of ROS is the xanthine oxidase, which is an enzyme that catalyzes the conversion of hypoxanthine into uric acid. Hypoxanthine accumulates in situations of metabolic stress (ie exercise and hypoxia) as a result from AMP degradation (32). Heunks et al. demonstrated, for COPD, that the oxidation of glutathione in blood during exercise can be inhibited by treatment with allopurinol, an xanthine oxidase inhibitor (6). In this study we found elevated levels of uric acid in the muscle biopsies from patients with COPD. Although it can be considered as an antioxidant itself, the observed increase of uric acid is probably of minor importance compared to the increased total antioxidant capacity in patients, as measured by TEAC. However, an increased uric acid level may also indicate increased xanthine oxidase activity, since uric acid is a degradation product of AMP degradation. This is in line with a previous study in which elevated IMP levels were observed in skeletal muscle biopsies from COPD patients, since IMP is an intermediate in AMP degradation (47).

The present data indicate that the total muscular glutathione level was normal in this COPD group. Rabinovich et al. also demonstrated that muscle glutathione was normal in COPD compared to controls (48). Previously, Engelen et al. reported reduced glutathione levels in vastus lateralis biopsies from emphysema patients, which was associated with reduced levels of its precursor, glutamate (49). This suggests that glutathione homeostasis may differ between COPD sub-groups. Alternatively, the discrepancy may reflect differences between the methodologies that were used: Engelen et al. expressed glutathione levels per wet weight of muscle tissue, whereas glutathione levels were corrected for total protein level in the other two studies. 
The present data provide some new starting points for future research. For example, the elevated TEAC remains largely unexplained Because the TEAC is measured in a deprotenated sample, the contribution of enzymes can be ruled out. Identification of the artioxidant(s) that is (are) responsible for this increase may provide perspectives for new therapies. The findings also suggest that vitamin $\mathrm{E}$ supplementation might be beneficial for $\mathrm{COPD}$ patients. Although evidence for a protective effect of vitamin $E$ intake on respiratory symptoms and lung function are inconsistent (50), there are some indications that vitamin $\mathbb{E}$ may prevent oxidative stress induced muscle damage, for example in immobilized rats (51) or in humans during surgical ischemia/reperfusion (52). More research is thus required to establish whether antioxidant supplementation in COPD patients is beneficial from a "muscular" point of view.

In summary, to our knowledge, this is the first detailed study in which several key antioxidants in peripheral skeletal muscle were examined in COPD. The collected data strongly suggest that the production and handling of oxygen free radicals is altered in muscles of COPD patients. It remains to be explored whether this alteration is instrumental in muscle weakness in COPD patients.

\section{REFERENCES}

1. MacNee W, Rahman I. Is oxidative stress central to the pathogenesis of chronic obstructive pulmonary disease? Trends Mol Med 2001;7:55-62.

2. Repine JE, Bast A, Lankhorst I. Oxidative stress in chronic obstructive pulmonary disease. Oxidative Stress Study Group. Am J Respir Crit Care Med 1997;156:341-57.

3. Mador $\mathrm{JM}$, Bozkanat $\mathrm{E}$. Skeletal muscle dysfunction in chronic obstructive pulntonary disease. Respir Res 2001;2:216-24.

4. Gosker HR, Wouters EF, van der Vusse GJ, Schols AM. Skeletal muscle dysfunction in chronic obstructive pulmonary disease and chronic heart failure: underlying mechanisms and therapy perspectives. Am J Clin Nutr 2000;71:1033-47.

5. Rahman I, Morrison D, Donaldson K, MacNee W. Systemic oxidative stress in asthrna, COPD, and smokers. Am J Respir Crit Care Med 1996;154:1055-60.

6. Heunks LM, Vina J, van Herwarden CL, Folgering HT, Gimeno A, Dekhujzen PN, Xanthine oxidase is involved in exercise-induced oxidative stress in chronic obstructive pulmonary disease. Am J Physiol 1999;277:R 1697-704.

7. Vina J, Servera E, Asensi $M$, et al. Exercise causes blood glutathione oxidation in chronic obstructive pulmonary disease: prevention by o 2 therapy. J Appl Physiol 1996;81:2199-2202.

8. Coulllard A, Koechlin C, Cristol JP, Varray A, Prefaut C. Evidence of local exercise-induced system oxidative stress in chronic obstructive disease patients. Eur Respir J 2002;20:1123 1129.

9. Allaire $J$, MaItais $F$, LeBlanc $P$, et al. Lipofuscin accumulation in the vastus lateralis muscle in patients with chronic obstructive pulmonary disease. Muscle Nerve 2002;25:383-9.

10. Bast A, Haenen GR. The toxicity of antioxidants and their metabolites. Environ Toxicol Pharmacol 2002;11:251-258.

11. ATS. Standards for the diagnosis and care of patients with chronic obstructive pulmonary disease. Am J Respir Crit Care Med 1995;1:52:S77-121.

12. Quanjer P, Tammeling GJ, Cotes JE, Pedersen OF, Peslin R, Yermault JC. Standardized lung function testing. Eur Respir J 1993;6:5-40.

13. Schols AM, Wouters EF, Soeters PB, Westerterp KR. Body composition by bioelectrical- 
impedance andisysis compared with deuterium dintion and skinfold anthropometry in patients with chronic obstructive pumonary disease. An J Clin Nutr 1991,53.421-4.

14. Vanltallie TB, Yang MU, Heymsfield SB, Funk RC, Boileau RA. Height-normalized indices of the body's fat-free mass and fat mass: potentially useful indicators of nutritional status. Am J Clin Nutr 1990;52:953-959.

15. Dvir Z. Isokmetics. Muscletesting, interpretation and clinical applications. 1st ed. Edinburgh: Churchill Livingstone, 1995.

16. Franssen FME, Wouters EFM, Baarends EM, Akkermans MA, Schols AMWJ. Am mechanical efficiency and arm exercise capacity are relatively preserved in COPD. Med Sci Sports Exerc 2002 .

17. Bergstrom L. Musele electrolytes in man. Determination by neutron activation analysis on needle biopsy specimens. A study on normal subjects, kidney patients, and patients with chronic dianthea. Scand J Clin Lab Invest 1962;68:1-110.

18. Smith PK, Krohn RL, Hermanson GT, et al. Measurement of protein using bicinchoninic acid. Anal Biochem 1985;150:76-85.

19. Habig WH, Jakoby WB. Assays for the differentiation of glutathione S-transferases. Methods Enzymol 1981;77:398-405.

20. Tiet $z \mathrm{NW}$. Method for the determination of erythrocyte glutathion reductase activity. Textbook of clinical chemistry. 1st ed. Philadelphia: WB Saunders Company, 1986949.

21. Paglia DE, Valentine WN. Studies on the quantitative and qualitative characterization of erythrocyte glutathione peroxidase. J Lab Clin Med 1967;70:158-69.

22. Vandeputte C, Guizon I, Genestie-Denis I, Vamier B, Lorenzon G. A microtiter plate assay for total glutathione and glutathione disulfide contents in cultured/isolated cells: performance study of a new miniaturized protocol. Cell Biol Toxicol 1994;10:415-21.

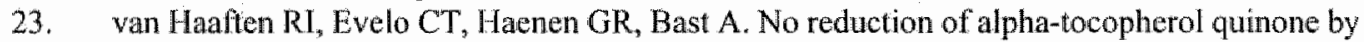
glutathione in rat liver microsomes. Biochem Pharmacol 2001;61:715-9.

24. Lux $\mathrm{O}$, Naidoo D, Salonikas C. Improved HPLC method for the simultaneous measurement of allantoin and uric acid in plasma. Ann Clin Biochem 1992;29:674-5.

25. Berg van den R, Haenen GRMM, Berg van den H, Bast A. Applicability of an improved Trolox equivalent antioxidant capacity (TEAC) assay for the evaluation of the antioxidant capacity measurements of mixtures. Food Chem 1999;66:511-517.

26. Lepage G, Munoz G, Champagne J, Roy CC. Preparative steps necessary for the accurate measurement of malondialdehyde by high-performance liquid chromatography. Anal Biochem $1991 ; 197: 277-83$

27. Altman DG, Gore SM, Gardner MJ, Pocock SJ. Statistical guidelines for contributors to medical journals. Br Med IClin Res Ed 1983;286:1489-93.

28. Ji LL. Exercise, oxidative stress, and antioxidants. Am J Sports Med 1996;24:S20-24.

29. Giullan $A$, Cestaro B. Exercise, free radical generation and vitamins. Eur J Cancer Prev $1997 ; 6.555-67$

30. Ji LL. Exercise-induced nodulation of antioxidant defense. Ann $\mathbb{N}$ Y Acad Sci 2002;959:82-92.

31. Reid MB. Invited Review: redox modulation of skeletal muscle contraction: what we know and what we don't. I Appl Physiol 2001;90:724-31.

32. Heunks LM, Dekhuijzen PN. Respiratory muscle function and free radicals: from cell to COPD. Thorax 2000;55:704-716.

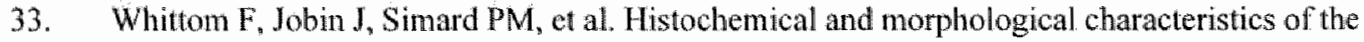
vastus lateralis muscle in patients with chronic olsstructive pulmonary disease. Med Sci Sports Exerc 1998; $30: 1467-1474$.

34. Gosker HR, van Mameren H, van Dijk PJ, et al. Skeletal muscle fibre type shifting and metabolic profile in patients with COPD. Eur Respir J 2002;19:617-626. 
35. Maltais $F$, Simard AA, Simard C, Jobin J, Desgagnes $P$, LeBlanc 1 . Oxidative capacity of the skeletal muscle and lactic acid kinetics during exercise in normal subjects and in patients with COPD. Am J Respir Crit Care Med 1996;153:288-93.

36. Jakobsson P, Jorfeldt L, Menriksson J. Metabolic enzyme activity in the quadriceps femoris muscle in patients with severe chronic obstructive pullmonary disease. Am I Respir Crit Care Med 1995;151:374-7.

37. " Baarends EM, Schols AM, Akkermans MA, Wouters EF. Decreased mechanical efficiency in clinically stable patients with COPD. Thorax 1997;52;981-6.

38. Eid AA, Ionescu AA, Nixon LS, et al. Inflammatory response and body composition in chronic obstructive pulmonary disease. Am J Respir Crit Care Med 2001;164:1414-8.

39. Di Francia M, Barbier D, Mege JL, Orehek J. Tumor necrosis factor-alpla levels and weight Ioss in chronic obstructive pulmonary disease. Am J Respir Crit Care Med 1994;150:1453-5.

40. Schols AM, Buurman WA, Staal van den Brekel Al, Dentener MA, Wouters EF. Evidence for a relation between metabolic derangements and increased levels of inflammatory mediators in a subgroup of patients with chronic obstructive pulmonary disease. Thorax 1996;51:819-24.

41. Reid MB. Reactive oxygen and nitric oxide in skeletal muscie. News Physiol Sci 1996;11:114. 119.

42. Supinski G, Stofan D, Nethery D, Szweda L, DiMarco A. Apocynin improves diaphragmatic function after endotoxin administration. J Appl Physiol 1999;87:776-82.

43. Li YP, Atkins CM, Sweatt JD, Reid MB. Mitochondria mediate tumor necrosis factoralpha/NF-kappaB signaling in skeletal muscle myotubes. Antioxid Redox Signal 1999;1:97104.

44. Langen RC, Schols AM, Keiders MC, Van Der Velden JL, Wouters EF, Janssen-Heininger YM. Tumor necrosis factor-alpha inhibits myogenesis through redox-dependent and -independent pathways. Am J Physiol Cell Physiol 2002;283:C714-21.

45. Callahan LA, Nethery D, Stofan D, DiMarco A, Supinski G. Free radical-induced contractile protein dysfunction in endotoxin-induced sepsis. Am J Respir Cell Mol Biol 2001;24:210-7.

46. Buck M, Chojkier M. Muscle wasting and dedifferentiation induced by oxidative stress in a murine model of cachexia is prevented by inhibitors of nitric oxide synthesis and antioxidants. EMBO J 1996; 15:1753-65.

47. Pouw EM, Schols AMWJ, Vusse van der GJ, Wouters EFM. Elevated inosine monophosphate levels in resting muscle of patients with stable COPD. Am J Respir Crit Care Med $1998 ; 157: 453-57$.

48. Rabinovich RA, Ardite $\mathbb{E}$, Troosters $T$, et al. Reduced musele redox capacity after endurance training in patients whth cluonic obstructive pulmonary disease. Am J Respir Crit Care Med $2001 ; 164: 1114-8$.

49. Engelen MP, Schols AM, Does JD, Deutz NE, Wouters EF. Altered glutamate metabolism is associated with reduced muscle glutathione levels in patients with emphysema. Am J Respir Crit Care Med 2000;161:98-103.

50. Smit HA, Grievink L, Tabak C. Dietary influences on chronic obstructive lung disease and asthma: a review of the epidemiological evidence. Proc Nutr Soc 1999;58:309- 19 .

51. Appell HJ, Duarte JAR, Soares $\mathrm{JMC}$. Supplementation of vitamin E may attenuate skeletal muscle immobilization atrophy. Int J Sports Med 1997;18:157-160.

52. Novelli GP. Adembri C, Gandini E, et al. Vitamin E protects human skeletal muscle from damage during surgical ischemia-reperfusion. Am J Surg 1997;173:206-9. 
CHAPTER 9

Summary \& general discussion 


\section{INTRODUCTION}

According to the definitions of the World Health Organization, chronic diseases are characterized not only by their local impairment, but also by disability and handicap (1). Besides symptoms such as dyspnea and fatigue, COPD patients and patients with chronic heart faillure (CHF) are progressively disabled by impaired exercise performance. Peripheral skeletal muscle dysfunction has been identified as an important contributor to exercise intolerance in both conditions independent of disease severity. Strength and endurance are two main determinants of muscle function and in chapter 3 it was shown that both components are reduced in COPD and CHF. On cross-sectional analysis, reduced muscle strength is strongly related to loss of muscle mass measured by means of the fat-free mass (FFM). Muscle endurance, in contrast, is independent of FFM and it is therefore likely that additional intrinsic muscular alterations are also involved in skeletal muscle dysfunction in these disorders. As discussed in chapter 2 of this thesis, reduced oxidative capacity and a decreased proportion of type I fibers have consistently been observed in vastus lateralis biopsies from patients with COPD and CHF. Since oxidative energy metabolism is crucial for muscle endurance, it is feasible that these abnormalities are somehow involved in earlier muscle fatigue in these disorders. The fact that besides pulmonary impairment muscular abnormalities are involved in exercise intolerance in COPD offers novel perspectives for therapy. However, in order to develop or optimize the effectiveness of these treatments, more understanding is required of the characteristics of and mechanisms underlying these muscular alterations in COPD. The overall aim of this study was therefore to investigate the muscular pathology in COPD at the functional, histopathological and molecular level.

\section{Muscle atrophy}

To provide more insight in the underlying pathology of muscle wasting, muscle morphology was evaluated in biopsies from the vastus lateralis of patients with COPD using a variety of histochemical techniques. First of all, a standard semiquantitative screening for myopathologic features was performed (chapter 4). Compared to healthy age-matched controls, marked muscle fiber atrophy was observed in COPD patients. The overall picture pointed towards a mild neurogenic atrophy in COPD patients, which was further characterized by fatty cell replacement and fibrosis. This was also present, but to a slightly lesser extent, in the control subjects. No other myopathological features (ie infiltrates of inflammatory cells, necrosis, apoptosis, central nuclei) were observed in these clinically stable patients compared to controls. Muscle fiber atrophy was studied in a more detailed manner by measuring the actual cross-sectional areas of muscle fibers using an interactive image analysis system (chapter 6). It was demonstrated that atrophy of muscle fibers is involved in the loss of FFM in these patients. The atrophy was specific for type IIX fibers, which suggests that the atrophy is more associated to nutritional depletion and/or chronic metabolic stress than to disuse of the affected muscles.

Besides muscle fiber atrophy, other clear morphological abnormalities that could account for a decreased muscle mass were not found in the present study (chapter 4). For example, loss of muscle mass can be the result of a reduction of the total amount of muscle fibers, caused by 
cell death. Apoptosis and necrosis are two main processes that lead to cell death. However, although necrosis has previously been reported in COPD patients diagnosed with steroidinduced myopathy (2), an abnormal degree of necrosis was not observed at all in the clinically stable COPD patients that we studied. Apoptosis of myocytes associated with low BMI has recently been reported for COPD, although a relation with fat-free mass or muscle fiber crosssectional area was not reported (3). However, these findings should be interpreted with great caution, because of several major drawbacks of the methods that were used (4). Furthermore, since niyocytes are multinucleated, apoptosis in these cells not necessarily leads to cell death. Instead, it has been suggested that apoptotic nuclei are involved in the remodelling process of myocytes, in order to adjust the amount of nuclei in atrophying fibers $(5,6)$. Such a relation between muscle atrophy and apoptosis was indeed found in patients with CHF (7). In the present study, no clear signs of myocyte apoptosis were observed in COPD and there was no relation between atrophy and the amount of apoptotic nuclei. However, the timing of the muscle biopsy in the clinical course of COPD should also be considered. In this study, COPD patients were in stable condition and not suffering from extreme weight loss. Therefore, the involvement of apoptosis and necrosis in cachectic COPD patients or during acute exacerbations, periods often characterized by severe weight loss, requires further investigation.

The mechanism and contributing factors underlying muscle fiber atrophy in COPD is unknown. An imbalance between protein synthesis and protein breakdown, in favor of the latter, is feasible. Findings pointing towards involvement of decreased muscle protein synthesis in muscle wasting have been reported for underweight patients with emphysema (8). Oxidative stress and systemic inflammation may be factors that are probably involved in the net protein loss. Enhanced oxidative stress probably occurs in the skeletal muscles of patients with COPD, as outlined in chapter 8 . Protein oxidation by reactive oxygen species (ROS) leads to formation of carbonyl groups on anino acid residues, thereby modifying the proteins structure and/or chemical properties. These altered proteins are more susceptible to proteinases or may even be recognized as foreign substances and be attacked by the immune system (9). Also, decreased protein synthesis has been demonstrated in studies in which oxidative stress inhibited muscle specific protein expression $(10,11)$, suggesting that, in theory, oxidative stress can suppress protein synthesis in skeletal muscle of patients with COPD. During acute inflammatory mediated metabolic stress, a redistribution of the body's protein content occurs, with preferential depletion of skeletal muscle in order to provide substrate and energy for acute phase protein synthesis in the liver but possibly also in other tissue (12). This process is tightly regulated by cytokines, of which TNF $\alpha$ is probably the most important one. An association between systemic inflammation, especially reflected by increased circulating levels of TNFa and the soluble TNF-receptors and chronic muscle wasting has indeed been observed in COPD (13). There is abundant evidence that the ubiquitin-proteasome pathway is responsible for most of the increased protein breakdown in various types of muscle atrophy (14). Whether this is the case in (subgroups) of patients with COPD however needs to be examined. Interestingly, in an animal model it has been demonstrated that the administration of various inflammatory cytokines enhanced ubiquitin gene expression in skeletal muscle (15). Oxidative damage to proteins also results in degradation through the ubiquitin-proteasome pathway (1.6). It can therefore be speculated that oxidative stress and/or elevated levels of circulating inflammatory mediators trigger muscular protein breakdown in COPD. Alternatively, impaired regeneration 
of muscle fibers may be involved in muscle atrophy as well. In normal conditions, replacement of damaged or diminished muscle fibers can be established by the proliferation of satellite cells into myoblasts, which subsequently differentiate into myocytes. Interestingly, Langen et al. recently demonstrated impaired differentiation of myocytes after exposure to TNF $\alpha$ and the possible involvement of ROS (10). It can therefore be hypothesized that impaired muscle regeneration is involved in muscle fibre atrophy in these patients.

\section{Intrinsic muscle abnormalities}

The redistribution of fiber types and the reduction of oxidative capacity in peripheral muscle of patients with COPD has been reviewed in chapter 2 . In short, reduced proportions of type I fibers and decreased activities of enzymes involved in oxidative energy metabolism have consistently been observed in vastus lateralis biopsies from patients with COPD. In the current thesis these alterations were examined in more detail. Several existing techniques were combined to assess fiber types. This made it possible to identify not only pure type I, IIA, and IIX fibers, but also hybrid I/IA and IIA/ILX fibers. Indeed more hybrid fibers were present in muscle biopsies from COPD patients than from control subjects suggesting that fiber type transitions $(\mathrm{I}-\mathrm{I} / \mathrm{IIA} \rightarrow$ IIA $\rightarrow$ IIA $/ I I X \rightarrow I I X)$ are involved in the fiber type redistribution in COPD (17). In addition, the resulting reduction of the fiber type I proportion is closely related to the loss of oxidative capacity, as assessed by the staining of oxidative enzyme activities. It is however unclear which is the chicken and which is the egg and whether these changes are related to muscle fiber type IIX atrophy. It can be speculated that the shift towards type IIX. fibers is a compensatory adaptation to the loss type IIX fibers due to atrophy. The reduction of oxidative capacity could then simply be the result of the reduced proportion of oxidative type I fibers. Alternatively, as discussed in chapter $\mathbf{5}$, changes in oxidative capacity may precede the fiber type transformations. Type IIX atrophy would then be an independent process. With the current cross-sectional comparison between COPD patients and healthy control subjects, this issue could not be resolved. Instead, in clinical studies the changes in oxidative capacity, fiber type distribution and fiber sizes need to be evaluated. As far as we know, such studies have not yet been performed in COPD or other clinical models. Phenotype transitions of muscle fibers occur under a variety of conditions (18). Disrupted innervation or decreased neuromuscular activity can lead to I $\rightarrow$ II transitions. However, no data are available on ininervation of peripheral muscles in COPD. The present data do indeed point towards a slightly more pronounced neurogenic atrophy in these patients compared to healthy controls (chapter 4), but these data are not conclusive. Unloading of muscles can also induce a I $\rightarrow$ II shift. It is generally assumed that COPD patients perform less daily activities than healthy age-matched controls, which was confirmed in this thesis (chapter 3). Reduced oxidative capacity and decreased fiber type I proportions have been associated with inactivity, although the literature is not consistent (19). Disuse may therefore be involved in the reduction of type I fibers in COPD. Finally, altered hormonal profiles, especially of testosterone and thyroid hormone, may have a influence on fiber type shifts as well. Serum thyroid hormone levels are normal in COPD (20), but hypogonadism has indeed been reported for COPD (21). To what extent the observed hormonal changes influence muscular alteration in COPD need to be further investigated. 
Direct relations between changes in muscle fiber types or metabolic profille found so far and the impairments at the functional level are scarce. In search of such a link, we tested the hypothesis whether an increased muscle uncoupling protein 3 (UCP3) level is involved in the reduced mechanical efficiency, measured as the gross efficiency, in COPD (chapter 7), since human UCP3 is potentially an important determinant of energy metabolism. Surprisingly, the outcome of the study was that the muscle UCP 3 content was reduced compared to controls. UCP3 is a mitochondrial protein, which poses the question whether the low UCP3 content in skeletal muscle of patients with COPD is a functional adlaptation or simply a reflection of the reduced proportion of oxidative type I fibers. UCP3 content, however, did not correlate significantly with cytochrome $\mathrm{c}$, a mitochondrial marker. Interestingly, human UCP3 gene expression requires MyoD (22), which is a transcriptional activator of muscle specific gene expression and also a master regulator of the differentiation program of myocytes. MyoD is predominantly expressed in fast muscles and probably plays a causative role in expression of type II myosin heavy chains $(23,24)$. Since it has also been found that UCP3 is predominantly located in type II fibers (25), it can be speculated that reduced MyoD, for instance due to enhanced systemic inflammation $(26,27)$, plays a role in both type IIX atrophy and in the reduced UCP3 content. Alternatively, it can be hypothesized that a lower UCP3 content is a compensatory adaptation to decreased mechanical efficiency caused by other factors in COPD. Indeed, in contrast to our initial hypothesis, an inverse, association was found between UCP3 and gross efficiency as a marker of mechanical efficiency, during cycle ergometry. Further studies are warranted to explore if this association reflects a causal link or is merely an epiphenomenon of disease severity.

The cause of a decreased mechanical efficiency of leg muscle in COPD remains unclear. Oxidative energy metabolism is more efficient than glycolytic energy metabolism and muscles composed of mainly type I fibers are therefore more efficient than those composed of mainly type II fibers (28). This suggests that the low fiber type I proportion and reduced oxidative capacity may play a role in the reduced leg mechanical efficiency in these patients. Oxidative stress could be another possibility. For the heart muscle it has been shown that preventing oxidative stress decreases its oxygen consumption and increases mechanical efficiency (29) and this may theoretically also apply to skeletal muscle. Despite a growing interest for the role of pulmonary oxidative stress in COPD, barely any data is available with respect to oxidative stress and antioxidant status in the peripheral skeletal muscles of these patients. A panel of key antioxidants was therefore analyzed in peripheral muscle biopsies from COPD patients and healthy volunteers, in rest. Total antioxidant capacity was increased in patients, whereas vitamin $\mathrm{E}$, a lipid soluble radical scavenger, was reduced. The malondialdehyde level, a marker of lipid peroxidation, was normal in patients. The collected findings indicate that, overall, the antioxidant capacity is chronically increased in patients, which may very well be a compensatory adaptation to elevated free radical formation in the affected muscle. In rest, muscular oxidative stress is either absent or not detectable with the currently used techniques. However, after exercise, increased serum levels of lipid peroxidation products and oxidized glutathione have been reported for COPD patients compared to healthy subjects (30-33). In addition, glutamate, a precursor of glutathione, is reduced in skeletal muscle of patients with emphysema (34). Since oxidative energy metabolism is impaired in COPD and glutanate is also a key intermediate of this oxidative metabolism, it is feasible that glutathione synthesis is 
impaired during exercise due to the lack of sufficient precursor. These data suggest that in COPD, the muscle antioxidant capacity is not adequate to prevent ROS production and it is therefore likely that oxidative stress occurs especially during bouts of exercise.

\section{Multifactorial origin?}

Hypoxia, oxidative stress, systemic inflammation, disuse, aging, and medication may all, to some degree, account for the intrinsic muscular abnormalities. In the present study, the role of aging can be ignored, since in all studies COPD patients were compared to age-matched controls. In the present study, the contribution of systemic glucocorticoids is probably of minor importance. First of all, the patients who received this medication were only on a maintenance therapy, for which low dosages of prednisolone were administered. Also, as discussed in ehapter 6, prednisolone is a non-fluorinated corticosteroid and therefore unlikely to cause the marked type IIX fiber atrophy in the present study. Furthermore, fiber type redistribution and fiber type IIX atrophy was not more pronounced in this subgroup of patients. Also, the mild degree of myopathologic features in muscle biopsies from patients who received corticosteroids was similar to those who did not. Disuse, as mentioned above, may be involved in the fiber type redistribution and altered metabolic profile of peripheral muscles in COPD. On the other hand, disuse induced fiber atrophy normally affects all fiber types or even predominantly type I fibers (19), whereas selective type IIX atrophy was observed. Hypoxemia, either chronic or intermittent, is frequently assumed to be involved in the observed muscular alterations in COPD. As outlined in chapter 2 , hypoxia may lead to a reduced oxidative capacity in skeletal muscle, but it is not clear if it also induces fiber type redistribution in adult muscles. Strikingly, neither in the present studies nor in the literature, consistent relationships between arterial blood gases and these muscle abnormalities have been found. In addition, it has never been shown that the muscle tissue itself is indeed hypoxic in COPD. This is an essential issue to investigate in future research. In vivo muscle oxygenation can be measured directly with polarographic needle electrodes (35) or indirectly by measuring deoxymyoglobin using near-infrared spectroscopy (36) or magnetic resonance spectroscopy (37). The "Oxygen Paradox" is that oxygen is dangerous to the very life forms for which it has become an essential component of energy production. Oxidative stress and hypoxia can go hand in hand, especially during periods of ischemia/reperfusion or intermittent hypoxia. COPD patients who have a low diffusing capacity ( $<55 \%$ predicted) often develop arterial oxygen desaturations, especially during exercise (38). Theoretically, these desaturations may result in intermittent hypoxia in muscles, and may therefore induce oxidative stress in COPD. Moreover, when the exerted muscle strength exceeds $15 \%-50 \%$ of its maximal voluntary strength, muscle contractions begin to interfere with blood flow due to extravascular forces that compress the vasculature (39), which causes repetitive episodes of ischemia/reperfusion. Because muscle strength is reduced in COPD, such situations are more likely to occur during normal daily activities in these patients than in healthy subjects. These physiological aspects of oxygen supply to the muscle may therefore induce oxidative stress in COPD, in addition to the biochemical abnormalities discussed earlier and in chapter 8. Systemic inflammation is another hallmark of COPD and, as mentioned earlier, has convincingly been associated with muscle wasting in this disorder. Although the present data suggest that the intramuscular proportion of inflammatory cells was normal in clinically stable COPD patients, it is very well possible that 
the elevated circulating inflammatory mediators affect the muscle cells of these patients. Moreover, recent work shows that the muscle itself can be a source of cytokines as well (40). However, here too, direct relationships between circulating cytokines and intrinsic muscle abnormalities in COPD have not yet been reported. Evaluation of muscular alterations in patients suffering from a primary chronic inflammatory disease may help us to understand the contribution of systemic inflammation. In summary, although the examination of muscle biopsies from COPD patients is essential to characterize abnomalities in the affected muscles, the multifactorial nature of many of the observed abnormalities is an obstacle in clarifying the underlying mechanisms. Another point that should be realized is that the muscular alterations described in this thesis do not necessarily apply to all skeletal muscles in COPD. First of all, as reviexed in chapter 2 , the muscle fiber type shift and changes in metabolic profile in the diaphragm are completely the opposite of those that occur in the vastus lateralis. In addition, it still not completely established whether muscle function of the upper limbs is relativaly preserved, as has been suggested (41), or whether muscle dystunction is generalized, as concluded in chapter 3 of this thesis. However, these findings do underscore the involvement of multiple factors, of which each of them may differentially affect the distinot muscle compartments.

To clarify the relative contributions of the various factors to the muscular alterations in COPD, future investigations should also be extended to experimental models, in which the involvement of a single factor can be studied. For example, the effect of hypoxia on the expression of the different myosin heavy chain isoforms and metabolic profile could be examined in cultured muscle cells. Likewise, the influence of oxidative stress or inflammatory mediators can be investigated. Animal models can subsequently be used to establish how these individual factors affect the musculature in the whole organism. The use of such models will further heip to clarify the underlying molecular pathways and identification of the key regulators involved. To this end, new technologies like RNAse protection assays and cDNA arrays may prove very useful, as these tools allow monitoring the expression of multiple genes of interest simultaneously. Then, if it is established how a certain factor induces muscular alterations as observed in skeletal muscles of patients with COPD, interventions could be tested using the same model. It is probably this kind of research that is essential to develop adequate therapies to counteract muscle wasting and dysfunction in chronic disabling diseases such as COPD.

\section{REFERENCES}

1. Wood PH. Appreciating the consequences of disease: the international classiflcation of impairments, disabilities, and handicaps. WHO Chron 1980;34:376-80.

2. Decramer $M$, de Bock $\mathrm{V}$, Dom $R$. Functional and histologic picture of steroid-induced myopathy in chronic obstructive pulmonary disease. Am J Respir Crit Care Med $1996 ; 153: 1958-64$.

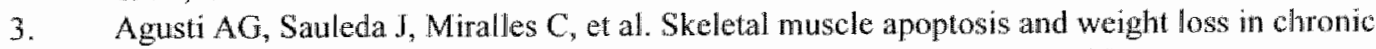
obstructive pulmonary disease. Am J Respir Crit Care Med 2002;166:485-9.

4. Lewis MI. Apoptosis as a potential mechanism of muscle cachexia in chronic obstructive pulmonary disease. Am J Respir Crit Care Med 2002;166:434-6. 


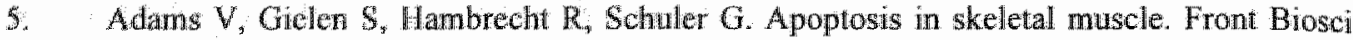
$2001 ; 6: D I-D 11$.

6. Sandri M. Apoptotic signaling man skeletal muscle fibers during atrophy, Curr Opin Clin Nutr Metab Care 2002,5:249-53.

7. Vescovo $G$, Votterani $M$. Zemnaro $R$, et al. Apoptosis in the skeletal muscle of patients with herart failure: investigation of clinical and biochemical changes. Heart 2000;84:431-7.

8. Morrison WL, Gibson JN, Scrimgeour C, Rennie MJ. Muscle wasting in emphysema. Clin Sci $1988 ; 75: 415-20$.

9. Dean RT, Fu SL, Stocker R, Dawies MJ. Biochemistry and pathology of radical-mediated protein oxidation. Biochem J 1997;324:1-18.

10. Langen RC, Schols AM, Kelders MC, Van Der Velden JL, Wouters EF, Janssen-Heininger YM. Tumor necrosis factor-alpha inhibits myogenesis through redox-dependent and -independent pathways. Am J Physiol Cell Pbysiol 2002;283:C714-21.

11. Buck M, Chojkier M. Muscle wasting and dedifferentiation induced by oxidative stress in a murine model of cachexia is prevented by inhibitors of nitric oxide synthesis and antioxidants. EMBO ग1996;15:1753-65.

12. Kotler DP. Cachexia. Ann Intern Med 2000;133:622-34.

13. Eid AA, Ionescu AA, Nixon LS, et al. Inflammatory response and body composition in chronic obstructive pulmonary disease. Am II Respir Crit Care Med 2001;164:1414-8.

14. Jagoe RT, Goldberg AL. What do we really know about the ubiquitin-proteasome pathway in muscle atrophyPPG - 183-90. Curr Opin Clin Nutr Metab Care 2001;4.

15. Llovera M, Carbo N, Lopez-Soriano J, et al. Different cytokines modulate ubiquitin gene expression in rat skeletal muscle. Cancer Lett 1998;133.

16. Tsirigotis $M$, Zhang M, Chiu RK, Wouters BG, Gray DA. Sensitivity of mammalian cells expressing mutant ubiquitin to protein-damaging agents. J Biol Chem $2001 ; 276$.

17. Parry 10 J Myosin heavy chain expression and plasticity: role of myoblast diversity. Exerc Sport Sci Rev 2001;29:175-9.

18. Pette D, Staron RS. Transitions of muscle fiber phenotypic profiles. Histochem Cell Biol $2001 ; 115: 359-72$.

19. Franssen FM, Wouters EF, Schols AM. The contribution of starvation, deconditioning and ageing to the observed alterations in peripheral skeletal muscle in chronic organ diseases. Clin Nutr 2002;21:1-14.

20. Dimopoulou I., Tlias I, Mastorakos G, Mantzos E, Roussos C, Koutras DA. Effects of severity of chronic obstructive pulmonary disease on thyroid function. Metabolism 2001;50:1397-401.

21. Kamischke $A$, Kemper DE, Castel MA, et al. Testosterone levels in men with chronic obstuctive pulmonary disease with or without glucocorticoid therapy. Eur Respir J 1998;11:41 * 5.

22. Solanes $\mathrm{G}$, Pedraza $\mathrm{N}$, Iglesias $\mathrm{R}$, Giralt $\mathrm{M}$, Villarroya $\mathrm{F}$. The human uncoupling protein-3 gene promoter requires MyoD and is induced by retinoic acid in muscle cells. Faseb $J 2000 ; 14: 2141$ 3.

23. Hughes SM, Koishi K, Rudnicki M, Maggs AM. MyoD protein is differentially accumulated in fast and slow sketetal muscle fibres and required for normal fibre type balance in rodents. Mech Dew 1997;61:151 63 .

24. Seward DJ, Haney JC, Rudnicki MA, Swoap SJ. bHLH transcription factor MyoD affects myosin heavy chain expression pattern in a muscle-specific fashion. Am J Physiol Cell Physiol $2001: 280: \mathrm{C} 408-13$.

25. Hesselink MK, Keizer HA, Borghouts LB, et al. Protein expression of UCP3 differs between human type 1, type 2a, and type 2 b fibers. Faseb J 2001; 15:1071-3.

26. Szalay $K$, Razga $Z$, Duda $E$. TNF inhibits myogenesis and downregulates the expression of 
myogenic regulatory factors myoD and myogenin. Eur I Cell Biol 1997;74:391-8.

27. Guttridge DC, Mayo MW, Madrid LV, Wang CY, Baldwin AS, Ir. NF-kappaB-induced loss of MyoD messenger RNA: possible role in muscle decay and cachexa. Science $2000,2892363-$ 6.

28. Barclay CI. Mechanical efficiency and fatigue of fast and slow muscles of the mouse. J Plysiol 1996;497:781-94.

29. Ekelund UE, Harrison $\mathbb{R} W$, Shokek $O$, et al. Intravenous allopurinol decreases myocardial oxygen consumption and increases mechanical efficiency in dogs with pacing-induced heart failure. Circ Res 1999;85:437-45.

30. Heunks LM, Vina J, van Herwaarden CL, Folgering HT, Gimeno A, Dekhuijzen PN. Xanthine oxidase is involwed in exercise-induced oxidative stress in chronic obstructive pulmonary disease. Am J Physiol 1999;277:R1697-704.

31. Vina J, Servera E, Asensi M, et al. Exercise causes blood glutathione oxidation in chronic obstructive pulmonary disease: prevention by o 2 therapy. J Appl Physiol 1996:81:2199-2202.

32. Couillard A, Koechlin C, Cristol .IP, Varray A, Prefaut C. Evidence of local exercise-induced system oxidative stress in chronic obstructive disease patients. Eur Respir J 2002;20:1123-1129.

33. Rabinovich $\mathrm{RA}$, Ardite $\mathrm{E}$, Troosters $\mathrm{T}$, et al. Reduced muscle redox capacity after endurance training in patients with chronic obstructive pulmonary disease. Am J Respir Crit Care Med 2001;164:1114-8.

34. Engelen MP, Schols AM, Does JD, Deutz NE, Wouters EF. Altered glutamate metabolism is associated with reduced muscle glutathione levels in patients with emphysema. Am J Respir Crit Care Med 2000;161:98-103.

35. Boekstegers P, Weidenhofer S, Kapsner T, Werdan K. Skeletal muscle partial pressure of oxygen in patients with sepsis. Crit Care Med 1994;22:640-50.

36. Jensen Urstad M, Hallback I, Sahlin K. Effect of hypoxia on musele oxygenation and metabolism during arm exercise in humans. Clin Physiol $1995 ; 15: 27-37$.

37. Mancini DM, Willson JR, Bolinger $\mathrm{L}$, et al. In vivo magnetic resonance spectroscopy measurement of deoxymyoglobin during exercise in patients with heart failure. Demonstration of abnormal muscle metabolism despite adequate oxygenation. Circulation 1994;90:500-8.

38. Owens GR, Rogers RM, Pennock BE, Levin D. The diffusing capacity as a predictor of arterial oxygen desaturation during exercise in patients with chronic obstructive pulmonary disease. $N$ Engl J Med 1984;310:1218-21.

39. Laughlin MH, Korthuis RJ, Duncker DJ, Bache RJ. Control of blood flow to cardiac and skeletal muscle. In: Rowell LB, Shepherd JT, eds. Handbook of Physiology. 1st ed. New Yoit: Oxford University Press, Inc., 1996:705-769.

40. Galdiz JB, Palacio J, Casadevall C, et al. Respiratory and peripheral muscles constitutively express TNF- $\alpha$. Eur Respir J 2002;20:221s.

41. Gea J, Orozco-Levi M, Barreiro E, Ferrer A, Broquetas J. Structural and functional changes in the skeletal muscles of COPD patients: the "compartments" theory. Monaldi Arch Chesi Dis 2001;56:214-24. 
Samenvatting 
"Chronic obstructive pulmonary disease", ofwel $\mathrm{COPD}$, is de engelstalige benaming voor chronisch obstructieve longziekten. De mate van obstructie of luchtwegvernauwing wordt bepaald door te meten hoeveel lucht een patiënt maximaal in één seconde kan uitblazen (FEV, ). Veelal wordt COPD onderverdeeld in chronische bronchitis en emfyseem. Chronische bronchitis wordt gekenmerkt door een voortdurend terugkerende overmatige slijmproductie in de luchtwegen, die vaak gepaard gaat met luchtweginfecties. Door het slijm raken de luchtwegen verstopt, hetgeen de ademhaling zwaar bellemmert. Bij emfyseem is er sprake van alveolair structuurverlies. Dit houdt in dat de wanden van de longblaasjes ernstig zijn beschadigd, waardoor zij hun normale elastisticiteit hebben verloren, of zelfs geheel zijn verdwenen. Door het verlies van longblaasjes kan de gasuitwisseling (van zuurstof en kooldioxide) minder goed plaatsvinden in de longen. In westerse landen is roken de voornaamste oorzaak van COPD en de verwachting is dat COPD in 2020 wereldwijd nummer drie zal staan op de lijst van doodsoorzaken.

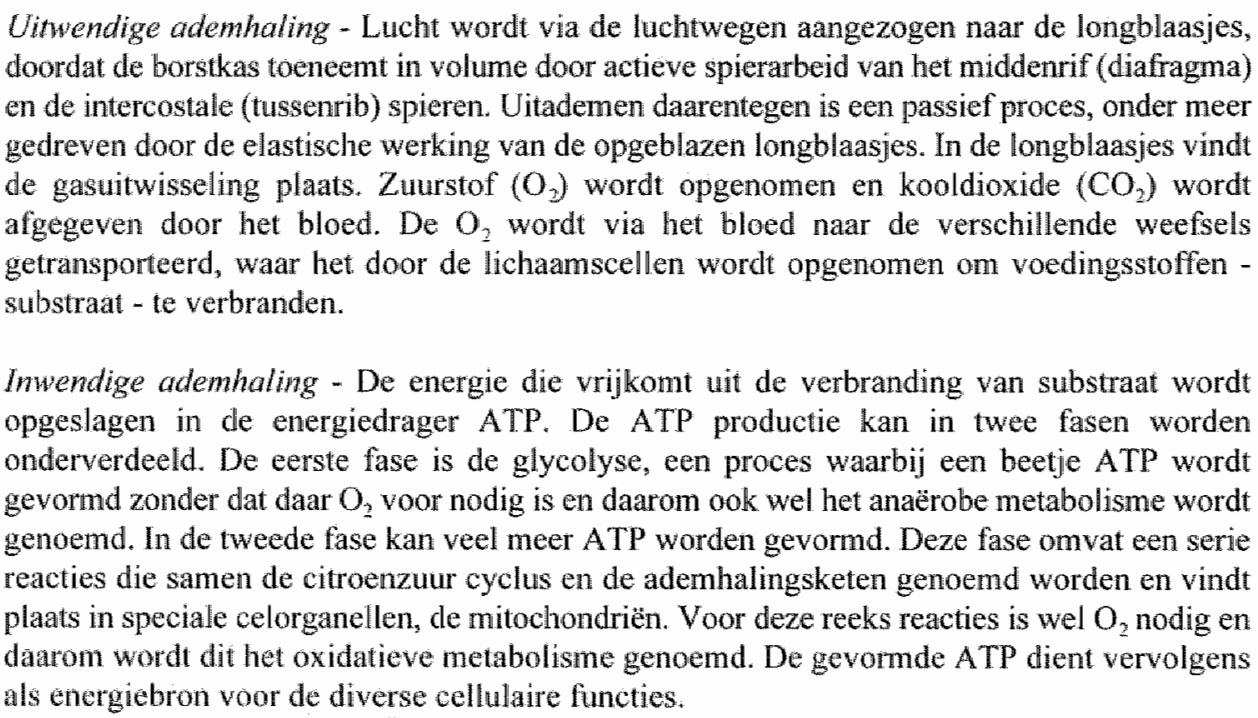
doordat de borstkas toeneemt in wolume door actieve spierarbeid van het middenrif (diafragma) en de intercostale (tussenrib) spieren. Uitademen daarentegen is een passief proces, onder meer gedrewen door de elastische werking van de opgeblazen longblaasjes. In de longblaasjes vindt de gasuitwisseling plaats. Zuurstof $\left(\mathrm{O}_{2}\right)$ wordt opgenomen en kooldioxide $\left(\mathrm{CO}_{2}\right)$ wordt afgegeven door het bloed. De $\mathrm{O}_{2}$ wordt wia het bloed naar de verschillende weefsels getransporteerd, waar het door de lichaamscellen wordt opgenomen om voedingsstoffen substraat - te verbranden.

Inwendige ademhaling - De energie die vrijkomt uit de verbranding van substraat wordt opgeslagen in de energiedrager ATP. De ATP productic kan in twee fasen worden onderverdeelld. De eerste fase is de glycolyse, een proces waarbij een beetje ATP wordt gevormd zonder dat daar $\mathrm{O}_{2}$ voor nodig is en daarom ook wel het anaërobe metabolisme wordt genoemd. In de tweede fase kan veel meer ATP worden gevormd. Deze fase omvat een serie reacties die samen de citroenzuur cyclus en de ademhalingsketen genoemd worden en vindt plaats in speciale celorganellen, de mitochondriën. Voor deze reeks reacties is wel $\mathrm{O}_{2}$ nodig en daatom wordt dit het oxidatieve metabolisme genoemd. De gevonmde ATP dient vervolgens als energiebron voor de diverse cellulaire functies.

Patiënten met COPD zijn door hun ziekte ernstig beperkt in hun dagelijkse doen en laten. Eén van de duidelijkste kenmerken waarin deze beperking zich uit is een verlaagde inspanningscapaciteit. Het longfalen en de daaruit voortvloeiende ademnood dragen daar natuurlijk in belangrijke mate aan bij, maar de laatste 10 jaar is duidelijk geworden dat lichamelijke of systemische beperkingen ook een zeer belangrijke rol spelen. Tot op heden zijn resultaten van de medicamenteuze behandeling gericht op het longfalen zelf eigenlijk teleurstellend te noemen en het verleggen van de aandacht naar de systemische consequenties van COPD kan nieuwe perspectieven voor behandeling bieden. Eén van de belangrijkste systemische beperkingen van COPD, maar ook van andere chronische ziekten als chronisch hartfalen (CHF), is een verminderde skeletspierfunctie. Echter, om nieuwe behandelmethoden te ontwikkelen of de effectiviteit te optimaliseren is meer inzicht nodig in de onderliggende pathologie en de oorzaken van de verstoorde spierfunctie. 
Hoofdstuk 2 geeft een uitgebreid overzicht van wat er reeds bekend is over verminderde spierfunctie en de spierpathologie in COPD and CHF. De spierfunctie wordt valk gemeten an de hand van de kracht- en de uithoudingscomponent. Deze parameters zijn onder meer afhankelijk van de vezelsamenstelling van de betreffende spier.

\begin{abstract}
Spiervezels - Skeletspieren of dwarsgestreepte spieren zijn opgebouwd uit spiervezels. Er bestaan grofweg drie soorten vezels: 1) type I vezels zijn afhankelijk van $\mathrm{O}_{\text {, voor een continue }}$ toevoer van energie en hebben daardoor een groot uithoudingsvermogen, maar hun contractie snelheid en kracht zijn laag; 2) type IIX vezels zijn afhankelijk van een reeds aanwezige energievoorraad en kunnen daardoor snel een grote kracht leveren, maar vernoeidheid treedt erg snel op; 3) type ILA vezels hebben intermediaire eigensehappen. Voor alle spiervezels geldt dat de contractie berust op het langs elkaar verschuiven van myosine en actine filamenten. Voor dit proces is energie nodig in de vorm van ATP. Type I vezels worden ook wel oxidatieve vezels genoemd, omdat deze vezels een grote capaciteit hebben on substraat met behulp van $\mathrm{O}_{2}$ te verbranden en op die manier ATP aan te maken. Type IX vezels worden daarentegen wel glycolytisch genoemd, omdat deze vezels een veel lagere oxidatieve capaciteit hebben en daardoor afhankelijker zijn van de glycolyse voor de ATP voorziening. De identificatie van spiervezels is gebaseerd op de eigenschappen van de verschillende myosine isovormen.
\end{abstract}

Juist op het niveau van de spier blijken verrassende overeenkomsten te bestaan tussen COPD en $\mathrm{CHF}$. Een verminderde spiermassa draagt bij aan de verminderde spierfunctie. Echter, in beide ziekten spelen waarschijnlijk ook intrinsieke afwijkingen in de spier een rol. Er is wel een verschil tussen de perifere spieren en het diafragma (middenrifspier). Vergeleken met gezondle personen vertonen de perifere spieren van patiënten een verschuiving van type I naar type II vezels, waarbij ook de activiteit van oxidatieve enzymen is verlaagd is. Dit is precies andersom in het diafragma. In theorie betekent dit dat de perifere spier minder uithoudingsvermogen heeft en het diafragma met name beperkt is door krachtsverlies. Dit is waarschijnlijk inderdaad het geval voor COPD en CHF: tijdens met name fietsoefeningen geven patiënten vaak aan dat ze willen stoppen omdat ze pijn hebben in de benen (vermoeidheid) of omdat ze ademnood hebben. Uit de literatuur blijkt dat het gevoel van ademnood nauw samenhangt met de verminderde kracht van het diafragma. Wat nog niet duidelijk wordt uit de beschikbare literatuur is de oorzaak van de spierafwijkingen in COPD en $\mathrm{CHF}$. De factoren die mogelijk betrokken zijn bij het ontstaan van de spierafwijkingen zoals, hypoxie, oxidatieve stress, systemische inflammatie, ondervoeding en medicatie, worden in dit hoofdstuk behandeld.

In hoofdstuk 3 zijn de functionele beperkingen van patiënten met COPD en CHF met elkaar en met die van een groep gezonde vrijwilligers vergeleken. Ondanks het feit dat COPD en CHF twee totaal verschillende ziekten zijn, waren de systemische overeenkomsten groot. Zowel in COPD als in CHF was de inspanningscapaciteit ongeveer $50 \%$ lager dan in gezonde controles. Verder werden beide patiëntengroepen gekenmerkt door een vergelijkbaar verlaagde vetvrije massa ( spiermassa), verlaagde kracht en uithoudingsvermogen van bovenste en onderste ledematen en een verminderd dagelijks activiteitenniveau. De ernst van longfalen in COPD en 
de emst van hartfalen in $\mathrm{CHF}$ bleken slechts in beperkte mate de verminderde inspanningscapaciteit te verklaren. Daarentegen waren de vetvrije massa en in mindere mate ook het dagelijkse activiteitenniveau wel goede voorspellers van de afname in inspanningscapaciteit. Ook bleek dat de verminderde vetvrije massa voor een belangrijk deel bepalend was voor de verlalagde spierkracht in patiënten, maar niet voor het uithoudingsvermogen. Vetvrije massa wordt vaak gemeten als maat voor spiermassa en het is dan ook eenvoudig te begrijpen dat met minder spiermassa ook minder kracht kan worden gegenereerd. Het verminderde uithoudingsvermogen van de perifere spieren moet echter gezocht worden in de intrinsieke veranderingen in de spier.

In de volgende alinea's zijn een aantal studies beschreven, waarin naar deze intrinsieke veranderingen in de perifere spieren van COPD patiënten is gekeken. Hiertoe werden spierbiopten genomen uit de vastus lateralis, een spier uit het bovenbeen, bij patiënten en bij gezonde vrijwilligers ter vergelijking. Van deze spierbiopten werden hele dunne plakjes gesneden, zogenaamde vriescoupes, op een dusdanige wijze dat een dwarsdoorsnede van het biopt werd verkregen. Door middel van verschillende kleuringstechnieken konden de bepaalde karakteristjeken onder de microscoop worden bestudeerd.

In hoofdstuk 4 zijn de spierbiopten onderzocht met "standaard" technieken in de spierpathologie. Duidelijke kenmerken van myopathologie, zoals die te vinden zijn in de spieren van patiënten met echte spierziekten, waren niet aanwezig. Wel was er duidelijk sprake van atrofie in de biopten van de patiënten, wat werd gekenmerkt door gemiddeld kleinere spiervezels en een lichte toename van bindweefsel en vetcellen tussen de spiervezels. Daar systemische inflammatie waarschijnlijk een rol speelt in de spierpathologie bij COPD is ook gelet op de aanwezigheid van ontstekingscellen in de spier. Echter, deze cellen waren in normale thoeveelheden aanwezig.

Necrose - Cellen gaan dood als ze abrupt verwond raken, of als van het ene op het andere moment hun energievoorziening stagneert. Al snel ontstaat het volgende beeld: de cel zwelt op, scheurt en barst open, en de vrijgekomen celresten worden opgeruimd door ontstekingscellen.

Apoptose - Door de activatie van apoptose inducerende eiwitten, waaronder caspase 3, wordt de cel geprogrammeerd om dood te gaan. Vervolgens treedt er een gecontroleerde reeks van activiteiten in de cel op, waaronder ook DNA fragmentatie, die er voor zorgt dat alle celonderdelen gerecycled worden.

Met het oog op spiermassaverlies is ook gekeken naar celdood van spiervezels. Necrose was niet of nauwelijks aanwezig. Het aantal apoptotische kernen, zichtbaar gemaakt door het kleuren van gefragmenteerd DNA, was lag en niet verschillend vergeleken met de gezonde controles. Daarnaast werden geen vezels met geactiveerd caspase 3 aangetroffen.

In hoofdstuk 5 zijn de eerder genoemde I $\rightarrow$ II vezeltype verschuiving en de gereduceerde capaciteit van enzymen die betrokken zijn in het oxidatieve energiemetabolisme, nader onderzocht in spierbiopten uit het bovenbeen. De klassieke methode om vezeltypes te 
identificeren is de zogenaamde mATPase kleuring, waarbij de enzymatische activiteit wordt gemeten van de verschillende myosine isovormen. Recentelijk wordt ook veelvuldig gebruikt gemaakt van detectie met behulp van antilichamen die specifiek aan myosine isovormen binden. In deze studie is gebruik gemaakt van een combinatie van deze technieken, wardoor vezeltypes veel nauwkeuriger geïdentificeerd konden worden. Zoals ook in andere onderzoeken is aangetoond, was het percentage type I vezels in COPD beduidend lager en het percentage type IIX vezels hoger dan in controles. Het beeld van een laag percentage type I vezels was het meest uitgesproken in biopten van patiënten met emfyseem, maar een duidelijke verklaring hiervoor is er nog niet. Een opvallende observatie was dat er duidelijk meer hybride vezeltypes (I/IIA en IIA/IIX) aanwezig waren in de biopten van patiënten. Het lijkt er dus sterk op dat transformaties van vezels van het ene type in het andere $(\mathrm{I} \rightarrow \mathrm{IIA} \rightarrow$ IIX) een rol speelt in de herverdeling van vezeltypes in COPD. Voorts is het metabole profiel van de vezeltypes in kaart gebracht door kleuring van een tweetal oxidatieve enzymen en van een glycolytisch enzym. Het aantal oxidatieve vezels was duidelijk lager in de COPD groep en dit bleek gekoppeld te zijn aan het verlies van type I vezels. Echter, ook binnen de type IIA vezels was de oxidatieve capaciteit lager in de patiënten vergeleken bij de controles. Het verlies van oxidatieve capaciteit kan dus voor een groot deel, maar niet volledig, worden verklaard door het verlies van type I vezels.

De relatie tussen vezeloppervlak ( $\sim$ vezeldikte) en vetvrije massa is bestudeerd in hoofdstuk 6. Naast de identificatie van de verschillende vezeltypes is nu ook met behulp van speciale computer software de zogenaande "cross sectional area" (CSA) van de individuele spiervezels gemeten. De gemiddelde vezel CSA was beduidend lager in COPD dan in gezonde vrijwilligers. In COPD was de vezel CSA sterk gerelateerd aan de vetvrije massa, wat er op wijst dat atrofie van spiervezels, in ieder geval deels, betrokken is bij het verlies van spiermassa in COPD. Tevens bleek dat de aangetaste vezels uitsluitend van het vezeltype IIX waren, wat duidt op selectieve IIX atrofie. Hoewel in sommige studies wordt gesuggereerd dat vezel type II atrofie kan worden veroorzaakt door bepaalde medicijnen, met name corticosteroïden, kon dit worden uitgesloten in dit onderzoek. Daarentegen lijkt de atrofie meer geassocieerd te zijn met de "ondervoede" toestand en/of de chronische metabole stress waarin de spier zich verkeert.

Mechanische efficiëntie - Dit geeft de efficiëntie van een bepaalde inspanning weer. Naarmate er bij een bepaalde geleverde arbeid meer energie (en ook meer zuurstof) wordt verbruikt, gaat de efficiëntie van die inspanning omlaag.

UCP3 - Dit is een zogenaamd ontkoppelingseiwit. Het bevindt zich in de mitochondriën, waar het de zuurstofconsumptie ontkoppelt van ATP productie. Hierdoor gaat energie verloren als warmte.

Directe relaties tussen de herverdeling van vezeltypes en metabole veranderingen die zijn aangetroffen in de spier en de functionele beperkingen zijn nog altijd schaars. Daar "uncoupling protein 3" (UCP3) een potentiele determinant is van energiemetabolisme in de mens, is in hoofstuk 7 de hypothese getest of UCP 3 betrokken is bij de verlaagde mechanische 
efficierntie in COPD. Hiertoe is in een homogenaat, een soort extract, gemaakt van spierbiopten, waarin vervolgens onder meer het UCP3 gehalte is bepaald. Verrassend genoeg bleek het UCP3 gehalte niet te zijn verhoogd in COPD, maar eerder verlaagd, vergeleken met de gezonde controle personen. Het is dan ook onwaarschijnlijk dat UCP3 een rol speelt bij de verlaagde mechanische efticièntie in COPD. Welke oorzaken en gevolgen het verlaagde UCP3 gehalle dan wel heeft, zal verder moeten worden onderzocht.

Oxidatieve stress - Onder meer bij de oxidatieve reacties in de mitochondriën ontstaan zeer reactieve moleculen of vrije zuurstof radicalen als bijproduct. Deze vije radicalen kunnen vervolgens reageren met omliggende eiwitten, celmenibranen of zelfs met DNA, waardoor deze moleculen beschadigd raken. Er is dan sprake van oxidatieve stress.

Antioxidanten - Dit zijn stoffen van natuurlijke of synthetische aard of enzymen die in staat zijn om vrije radicalen onschadelijk te maken. Indien de antioxidantcapaciteit onvoldoende is om de wrije radicalen te neutraliseren is er ook sprake van oxidatieve stress.

Ondanks het feit dat er een overweldigende hoeveelheid aandacht uitgaat naar de rol van oxidatieve stress in de longen, is er nog nauwelijks onderzocht wat de rol is van oxidatieve stress in de aangetaste spieren in COPD. Hiertoe is in hoofdstuk 8 in spierbiopten, genomen in rust, gekeken naar een uitgebreid panel van antioxidanten en naar malondialdehyde, een marker van oxidatieve stress. De resultaten toonden aan dat de algehele antioxidantcapaciteit verhoogd is in COPD. Het meest voor de hand liggende mechanisme dat deze verhoging kan verklaren is stimulatie door vrije radicalen. Vitamine $\mathrm{E}$ was het enige antioxidant dat verlaagd was in COPD. Echter, vitamine $\mathrm{E}$ is een antioxidant dat niet door het lichaam zelf kan worden aangemaakt en via de voeding opgenomen moet worden. Een laag vitamine $E$ gehalte in de spier duidt dan ook wellicht op een verhoogde vorming van zuurstof radicalen. Dit gebeurt waarschijnlijk met name tijdens het leveren van inspanning, daar in deze studie (de patiënten waren in rust tijdens de bioptname) geen verhoging van malondialdehyde kon worden aangetoond.

Ten slotte worden in hoofdstuk 9 de belangrijkste bevindingen en conclusies nog eens op een rij gezet, zoals in deze samenvatting is gedaan. Het is gebleken dat de analyse van spierbiopten cruciaal is voor de verschaffing van nieuwe informatie en inzichten over datgene wat er mis is in de perifere skeletspieren van patiënten met COPD. Het is echter zeer moeilijk om de individuele invloed van de verschillende factoren, zoals bijvoorbeeld hypoxie, oxidatieve stress en systemische inflammatie, op deze afwijkingen in de spier te bepalen. Daarom zal de rol van deze factoren in de toekomst in experimentele modellen verder onderzocht moeten worden. Op deze wijze kunnen de moleculaire mechanismen wellicht ontrafeld worden, wat een cruciale stap is in de ontwikkeling van gerichte interventies om de spierstoornissen in COPD te behandelen en daarmee de nadelige gevolgen van COPD op het algehele welbevinden van de patiënt te verminderen. 
Het is half december, ongeveer teen weelk voordat ik het manuscript naar de drakker wil brengen. Ik realiseer me dat ik de pagina* $s$ die het zonder enige twijfel het meest gelezen zullen worden nog moet gaan schrijven. Gelijk speelt de gedachte door mijn hoofd dat, als ik mijn onderzoeksresultaten echt aan de man wil brengen, ik dit düs het beste in dit dankwoord zou kunnen doen, zo even tussen de bedankregeltjes door. Ik doe een poging.

Allereerst wil ik Annemie Schols bedanken. Als jij er niet was geweest had Professor Wouters mij, doordat ik het bij de sollicitatiebrief behorende $C V$ vergeten was mee te sturen, zonder enig pardon voor het eerste gesprek geweigerd. Ik ben dit niet vergeten, met name omdat jij me er zo vaak aan herinnert. Als tweede wil ik dan ook Professor Wouters hartelijk danken voor de herkansing. Maar vooral wil ik jullie bedanken voor de goede begeleiding in jullie rol als promotor en co-promotores. Hierbij wil ik ook zeker mijn tweede promotor, Ger van der Vusse, betrekken. Professor Wouters, zoals altijd bewaakte u de grote lijnen, maar gaf mij tevens de ruimte om mij te ontplooien op andere gebieden, zoals het inspanningsonderzoek (en IT). Annemie, je was (bent) er (bijna) altijd voor me en ook jij gaf me de ruimte. Je onbegrensde enthousiasme voor statistiek kan ik niet altijd bevatten, maar je was significant de beste dagelijkse begeleider die een AIO zich wensen kan. Ger, in de rol van "advocaat van de duivel", zoals je het zelf wel eens verwoord hebt, ben je vooral bij het schrijven voor mij van onschatbare waarde geweest.

Hoewel COPD een longziekte is, werd ik aangenomen als AIO om "afwijkingen in de skeletspieren van patiënten met COPD" te bestuderen. Eén wezenlijk onderdeel van onderzoek naar spierafwijkingen vormden de spierbiopten. $\llbracket \mathrm{k}$ wil alle patiënten en gezonde vrijwilligers danken voor het afstaan van een klein stukje van henzelf. Joan Does ben ik - zeer - dankbaar voor het feit dat zij de spierbiopten heeft genomen. Omdat de data uit spierbiopten pas goed geïnterpreteerd kunnen worden in combinatie met de functionele gegevens van de proefpersonen moet ik eigenlijk heel Hornerheide bedanken, met name de afdelingen fysiotherapie, longfunctie en diëtiek, wat ik dus bij deze doe. Clarie Weling, je bent de gezelligste chauffeuse die ik ken, maar ik blijf wel achterin zitten. Petra Heuts en Femke Ellens hebben gedurende hun stage een belangrijke rol gespeeld bij de spierfunctie metingen, dank daarvoor. Matthijs Hesselink, bij jou kon ik altijd binnenlopen met benullige en minder benullige vragen over spierfunctie en hoe je dat ook alweer moet meten. Bovendien hadden we gewoon een BW-er nodig, want als geneeskunde AlO mocht ik geen eerste begeleider zijn van een BW-student. Nicole Lencer wil ik bedanken voor de goede samenwerking met de cardiologie, waardoor we hebben kunnen inzien dat COPD en CHF patiënten wellicht minder verschillend zijn dan we dachten. Zo zijn de perifere spieren in beide groepen minder sterk en zijn sneller vermoeid. Die verminderde kracht is o.a. te wijten aan de verminderde spiermassa, waarbij spiervezelatrofie een rol speelt. Bèla Kubat wil ik bedanken voor het feit dat zij geregeld even tijd vond om met mij, achter een microscoop, de spierpathologie in COPD, die overigens best meeviel, te bestuderen. De oorzaak van het verlies van uithoudingsvermogen moet worden gezocht in intrinsieke veranderingen in de spier. Zo wijkt bijvoorbeeld de verdeling van vezeltypes af in COPD. Paul van Dijk, jij leerde me de fijne kneepjes van het vezeltyperen, bedankt! Henk van Mameren, bedankt voor het beschikbaar stellen van lab en materialen en voor de eeuwige discussies: $2 \mathrm{~B}$ or not $2 \mathrm{~B}$, that's still the question. Verder wil ik de rest van de capgroep Anatomie \& Embryologie bedanken voor de gezellige koffiepauzes, 
waarbij de vlaai natuurlijk niet mocht ontbreken. Johan Hekking, wanneer gaan we weer squashen? Daar de ontkoppelaar UCP3 wellicht een rol speelt in het verstoorde energiemetabolisme in COPD, wil ik Patrick Schrauwen, Gert Schaart en Matthijs bedanken voor de expertise rondom de UCP3 studie, ook al vonden we een verlaging in plats van de verwachte verhoging. Ik hoop stellig dat onze samenwerking een vervolg krijgt, het begin is er. Ook wil ik Aalt Bast, Guido Haenen en Marc Fischer bedanken voor alle hulp bij het antioxidanten onderzoek. Nu moeten we nog onderzoeken of er, ondanks de verhoogde antioxidantstatus, oxidatieve stress in de spieren van COPD optreedt, bijvoorbeeld tijdens inspanning.

De gehele capgroep Pulmonologie wil ik bedanken voor de prettige samenwerking en collegialiteit: Eva Creutzberg, Mariëlle Engelen, Roelinka Broekhuizen, Juanita Vernooy, Mieke Dentener, Erica Rutten, Marco Kelders, Jos van der Velden, Suzanne Hendriks, Kirsten Cosemans, Marja Vermeeren, de gehele staf longziekten, de arts-assistenten en natuurlijk het secretariaat. In het bijzonder wil ik Frits Franssen en Ramon Langen bedanken, als (ex)kamergenoten, als vrienden, en recentelijk ook als paranimfen.

De leden van de beoordelingscommissie wil ik bedanken voor het beoordelen van dit proefschrift: Prof. van Dieijen-Visser, Prof. Borgers, Prof. J. Roca, Prof. Kuipers, Prof. Daemen. Prof. Roca, thank you for your critical evaluation of the thesis.

Ook mijn familie kan de dans niet ontspringen in dit dankwoord. Niek en Fennie, jullie zijn best goede ouders hoor ... op zich. Nee, echt, bedankt voor de fijne jeugd, alle warmte en liefde. Dat geldt vanzelfsprekend ook voor mijn broers en zussen! Tot slot wil ik één persoon in het bijzonder bedanken. Mijn rotsin in de branding vond ik en zal ik altijd blijven vinden in mijn lieve vriendin. Marlies, als ik het weer eens helemaal niet meer zag zitten, dan vrolijkte jij me weer op en als zelfs dat niet werkte dan zei je "we hebben altijd elkaar nog"... en dat houwe we zo! 
Publications 
Gosker HR, Lencer NHMK, Franssen FME, van der Vusse GJ, Wouters EFM, Schols AMWJ. Striking similanties in systemic factors contributing to decreased exercise capacity in patients with severe chronic heart failure or chronic obstructive pulmonary disease. Chest; In press

Gosker HR, Engelen MPKJ, van Mameren H, van Dijk PJ, van der Vusse GJ, Wouters EFM, Schols AMWY. Muscle fiber type IIX atrophy is involved in the loss of fat-free mass in chronic obstructive pulmonary disease. Am J Clin Nutr 2002; 76:113-119.

Gosker $\mathbb{H R}$, van Mameren H, van Dijk PJ, Engelen MPKJ, van der Vusse GJ, Wouters EFM, Schols AMWJ. Skeletal muscle fibre type shifting and metabolic profile in patients with COPD. Eur Respir J 2002; 19:617-626.

Gosker HR, Uszko-Lencer NHMK, Wouters EFM, van der Vusse GJ, Scholls AMWJ. Muscular alterations in chronic obstructive pulmonary disease and chronic heart failure at rest and during exercise. Prog Respir Res 2002; 32: 18-29.

Gosker HR, Wouters EF, van der Vusse GJ, Schols AM. Skeletal muscle dysfunction in chronic obstructive pulmonary disease and chronic heart failure: underlying mechanisms and therapy perspectives. Am J Clin Nutr 2000; 71:1033-47.

Pouw EM, Koerts-de lang E, Gosker HR, Freling G, van der Vusse GJ, Wouters EF, Schols AM. Muscle metabolic status in patients with severe COPD with and without long-term prednisolone. Eur Respir $J$ 2000; 16: 247-52.

Engelen MPKJ, Schols AMWJ, Does JD, Gosker HR, Deutz NEP, Wouters EFM. Exercise-induced lactate increase in relation to muscle substrates in patients with chronic obstructive pulmonary disease. Am J Respir Crit Care Med 2000;162: 1697-1704.

den Blaauwen T, de Wit JG, Gosker H, van der Does C, Breukink EJ, de Leij L, Driessen AJ. Inhibition of preprotein translocation and reversion of the membrane inserted state of SecA by a carboxyl terminus binding mAb. Biochemistry 1997;36:9159-68.

Gosker HR, Bast A, Haenen GRMM, Fischer MAJG, van der Vusse GJ, Wouters EFM, Schols AMWJ. Antioxidant capacity is increased in the vastus lateralis of patients with COPD. Submirred

Gosker HR, Schrauwen P, Hesselink MKC, Schaart G, van der Vusse GJ, Wouters EFM, Schols AMWJ. Uncoupling protein 3 content is decreased in skeletal muscle of patients with COPD. Submitred

Gosker HR, Kubat B, Schaart G, van der Vusse GJ, Wouters EFM, Schols AMWJ. Myopathologic features in skeletal muscle of patients with COPD. Submitted 


\section{Curriculum Vitae}


Harry Gosker was bon November 9th, 1973 in Zwolle, the Netherlands. After he finished high school (CSG Dingstede, Meppel) he started the study biology in 1992 at the University of Groningen. He has been working on the optimization of the sporulation of the nematodetrapping fungus Arthrobotrys oligospora at the TNO Food and Nutrition institute in Zeist. During his study he also worked as a freelance interviewer for the market research institute NIPO (Amsterdam). He graduated at the department of Molecular Microbiology on a research project on Sec-dependent protein translocation in the bacterium Escherichia coli, under the supervision of A. Driessen $(\mathrm{PhD})$ and W. Konings $(\mathrm{PhD})$. From September 1997 until October 2002 he worked as a PhD student at the Department of Respiratory Medicine (formerly known as Department of Pulmonology) of the University of Maastricht, supervised by $\mathrm{E}$. Wouters $(\mathrm{MD}, \mathrm{PhD}), \mathrm{G}$. van der Vusse (PhD) and $\mathrm{A}$. Schols $(\mathrm{PhD})$. The research project he has been working on was focussed on skeletal muscle wasting and the underlying muscle pathology in patients with COPD, which resulted in the present thesis. Currently, he has a position as a post-doc at the Department of Respiratory Medicine. 